

\section{FY2002 Annual Self-Evaluation Report for the Pacific Northwest National Laboratory}

October 2002

This document directly supports the DOE-RL Contract for the Management and Operation of the Pacific Northwest National Laboratory Contract DE-AC06-76RLO1830, Appendix E. 


\subsection{Purpose and Format of this Report}

This Annual Self-Evaluation Report, a deliverable under Contract DE-AC0676RL01830, satisfies the requirements of PNNL's Performance Evaluation and Fee Agreement and DOE Order 224.1. This year's document has been redesigned to enhance the clarity and coherence of our appraisal.

\section{Purpose of this Self-Evaluation Report}

This year's FY2002 Self-Evaluation Report presents a focused, quantitative, and objective approach to evaluate the performance of Pacific Northwest National Laboratory (PNNL). It summarizes PNNL's progress toward accomplishing the Critical Outcomes, objectives, and performance indicators developed in partnership with the U.S. D epartment of Energy (DOE) and codified in the FY 2002 Performance Evaluation and Fee Agreement. In addition, this report summarizes PNNL's analysis of its readiness to achieve its 2010 vision, the state of the Laboratory's self-assessment process, and the results of FY2002 Peer Reviews.

This report has several parts and appendices

Executive Summary - This section provides an overall performance summary and individual performance summaries for each of the three Critical Outcomes.

Part I: Status of Performance Against Critical Outcomes - This part of the report presents the results and analysis of progress made against the key outcomes and expectations. Modules for Objectives 1.1 - 1.4 are grouped by mission area; their relation to quality, relevance, facilities, or management is shown in footers. All other module numbers correlate to those in the FY2002 Fee Agreement.

Part II: Readiness to Achieve PN NL 2010 Vision - This portion of the report presents PNNL's analysis of its strengths and opportunities for improvement relative to its ability to achieve the five strategic objectives of the Laboratory Agenda that must be met for the vision to become a reality.

Part III: Adequacy of PNNL's Self Assessment Process - This portion of the report describes how we use the results of our self-assessment process to influence Laboratory strategy, and provides an overview of our vision and strategy.

Appendix A addresses the Peer Review summaries for all four Research Directorates.

Appendix B presents the National Security mission and its support to the Office of D efense Nuclear Nonproliferation (D OE-NA-20), the Office of Intelligence (DOE-IN), and the Office of Counterintelligence (D OE-CN).

Appendix $\mathbf{C}$ shows the adjectival and value ratings for all of the FY 2002 Critical Outcomes, objectives and performance indicators.

Appendix D contains a listing of all acronyms listed in this report.

\section{Format of this Report}

- The format of this year's report is designed to improve clarity, readability, and coherence.

- While adhering to the structure prescribed in Contract Appendix E, "Standards of Performance-Based Fee," the report has been conceived and portrayed as a series of two-page modules, each with a topic, a thesis statement, and supporting text and graphics.

- Modules begin on left-hand pages. An icon (see graphic, next page) shows you at once which section you're in. A topic, in large, bold type, shows the kind of information the module contains; a thesis statement makes the main point of the module; the text clarifies and demonstrates the thesis; and a graphic, with its own thesis statement for a caption, adds value to the module by amplifying, contextualizing, or exemplifying one or more aspects of the text. 


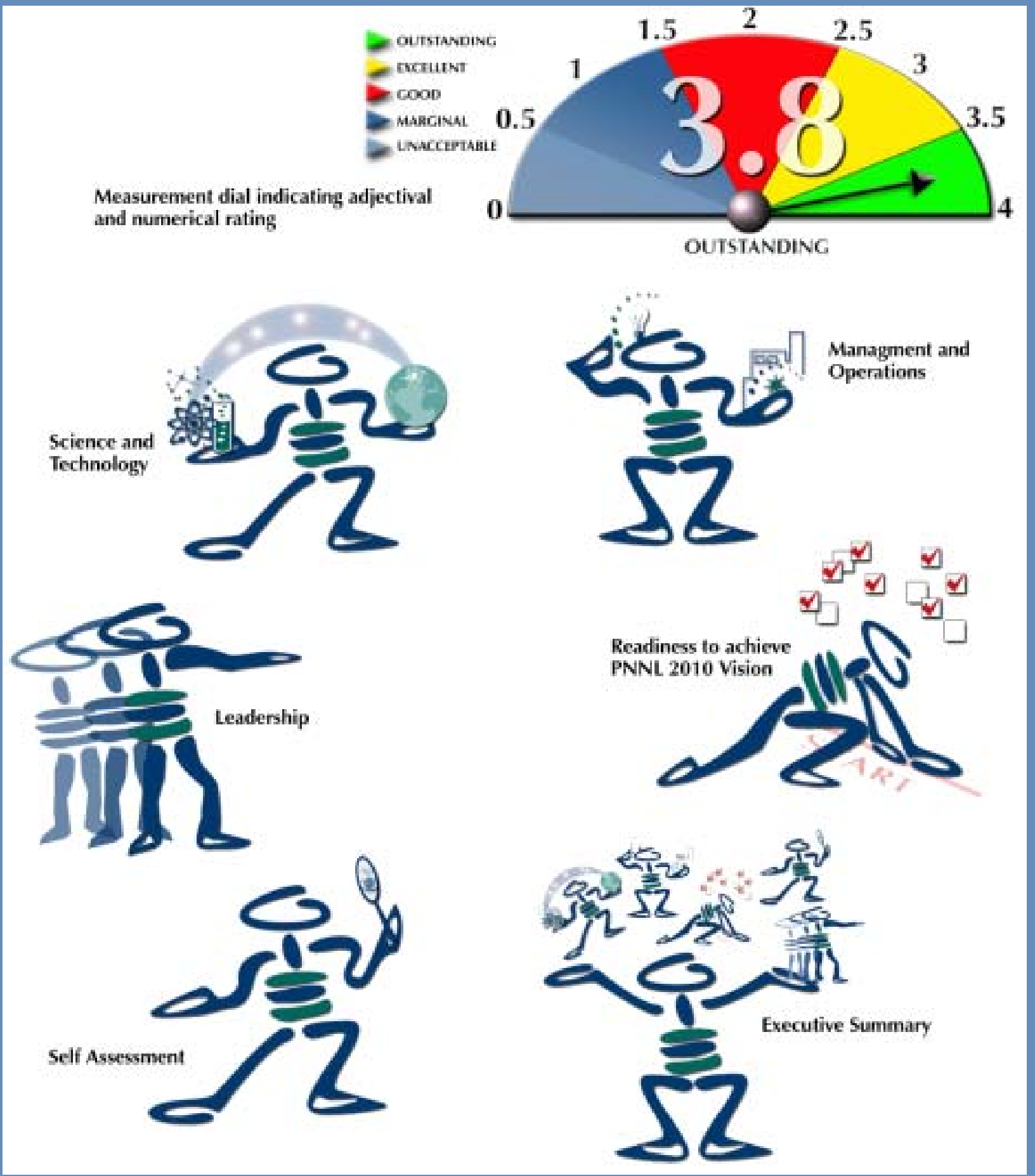

Figure $\mathbf{0 . 0}$. Icons key the reader to the report's content areas. 
Executive Summary<smiles></smiles> 

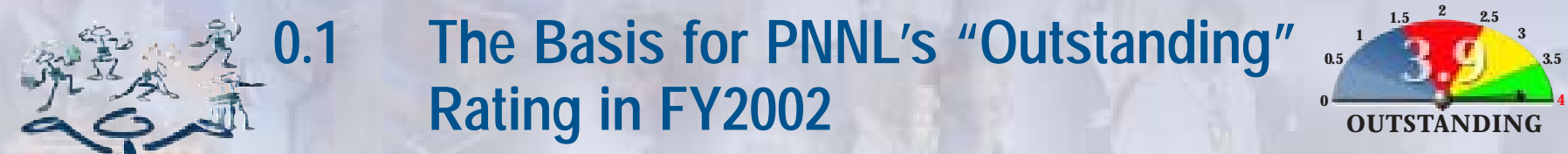

In FY2002, Battelle met or exceeded nearly all U.S. Department of Energy (DOE) expectations in Scientific and Technological Excellence, Management and Operations Excellence, Leadership Excellence, and other specified areas. Based on the results of this self-evaluation, we calculated an overall performance score of 3.9 out of a possible 4.0 points, which translates to an adjectival rating of O utstanding (Table 0.1).

\section{Critical Outcome Performance}

Performance in accomplishing our critical outcomes was weighted as follows: $60 \%$ scientific and technological excellence, 25\% management and operational excellence, and 15\% leadership excellence. In FY2002, each outcome received 3.9 points or higher to create a weighted, overall score of 3.9 points, which translates to an adjectival rating of O utstanding ( 3.5 or higher is O utstanding). For more information, refer to Part I of this report and to Appendix C for scores.

\section{Scientific and Technological Excellence}

The Laboratory's science and technology programs support critical DOE mission needs and provide new insights and solutions to challenges facing the nation and the world. Progress in our science programs during FY2002 supported critical goals for the Office of Science and promise beneficial application to all four of D OE's missions. High-value technologies and significant program accomplishments have been delivered to our customers in national security, environmental management, and energy. The quality of our scientific efforts are reflected by the long list of staff recognized for scientific and engineering excellence through awards, invited talks, and participation on scientific committees.

Another indicator of the quality and relevance of our research comes from annual external peer reviews. O ur external peer reviewers state that the Laboratory contributes substantially to national and global imperatives associated with counter-terrorism, global climate change, environmental cleanup, and energy systems. O verall our programmatic work, is highly relevant to the national research agenda and provides the "state-of-the-art" and, in some cases, "... the very best of the world's scientific ex- perts... ." O ur reviewers remind us that retaining key scientific staff is a high priority across our programs and caution us to continue to develop business plans strategically aligned with D OE program directions.

\section{Management and Operational Excellence}

The Laboratory conducts work and operates facilities with distinction and in a manner that supports its science and technology mission. The overall performance of Laboratory operations is exemplary, including strong performances in Environmental Safety and Health (ES\&H) management, operational excellence, facility maintenance, energy efficiency, business management, safeguards and security, capability alignment with current and future mission needs, and the development of integrated management systems capable of delivering appropriate and relevant products and services.

\section{Leadership Excellence}

Battelle's leadership in Research and D evelopment $(R \& D)$ and regional partnerships helps ensure PNNL remains an enduring national asset. O ur programs helped establish a robust, sustainable, regional economy, and served to attract, develop, and retain critical staff necessary to achieve simultaneous excellence in science and technology, operations, and community trust. We have also shown the Laboratory's relevance to economic and Science and Technology (S\&T) needs of the region and have enhanced science education by involving teachers and students in Laboratory research.

In addition to these three critical outcomes, Battelle is committed to continuous improvement and a strong self-assessment process. Neither of these management functions per se is scored in the performance rating, but they underpin and reinforce our ability to achieve the Critical Outcomes. 
Readiness to Achieve

\section{PNNL 2010 Vision: Strengths and Opportunities for Improvement}

O ur strengths in S\&T innovation and thought leadership are the principle reasons we consistently deliver high quality, relevant results. O ur commitment to the continual improvement of our management processes through critical self-assessment allows us to maintain outstanding operational performance in the face of many challenges. O ur staff and managers are the key success factor in our ability to deliver S\&T results as well as maintain PNNL as a vital national asset, and we take pride in ensuring that our staff and managers continue to be refreshed and engaged.

We also maintain strong regional partnerships and collaborations that serve us well in our goal to be a regional and community asset. We continue to anticipate and meet the challenges of upgrading our infrastructure and broadly communicating the multi-program nature of our work and its unique value to our customers. In the upcoming year we look to improve the internal clarity and communication of our strategic direction and performance expectations, improve our management focus on funds control, and execute our strategy for intellectual-property revenue reinvestment in the Laboratory. For more information, please refer to Part II of this report.

\section{Adequacy of PNNL's Self-Assessment Process}

We use the results of our increasingly mature self-assessment process to drive performance improvement. O ur Level 1 managers agree that the process is robust and are committed to achieving even greater levels of effectiveness. Both D OE-RL and the Level 1 managers agree benefits can be increased by improving the clarity and communication of the Lab's strategic direction, research and operational performance expectations, and acceptable levels of risk. For more information, please refer to Part III of this report.

\section{Partnering for Success}

The Laboratory's success hinges on a strong partnership with DOE. Noteworthy examples include:

- Development of a new contract approach that relies more strongly on line management and contractor accountability, national standards to establish contractor requirements, and financial and non-financial incentives for contractor performance.

- D eveloped the "nuclear island" concept for managing nuclear materials under the new contract.

- Proposed the use of the Requirements Integration Tailoring process as an approved contracting approach for defining appropriate requirements for all areas of Laboratory operations, not just ES\&H.

- Started development of a strategic facilities plan for addressing research capabilities in the 300 Area that will be affected by accelerated cleanup.

- Planning for a new high-throughput biology facility under the $\mathrm{G}$ enomes to Life program.

- Supported long-term access to the Arid Lands Ecology Reserve (ALE) for scientific research now that ALE is under the management of the U.S. Fish and Wildlife Service.

Table 0.1. This table shows the value points and the associated adjectival ratings that PNNL believes are justified based on our performance, leading to an overall FY2002 self-rating of "Outstanding." Value points and the associated adjectival ratings for all of the FY2002 Critical Outcomes, objectives and performance indicators are provided in Appendix C.

\begin{tabular}{|c|c|c|c|c|c|c|}
\hline \multicolumn{2}{|c|}{ Critical Outcome } & \multirow{2}{*}{$\begin{array}{c}\text { Value } \\
\text { Points } \\
3.95\end{array}$} & \multirow{2}{*}{$\begin{array}{l}\text { Adjectival } \\
\text { Rating } \\
\text { Outstanding }\end{array}$} & \multirow{2}{*}{$\begin{array}{c}\text { Weight } \\
60 \%\end{array}$} & \multirow{2}{*}{$\begin{array}{c}\text { Weighted } \\
\text { Score } \\
2.37\end{array}$} & \multirow[t]{2}{*}{$\begin{array}{l}\text { Total } \\
\text { Score }\end{array}$} \\
\hline & $\begin{array}{l}\text { Scientific and Technological } \\
\text { Excellence }\end{array}$ & & & & & \\
\hline 2.0 & $\begin{array}{l}\text { Management and Operations } \\
\text { Excellence }\end{array}$ & 3.91 & Outstanding & $25 \%$ & 0.98 & \\
\hline 3.0 & Leadership Excellence & 4.00 & Outstanding & $15 \%$ & 0.60 & \\
\hline
\end{tabular}




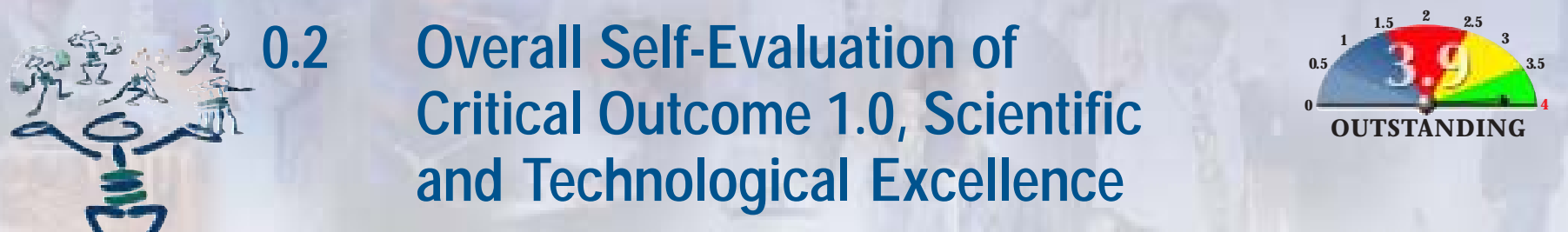

\section{In FY2002, PNNL met or exceeded nearly all DOE expectations in Scientific and Technological Excellence.}

Part I, Section 1 of this report details PNNL's self ratings of the adjectives and value points that lead to PNNL's Critical Outcome 1.0 FY2002 point total of 3.9 and performance rating of O utstanding for Scientific and Technological Excellence. Appendix C shows the adjectival and value ratings for FY 2002 Critical Outcome 1.0 and all of its objectives and performance indicators (Tables C.3 - C.8).

\section{Highlights of the Six Performance Objectives}

\subsection{Quality of Science \& Technology}

- In a biological application of nanotechnology, PNNL scientists successfully immobilized enzymes while simultaneously enhancing their activity and stability, opening up new possibilities for using tailored nanoporous materials. The findings could enable development of novel sensor and enzymatic engineering systems for homeland security, environmental protection, and energy generation as well as new industrial chemicals and separations.

- PNNL strengthened its scientific R\&D capabilities in the area of biomass catalysis and biomolecular technology. The catalysis research involves a range of approaches to create bio-based products, fuels, and energy from biomass.

- PNNL, in conjunction with the Savannah River Technology Center, developed Fast G lass, a new formula for vitrifying radioactive waste that is likely to result in $\$ 1$ billion in life-cycle savings with lower operational risk.

- Five PNNL technologies were chosen to be briefed to Secretary Abraham and Governor Ridge at the Counter Terrorism Expo in November 2001. These technologies are now being evaluated for inclusion in solving specific requirements within Homeland Security.
- The Western Regional Information Science Research Center established by PNNL for ARDA in late FY2001, has successfully completed and demonstrated a key technical solution to its first "Community Challenge" research problem.

- PNNL has made important discoveries in how cracks propagate in nuclear reactor components. The Lab's unique ability to characterize and understand this cracking behavior will be used to support the Nuclear Regulatory Commission and the nuclear power industry by helping identify root causes for the reactor vessel head degradation at the $\mathrm{D}$ avis Besse nuclear power plant in O hio.

\subsection{Relevance to DOE R\&D Portfolios and National Needs}

- PNNL scientists have obtained the most complete protein coverage of any organism to date with the study of a radiation-resistant microbe known to survive extreme environments. To achieve this unprecedented coverage, researchers used a new high-throughput mass spectrometer based on Fourier-transform ion cyclotron resonance developed at PNNL. This instrumentation allows scientists to identify thousands of proteins within hours.

- A newly patented way to deposit metal atoms on very thin oxide layers may help next-generation computers boot up instantly, making entire memories immediately available for use. The technique also may help fabricate less expensive catalysts for chemical reactions and lead to better nanotechnology devices and ceramic/ metal seals.

- Chemical Physics, Chemical Sciences, and Materials Sciences programs supported by the Office of Basic Energy Sciences consistently receive outstanding marks in peer reviews.

- PNNL researchers secured a significant role in the Genomes to Life program as a result of the first round of peer-reviewed proposals. 
- Because of the geographical and logical connectedness of the work required to cleanup both the Columbia River Corridor and the Central Plateau, and because of the separateness of the field offices, PNNL has been working with DOE-RL for the past year via the Cleanup Challenges and Constraints Team (C3T) process to find technically defendable methods to accelerate the cleanup and reduce overall cleanup costs. The C3T process was hailed by DOE as instrumental in Hanford receiving \$433 million for accelerated cleanup.

- PNNL's research efforts in support of the DOE Transmission Reliability Program include real-time power system monitoring and control, analysis of load as a reliability resource, and a study of distributed energy resource impacts on the transmission system's dynamic performance.

- The concept of D ebt for Nonproliferation, which was originated at PNNL, was included as part of the President's Global Partnership Initiative announced at the G 8 Summit, was unanimously accepted by the Senate, was improved upon and endorsed by the House, and was signed into law as the D ebt Reduction for Nonproliferation Act of 2002 by President Bush on Sept 30, 2002.

- The PNNL D ecision Support for Operations and Maintenance (D SO M) system has been developed and installed at multiple U.S. Marine Corp bases resulting in significant energy saving and improved self-sufficiency. The system has been extended to Public Housing Authorities with a pilot installation for the New York City Housing Authority which resulted in a \$400,000 savings during the first year of operation.

\subsection{Success in Constructing and Operating Research Facilities}

- EMSL's action plan in response to DOE's November 2001 review will enhance the user program and the impact of the science conducted within EMSL.

- ARM is viewed by expert peer reviewers, including JASO N, as a valuable national asset for the nation's climate research program.

- The new EMSL Supercomputer prototype was delivered on schedule in May and is performing at very high levels of efficiency. Full installation is expected to be completed in 2003.
- The $900 \mathrm{MHz}$ magnet was made cold April 29, initially energized in early May, and brought to field on June 24. The final installation phase of the magnet is now proceeding with installation of NMR systems including consoles and probes.

\subsection{Effectiveness and Efficiency of Research Program Management}

- The June 2002 bi-annual inspection of PNNL's Counterintelligence (CI) Program was very complimentary toward our CI staff and their accomplishments. The Lead Inspector, during his out-briefing, summarily rated the CI Program as "excellent" - the highest evaluation possible.

- Already recognized as a top-notch technical management entity, the Tanks Focus Area Technical Team further enhanced its record of sustained, exceptional customer and user satisfaction by developing and deploying several technologies to make tank waste sampling safer and more efficient and effective, and by developing and improving web-based communication tools and processes that enable wide access to technical data.

- The Solid-State Energy Conversion Alliance (SECA) is the highest priority program in DOE-FE. It is the foundation for the Vision 21 program, which represents one of the primary long term (2015) goals for DOE-FE. PNNL and NETL have partnered to bring SECA to fruition. There are currently four industrial teams developing solid oxide fuel cell systems for future energy needs. The SECA program is currently being leveraged by D OE-EE for auxiliary power units for the 21st Century Truck Partnership and by NASA for Aviation Power and Propulsion.

- PNNL developed a new national technology program entitled "Essential Power Systems" with D OE and the $21^{\text {st }}$ Century Truck Partnership. The goal of this program is the development of advanced heavy vehicle technologies (such as a fuel cell auxiliary power unit) that will reduce energy consumption and reduce fuel usage by up to 1 billion gallons per year if successful. Initial D O E solicitation went out in July 2002.

\subsection{Create Leading-Edge Scientific Capabilities to Support Evolving DOE Mission Needs}

- Winning Goal 1 of the Genomes to Life (GTL) call in collaboration with Oak Ridge National Laboratory opens the door for PNNL to participate fully in the 
DOE GTL initiative, a program that will help move biology from genome to proteome - the next frontier.

- Achievement of CS\&EI technical goals established computational capabilities in different scientific disciplines while simultaneously building a multidisciplinary advisory committee to help set new direction and review progress.

- PNNL's Nanoscience \& Nanotechnology Initiative produced excellent science and increased its internal and external visibility while simultaneously improving program focus and using peer review to establish direction and check progress.

\subsection{Create and Maintain Strategic Academic Partnerships that Strengthen Scientific Capabilities}

- PNNL's second year of collaboration with the University of Washington in Nanoscience and Cell Signaling was outstanding. This Joint Research Institute was productive in terms of both proposal and programmatic activity, expanding the horizons of both institutions and making possible an unprecedented range of interactions directed at supporting and expanding critical DOE programs and addressing important national problems.

- The Joint G lobal Change Research Institute (JGCRI), formed in 2001, has made significant progress in developing collaborative relationships between PNNL and the faculty and students of the University of Maryland. The strong global ties and network of the Joint Institute connect its efforts in climate change to national and international policy communities. We rate our performance on the JGCRI "good." Although the publication rate was high, progress on joint proposals was much slower than expected.

Additional partnerships were developed or strengthened during FY 2002, significantly enhancing PNNL's ability to address specific mission needs. These include:

- The High Temperature Electrochemistry Center (HiTEC) was formed in June 2002 to address the underpinning technology necessary to achieve the goals of Vision 21 as well as other advanced energy conversion devices. HiTEC is centered at PNNL with satellite centers at universities throughout the US. The center was initiated with a contract to Montana State University for \$1 million, and it is intended to add two additional universities next year. The goal is to add two universities per year until all technical bases are covered (seven universities are anticipated). Each university will receive approximately $\$ 1 \mathrm{million} /$ year.

- Northwest Water Research Partnership - A Memorandum of Understanding (MOU) was finalized in May between PNNL; the Idaho Water Resources Research Institute, University of Idaho; O regon State University, the O regon Center for Water \& Environmental Sustainability \& Institute for Natural Resources; and the State of Washington Water Research Center to productively pursue "Research and Technology Development Contributing to Optimal Water Resources Utilization for Fish and Wildlife Recovery in the Pacific Northwest."

- Northwest Bio-Products Research Institute Formed by PNNL, Idaho National Engineering and Environmental Laboratory, Washington State University, and the University of Idaho, this Institute has enhanced our ability to pursue joint research around the creation of high-value chemical products from agricultural material.

- Oregon Universities System/ Oregon Health \& Sciences University Collaborative Working Group - D uring FY2002, PNNL continued to engage in and strengthen this cooperative relationship for research and educational activities among O regon's higher education institutions (Eastern O regon University, O regon Institute of Technology, O regon State University, Portland State University, Southern O regon University, University of O regon, Western $O$ regon University, and the O regon Health and Science University).

- Micro-products Breakthrough Institute - Oregon State University and PNNL have teamed to establish the Micro-products Breakthrough Institute in order to accelerate the development and application of science and technology to transform chemical, energy and biological systems by employing micro and meso-scale processes. 

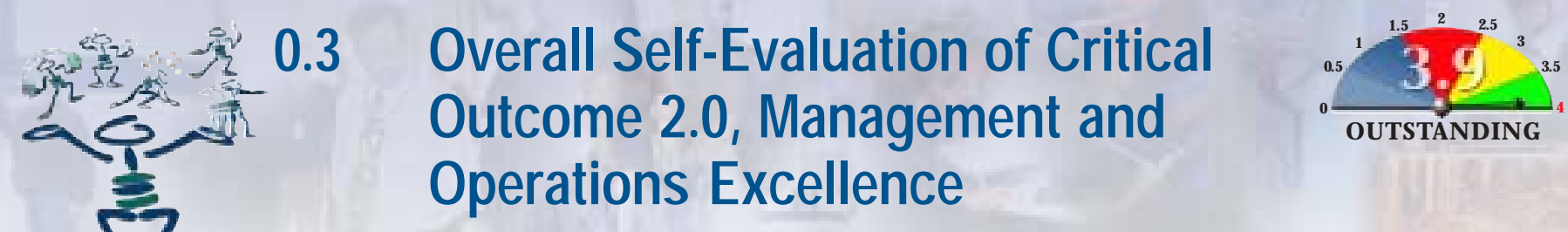

\section{In FY2002, PNNL met or exceeded nearly all DOE expectations in Management and Operations Excellence.}

Part I, Section 2 of this report details PNNL's self ratings of the adjectives and value points that lead to PNNL's Critical Outcome 2.0 FY2002 point total of 3.9 and performance rating of Outstanding for Management and Operations Excellence. Appendix $\mathrm{C}$ shows the adjectival and value ratings for FY 2002 Critical Outcome 2.0 and all of its objectives and performance indicators (Tables C.9 - C.12).

\section{Highlights of the Three Performance Objectives}

\subsection{Provide Management and Operational Excellence in Achieving Key Contract Performance Requirements}

In FY 2002, ES\&H management systems sustained and enhanced excellence in Laboratory O perations. PNNL continues to integrate sound safety and environmental management practices into daily operations. This is evidenced by lower accident rates for staff, no environmental releases, $99.7 \%$ of staff completing their assigned ES\&H training, and no reportable radiation dose or contamination events. The Lab consistently exceeds D OE's pollution prevention expectations for lowlevel waste, continues to achieve sustained environmental compliance, and this year, the Laboratory received the DOE "National Pollution Prevention" award. However, two items related to ES\&H warrant specific mention, the first being an uptake of depleted uranium which did not meet reporting thresholds, and the second involving a refrigerator with low levels of beryllium on the surface. In both instances, corrective actions are in progress and steps are being taken to prevent recurrence.

PNNL is committed to providing high quality science and technology at a competitive cost and has continued to improve its cost performance over the past decade. PNNL's overhead cost savings of $\$ 81$ million from FY 1994 to FY2002 in constant FY2002 dollars has translated in decreasing overhead rates and cost to our clients. PNNL's attention to cost management is apparent in the metrics performance in section 2.1.2. However, FY 2002 did highlight a weakness in funds control and work authorization policy. A corrective action plan is being implemented and significant progress has been made.

Safeguards and Security (SAS) continues to be more deeply integrated into the PNNL culture, and staff have the knowledge and training to carry out their responsibilities. In FY 2002, we had a higher number of staff with current SAS training and high marks in two external S\&S system evaluations. The bi-annual inspection by the Office of Counterintelligence rated the SAS program as "excellent," the highest evaluation possible. PNNL is the first national Laboratory to receive this rating. We had only one reportable security incident for the second straight year.

PNNL's FY2002 results exceed those in FY2001 in achieving adequate investment in maintenance and energy conservation. Highlights include:

- cycle time for dispatch work fell 17\%;

- preventative maintenance completed on schedule $99.6 \%$ of the time;

- energy reduced by $30.2 \%$, which already exceeds D OE's 2010 goal of 25\%;

- annual energy consumption reduced by $6 \%$;

- qualification of Sigma 5 as an Energy Star Building; and

- water consumption reduced by more than $30 \%$.

We won the International Facility Management Association Golden Circles Award, arguably one of the most prestigious awards in facility management, and received two Federal Energy Management Program awards and two DOE Departmental awards for energy conservation. 
In addition, the Laboratory signed an agreement to purchase and use 8.8 million kilowatt hours of power produced by a wind-generated energy project in FY 2003. The purchase covers more than 10 percent of the Laboratory's energy needs, and it means the Laboratory will be one of the federal government's leaders in the use of Green energy, with 13.7 percent of its energy coming from renewable resources. This level of usage surpasses goals set earlier in FY2002 by D OE for national laboratories and other sites to purchase three percent of their power from $\mathrm{G}$ reen sources by 2005 and 7.5 percent by 2010 . The PNNL purchase also will diversify the region's electricity portfolio and stimulate a new energy economy in the Pacific Northwest.

\subsection{Maintain and Enhance Laboratory Capabilities to Meet Current and Future Mission Needs}

PNNL demonstrated progress toward providing the information technology environment we need to help solve the nation's critical challenges in science, energy, environmental quality, and national security. Highlights include:

- $97.6 \%$ of PNNL desktop systems are connected via high speed connections;

- wireless coverage extends to $75 \%$ of staff;

- over 3100 staff are using the capability for digital signatures or encryption of sensitive information; and

- PNNL's collaboration environment now includes new electronic capabilities.

PNNL revitalized existing facilities and infrastructure and made progress toward building new facilities and infrastructure, providing additional capabilities and space essential to support research and development missions. Highlights include:

- upgrading two safety significant systems within RPL;

- eliminating legacy waste and contamination from PNNL assigned facilities;

- completing construction of the 331 and LSL II Laboratories in support of the Biomolecular Systems Initiative;
- completing revitalization of the National Security Building; and

- completing Phase 2 of the PNNL Site Master Plan.

\subsection{Provide Integrated Management Systems that Enable Effective and Efficient Business Performance}

PNNL continues to improve the effectiveness and efficiency of our ES\&H and business-related management systems by developing innovative approaches to Laboratory business operations that enable outstanding research, maximize value per research dollar, maintain forefront facilities and equipment, and protect DOE's information assets. Highlights include:

- D emonstrating the improvement of our Integrated Safety Management System through third-party verification, evidenced by the recent recommendation for PNNL's registration to ISO 14001 Environmental Management System standard, Voluntary Protection Program (VPP) G old Star status, the VPP Superior Star award, and Integrated Safety Management (ISM) validation.

- Completing a three-year effort to deploy the Integrated Operations System (IOPS) to all PNNL's Richland facilities. We also completed the initial system development for the Hazard Analysis Initiative, which, when deployed in FY2003, will provide an efficient mechanism to close the loop between proposal risk identification and mitigating the identified hazards of funded projects.

- Implementing three focused improvements in our radiological control program to better meet the needs of our research staff.

- Combining the Integrated Planning and Integrated Assessment into a single management system, reducing overhead costs by $\$ 215,000$. 


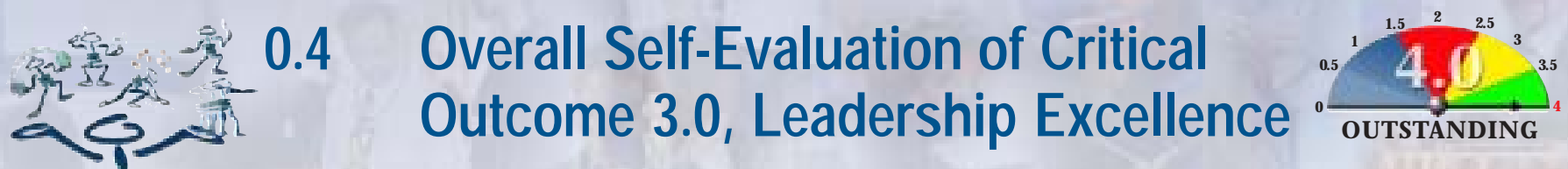

\section{In FY2002, PNNL met or exceeded all DOE expectations in Leadership Excellence.}

Part I, Section 3 of this report details PNNL's self ratings of the adjectives and value points that lead to PNNL's FY2002 point total of 4.0 and performance rating of Outstanding for Critical Outcome 3.0, Leadership Excellence. The adjectival and value ratings for this Critical O utcome and its objectives and performance indicators are provided in Appendix C (Table C.13).

\section{Highlights of the Four Performance Objectives}

\subsection{Attract, Develop and Retain the Critical Staff Necessary to Achieve Simultaneous Excellence in S\&T, Operations, and Community Trust}

The Laboratory's success depends on the ability of its leaders and managers to attract, motivate, and retain people who are committed to the objectives of the organization. PNNL attracts, develops, and retains staff by providing stimulating work, excellent salary and benefits, first-class facilities and equipment, and a highly engaged workplace. PNNL offers an attractive total compensation package composed of competitive base pay, comprehensive benefits, and flexible, variable compensation programs. In addition, we are making great strides in building a workplace where staff can grow and develop in their careers and where talents and strengths of frontline managers are fully developed and deployed. PNNL's Voluntary Separations Rate continues to be well below industry norms.

\subsection{Define and Shape the Future of the Region by Helping to Establish a Robust, Sustainable, Regional Economy}

In FY2002, we helped establish, relocate, or expand six new businesses, bringing our six-year total to 56. We also provided technical assistance, such as product development, materials testing, and resolution of technical problems, to 52 additional businesses. Ninety-three percent of the technical assistance recipients said they were satisfied with the assistance provided. In addition, the Laboratory helped fund and implement three new economic development initiatives designed to help small businesses find funding and attract key staff.

\subsection{Demonstrate the Relevance of the National Laboratory and Other Northwest Research Institutions to the Economic, Science and Technology Needs of the Region}

PNNL led an effort that focused the S\&T of the region's major public $R \& D$ institutions on solving the critical needs of the Northwest. PNNL established meaningful partnerships to link regional needs to science and technology strategies by reconvening the Linking Regional Resources (LRR) group to identify a set of critical needs amenable to S\&T solutions. The LRR is now focusing on the needs by finding technologies and technical resources that, if made commercially available, would both address those needs and stimulate new business and economic activity in the Northwest. The LRR group focused its initial effort on identifying bundles of technologies that might address regional energy needs. Based on that effort, the LRR group found four water resource technologies from the region's cooperating research institutions that could be used to address regional needs.

PNNL, with the Washington Technology Center, led the development of the Northwest Energy Technology Collaborative, a regional organization to accelerate the emergence and growth of the energy technology industry in the Pacific Northwest. The Collaborative is a joint, voluntary effort of business, government, non profit, industry and educational institutions in the Pacific Northwest who share the common goal to position the Pacific Northwest region of the United States as a recognized leader for innovative research, education and product development for energy technology markets around the world.

\subsection{Continue Excellence of the Laboratory's K-20 Programs to Further and Enhance Science, Mathematics and Technology Education}

For the third straight year, surveys confirm that PNNL has enhanced science education by introducing both teachers and students to research at the Laboratory. These programs were rated outstanding by $88 \%$ of the 62 teachers and $92 \%$ of the 112 students who participated. 


\section{Contents}

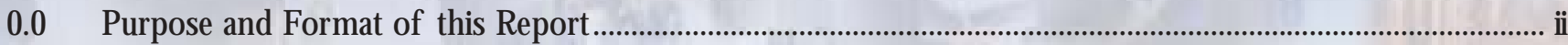

\section{Executive Summary}

0.1 The Basis for PNNL's "Outstanding” Rating in FY2002 _................................................................................. vi

0.2 Overall Self-Evaluation of Critical O utcome 1.0, Scientific and Technological Excellence ............................. viii

0.3 Overall Self-Evaluation of Critical O utcome 2.0, Management and Operations Excellence ............................ $\mathrm{x}$

0.4 Overall Self-Evaluation of Critical O utcome 3.0, Leadership Excellence ....................................................... xiii

\section{Part I-Status of Performance Against Critical Outcomes, 1.0 Science and Technology Excellence}

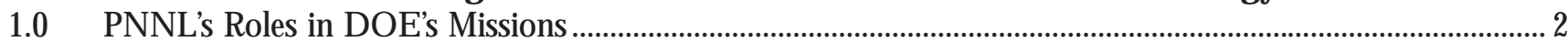

1.1.1 FY2002 Quality Recognition: Honors and Awards .................................................................................. 4

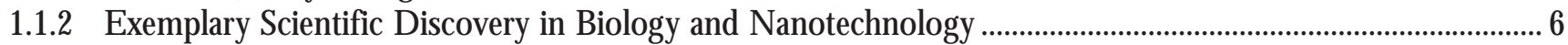

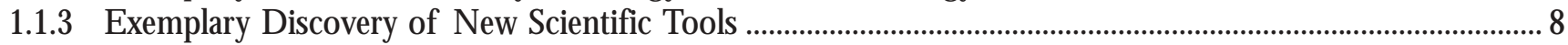

1.1.4 Exemplary Scientific Discoveries in Chemistry, Materials, and Climate Modeling ..........................................10

1.1.5 Operation of User Facilities - EMSL, ARM, and G-1 Aircraft ......................................................................12

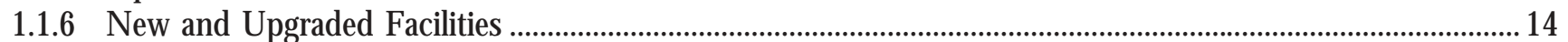

1.1.7 Effectiveness of Research Program Management ........................................................................................16

1.1.8 Efficiency of Reesarch Program Management .............................................................................................. 18

1.2.1 PNNL's Contributions to DOE's Environmental Management Science Program (EMSP) Targeting Complex-Wide Progblems ......................................................................................................................220

1.2.2 PNNL Leadership in the Tanks Focus Area ...........................................................................................................2 22

1.2.3 PNNL Support to Hanford Tank Waste Safe Storage and Retrieval ..............................................................24

1.2.4 Public Safety and Resource Protection Program ..................................................................................................2. 26

1.2.5 PNNL Support to River Corridor Restoration Assessment and Monitoring ...................................................28

1.2.6 PNNL Technical Integration Support to the Project Hanford Management Contractor

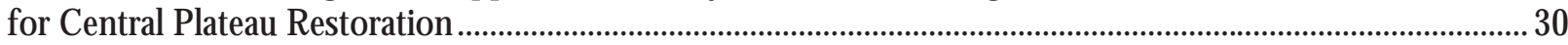

1.2.7 PNNL's Site-Wide Planning and Integration Support to DOE-RL .............................................................32

1.2.8 PNNL's Site-Wide Dosimetry Services Support for D OE-RL ….....................................................................34

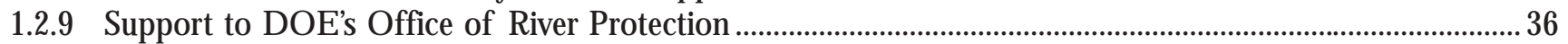

1.2.10 PNNL's Science and Technology Contributions to Hanford Site Environmental Restoration ........................ 38

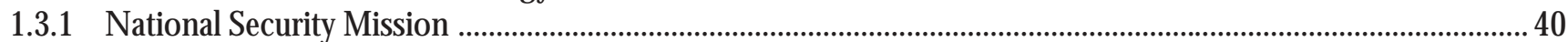

1.4.1 Improving the Nation's Energy Systems to Provide Secure, Clean, Affordable Energy: Distributed Energy and Energy Systems

1.4.2 Improving the Nation's Energy Systems to Provide Secure, Clean, Affordable Energy: High-Efficiency Transporation Systems

1.4.3 Improving the Nation's Energy Systems to Provide Secure, Clean, Affordable Energy:

Bio-based Products and Processes

1.4.4 Vision 21 Goals Advanced Through Zero-Emissions Fossil Energy Conversion Technologies:

Fuel Cell Technology

1.4.5 Vision 21 Goals Advanced Through Zero-Emissions Fossil Energy Conversion Technologies:

Carbon Management .....

1.4.6 Nuclear Science and Technology in Support of D OE Nuclear Energy and $\mathrm{O}$ ther National Security Missions

1.5.1a Building a Multidisciplinary Research Program in Systems Biology .....................................................................54

1.5.1b Importance of the DOE Genomes to Life Proposal Win and Advancements in Single Chain Antibody Generation

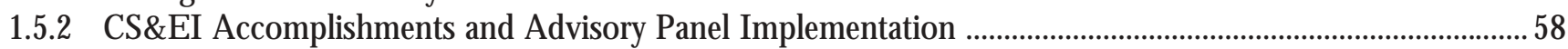

1.5.3 Nanoscience \& Nanotechnology Efforts at PNNL 
1.6.1 Impact of Joint Global Change Research Institute with University of Maryland 62

1.6.2 Impact of Joint Research Institute with University of Washington

Part I-Status of Performance Against Critical Outcomes, 2.0 Management and Operational Excellence

2.1.1 ES\&H Management systems that Sustain and Enhance Excellence in Laboratory O perations .......................68

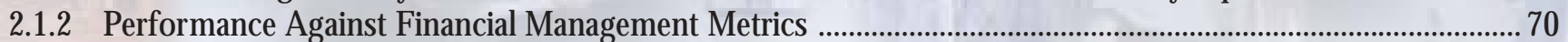

2.1.3a Permeation of Safeguards and Security (SAS) Integration and Training Throughout the PNNL Organization

2.1.3b Congruence of High External Evaluations of SAS Performance with Actual Identification, Reporting, and Mitigation of Threats ..................................................................... 74

2.1.4 Adequacy of Investments in Maintenance and Energy Conservation ................................................................ 76

2.2.1 Effective Execution of the Information Technology (IT) Infrastructure Strategic Plan to Achieve the 2010 Vision of the Laboratory ..................................................... 78

2.2.2 Progress Toward Needed Upgrades of Existing Facilities and Infrastructure .................................................8 80

2.2.3 Progress Toward Building Needed New Facilities and Infrastructure ................................................................. 82

2.3.1a Commitments to Improve the Effectiveness and Efficiency of Integrated ES\&H Management Systems

2.3.1b Commitments to Improve the Effectiveness and Efficiency of O ur Business-Related Management Systems

Part I- Status of Performance Against Critical Outcomes, 3.0 Leadership Excellence

3.1.1/ 3.1.2 How PNNL Attracts and D evelops the Best People to Carry O ut Its Mission .....................................90

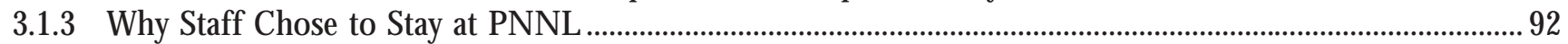

3.2.1 Number of New Businessess Started or Expanded in the Local Area Where Battelle Had a Material Role in their Establishment ........................................................................... 94

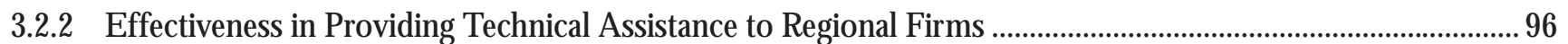

3.2.3 Developing and Championing New Economic Development Initiatives .........................................................98

3.3.1/ 3.3.2 Relevance of PNNL and Other National Research Institutions to the Economic, Science, and Technology Needs of the Region .

3.3.3 Relevance of PNNL and Other National Research Institutions to the Economic, Science, and Technology Needs of the Region .

3.4.1/ 3.4.2 Impacts of Laboratory-Sponsored Programs on Science and Math Teachers and Students... 104

\section{Part II- Readiness to Achieve PN N L 2010 Vision}

II.1 Readiness to Achieve the PNNL 2010 Vision: Strengths and O pportunities for Improvement .................. 108

II.2 Strengths and O pportunities for Improvement That Support Achievement of Strategic Objective 1.0, Science and Technology Excellence.

II.3 Strengths and Opportunities for Improvement That Support Achievement of Strategic Objective 2.0, O utstanding Managers and Staff...

II.4 Strengths and Opportunities for Improvement That Support Achievement of Strategic Objective 3.0, Leadership in R\&D Management and Operations

II.5 Strengths and O pportunities for Improvement That Support Achievement of Strategic Objective 4.0, Deployment of Highly Beneficial Technologies.

II.6 Strengths and Opportunities for Improvement That Support Achievement of Strategic Objective 5.0, Valued Regional \& Community Asset.

\section{Part III-Adequacy of PNNL's Self-Assessment Process}

III.1 DOE-RL's Satisfaction with PNNL's Self-Assessment Processes

and Use of Results to Improve Performance

III.2 Adequacy of the Performance-Based Self-Assessment Process ....

III.3 How Top Management Needs to Increase Clarity of Strategic Direction to Optimize Self-Assessment . 


\section{Appendix A- Peer Review}

A.1 Assuring the Scientific Quality and Relevance of O ur Work

to O ur DOE Customers through Peer Review ...................................................................................................1130

A.2 Fundamental Science Peer Review .......................................................................................................................132

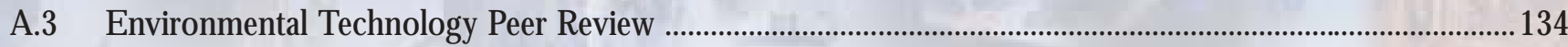

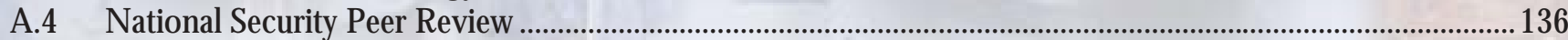

A.5 Energy Science \& Technology Peer Review ……………………………………………………………………....138

\section{Appendix B-National Security Mission}

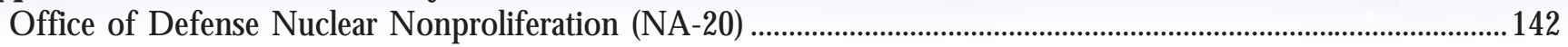

O ffice of Intelligence (IN) and Related Intelligence Work for O thers (IWFO ) Programs ........................................144

Office of Counterintelligence $(\mathrm{CN})$.......................................................................................................................... 146

Appendix C-Critical Outcome Performance Ratings …………………………………………………………....... 156

Appendix D-Acronyms ........................................................................................................................................... 


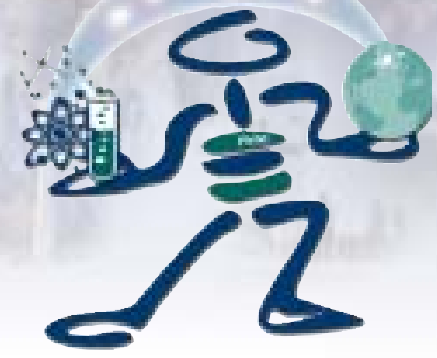

Part I

\section{Status of Performance Against Critical Outcomes 1.0 Science and Technology Excellence}

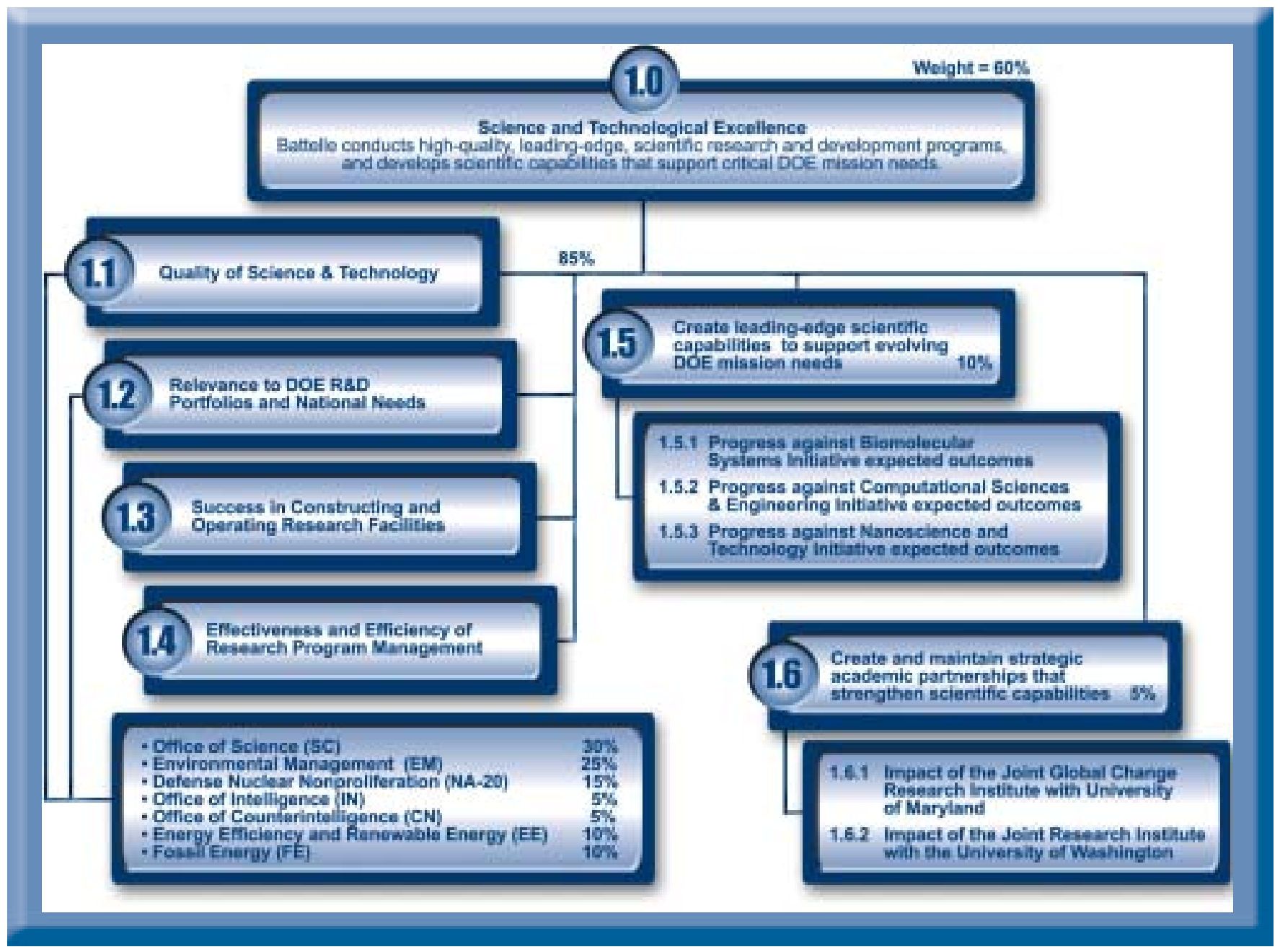




\subsection{PNNL's Roles in DOE's Missions}

\section{Battelle conducts high quality, leading-edge, scientific research and development programs, and develops scientific capabilities that support critical DOE mission needs.}

\section{Science Mission}

The Fundamental Science D irectorate (FSD ) manages PNNL's role in DOE's Science mission and is the primary customer interface for D OE's O ffice of Science (SC).

PNNL partners with DOE in advancing scientific discovery in the environmental, biological, computational and energy sciences. We advance the fundamental understanding of complex systems from molecular to global scales by building multidisciplinary, multi-institutional teams across the physical, chemical, computational and biological sciences. We develop unique instrumentation that is the hallmark of our national user facility, the W.R. Wiley Environmental Molecular Sciences Laboratory (EMSL).

In FY2002, FSD made some changes to enhance alignment with the DOE Office of Science, and to create leadership and programmatic opportunities for staff. The FSD organization now includes four research divisions and the EMSL research facility and user program. The new structure within EMSL will assure better integration into the divisions and the Laboratory, as well as a user facility focused on delivering world-class science in collaboration with leading experts in the scientific community.

The research in FSD is peer reviewed annually and the results for FY2002 are summarized in Appendix A.2.

\section{Environmental Quality Mission}

The Environmental Technology Directorate (ETD) manages PNNL's role in D OE's Environmental Q uality mission and is the primary customer interface for D OE's Assistant Secretary for Environmental Management (EM).

Researchers at PNNL support the DOE and other government and industrial clients in making informed environmental decisions and provide high-value science and technology to implement these decisions. We do this primarily through scientific research and engineering designed to develop and deploy new environmental technologies. We also work closely with our clients in many other areas associated with environmental deci- sion-making, including identification and assessment of environmental risks and impacts, analysis of costs and benefits, analysis of institutional and social factors, and articulation of policy options. Above all, our goal is to apply the full range of PNNL's resources to solve our clients' most challenging and pressing environmental problems.

The research in ETD is peer reviewed annually and the results for FY2002 are summarized in Appendix A.3.

\section{National Security Mission}

The National Security D irectorate (NSD) manages PNNL's role in DOE's National Security mission and is the primary customer interface for three key DOE-HQ Program O ffices: the Office of D efense Nuclear Nonproliferation (NA-20); the Office of Intelligence (IN); and the Office of Counterintelligence $(\mathrm{CN})$.

Researchers in NSD are developing solutions of national and international significance in counter-terrorism; nonproliferation of nuclear, chemical and biological weapons; medicine; and law enforcement. PNNL provides government agencies with policy guidance, and innovations to ensure that other countries are complying with the START and Comprehensive-Nuclear-Test-Ban treaties. In addition to technologies to detect nuclear weapons testing, the Laboratory's tools and training help detect and prevent smuggling of nuclear materials at international borders. Nonproliferation projects include advising the Russian government on security improvements at former weapons production facilities and managing the successful canning, and safeguarding of plutonium-bearing fuel rods in North Korea.

Research in NSD is peer reviewed annually and the results for FY2002 are summarized in Appendix A.4.

\section{Energy Mission}

The Energy Science \& Technology Directorate (ESTD) manages PNNL's role in D OE's Energy Resources mission and is the primary customer interface for the Assistant Secretary for Energy Efficiency and Renewable Energy (EERE), Assistant Secretary for Fossil Energy (FE), and Office of Nuclear Energy (NE). 
Researchers at PNNL demonstrate leadership, innovation, impact, and technical quality in converting, transporting and using energy consistent with national priorities and DOE's Energy missions and program plans. We provide science and engineering that result in significant improvements for secure, clean and affordable energy technologies. We emphasize technology and systems innovations that target improvements in energy infrastructure and security, and the development of low-cost, high performance, solid oxide fuel cells, hybrid fuel cell systems, energy storage systems, bio-based products, and essential technology for a hydrogen economy. Other areas of emphasis include leadership in climate modeling, integrated assessment, and $\mathrm{CO} 2$ capture and sequestration science and technology, and providing unique capabilities in advanced materials, processes and diagnostics critical to the development of next-generation nuclear reactors, and securing a safe and viable nuclear energy option.
FY 2002 was a critical transition year for D OE's EERE with several important changes in strategic budget priorities and organizational structure. As a result of these and other market conditions, PNNL made some key strategic changes during FY 2002 to strategically align PNNL energy resources with the new EERE structure, and to enhance our alignment with FE and NE.

Research in ESTD is peer reviewed annually and the results for FY2002 are summarized in Appendix A.5.

\section{Modules for Objectives 1.1 - 1.4}

Modules for Objectives 1.1 through 1.4 are grouped by mission area. Their relationship to quality, relevance, facilities, or management is shown in Table 1.0 and are referenced, for the reader's convenience, on page footers. All other module numbers for Critical Outcome 1.0 correlate to those in the FY2002 Fee Agreement.

Table 1.0. Relationship between FY2002 PEFA Objectives 1.1, 1.2, 1.3, and 1.4, HQ Program Offices, and the modules of this report.

\begin{tabular}{|c|c|c|c|c|c|}
\hline \multirow[b]{2}{*}{ HQ Program Office } & \multirow{2}{*}{$\begin{array}{l}\text { Report } \\
\text { Module }\end{array}$} & \multicolumn{4}{|c|}{ PEFA Section* } \\
\hline & & 1.1 & 12 & 1.3 & 1.4 \\
\hline \multirow{8}{*}{ O ffice of Science } & 1.1.1 & $\mathrm{X}$ & & & \\
\hline & 1.1 .2 & $\mathrm{X}$ & & & \\
\hline & 1.1 .3 & & $\mathrm{X}$ & & \\
\hline & 1.1 .4 & & $\mathrm{X}$ & & \\
\hline & 1.1 .5 & & & $\mathrm{X}$ & \\
\hline & 1.1 .6 & & . & $\mathrm{X}$ & \\
\hline & 1.1 .7 & & & & $\mathrm{X}$ \\
\hline & 1.1 .8 & & & & $\mathrm{X}$ \\
\hline \multirow{10}{*}{ A ssistant Secretary for Environmental Management } & 1.2 .1 & $\mathrm{X}$ & $\mathrm{X}$ & & \\
\hline & 1.2 .2 & $\mathrm{X}$ & $\mathrm{X}$ & & $\mathrm{X}$ \\
\hline & 1.2 .3 & $\mathrm{X}$ & $\mathrm{X}$ & & \\
\hline & 1.2 .4 & $\mathrm{X}$ & $\mathrm{X}$ & & \\
\hline & 1.2 .5 & $\mathrm{X}$ & $\mathrm{X}$ & & $\mathrm{X}$ \\
\hline & 1.2 .6 & $\mathrm{X}$ & $\mathrm{X}$ & & \\
\hline & 1.2 .7 & $\mathrm{X}$ & $\mathrm{X}$ & & $\mathrm{X}$ \\
\hline & 1.2 .8 & $\mathrm{X}$ & $\mathrm{X}$ & & $\mathrm{X}$ \\
\hline & 1.2 .9 & $\mathrm{X}$ & $\mathrm{X}$ & & $\mathrm{X}$ \\
\hline & 1.2 .10 & $\mathrm{X}$ & $\mathrm{X}$ & & $\mathrm{X}$ \\
\hline \multirow{2}{*}{$\begin{array}{l}\text { Office of D efense Nuclear Nonproliferation } \\
\text { O ffice of Intelligence } \\
\text { O ffice of Counterintelligence }\end{array}$} & 1.3 .1 & $\mathrm{X}$ & $\mathrm{X}$ & & $\mathrm{X}$ \\
\hline & App. B & $\mathrm{X}$ & $\mathrm{X}$ & & $\mathrm{X}$ \\
\hline \multirow{4}{*}{ Assistant Secretary for Energy Efficiency and Renewable Energy } & 1.4 .1 & $\mathrm{X}$ & $\mathrm{X}$ & & $\mathrm{X}$ \\
\hline & 1.4 .2 & $\mathrm{X}$ & $\mathrm{X}$ & & $\mathrm{X}$ \\
\hline & 1.4 .3 & $\mathrm{X}$ & $\mathrm{X}$ & & \\
\hline & 1.4 .4 & $\mathrm{X}$ & $\mathrm{X}$ & & $\mathrm{X}$ \\
\hline Assistant Secretary for Fossil Energy & 1.4 .5 & $\mathrm{X}$ & $\mathrm{X}$ & & $\mathrm{X}$ \\
\hline Office of Nuclear Energy & 1.4 .6 & $\mathrm{X}$ & $\mathrm{X}$ & & $\mathrm{X}$ \\
\hline
\end{tabular}




\subsubsection{FY2002 Quality Recognition:}

Honors and Awards

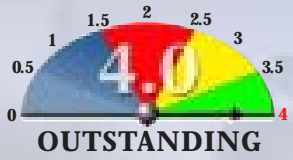

\section{Awards and professional honors demonstrate PNNL's continuing success in producing original, creative science and technology.}

\section{Honors}

Richard Benedick was elected to the American Academy of Diplomacy, an association of 100 former cabinet members, ambassadors and statesmen who have made notable contributions to American foreign policy.

\section{Governmental Awards}

Tom Ackerman received the NASA Distinguished Public Service Medal for making substantial contributions to the NASA mission. The medal is the highest honor NASA awards to anyone who was not a Government employee when the service was performed.

Ann Lesperance received the Bronze Medal for commendable service from EPA.

\section{Society Awards}

David Dixon received the American Society's 2003 national award for creative work in Fluorine Chemistry.

Richard Smith received the American Chemical Society's 2003 national award for creative work in Analytical Chemistry.

Allison Campbell has been selected by the American Chemical Society Women's Committee as one of the most promising female chemists in the nation.

Jeffery Dagle was named Tri-Cities Engineer of the Year for 2001 by the Tri-Cities Chapter, National Society of Professional Engineers.

Steven D octor received the International Society for Optical Engineering and the NDE Organizing Committee 2002 NDE Lifetime Achievement Award.

Shawn Knowles was named a 2002 Young Leader of The Minerals, Metals and Materials Society.

\section{Society Fellowships}

Deborah Dickman was elected a Fellow of the Institute of Nuclear Materials Management.

David Dixon has been named a Fellow of the American Physical Society.

David Geist has been named a Fellow in the American Institute of Fishery Research Biologists.
Landis Kannberg has been named a Fellow in American Society of Mechanical Engineers International.

Bruce Kay and Charles Peden were elected Fellows of the American Vacuum Society.

Robert Schenter was elected a Fellow in the American Nuclear Society.

\section{Election to Society Offices}

Walt Apley was elected to a three-year term on the National Board of Directors of the American Nuclear Society.

Evelyn Hirt was elected to the Aerospace and Electronics Systems Society (AESS) Board of Governors for 2002-2003.

Bruce Napier and Dan Strom were elected to six-year terms as members of the National Council on Radiation Protection and Measurement.

Steven Parker was elected president of the National Association of Energy Engineers.

Tom Tenforde was elected president of the National Council on Radiation Protection and Measurements.

Jean Futrell was appointed as a member of the National Research Council's Committee on Challenges for the Chemical Sciences in the $21^{\text {st }}$ Century: O rganizing Committee for the Workshop on Environment.

\section{Other Honors/Appointment}

Ann Lesperance was appointed to the University of Washington's Business School Advisory Board.

Michael Goshe received the prestigious M.T. Thomas Award for O utstanding Postdoctoral Achievement, for developing a new method to quickly isolate and identify selected proteins.

Roby Enge was elected to a three-year term as executive director of the Energy Facility Contractors G roup (EFCOG).

Mike Alexander, Nancy Forster-Mills, Jim Campbell, Margaret Romine, S.K. Sundaram, and Karla Thrall received Outstanding Mentor Awards from the Office of Science. 


\section{Technology Awards}

\section{R\&D 100 Award}

0 mniViz $^{\mathrm{TM}}$ represents an innovative breakthrough in retrieving and analyzing information from large, disparate numerical databases and text collections, with an unprecedented breadth of coverage, speed, and output options. $\mathrm{OmniViz}{ }^{\mathrm{TM}}$ enables the integrated analysis of scientific data and literature through the use of a variety of visual formats and query tools.

\section{FLC Awards}

Because of a change in the number of entries each laboratory could submit, PNNL submitted three rather than four entries this year. All three received awards. PNNL continues to lead all federal laboratories in the number of Federal Laboratory Consortium (FLC) Awards won (51). Brief descriptions of the three awards follow.

\section{Molecular Beam Epitaxy for Semiconductor Wafer Development}

MBE uses separately generated and controlled beams of atoms and molecules to deposit a thin film of crystalline material on a solid substrate. PNNL helped Motorola Labs obtain an advanced MBE deposition and analysis system, then collaborated with Motorola researchers to understand the basic science underlying the challenge to create the next generation of semiconductor wafers. In September 2001, Motorola announced that the MBE system and interactions with PNNL staff, combined with their own significant internal research, provided them with the information necessary to successfully combine properties of silicon with the speed and optical capabilities of high-performance compound semiconductors.

\section{Radio Frequency Identification Tags for Tracking and Inventory Radio frequency tags are small, inexpensive tags that can be used to identify, inventory and track assets. The tags range in size from a grain of rice to a credit card, and can be encoded with detailed information. Groups of items may be inventoried in minutes instead of days,}

and the exact location of a specific item can be determined at any time. Wave ID manufactures, markets, and distributes these radio frequency tags.

Ultra-Barrier Coatings for Flat-Panel Displays Electronic displays in cell phones, handheld computers, etc. typically are built with glass, but plastic offers the allure of thinness, ruggedness and light weight. But there are major technical obstacles to plastic displays. Water vapor and oxygen can pass through plastic and cause harm to sensitive display devices. PNNL researchers found a way to make plastic virtually impermeable, which may allow plastics to replace glass in electronic displays. Vitex Systems Inc. is bringing two products to market that are based on PNNL's ultrabarrier coating technology.

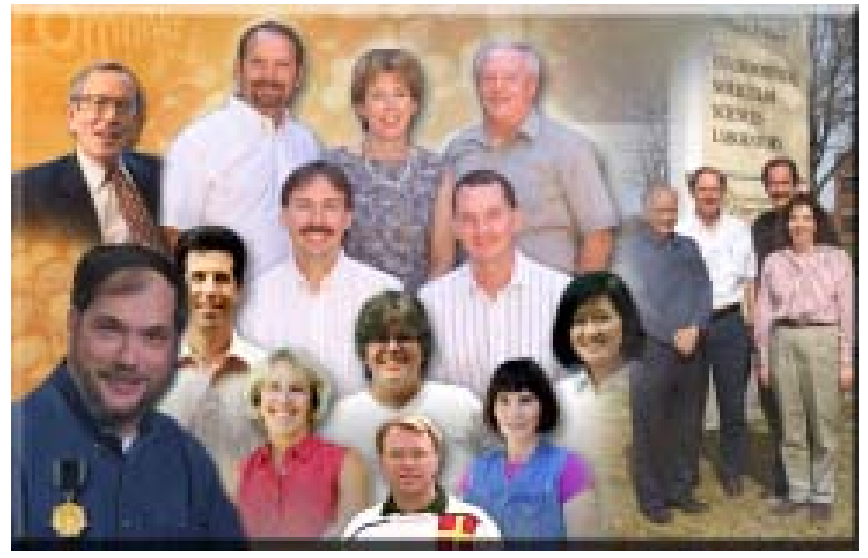

Figure 1.1.1a. PNNL appears routinely and prominently in the most prestigious of the scientific community's acknowledgments of excellence.

\begin{tabular}{|lcc|}
\hline \multicolumn{3}{|c|}{ R\&D 100 and Federal Laboratory Consortium } \\
Awards by National Laboratory \\
\hline \multicolumn{3}{|c|}{ R\&D Awards } \\
Multiprogram & $1964-2002$ & FLC Awards \\
Laboratories & $($ rank) & $1984-2002$ \\
Argonne & $64(3)$ & $($ rank) \\
Brookhaven & $23(9)$ & $21(4)$ \\
Idaho & $27(8)$ & $10(9)$ \\
Lawrence Berkeley & $32(7)$ & $8(11)$ \\
Lawrence Livermore & $80(2)$ & $18(5)$ \\
Los Alamos & $80(2)$ & $26(3)$ \\
Oak Ridge & $112(1)$ & $13(7)$ \\
Pacific Northwest & $59(4)$ & $29(2)$ \\
Sandia & $54(5)$ & $51(1)$ \\
\hline
\end{tabular}

Figure 1.1.1b. PNNL ranks fourth and first, respectively, among the other multiprogram labs in R\&D 100 and FLC Awards. 
1.1.2 Exemplary Scientific Discovery
in Biology and Nanotechnology

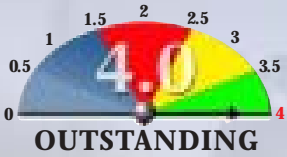

\section{In FY2002, PNNL advanced fundamental science, creating the potential for important new applications.}

\section{Enzymes have Broad Mission Benefit}

In a biological application of nanotechnology, PNNL scientists successfully immobilized enzymes while simultaneously enhancing their activity and stability, opening up new possibilities for using tailored nanoporous materials. The multi-disciplinary team of researchers developed a unique approach to boost enzyme activity and stability by entrapping enzymes in functionalized mesoporous silica (FMS). The findings recently reported in J. A m. Chem. Soc, could enable development of novel sensor and enzymatic engineering systems for homeland security, environmental protection, and energy generation, as well as new industrial chemicals and separations.

"For decades, scientists have been searching for ways to immobilize soluble enzymes with a variety of solid materials. But the results have been disappointing because only small amounts of the immobilized enzymes show any biological activity," said Eric Ackerman, PNNL molecular biologist. "For the first time, we have immobilized an enzyme at high concentrations in a way that actually enhances its stability and activity."

Enzymes, which are proteins found in all organisms from humans to viruses, function as catalysts. Increasing an enzyme's activity - while enhancing enzyme stabilitycould facilitate more efficient chemical processes. To achieve enhanced stability and activity, scientists modified existing nanoporous silica originally developed at PNNL to sequester mercury for environmental remediation. This material, called SAMMS- for Self-Assembled Monolayers on Mesoporous Supports- contains uniform pores that can be prepared with a variety of pore sizes according to the application. In this case, researchers enlarged the pores to 30 nanometers, which is a size sufficiently spacious to accommodate the immobilized enzymes. The pore surfaces were coated with carboxylethyl- or aminopropyl- groups, resulting in
FMS. The combination of high protein loading, high immobilization efficiency and stability is attributed to the large and uniform pore structure, and to the optimum environment introduced by the functional groups interacting with the charged amino acid residues of protein molecules.

PNNL scientists first selected the enzyme organophosphorus hydrolase $(\mathrm{OPH})$ because of its potential in a wide range of applications for biosensors, decontamination, and destruction of neurotoxic organophosphorus poisonous agents, including chemical weapons such as Sarin, Soman, VX, and Tabun. In lab tests entrapping the enzyme in FMS, the scientists nearly doubled its activity.

"Furthermore, we've been able to see more proteins successfully entrapped using this strategy," said Ackerman.

"Since amino groups and carboxyl groups form a naturally electrostatic couple in aqueous solution, we initiated our enzyme immobilization concept using the high affinity of amino-FMS and carboxyl-FMS to the surface amino acid residues of proteins. Since such entrapping mechanism is general, the appropriately functionalized and pore size-controlled FMS should work with most known enzymes and proteins. Besides O PH, we have already tested oxidase and isomerase as well," added Chenghong Lei, lead author of the recent study published in J. A m. Chem. Soc. 2002, 124(38): 11242-11243.

$\mathrm{OPH}$ used in these lab tests is not commercially available. It is a recombinant protein expression in the lab. "This research is a practical application of nanobiology," molecular biologist, Ackerman said. "By using highly active and stable immobilized OPH, we could potentially make enzymatic systems that could inactivate certain chemical weapons, thus serving as a protective barrier in air filtration systems of buildings or tanks." 


\section{Other Potential Benefits}

Fabrication of a more stable and active enzyme delivery method could potentially benefit other industries as well. For example, food processing companies use natural enzymes to produce items such as cheese, beer, and soft drinks, while the biomedical industry uses them to manufacture drugs.

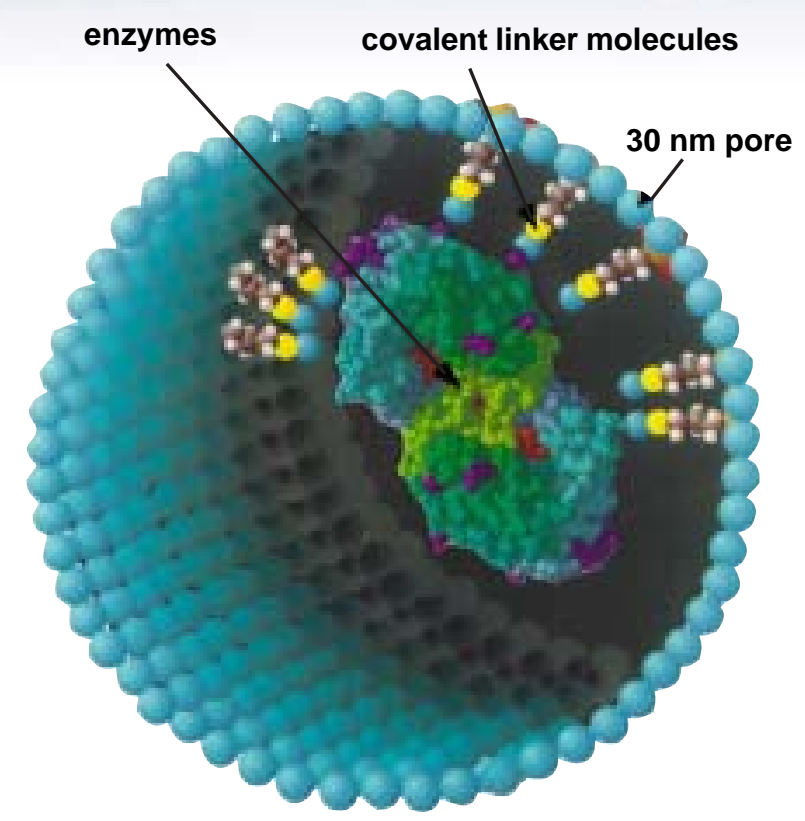

Figure 1.1.2. PNNL scientists have created a nanoporous silica that increases enzyme activity and stability by binding part of an enzyme to the walls of a 30-nanometer pore. 


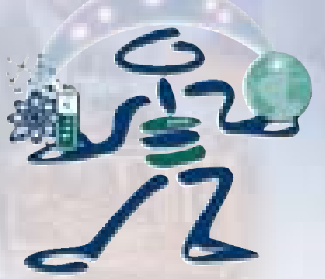

1.1.3 Exemplary Discovery
of New Scientific Tools

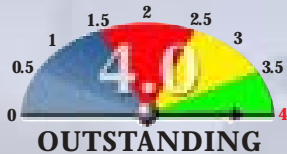

\section{A novel mass spectrometer, developed by PNNL, gives researchers access to never-before obtained information on microbes of interest.}

\section{A New Tool for Understanding Microbes}

PNNL scientists have obtained the most complete protein coverage of any organism to date with the study of a radiation-resistant microbe known to survive extreme environments. This research potentially could open up new opportunities to harness this microorganism, called D einococous radiodurans, for bioremediation.

To achieve this unprecedented coverage, researchers at PNNL developed and used a new high-throughput mass spectrometer based on Fourier-transform ion cyclotron resonance. This instrumentation allows scientists to identify thousands of proteins within hours. The system relies on a two-step process that first uses tandem mass spectrometry to identify biomarkers for each protein.

"We've not only identified the proteins, we have validated our results by using two mass spectrometry techniques," said Richard D. Smith, PNNL principal investigator. "O nce we've identified the protein biomarkers, then we never have to repeat the identification step, thereby speeding up our experiments. As a result we not only have a much more complete view of the proteome than existed previously, but we also can follow changes to it much faster."

Before Smith's team developed the high-throughput method of mass spectrometry, it took scientists two to three years to analyze a proteome with much less accuracy and depth than the recently completed analysis of D. radiodurans. With the high-throughput instrumentation and systems, Smith's team can now complete five to six such analyses of the proteins of a proteome in a day with sensitivities 100 times greater than other methods.

A study published in the Aug. 20 issue of the Proceedings of the $\mathrm{N}$ ational A cademy of Scienos observed 61 percent coverage of the microbe's possible predicted set of proteins, or its proteome. This is the most complete proteome reporting to date of any organism. PNNL scientists identified more than 1,900 proteins in D. radiodurans.

A "proteome" is the collection of proteins that make up a cell (or organism) under a specific set of conditions at a specific time. Studying the amount of each protein present at any time has become more important as scientists attempt to learn which proteins are involved in important cellular functions. D OE's Microbial Genome Program, an element of the Genomes to Life Program, provided the genomic information for various microorganisms, including D. radiodurans, and developed ways to predict the set of possible proteins, which hold the key to why and how these microbes carry out different functions.

\section{Microbe Could "Eat" Radioactive Materials}

D. radiodurans is of interest because of its potential to degrade radioactive materials, its ability to withstand high levels of radiation, and its impressive D NA repair capabilities. The Guinness Book of World Records once called it the world's toughest bacterium.

"We've been able to see more of the proteins, especially those proteins that exist in small quantities," said Mary Lipton, PNNL senior research scientist and lead author of the PNAS paper. "Because our coverage is unprecedented, we're now able to provide biologists with protein-level information they never had access to before."

To identify proteins involved in various functions, PNNL researchers exposed D. radiodurans to several stresses and environments: heat shock; cold shock; exposure to chemicals that damage D NA such as trichloroethylene; exposure to ionizing radiation; and starvation. They were able to identify many proteins previously only hypothesized to exist on the basis of DNA information and also proteins that seemed to have little function. 
New proteins that became active only during a specific condition also were identified, as were proteins that appeared to exist all the time.

Work on the D. radiodurans proteome dovetails nicely with a broad range of concurrent "science-to-cleanup" efforts at PNNL. These studies may be grouped into science themes with funding provided across a spectrum of DOE Programs:

\section{- BES Geosciences}

Mineral surface structure and reactivity, microbe membrane structure, biomineralization, nanogeochemistry

- OBER NABIR Biogeochemistry of Tc, U, Fe, and Mn; complex mineral-biologic systems
- OBER EMSP

Radionuclides chemistry; subsurface reaction kinetics; tank waste chemistry, thermodynamics, and molecular speciation

\section{- EMSP/ EM}

Resolving key science issues at Hanford

PNNL's unique capabilities, particularly within the EMSL, are being utilized to facilitate the transition from science to cleanup for such problem sites as Hanford's B-BX-BY Tank Farm where Uranium contamination is found in the soil column.

\title{
Commentary
}

\section{New technology may reveal mechanisms of radiation resistance in Deinococcus radiodurans}

\author{
Jan Mrázek* \\ Decartment of Mathematics, Seantort Lrvivenify, Stanford, CA 94305-2125
}

\begin{abstract}
A dvances in DNA sequencing technology in the past decade have resulted in rapid production of DNA data including more than 70 complete prokaryotic genomes and several cukaryotic genomes currently availahle. This accumulatike of sequence data has provided opportunities for development of proteomics. Proteomic analyses focus on composition of the protein mixture extracted from a cell culture and its changes in response to environmental disturtances of durine the cell cycle. A standard secmario is as follows: First, exlract the complex protein mixture from cell cultures groming under controlled conditions. Then rus a twodimensional PAGE to separate different proteins into a lares number of often partly overlapping spots. Finally, identify the spot rd assign them to known nnota if $\mathrm{m}$ it $\mathrm{w}$
\end{abstract}

\begin{abstract}
genic, red-pigmented hacterium. Although technically Gram-positive, D. nuliodurans features pilasma and outer membranes and a multilayer cell envelope reminiseent of Gram-negative bucteria (5). Its radioresesbance makes it one of the leading candidates for bioremodiation of radioactive waste sites that contain harardous mivelures of radionuctister, heavy metals and other tovic chemicals. Engi-
\end{abstract} neered strains of $D$ nadiodunens are ca: pable of transforming these mistures to les hazardous ones by degrading soene of the toxic components $(6,7)$. Understanding molecular mechanisms that allow cells to sarvive damagine - tots of UV radiation is alko of scal rescarch espccially in late numerous doublestrand DNA breaks during irradiation and imokes its extraordinary DNA repair facility to reconstroct its genome from the remaining frapments (11, 12), Simitar repair mechanisms are also apparently involved in fadioresistance of Arococomes furiosus (13) and possibly other Inperihermoghilic archaea. Mam bacteria incloding $D$. rafiodurms porscso multiple copics of their ctiromotames and can recover from a lim: ited number of dou. ble-strand DNA breaks by reassembling an intact chroenosome from cwerlapping frugments via homologous re* coenhination. However, multiple copoes of chromosomes do nex themselves confer ratdiation resistance, $D$ maxivfurmens can rerthan $10 \mathrm{kit}$ inva?

Figure 1.1.3. PNNL's microbial work receives praise in Proceedings of the National Academy of Sciences (8/20/02). 


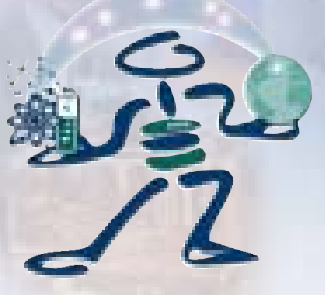

\subsubsection{Exemplary Scientific Discoveries in Chemistry, Materials, and Climate Modeling}

\section{In FY2002, PNNL developed new science and technology to advance DOE \& other national missions.}

PNNL is advancing science in numerous areas relevant to the D OE mission. In this section we present three brief examples to illustrate the breadth of scientific areas being investigated.

\section{A Fundamental Quantity in Chemistry Revised}

Few thermochemical quantities are more fundamental to chemistry than the $\mathrm{O}-\mathrm{H}$ bond dissociation energy in water. This bond energy - or, equivalently, the enthalpy of formation of the hydroxyl radical, D Hf $0^{\circ}(\mathrm{OH})$ - is a critical parameter in models that describe complex environments, such as flames or the troposphere, where the balance between production and consumption of hydroxyl radicals is important in shaping the overall chemistry. The value of $\mathrm{DHf} 0^{\circ}(\mathrm{OH})$, has recently been revised to $8.85 \mathrm{kcal} / \mathrm{mol}$ based on scientific data obtained by a multi-institutional team of scientists using leading-edge experimental and computational approaches (cover article of the March 21, 2002 issue of the J. Phys. Chem. A .). Models describing flames or the atmosphere typically include a very large number of intertwined chemical reactions, and their predictive ability can be quite sensitive to minute inaccuracies in the enthalpies of formation of key intermediate species, such as $\mathrm{OH}$. In addition, $\mathrm{OH}$ radicals play a key role in radiation chemistry and as highly reactive species in biological systems.

A team of scientists from Argonne National Laboratory (ANL), Pacific Northwest National Laboratory (PNNL), Washington State University (WSU), Ames Laboratory and Iowa State University (ISU), Lawrence Berkeley National Laboratory (LBNL), and NASA Ames Research Center (ARC) used advanced experimental, including the Advanced Light Source at Lawrence Berkeley National Laboratory, and computational capabilities to revise the heat of formation of the $\mathrm{OH}$ radical. The new value is $0.5 \mathrm{kcal} / \mathrm{mol}$ below the previously accepted values of the heat of formation of $\mathrm{OH}$.

\section{Anchoring Metals to Thin Metal Oxide Layers}

A newly patented way to deposit metal atoms on very thin oxide layers may help next-generation computers boot up instantly, making entire memories immediately available for use. The technique also may help fabricate less expensive catalysts for chemical reactions and lead to better nanotechnology devices and ceramic/ metal seals. The method, described in the August 2 issue of Scieno, anchors ultrathin metallic layers to metal oxides by using a chemical reaction discovered at the Pacific Northwest National Laboratory. The inexpensive trick bypasses the hurdle created when metal atoms cluster together into three-dimensional islands when deposited on oxide surfaces. These ultrasmall islands of metal - similar to water beads on a waxed car- produce discontinuous, noncrystalline metal films. The new smooth interfaces achieve crystallinity by only a few atomic layers and should also produce greater durability in electronic devices.

"Many advanced technologies rely on strong interfaces between metals and oxides," said Scott Chambers, PNNL chief scientist and lead author of the Scieno paper. "T hese findings are very exciting because they may provide the molecular insight industry needs to create better materials for microelectronics and sensors."

The findings may have the most immediate bearing on magnetic tunnel junctions, slated for use in magnetoresistive random access memory, or MRAM. MRAM will allow computers to store information in a nonvolatile fashion, meaning that the information is not lost when the computer is turned off. As a result, MRAM promises a day when computers would boot up instantly once turned on. Major corporations have begun developing MRAM modules in hopes of generating robust nonvolatile memory in the next few years. 
Catalysts are involved in approximately two-thirds of the gross domestic product of the United States, particularly oil. Their wide applications allow chemists to turn one molecule into another. The new discovery should also enable the production of catalysts where the reactive metal on an oxide support is only one atomic layer thick, thereby saving considerable cost. The new method can use equipment already in place in chip manufacturing plants.

\section{Mid-Century Effects of Climate Change on Water Resources}

D OE's Accelerated Climate Prediction Initiative (ACPI) is a bold response to previous findings of the National Research Council Report (NRC, 1998: Capacity of U.S. Climate Modeling To Support Climate Change Assessment Activities) that " ... the U.S. lags behind other countries in its ability to model long-term climate change," and that "... it is inappropriate for the U.S. to rely heavily upon foreign centers to provide high-end modeling capabilities." Results of this project demonstrate that climate change can have significant effects on water resources in western U.S. in 50 years. The warming associated with the projected build-up of greenhouse gases can potentially lead to more than 50\% reduction in snowpack along coastal mountains, along with increased likelihood of wintertime flooding and decreased summertime water supply in major river basins.

Using a regional climate model developed at PNNL, Ruby Leung and colleagues have compared the present climate and three possible realizations of future climate between 2040-2060. Results show that by mid-century, the warming of $1-2.5^{\circ} \mathrm{C}$ strongly affects snowpack in the western U.S. along coastal mountains and can lead to a reduction in annual snowpack greater than $50 \%$. In addition, extreme precipitation is found to increase by $5-15 \mathrm{~mm} /$ day along the Cascades and the Sierra. These changes in snowpack and extreme precipitation suggest higher likelihood of wintertime flooding and reduced water supply in the summer, with serious impacts on water resources in the western U.S.

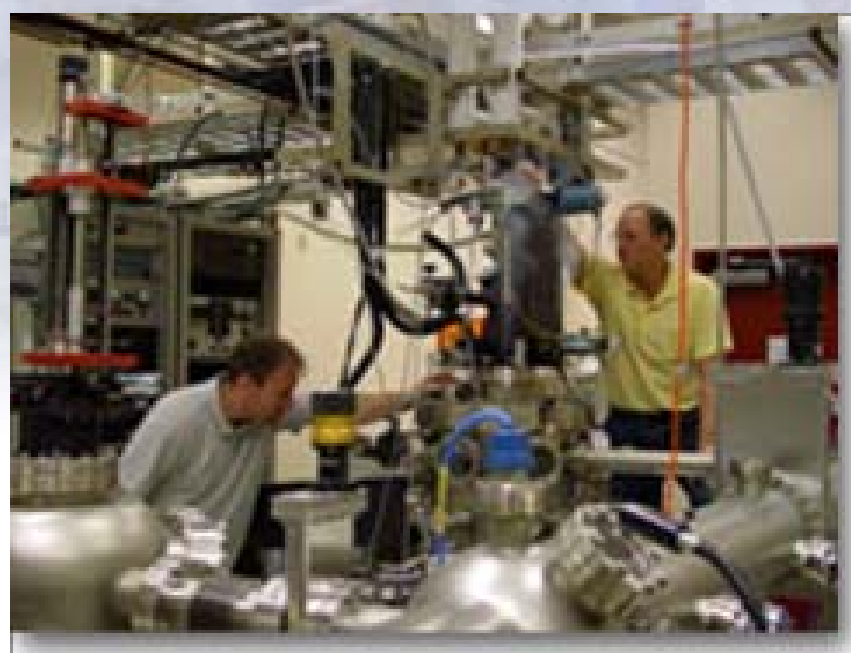

Figure 1.1.4a. Tim Droubay and Scott Chambers use a molecular beam epitaxy system to create a continuous thin film of metal layer on metal oxide.

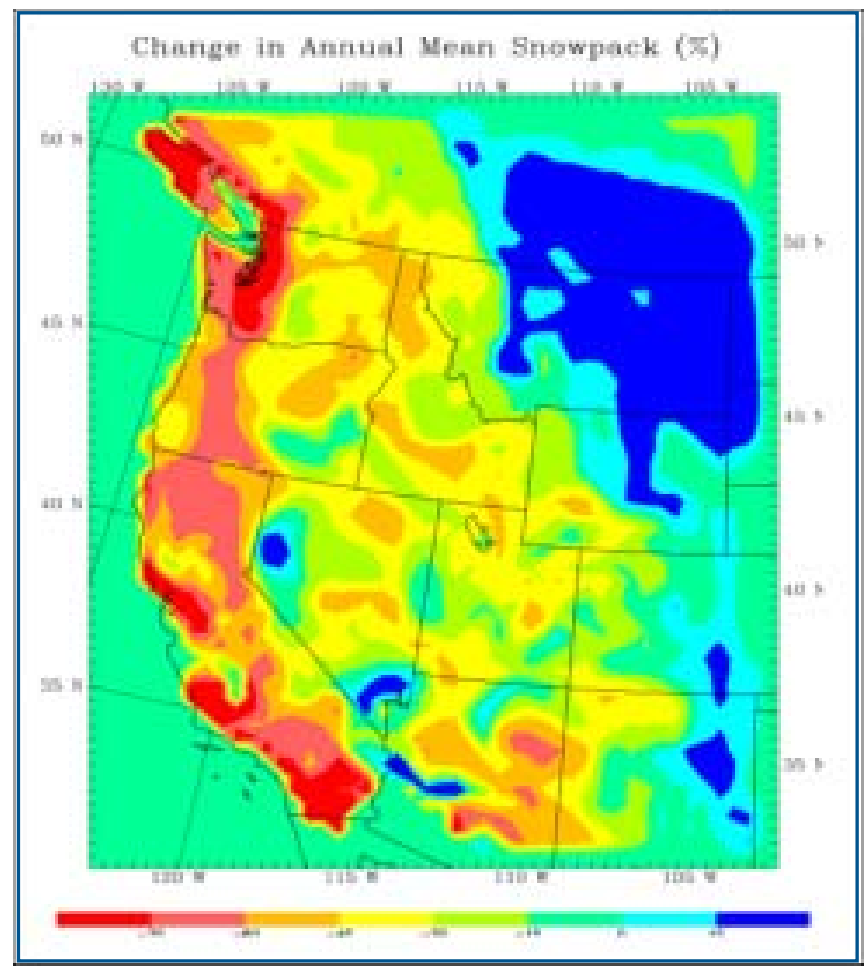

Figure 1.1.4b. Projected changes in mean annual snowpack predict dire consequences for water resources. 


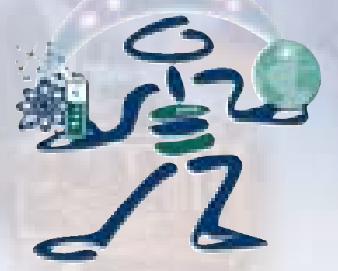

1.1.5 Operation of User Facilities -
EMSL, ARM, and G-1 Aircraft

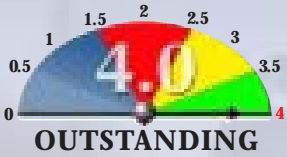

EMSL's action plan in response to DOE's November 2001 review will enhance the user program and the impact of the science conducted within the EMSL. ARM is touted by expert peer reviewers as a valuable national asset for the nation's climate research program. The G-1 Aircraft continues to provide a unique user facility that contributes to resolving fundamental questions about the atmosphere.

\section{EMSL}

While generally complimentary of EMSL's "first rate" instrumentation and ability to "attract outstanding staff," the November 2001 D OE-SC peer review identified nine improvement needs. These needs are listed below, along with actions taken or planned. Three additional improvement needs identified by the D OE/ OIG in a separate report have also been addressed.

\section{User Operations}

1. Better definition of the U ser A dvisory $\mathrm{C}$ ommittee role and more active engagement of the committee in assessing short-term needs and long-term planning - The Committee has been greatly expanded in size and scope. New duties will include external peer review of proposals, strategic planning for EMSL, and facility development. The new committee will meet in November 2002.

2. Better usage tradking of all major E M SL instrumentation The EMSL Resource System (ERS) was developed and beta-testing is complete to track EMSL instrumentation. ERS will be operational by the end of October 2002.

3. More timely and omplete input on user satisfaction -At the completion of each EMSL User Proposal, the user will receive a Satisfaction Survey by e-mail. Follow up emails will be sent periodically to non-responsive users.

\section{User Accomplishments}

4. Clear distinction between E M SL scientist and user accomplishments while continuing to encourage collaboration - EMSL has been substantially reorganized effective 0 ctober 1, 2002. Under this reorganization, all EMSL scientists will be users.

5. E nhanoed efforts to identify and increase scientific impact of E MSL user research - In coordination with OBER staff, the EMSL user program is being refocused around a set of scientific grand challenges to increase its impact. Several workshops intended to define the grand challenges are planned for the first quarter of FY03, and at least two grand challenges will be piloted in EMSL by the end of FY 03 .

\section{Leadership and Planning}

6. E M SL strategic planning needs to be focused with improved planning for maintaining the capital investment in E M SL Planning for EMSL capital equipment needs (3-year basis) was completed in February 2002 and included in the FY 2003-2008 Institutional Plan, presented at the On-Site Review on O ctober 1, 2002. Annual planning will be reflected in EMSL's FWP.

7. Plans need to be developed in ollaboration with BE R to replaœe ex isting instrumentation as the state of-the art advanos, adding new capabilities as appropriate - Planning for EMSL's next generation facility and equipment needs, completed in August 2002, was included in the FY 20032008 Institutional Plan and presented at the O n-Site Review on O ctober 1, 2002. Planning will continue annually.

8. Relevance of research to D OE missions needs to be strengthened - All Lab-level and FSD LD RD investments were evaluated this year with "relevance to DOE missions," used as a funding priority. EMSL directed significant funds to build a capability in support of OBER's Genomes to Life Program, e.g., highthroughput mass spectrometry to serve as the cornerstone for a BER Pilot Production Facility.

9. E M SL needs to expand its interactions with SC managers as well as its mark eting efforts to the scientific community for the marquee instruments/ capabilities and for its problem-solving environment - EMSL management has met frequently with our SC clients (BER, BES, and ASCR) to address their specific needs and requests. The 
October 1, 2002 reorganization of FSD, was undertaken, in part, to increase client focus of all research programs, including EMSL. EMSL sponsored a series of outreach activities to market our capabilities, including EMSL 2002 User Meeting, NLCat2002, EPSCoR 2002, and a series of workshops for our SC clients (e.g., "Understanding the role of water in electron-initiated and radical reactions," September 26-28, 2002, organized by BES).

\section{DOE/OIG Report}

There were three recommendations from the OIG . - Over the past year, the Lab has improved the Electronic Records and Information Capture Architecture (ERICA) tool, and implemented performance metrics to resolve the first two issues about making sure that all appropriate non-proprietary research results are forwarded to Office of Scientific and Technical Information (OSTI). The third recommendation calls for a project management system to track EMSL non-proprietary research through its lifecycle. The EMSL user proposal system was replaced with a significantly improved version on October 1, 2002, which implements this recommendation. The project summaries and publications will be sent to OSTI via PNNL's ERICA system.

\section{ARM}

PNNL's involvement in managing ARM has contributed to a steady increase in user publications and access to data. ARM continues to grow with the addition of a new site in D arwin, Australia. The Directorate Review Committee was especially complimentary of the ARM program, viewing it as "best in class." The committee concluded that "ARM addresses the central scientific issue in global change, the role of clouds in climate modeling. The ARM program has been a resounding success, with output of the program incorporated worldwide into global climate prediction models. The scientific staff internally, and the scientific collaborations, represent the very best of the world's scientific experts in this area."

An FY2001 JASON G roup review, received this year, concluded that "ARM is a valuable component of the U.S. G lobal Change Research Program, and its work should be fostered and enhanced in the future." Further it noted that "Significant progress has been made in a number of important scientific areas, including radiative transport properties in clear skies and of skies in the presence of certain types of clouds, improvement and validation of parameterizations that are used in certain types of general circulation models of the earth's climate, and development of observational tests of various modeling efforts on space/ time scales that range from weather forecasts of hours/ days to climatic time scales that are relevant to global change on the decadal to centurial time scale. ARM is also serving a valuable role by providing primary ground validation sites for several NASA satellite missions and by providing many well-calibrated time series of important atmospheric data on a climatologically significant time scale."

\section{G-1 Research Aircraft}

The G-1 continues to perform its unique role in atmospheric research as a flying research platform. The G-1 completed a three-pronged research program based in Worcester, MA with $\sim 72$ research flight hours over a 35-day period with no unscheduled downtime. The studies involved collaborators from Aerodyne Research Inc., who tested their new Aerosol Mass Spectrometer as part of a DOE SBIR project; Brookhaven National Laboratory, who investigated daytime air quality over upwind New England; and PNNL, who studied the nighttime chemistry of air pollutants downwind of Boston. The latter two studies were funded through D OE's Atmospheric Chemistry Program and also involved several university collaborators.

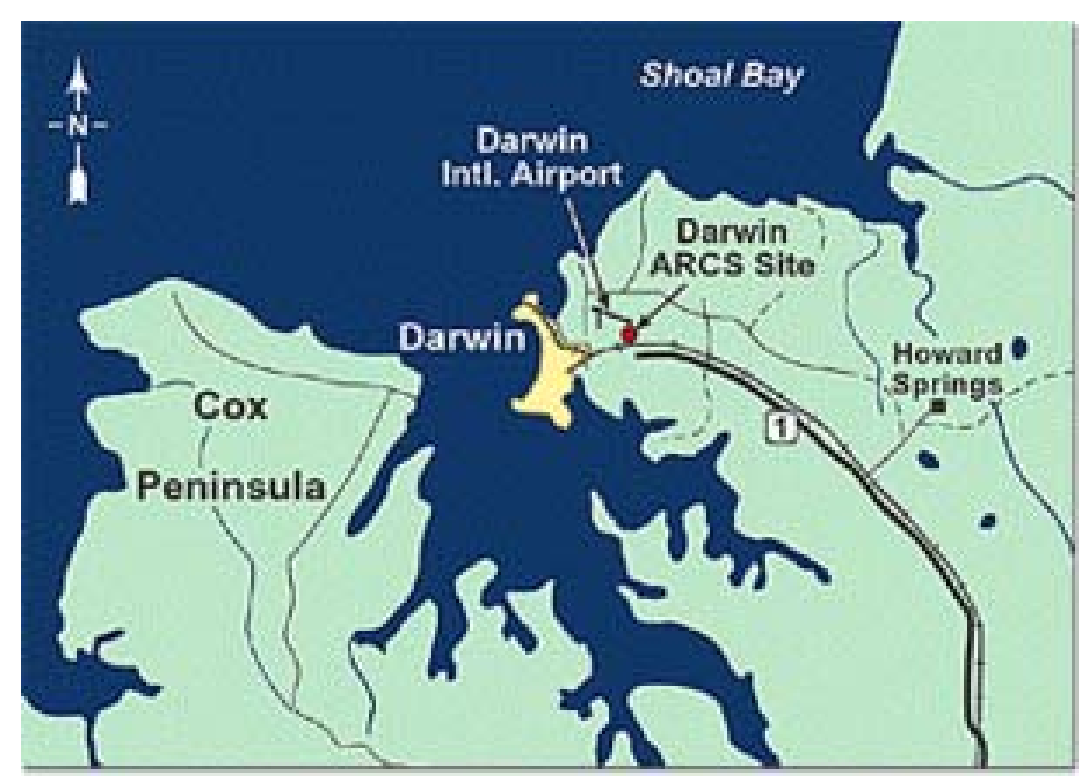

Figure 1.1.5 The new ARM site at Darwin, Australia, will expand our understanding of regional climates. 
1.1.6 New and Upgraded Facilities

PNNL is progressing towards establishment of Systems Biology Research Centers, construction

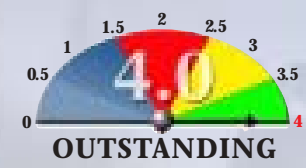
of a new Computational and Analytical Sciences Building, and installation of the EMSL Supercomputer and 900MHz NMR.

\section{Systems Biology Research Centers}

PNNL is supporting DOE-BER in its Genomes to Life Program facility planning, eventually leading to establishing Systems Biology Research Centers at PNNL that will complement centers at other locations. Systems biology research centers will support PNNL's goal to have a forefront program in systems biology.

PNNL has completed a pre-conceptual plan for systems biology facilities aligned with DOE-BER's G enomes to Life Program facility planning. With considerable PNNL input, DOE-BER is preparing various documents for D OE-SC and the budget office to support the planning and budgeting process. D OE-BER GTL facility needs are described in a planning document on their website: http:/ / doegenomestolife.org/ research/ facilities.pdf

D OE-BER Genomes to Life (GTL) Program facilities planning is making excellent progress and taking extremely proactive and timely actions:

- April 2002 - DOE-BER Advisory Committee (BERAC) meeting - GTL Program facilities and resources needs presented and discussed

- May 2002 - D OE-BER completed report on the facilities and resources needs of GTL Program "DOE Resources and Technology Centers for Biological Discovery in the $21^{\text {st }}$ Century" - document referenced above

- June 2002 - Initial D OE-BER GTL Facilities planning workshop was held in San Francisco

- August 2002 - Follow-up DOE-BER GTL Facilities planning workshop was held in Chicago

- September 2002 - Outcome from above actions and related activities and effort are D OE-BER GTL Facilities plan documentation for the DOE-O ffice of Science to support continuing forward.
PNNL is strongly supporting and engaged in DOEBER GTL facilities planning:

- PNNL staff are participating in workshops and assisting in report and documentation preparation

- Feedback from DOE-BER on PNNL's scientific and project/ business management support has been extremely positive.

- PNNL support and contribution will continue into FY 2003

With continued favorable progress in the GTL facilities planning, D OE and PNNL are planning on obtaining mission need approval (Critical D ecision 0) for appropriate systems biology research centers in the $1^{\text {st }}$ half of FY 2003.

\section{RFP Ready To Go}

- All documentation (Performance Specifications, Room Data Sheets, SEPA, Biological/ Cultural Review, etc.) required to issue the RFP for the

- Computational \& Analytical Sciences Building (CASB) has been developed and is ready for release. Completion of the Battelle Site Master Plan allowed the siting of the facility and location for utility services.

- Financing alternatives are being explored to provide the best value for D OE and Battelle.

- An external web site has been developed to expedite communication to potential bidders where they can get the necessary documentation for responding to the RFP.

- D OE programmatic support has been well received and D OE Market Sector and BMI support is on the way. DOE-RL approval will be sought once Battelle approves. 
EMSL Supercomputer Installation Is On Track.

Installation is going exceptionally well. The

Supercomputer prototype was delivered in May, 2002.

We reached $96 \%$ of peak on a single processor for a matrix multiply. As part of Phase 1, a 1TFlop system from HP was installed in August and September, 2002. Phase 1 is already obtaining $83 \%$ of peak on Linpack benchmark on the full system within 1 week of installation. Phase 1 will be available to users in Nov. 2002. D elivery of the Phase 2 system with 9.1 Tflop peak, 3.8 Tbytes memory, 173 Tbytes of disk, and the Q uadrix Elan switch is planned for February or March 2003 and will be made available to users in June 2003.

\section{Installation of The $900 \mathrm{MHz}$ NMR Is On Track.}

The $900 \mathrm{MHz}$ Magnet was made cold April 29, initially energized early May, and brought to field June 24. The final installation phase of the magnet continues with installation of NMR systems (consoles, probes). As of year-end, the magnet was undergoing acceptance testing (magnetic field homogeneity and stability $<10 \mathrm{ppb}$ ) and completion of final punch-list items. It is expected that the magnet will be accepted during $1^{\text {st }} \mathrm{Q}$ uarter, FY 03. Plans are to make the magnet available to the full user community by $3^{\text {rd }}$ quarter, FY2003 (after commissioning operations/ preparation by PNNL staff). Facility issues related to cryogen (liquid $\mathrm{He}$ ) delivery/ recovery are being addressed.

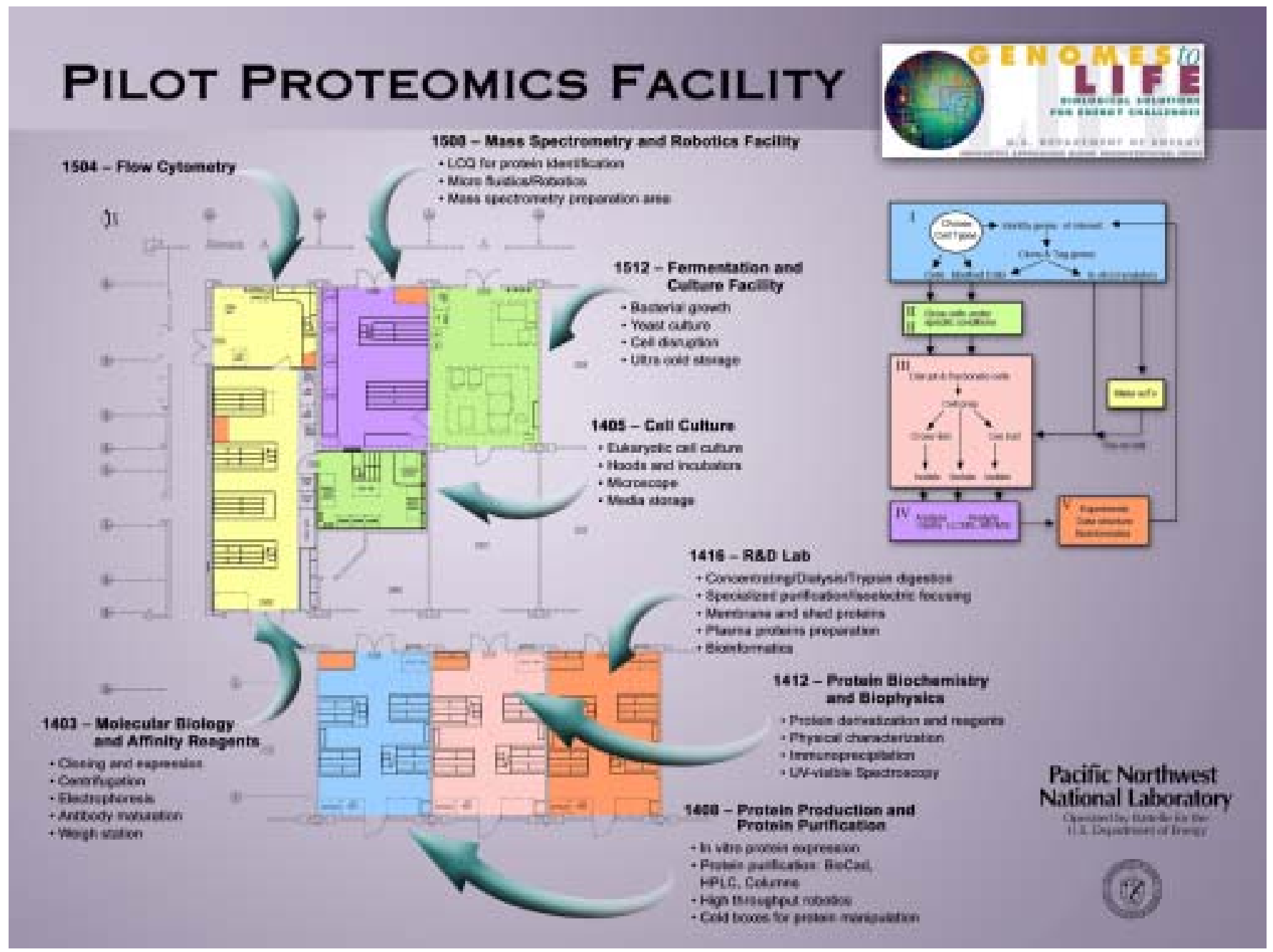

Figure 1.1.6. A Pilot Proteomics Facility (first stage of the Systems Biology Research Center) will be housed in upgraded existing space. 
1.1.7 Effectiveness of Research Program Management

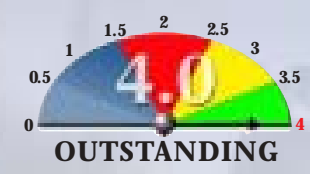

\section{Office of Science customers provide feedback; identify opportunities for improvement.}

D uring September, the FSD ALD conducted customer satisfaction conference calls with the Associate Directors of BER and ASCR and the Director of the BES Chemical Sciences, Geosciences and Biosciences Division.

\section{BER Feedback}

BER rates the overall quality of our leadership as excellent. BER and the Labs share a frustration regarding the difficulty of recruiting high level scientists, particularly in the Life Sciences. We all need to continue to be persistent and creative in this area.

The Program Manager of ARM would like more communication and responsiveness from the ARM Chief Scientist. Due to the increased visibility of ARM now and in the next few years, ARM requires more attention in the areas of leadership and teaming. BER is pleased that ARM is now considered a flagship program.

BER has high regard for how PNNL has teamed with other laboratories and universities. PNNL has made tremendous strides in this area in the last couple years.

$B E R$ is very pleased by the institutional support $B E R$ programs have received at PNNL.

Overall, while several people in BER are concerned about the many organizational changes that have occurred in FSD recently, the Associate Director is confident that we are on the right track and will succeed. He is pleased by the support of both PNNL and Battelle during the transition. There is a heightened awareness of the importance of managing EMSL well, and the Associate D irector believes PNNL is listening to BER in this area.

\section{BES Feedback}

O verall the Chemical Sciences, G eosciences and Biosciences Division is happy with the programs it supports at PNNL. There are only a few issues, and they are being dealt with expeditiously by the Lab. The Director has been very satisfied with the responsiveness of each of the PNNL management levels with which he has interacted.

The D irector rates the overall quality of scientific leadership excellent to outstanding. Minor problems are being resolved in part by FSD's reorganization.

The Director believes PNNL demonstrated very well its ability to team with other labs in the SciDAC proposal effort. PNNL played a pivotal role in coordinating that proposal effort.

From the BES perspective, PNNL's main agenda is biological not chemical, but we are still doing a very good job of supporting the BES-funded work.

The Director gave high marks to our overall program management, emphasizing that management at all levels has been very responsive. He believes we could all improve our strategic planning. BES and PNNL should increase our strategic planning interface. While we are not a major BES lab, the Director is very interested in the Lab's plans and how they may affect BES programs.

\section{ASCR Feedback}

With the addition of the new supercomputer, ASCR believes that PNNL has increased opportunities to become a serious player in the near term, as well as in future. To capitalize most effectively on these opportunities, PNNL needs to build its applied math staff resources.

While PNNL did well in SciDAC, it has not done as well in the core programs as the other labs. We need to recruit more seasoned principal investigators in the applied math area who can be effective proposal leaders.

PNNL's work in the past has been good, particularly our involvement with the collaboratory, and ASCR would like to see us play a bigger role as the new supercomputer comes on line. The supercomputer was a "heroic move," which gives us a window of opportunity. 
The FSD ALD reported that on the supercomputer installation to date we have achieved $83 \%$ effectiveness on the $1^{\text {st }}$ teraflop with 256 processors. The Associate Director indicated that very good opportunities will exist if we can maintain even half that effectiveness when fully scaled up. The decision to contract with Hewlett Packard, while considered risky, seems to be paying off.
The Associate Director feels that it is important to test out the concept of topical centers, and feels that PNNL has embodied the concept well.

PNNL stated its desire to be a team player on the Earth Simulator Response Project. The Associate Director responded that he appreciated our taking the collegial high ground with respect to working with other labs.

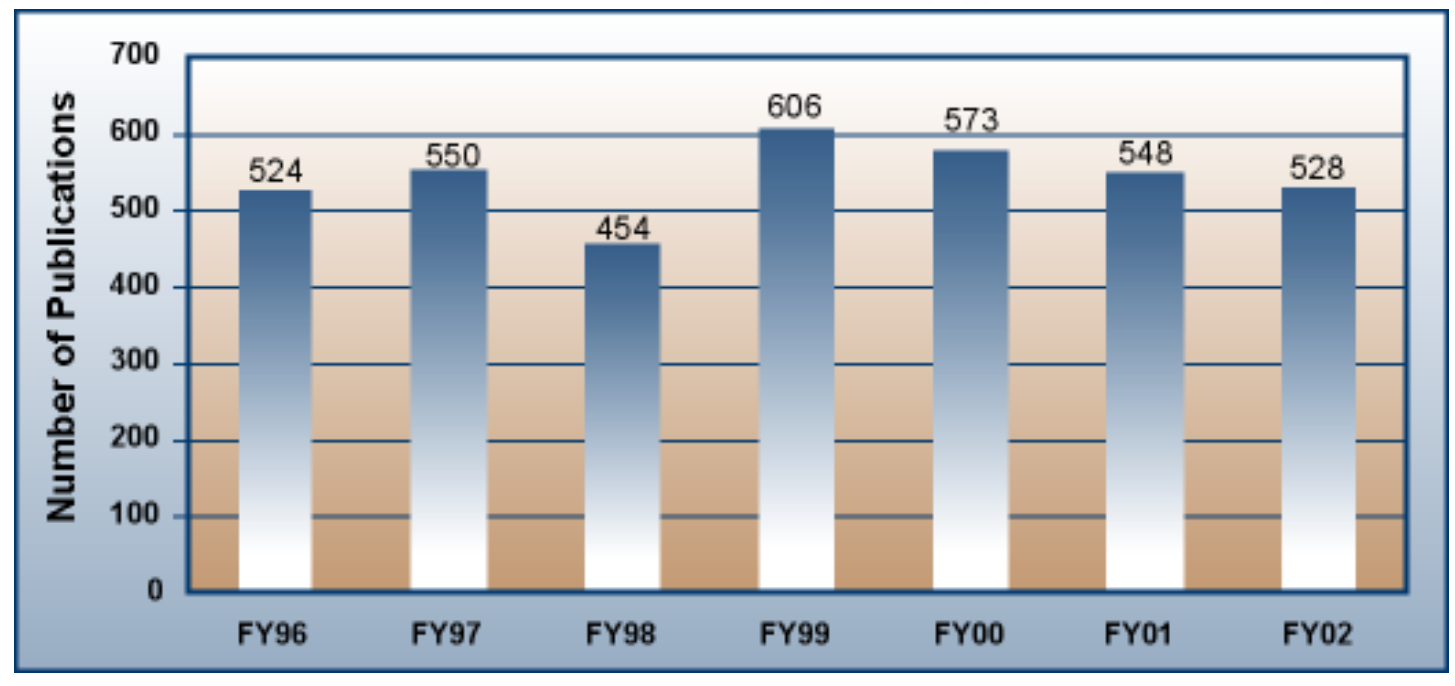

\begin{tabular}{|lc|}
\hline & PNNL Articles FY2002 \\
\hline Journal Title & 30 \\
\hline Journal of Chemical Physics & 16 \\
\hline Journal of Physical Chemistry A & 14 \\
\hline Journal of the American Chemical Society & 13 \\
\hline Journal of Physical Chemistry B & 12 \\
\hline Physical Review B--Condensed Matter & 9 \\
\hline Environmental Science and Technology & 8 \\
\hline Analytical Chemistry & 8 \\
\hline Journal of the American Society for Mass Spectrometry & 7 \\
\hline Applied Physics Letters & 7 \\
\hline Journal of Nuclear Materials & 7 \\
\hline Nuclear Instruments and Methods in Physics Research B & \\
\hline
\end{tabular}

Figure 1.1.7. Technical results are largely communicated through peer reviewed publications. In FY2002 the Lab published 528 peer reviewed articles compared to 548 in FY2001. These publications were distributed among prestigious journals. In addition to peer reviewed publications, PNNL develops science highlights and news releases. One example of the Lab's efforts to publicize its research activities is in the submission of highlights to DOE's websites. In FY2002, 10 out of 69 highlights published on the DOE-SC Science News website were from PNNL. This is a substantial fraction considering that a total of 9 DOE Labs contribute to the website and some of the news items aren't contributed by any of the Labs. 


\subsubsection{Efficiency of Research Program Management}

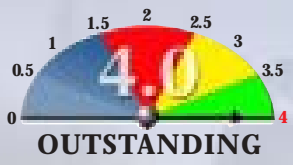

\section{PNNL optimizes personnel, facilities, and equipment to maximize the value of research results and gain appropriate recognition for DOE and the Laboratory.}

\section{EMSL}

As a D OE user facility, the EMSL provides the nation's research community with a range of specialized equipment and technical expertise in one location. In many cases, it would be financially and technologically infeasible for these capabilities to be duplicated elsewhere. This year the EMSL provided service to 1613 users (distributed as shown in Figure 1.1.8a). This is an increase of approximately 200 users from FY2001. A User is a non-EMSL staff member-postdocs and students working for EMSL staff are not Users- who derives a direct benefit from the EMSL facility, e.g., someone who (1) visits EMSL to take or analyze data, perform calculations or work with EMSL staff, (2) uses special EMSL facilities remotely, or (3) uses results obtained at EMSL for them with special EMSL facilities, possibly on samples they have prepared. Thus, from a national research perspective, the EMSL as well as PNNL's other user facilities, ARM and the G-1 Research Aircraft, represent an efficient use of resources.

EMSL also developed and beta tested a new equipment use tracking system in FY2002. It is expected to be fully operational in early FY 2003 and provide for more efficient scheduling and tracking of equipment.

\section{Renovation of Lab Space}

D uring FY2002, PNNL undertook significant lab space renovation in part to address the need for interim space for the Systems Biology initiative. This approach represents efficient use of space to meet the near and far term needs of this expanding program.

In LSL-II, 4500 square feet of lab space were successfully renovated and turned over to FSD on schedule and within budget to address the Systems Biology needs while new facilities are being planned and constructed. LSL-II's planned use as a pilot Proteomics Facility is important to meet the long-term facility needs for D OE's Genomes to Life Program.

In addition, PNNL facilitated efficient lab-space utilization by completing the $3313^{\text {rd }}$ Floor South Lab Renovation Project. 3654 square feet of standard wet chemistry and one radiological lab were renovated. The project was completed ahead of schedule and under budget. These projects are examples of how PNNL is making effective use of its existing lab space to meet current and future needs. 


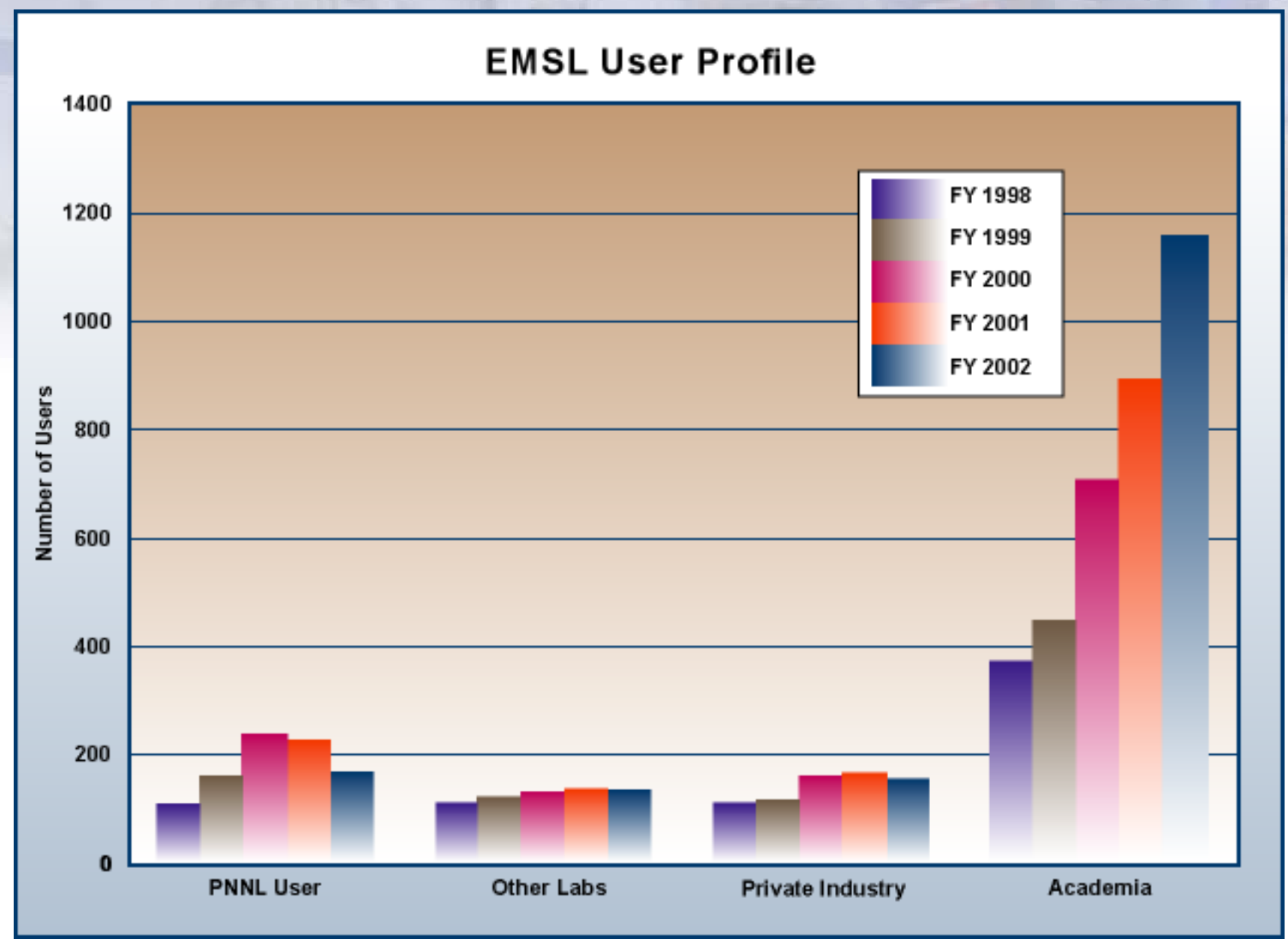

Figure 1.1.8a. Total EMSL use continues to rise.

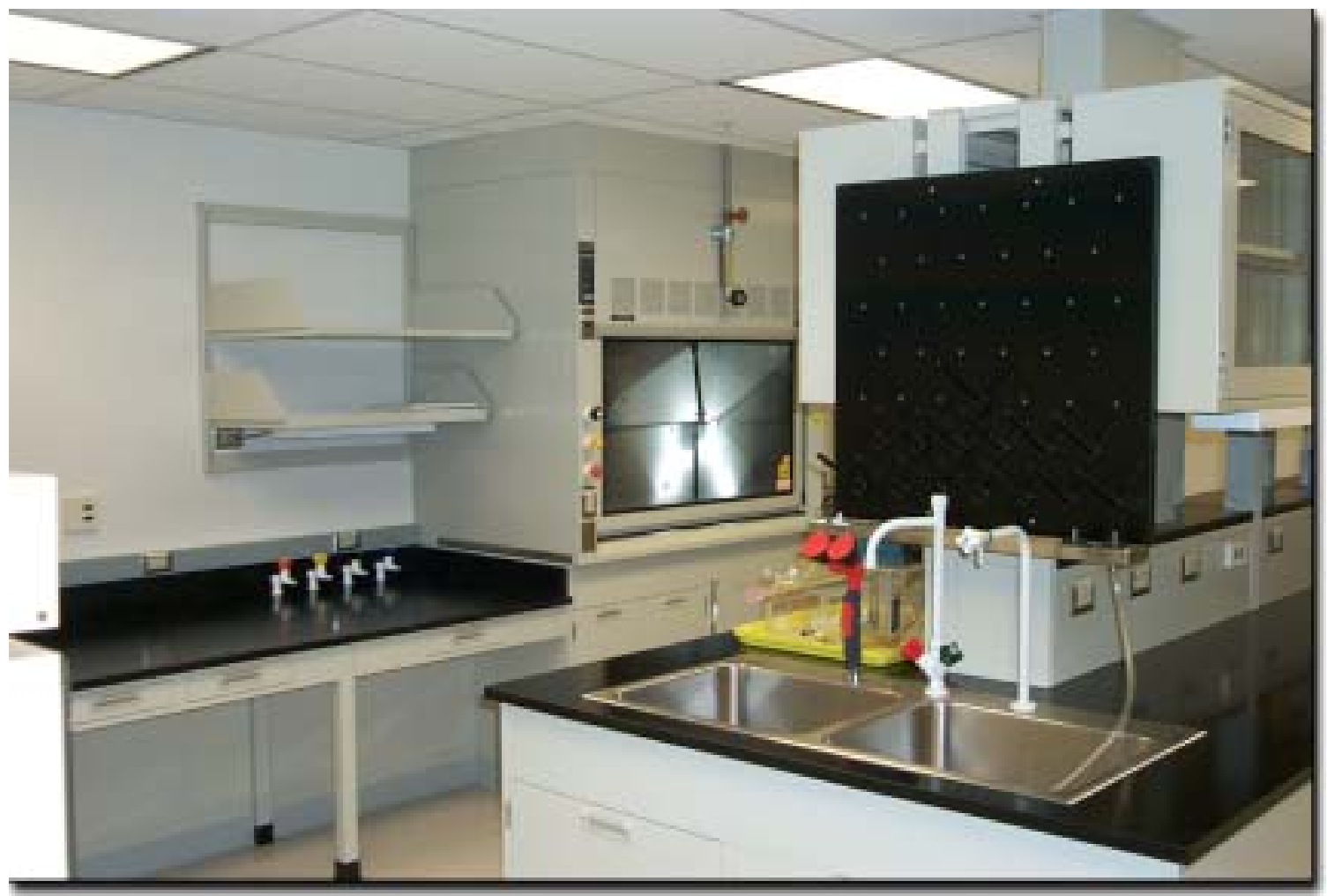

Figure 1.1.8b. Newly renovated LSL--II lab space brings additional state-of-the-art facilities to the GTL program. 


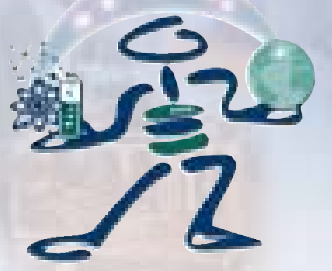

\subsubsection{PNNL's Contributions to DOE's Environmental Management Science Program (EMSP) Targeting Complex-Wide Problems}

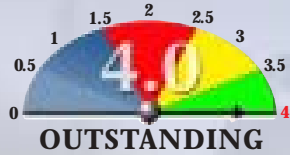

\section{PNNL is the leading provider of high-quality science to support DOE's complex- wide legacy waste clean-up challenges.}

PNNL continues to deliver high-quality science to the D OE through the Environmental Management Science Program (EMSP). Since the program's inception in 1996, PNNL has been awarded a total of 103 EMSP research grants. Of these, 54 were PNNL-led and 49 were collaborations on EMSP awards with funding received through other institutions. This makes PNNL the clear leader in numbers of awards granted. More significantly, our work has led to the solution of some of D OE's most critical clean-up problems. For example, our work this year provided data to verify the accuracy of a thermodynamic model of the $\mathrm{Na} / \mathrm{Al} / \mathrm{Si} / \mathrm{OH}$ system during operation of the $2 \mathrm{H}$ Evaporator at the Savannah River Site (SRS). The data obtained at PNNL resulted in the development of an operational control strategy for evaporator operations that will prevent the formation of solids in the evaporator and forms an integral part of the technical basis for evaporator operations at SRS.

We continue to communicate the successes achieved at both PNNL and throughout the program. Our work is documented in peer reviewed journals such as the Journal of the A merican Chemical Society and Science, in presentations given across the DOE complex, and in feature articles on the Office of Science's website. PNNL staff are frequently asked to present their findings at conferences and symposia and to host conferences such as the EMSP 2002 Vadose Zone Principal Investigator's (PI) Workshop held at PNNL in November 2001. More than 100 PIs of FY1999, FY2000, and FY2001 EMSP Subsurface awards attended this workshop to discuss relevant problems and to allow need-holders to voice fertile areas for future research.

\section{Work on EMSP-Sponsored Projects}

Our work on EMSP-sponsored projects in FY2002 addressed critical D OE needs in three areas-Tank Waste Remediation, D econtamination and D ecommissioning, and Soil and Groundwater Cleanup. PNNL researchers are directly involved in 43\% of all EMSP awards directed at one of DOE's most pressing problems, the high-level waste legacy. In addition, PNNL staff are involved in approximately $25 \%$ of all awards related to Subsurface Contamination.

One of the key problems confronting DOE is the 350,000 cubic meters of mixed chemical and radioactive waste stored in more than 300 underground storage tanks at various D OE sites. The remediation of tank wastes is one of the most technically complex, scientifically challenging, and potentially expensive problems with which DOE is faced. PNNL staff are currently working on 21 EMSP-sponsored projects to help understand the science of high-level radioactive tank wastes. Three examples of this work follow.

Chemical reactions, including those caused by radiation and the slow corrosion of the steel tank walls, produce gases such as hydrogen, nitrogen, nitrous oxide, ammonia, and methane. Many of these gases are flammable, toxic, or both. In addition, the reactions degrade organic compounds in the waste, change organic fuel and oxidant concentrations, and alter the surface chemistry of insoluble colloids, influencing sedimentation and gas/ solid interactions. PNNL's work on M echanisms and Kinetics of 0 rganic $A$ ging and Characterization of Intermediates in $\mathrm{H}$ igh-L evel Waste is helping determine and understand the radiation-induced physical and chemical changes in the wastes and the rates at which they occur.

O ur work on Radioanalytical Chemistry for A utomated $\mathrm{N}$ udear Waste Process M onitoring is developing rapid, sensitive, and selective techniques for determining lowenergy beta- and alpha-emitting radionuclides in wasteprocessing streams.

One identified knowledge gap at Hanford was the rate of migration of radioactive cesium and other contaminants in the subsurface from tank leakage or waste cribs. Cesium appears to be moving toward the groundwater 
and, ultimately, the Columbia River, faster than previously thought possible. Fix ation M echanisms and D esorption Rates of Sorbed C s in H igh-L evel Waste Contaminated Subsurface Sediments is investigating the geochemistry of cesium ion adsorption under conditions appropriate to highlevel waste tank releases. This work will expand our understanding of cesium mobility.

\section{Management of EMSP Projects}

O ur management of EMSP work continues to demonstrate effective and efficient program leadership and results in technology solutions to clean-up problems. In FY 2002 we received seven new awards and the renewal of two awards from FY2001. The new awards repre- sent some $20 \%$ of the total awards given in FY2002, demonstrating that PNNL's work is addressing key DOE needs.

O ur high EMSP award success rate is due, in part, to how we choose pre-proposals to put forward. By pre-screening proposals for relevance to critical EM problems, coaching principal investigators during the early stages of awards, and actively transitioning the projects to the next stage in maturity, PNNL helps EMSP projects achieve major goals with a high level of networking to end-users and delivering technology and/ or data to facilitate clean-up activities across the DOE complex.

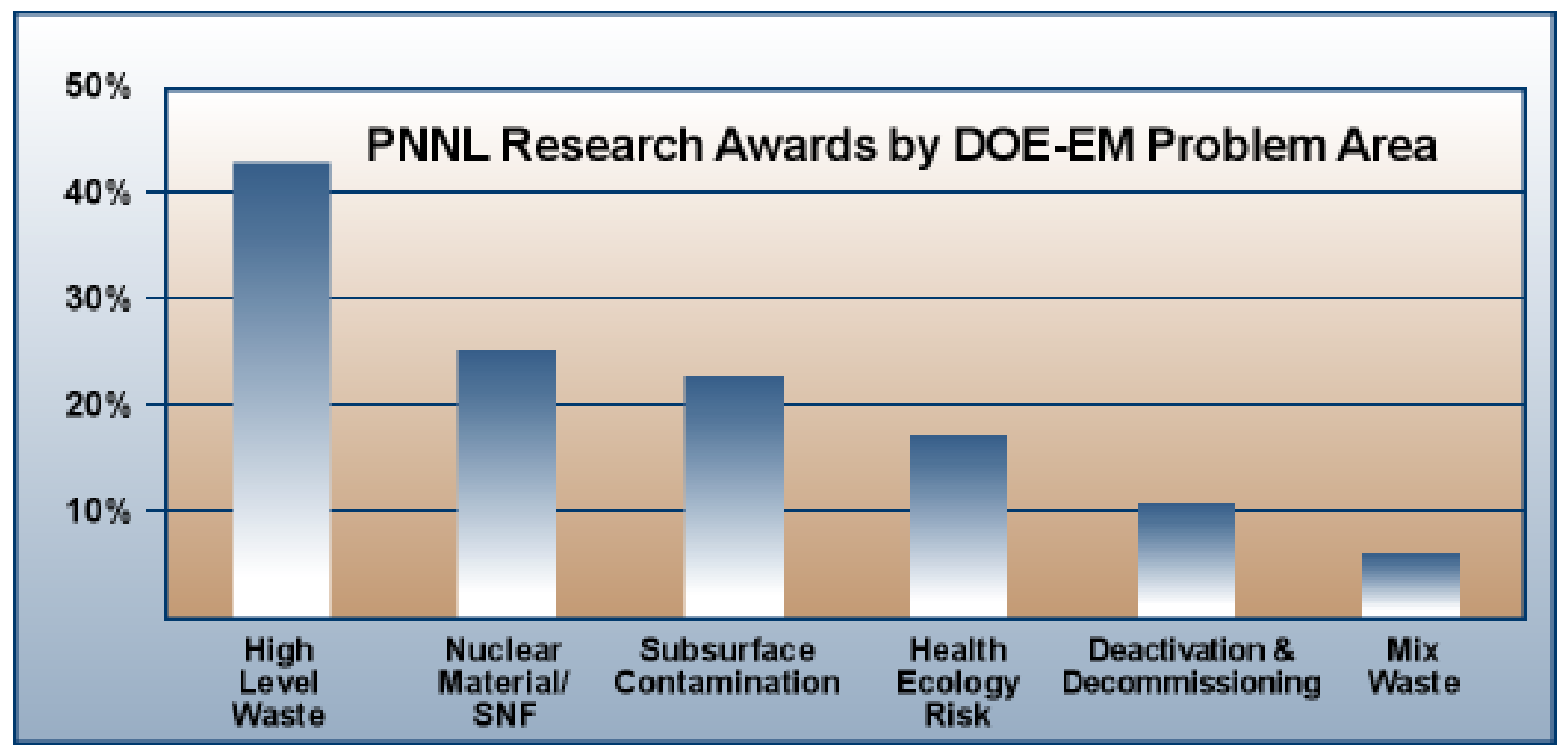

Figure 1.2.1. Graph shows EMSP research awards granted to PNNL as a percentage of total available program awards in each DOE-EM problem area. PNNL researchers are directly involved in $43 \%$ of all awards directed at DOE's High Level Waste legacy, and approximately $23 \%$ of all awards related to Subsurface Contamination. 


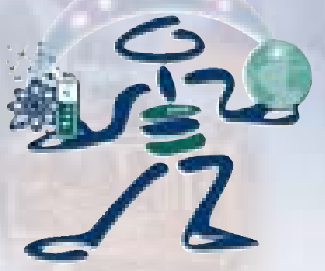

\subsubsection{PNNL Leadership in the Tanks Focus Area (TFA)}

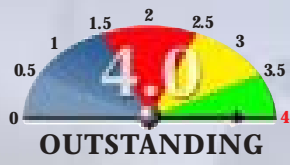

\section{PNNL leadership of the Tanks Focus Area technical program provided science and technology solutions and integration to solve radioactive tank waste cleanup challenges throughout the DOE complex.}

Already recognized as a top-notch technical management entity, the TFA Technical Team further enhanced its record of sustained, exceptional customer and user satisfaction in FY2002. We refined and continued to implement a robust technical program that met the quality assurance needs of DOE management, and more importantly led to the delivery of technical solutions for the end users at DOE sites. We also strengthened our technical assistance capabilities by broadening our base of national experts to help end users make critical decisions related to science and technology deployment activities at their sites.

Particularly noteworthy is PNNL's development, in conjunction with the Savannah River Technology Center (SRTC), of a new formula for vitrifying radioactive waste that is likely to result in $\$ 1$ billion in life-cycle savings with lower operational risk. The new PNNL/ SRTC formula (Frit 320) showed a melt rate 20\% faster than the previous frit in small-scale melter tests.

\section{Additional Key Technical Highlights}

- Deployed in Tank WM-182 at INEEL, a Vault Sump Sampler to obtain material samples from the tank vault, and a Sprayball/ Steamjet Heel Retrieval System to clean residual waste from tank internals. These technologies supported critical progress in enabling accelerated tank closure at the site.

- Deployed a robotic Pit Viper in the pump pit of Tank C-104 at Hanford to demonstrate a variety of remote pit cleaning and debris removal functions that significantly reduce worker exposure to radiation.

- Deployed a Modified Beta Gamma Detector in Tank 8D-2 at WVDP to collect scans of the tank walls and internal structures in support of establishing residual contamination levels to enable accelerated tank closure.
- D emonstrated a G rapple D evice and attachments for use in removing discarded vitrification process material in the D efense Waste Processing Facility melt cell at SRS.

- Sponsored an Interim Stabilization Workshop with subject matter experts to identify, evaluate, and recommend baseline alternatives and/ or enhancements to three priority issues related to saltwell pumping activities at Hanford.

- Provided technical assistance to Fernald in the form of exchanging complex-wide retrieval experiences to support closure site planning.

- Facilitated discussions related to Hanford's Mission Acceleration Initiative to define, evaluate, and rank viable treatment alternatives for treatment of lowactivity waste stored at the Hanford Site's 200 Area tank farms and enable accelerated closure.

- Hosted a Saltcake D issolution/ Waste Chemistry Workshop for SRS and Hanford to develop recommendations for focusing waste chemistry technology development to support accelerated waste treatment schedules.

- Coordinated an independent review of Single-Shell Tank Retrieval Projects for the Office of River Protection in August, 2002.

\section{Working Successfully with Users}

The radioactive waste arena represents D OE's most visible, costly, and complex cleanup challenge. We ensure relevance by focusing our investments on priority issues identified by D OE Headquarters, site, and contractor management staff at each tank site. Through this level of close user collaboration, our program development and execution activities continue to result in delivery and deployment of beneficial technical solutions. In addition, an improved comprehensive approach to technical 
reviews, and our efficient process for providing siterequested technical assistance on critical tank remediation plans and processes, further strengthened the TFA's reputation for providing thorough, independent assessments of technology development and ongoing tank cleanup activities in support of key technology decisions.

PNNL's leadership and partnership with DOE/ RL served as the technical backbone of the TFA and was the force behind good management practices that earned the TFA its widely acclaimed reputation for outstanding quality, technical competency, user involvement, and unsurpassed management and fiscal integrity. Improvements to existing web-based communication tools and processes also contributed to increased customer satisfaction and access to desired information.

\section{What's After TFA?}

In light of DOE's efforts to realign its approach to Environmental Management research and development beginning in FY2003, we stepped forward and served as translator between D OE and site users, expeditor of information and idea development, advisor to the sites, catalyst for prompting site users to actively and seriously engage in the transition process, and the generator of initial FY2003 science and technology alternative projects consistent with EM's new business model. We also maintained our commitment to program integrity and professionalism by planning and implementing a structured, comprehensive closeout strategy. This activity ensured the products, processes, and lessons learned from the TFA's nearly eight-year existence would be available for future programmatic and technical management organizations under similar circumstances. The professional and sensitive approach employed by the TFA in closing out its relationships with program partners around the country, including federal, DOE contractor, university, international, and private industry, created a firm basis for future teaming.

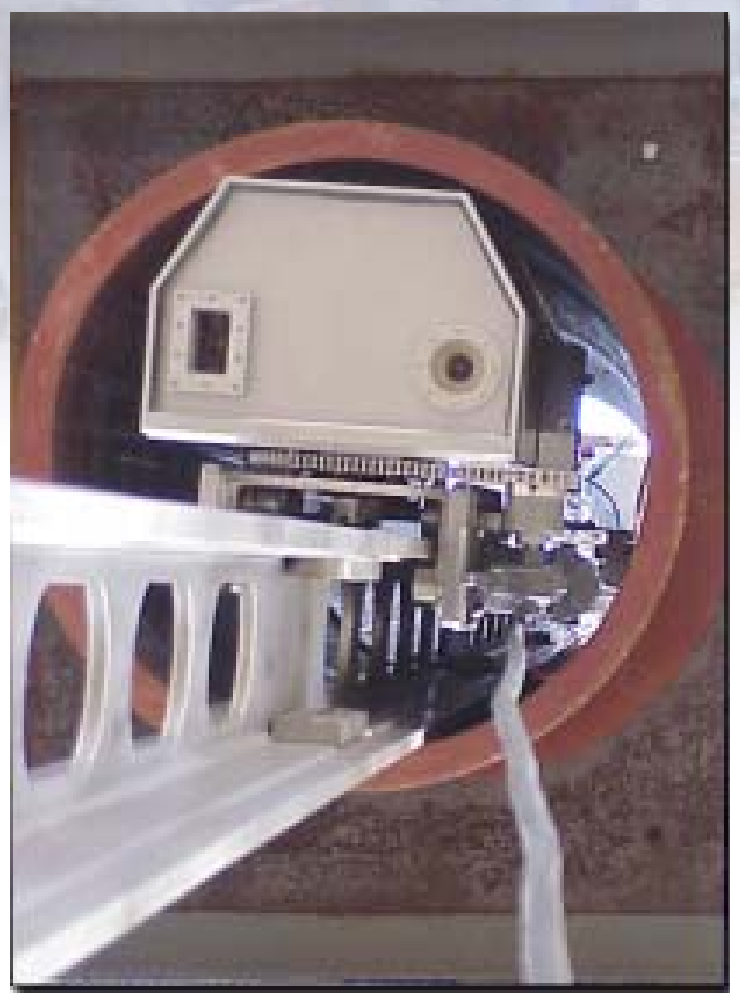

Figure 1.2.2. To help enable accelerated tank closure at DOE highlevel waste sites, the Tanks Focus Area sponsored deployment of technologies like the beta gamma detector used in Tank 8D-2 at the West Valley Demonstration Project in New York. 


\subsubsection{PNNL Support to Hanford Tank Waste Safe Storage and Retrieval}

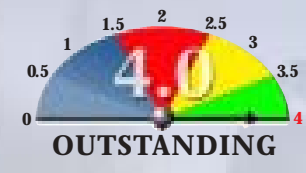

\section{PNNL's science and technology contributes cost-effective, real time deployable solutions to accelerate risk reduction and cleanup associated with Hanford's Tank Waste Safe Storage and Retrieval program.}

For more than ten years, PNNL has dedicated staff to support resolution of Hanford waste tank safety issues. Studies and laboratory analysis of the composition of waste organic compounds, gas generation and retention behavior, bubble transport behavior, and modeling of gas release mechanisms contributed to the closure of the flammable gas safety issue in FY2001. This work directly supported work in FY2002 on the hazards associated with waste retrieval in support of waste treatment.

\section{PNNL Equal to the Challenge}

D uring its 40 years of operations, the Hanford Site, the largest of the three original defense production sites, produced approximately 74 tons (64 metric tons) of plutonium - nearly two-thirds of all the plutonium produced for government purposes in the United States. The resulting environmental legacy is multifaceted and immense. An estimated forty percent of the approximately one billion curies of human-made radioactivity that exists across the nuclear weapons complex resides in or on the Hanford Site and must be dealt with to protect human health and the environment. The cleanup challenges addressed by PNNL Tank Waste Support include:

- More than 50 million gallons of high-level liquid waste in 177 underground storage tanks, 67 of which are known or suspected to have leaked;

- About 270 billion gallons (1 trillion liters) of groundwater contaminated above EPA drinking water standards, spread out over about 80 square miles (208 square kilometers). The contaminants include metals, chemicals, and radionuclides.

\section{FY2002 PNNL Tank Waste Support Highlights}

- Hanford tank safety issues, including flammable gas, toxicological source term, and general safety analyses,

- D evelopment of leak detection capabilities for Hanford Single-Shell Tank (SST) Retrieval

- Vadose Zone characterization

- Development of technical bases for SST retrievals including S-112, C-104, C-106, S-102 and U-107

- Assessment of technical issues related to Hanford D ouble-Shell Tank (D ST) waste retrieval, including slurry properties and tank pumpability, and D ST Integrity Assessments

- Risk Analysis associated with tank closure

- Technical assessment of SST Interim Stabilization

O ur work in support of Hanford Tank Waste Safe Storage and Retrieval activities is addressing one of D OE's most critical missions and a growing national need. O ur understanding and resolution of Tank Safety issues have provided the strong technical basis required to satisfy the D NFSB and external reviewers that Hanford has adequately addressed the tank safety issues. O ur development of leak detection capabilities and characterization of the Vadose Zone under the Tank Farms helps D OE understand the nature, extent, and migration of contaminants that may be making their way into the soil column.

\section{Partners in Success for DOE}

PNNL has successfully partnered with the Tank Farm contractor, CH2M HILL, in tank waste remediation activities on the Hanford Site since 1999 when CH2M 
HILL first took over the tank farm operations. This partnership, combined with our effective and efficient program leadership has led to significant breakthroughs in retrieval technology, worker safety, and enhanced understanding of the physics and chemistry associated with waste behavior.

Recognizing the value of close partnership on key projects, CH2M HILL and PNNL management have forged a formal collaboration through a Memorandum of Agreement, establishing a co-led senior management position for Technology Integration. Four key areas of PNNL emphasis in this collaboration include:

- Providing Direct Technical Support to Projects

- Coordinating External R\&D Interfaces

- Planning, Analysis, and Risk Management

- Establishing the Scientific Basis for Closure.

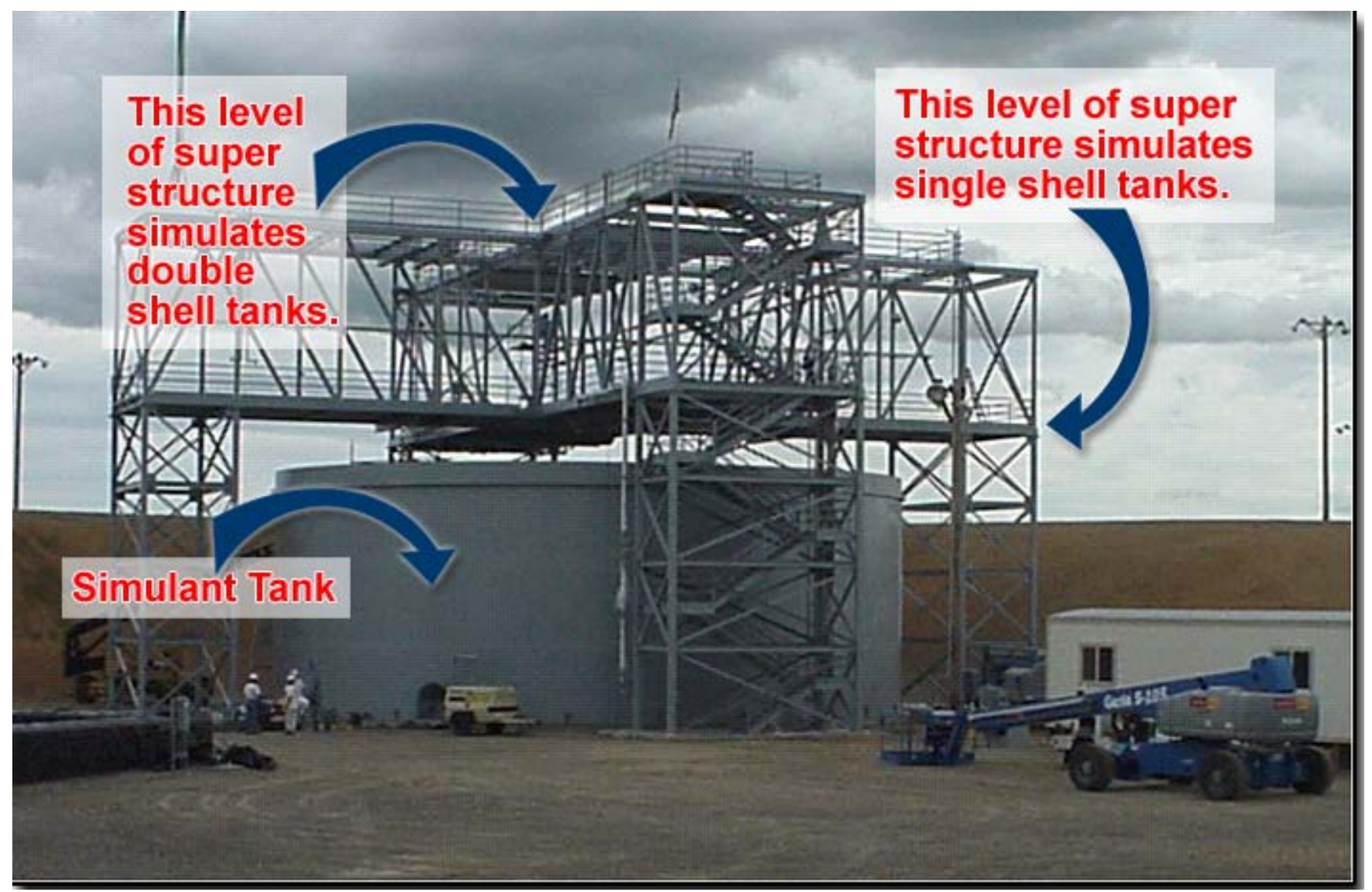

Figure 1.2.3. PNNL prepared for and executed tests for the S-112 Retrieval Project, prepared plans for C-104 Retrieval Testing, and provided peer reviews for the $\mathrm{CH} 2 \mathrm{M}$ HILL-operated Hanford Cold Test Facility, a new Hanford user facility. 
1.2.4 Public Safety and Resource
Protection Program (PSRPP)

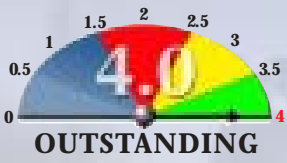

The PSRPP safeguards the public, Hanford Site workers, and ecological and cultural resources through the cumulative assessment of onsite and offsite impacts of Site operations.

\section{PNNL-Managed PSRPP}

Program reviews conducted by recognized experts both within DOE and from university, regulator, and private sectors, continually confirm the quality, relevance, and value of the information generated through the PNNLmanaged PSRPP.

The PSRPP is composed of five key projects:

- Hanford Environmental Oversight Project responsible for Program management and integration as well as NEPA characterization

- Meteorological and Climatological Services provides Site weather forecasts in support of special and routine Site operations, and emergency response activities

- Site Environmental Surveillance Project - assesses and monitors the impact of Site operations on human health and the environment

- Ecosystems Monitoring and Compliance Project monitors the health, abundance and distribution of biotic populations onsite and performs ecological pre-activity reviews, and

- Hanford Cultural Resources Project - performs cultural resources reviews to determine potential impacts of planned Site activities prior to initiating operations.

The PNNL-managed PSRPP, environmental surveillance, ecological monitoring, and cultural resource protection projects, are recognized as high-quality and among the best across the DOE-complex. The annual Hanford Site Environmental Report, the key product of the PSRPP, continually serves as the model for other $\mathrm{DOE}$ sites and is the recipient of numerous national communication awards for publication excellence. This report is used by Hanford Site contractors, the D OE, and state and federal regulators in various-decision making and oversight processes. It documents the environmental condition of the Hanford Site and has been hailed by members of the G roundWater/ Vadose Zone Expert Panel as a classic example of the integration of environmental information. Similarly, the Hanford Environmental Monitoring Plan, Hanford Biological Resources Management Plan, and Hanford Cultural Resources Management Plan are considered to be the leading edge models of effective work planning documents across D OE sites.

As a result of the demonstrated and sustained high quality of meteorological and climatological data, the PNNL-operated Hanford Meteorological Station is being considered to become a national Climate Reference Network (CRN) node for the National O ceanic and Atmospheric Administration (NOAA).

PSRPP monitoring provides relevant, critical baseline data for all Hanford Site Activities. The monitoring of potential environmental impacts on the Hanford Site began in the early 1940's, before construction of the first reactors. The information generated today is used extensively in the Hanford decision-making process to:

- support waste management activities,

- assess the adequacy of waste clean-up and effluent monitoring activities,

- evaluate potential land-uses,

- support the Hanford Site radiological land release process,

- assess human health and environmental impacts, and

- assure the protection of public health and ecological and cultural resources at Hanford.

D uring FY2002, PSRPP performed:

- 127 ecological compliance assessment reviews,

- 147 cultural resource reviews required by NEPA prior to project start-up, 
- Received and responded to 7,659 direct inquiries for meteorological information,

- Issued 74 weather advisories, and

- Analyzed some 2,876 environmental samples, including 1617 air, 364 biota, 62 soil and sediment, 524 surface water and 309 external radiation samples, yielding nearly 13,700 analytical results.

\section{National and International Prominence}

That PSRPP is considered a leader for D OE in environmental and ecological monitoring is evident by our long-term lead role in the preparation of the Hanford Site Environmental Report and the Hanford Site Environmental Monitoring Plan. In addition, PSRPP staff are routinely invited to chair and present their results at topical symposia such as the Fifth International Conference on Environmental Radioactivity in the Arctic and Antarctic, held in June, 2002 in St. Petersburg,
Russia, and the Third International Symposium on the Protection of the Environment from Ionizing Radiation, held in July, 2002 in D arwin, Australia.

PSRPP staff regularly make presentations at national society meetings, including annual meetings of the Health Physics Society and the American Nuclear Society. Staff are also active on national programmatic committees such as the DOE Long-Term Stewardship Committee, and in the development and review of environmental regulations and implementation guidance. PSRPP staff members recently received the National Environmental Excellence Award for Environmental Management in recognition of their efforts on the D OE-HQ -sponsored Biota D ose Assessment Committee, and in the development of a "Graded Approach for Evaluating Radiation D oses to Aquatic and Terrestrial Biota."

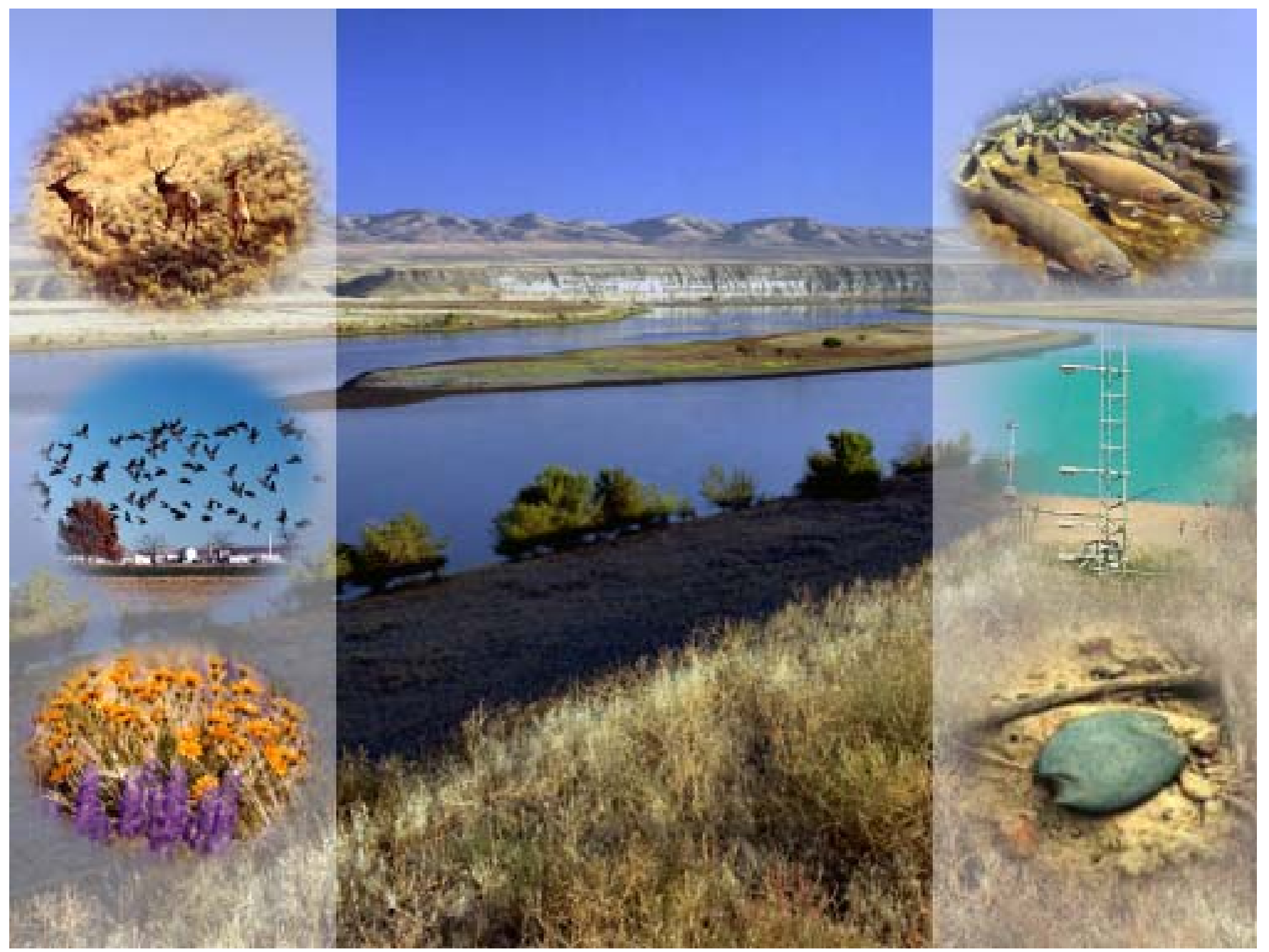

Figure 1.2.4. The Public Safety and Resources Protection Program assures the protection of the public, Hanford Site workers, and ecological and cultural resources by assessing the impacts of Hanford operations to the local environment. 


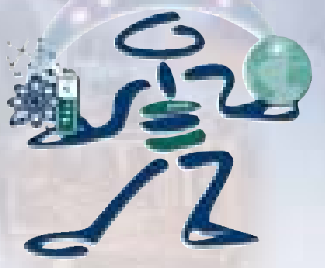

\subsubsection{PNNL Support to River Corridor Restoration Assessment and Monitoring}

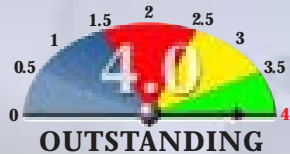

\section{PNNL gives DOE-RL the scientific and technical information and tools to make sound decisions to protect and remediate Hanford Site groundwater and the Columbia River.}

PNNL has developed, and is refining, the technical data and models necessary to assess risk at the Hanford Site under alternative cleanup scenarios providing additional basis for making critical cleanup decisions.

\section{Significant FY2002 Accomplishments}

- Use of the PN N L -developed System A ssessment Capability (SA C) tool to model the movement of contaminants from all waste sites at Hanford through the vadose zone, groundwater and the Columbia River, and to estimate the impact of contaminants on human health and ecology, and the local cultures and economy. In 1998, D OE established the Integration Project Expert Panel (IPEP), a group of national experts, to advise on the direction and performance of the various $\mathrm{G}$ roundwater/ Vadose Zone Integration Project efforts. In its final report, the Integration Project Expert Panel said that the System Assessment Capability had become "a useful tool for guiding Hanford Cleanup."

- Publication of the draft Initial A ssessment of the $\mathrm{H}$ anford Impact Performed with the System A ssessment C apability. This report documents SAC's use to model contaminants through the vadose zone, groundwater and Columbia River, from more than 500 locations, representing 890 waste sites, and incorporates data on 10 radionuclide and chemical contaminants, and focuses on subsurface transport, the Columbia River, and risks to human and ecological health, and the regional economy and culture. This represents a significant improvement over previous comprehensive assessments.

- D evelopment of Technetium and U ranium Inventory Maps. Developed from the Characterization of Systems inventory database, these maps were widely used to illustrate where significant masses of mobile longlived radionuclides remain at Hanford. These maps were also used in C3T workshops, workshops with the Hanford Advisory Board (HAB) Risk Framework committee, and for D OE strategic planning.
- The application of innovative statistical concepts to improve the efficiency of monitoring networks.

- Creation of a consistent 200 E ast A rea geological onceptual model. This model will guide decision making in the 200 East Area.

- Creation and calibration of an alternate conœeptual model of $\mathrm{H}$ anford groundwater flow. An innovative inverse calibration approach was used to calibrate the model to all available hydraulic head data. This alternate conceptual model, and others yet to be developed, will allow analysts to quantify the full range of uncertainty in groundwater model results.

\section{Importance of the Initial Assessment}

PNNL's work at modeling, assessing, and monitoring contaminant movement at the Hanford Site contributes significantly to one of DOE's most critical mission needs: the waste cleanup of the Hanford Site.

The Initial A ssessment, derived from the System Assessment Capability, directly addressed Hanford's need for a baseline statement of environmental risk that DOE and contractor staff rely on as a technical resource to explain the origin and movement of Hanford Contaminants in groundwater and to resolve technical issues with vadose zone and groundwater models. The initial assessment and future updates and refinements will provide a scientific base for cleanup decisions. This work addresses recommendation 2 of the Top-to-Bottom Review to "Move EM to an accelerated risk based cleanup strategy."

The results of the Initial A ssessment performed with the System Assessment Capability were used to identify waste sites warranting accelerated cleanup in the development of Initiative 6 of the Project Management Plan for A coelerating $\mathrm{H}$ anford Cleanup. PNNL staff participated in drafting the initiative and developing work plans to implement the initiative. The results are also being used to identify high priority sites for protective barriers and the barrier design requirements for those sites. 


\section{Programmatic Leadership}

PNNL's programmatic leadership in assessment and monitoring of the Hanford Site is evidenced by:

- The development of a single geologic and hydrologic database from multiple databases. This single database provides a common technical database for making risk assessments at Hanford.
- In response to a pressing need to coordinate groundwater modeling at Hanford, PNNL worked with DOE to develop the Modeling Coordination Board. PNNL drafted a charter and worked with the DOERL and ORP leads for modeling to hold the initial meetings of this organization.

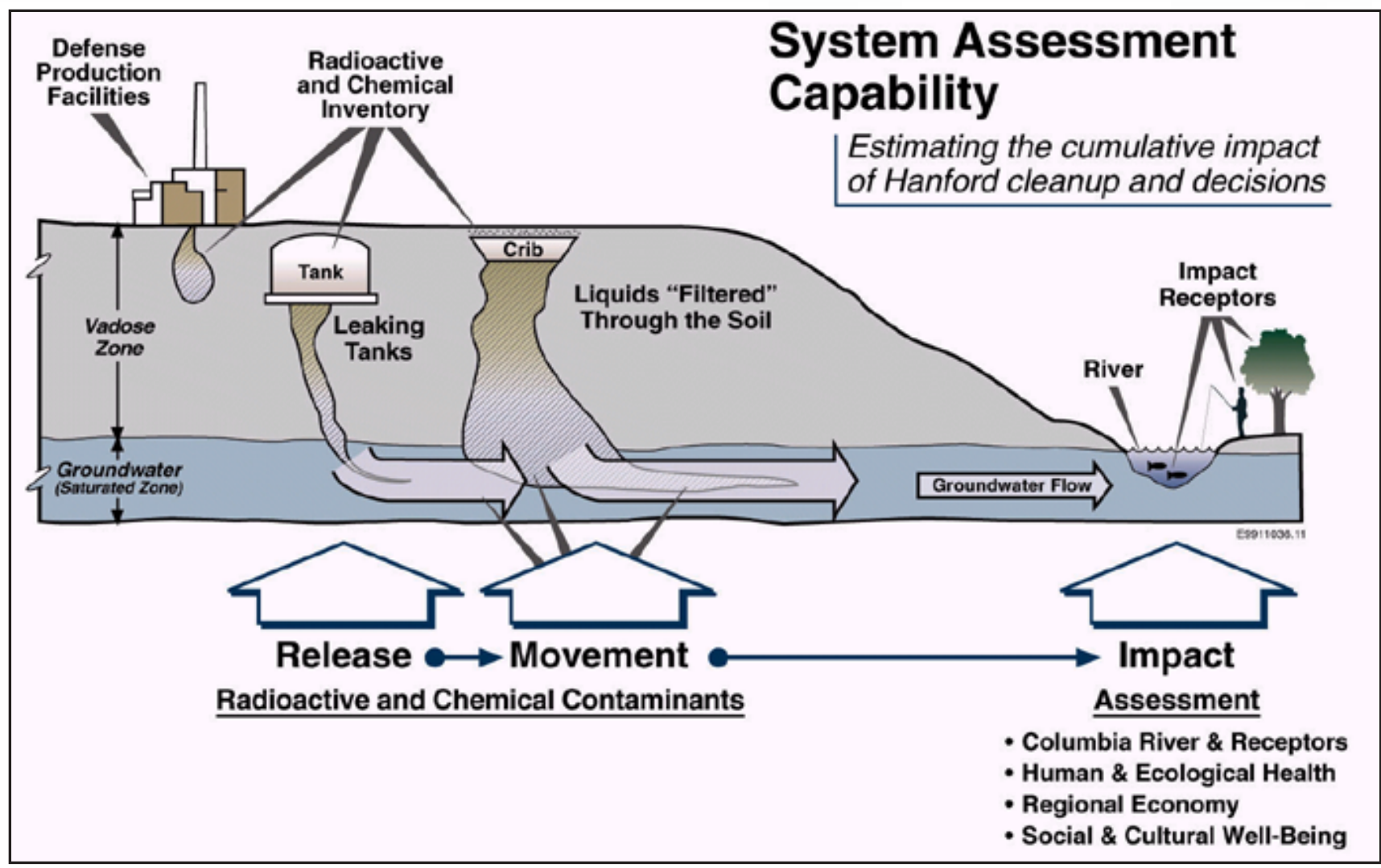

Figure 1.2.5. The System Assessment Capability model estimates the cumulative impact of Hanford residual contaminants from their source to an accessible environment in the region. 


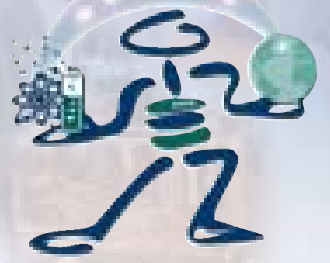

1.2.6 PNNL Technical Integration Support
to the Project Hanford Management
Contractor for Central Plateau Restoration

PNNL's science and technology solutions were key to resolving
critical technical issues in processing spent nuclear fuel and
stabilizing and safely storing plutonium at the Plutonium
Finishing Plant.

This work is directly relevant to two of Hanford's most technically challenging problems; (1) dispositioning 2,300 tons of legacy spent nuclear fuel stored in waterfilled basins near the Columbia River; and (2) stabilizing 12 tons of plutonium in various separated forms located at the Plutonium Finishing Plant and at other Hanford facilities. Both projects represent major sources of potential risk in the site's overall cleanup effort. PNNL's delivery of critical information following thorough investigation and analyses resulted in numerous recommendations for improvement in both the nuclear materials stabilization (NMS) and spent nuclear fuel (SNF) projects, as well as providing defensible evidence of key safety basis documentation.

\section{Plutonium Stabilization Highlights}

Completion of laboratory and engineering studies to confirm flowsheet improvements for plutonium solutions processing. PNNL laboratory and engineering studies enabled production enhancements for plutonium stabilization that allowed Fluor Hanford (FH) to meet the DOE milestone of July 31,2002 , for the completion of plutonium solution processing. This milestone satisfied a key D efense Nuclear Facilities Safety Board (D NFSB) requirement. Its promise of lower product volume and improved throughput led FH to choose the oxalic acid precipitation process to replace the established magnesium hydroxide process for plutonium solution stabilization. Rapid implementation of the oxalic acid flowsheet raised technical questions related to process technology and optimization, equipment, reagents, and safety, required expeditious investigation, and PNNL was there with prompt resolution of these issues through laboratory and engineering study.

D eployment of an advanood, wireless canister monitoring system (D OE-ST D 3013). Materials surveillance requirements under the 3013 Standard call for periodic examination of containers for integrity and internal pressure, while

materials control and accountability requires examination for the items' presence. PNNL developed an instrumented device and wireless sending unit for monitoring internal pressure, can temperature, and container identification. Remote querying of item identification and status radically decreases worker exposure, provides superior sensitivity to internal pressure (compared with baseline lid deflection measurements), and gives realtime knowledge of can position and condition.

Confirmation of feasibility of prooess to stabilize high chloride plutonium oxides. More than 900 items of plutonium oxide containing variable concentrations of chloride salts must be stabilized and packaged for safe storage. The chlorides present a challenge because they are extremely corrosive at the high stabilization temperatures, and so must be removed before the materials are introduced to the furnace. PNNL studied several potential options to remove the salts, and recommended the use of idle equipment remaining from earlier solutions processing in a slightly altered configuration. Subsequent prototype testing confirmed that this approach would be effective and practical. This conclusion allowed the stabilization project to avoid the significant cost, time, and dose that would be involved in cleaning out a glovebox and installing new equipment.

\section{Spent Nuclear Fuel Processing Highlights}

Completion of laboratory testing to support preparation and defense of safety basis documents for spent nudear fuel processing. PNNL completed a technical evaluation of data gathered from literature and from cold vacuum drying operations. This work showed that fuel surface area, the most critical and difficult parameter to measure for predicting reactivity, could be estimated accurately by hydrogen gas generation data. Further, analysis of data from operations showed that one 8-hour step could be safely eliminated, and confirmed that the multicanister overpacks (MCOs) for which data were analyzed were 
indeed within the safety envelope. Proving the adequacy of the existing safety bases helped the project avoid significant potential costs related to revising the safety documentation.

Completion of a risk analysis on the failure of the multicanister overpack during routine leak testing. Before transfer to longterm storage, the MCO s containing SNF undergo a routine leak test to confirm container integrity. PNNL conducted an independent analysis of MCO \#63, which failed the integrated leak rate test. The risks of failure from various possible causes throughout the life cycle of the MCO (from fabrication to processing) were determined. Recommendations were made for actions to lower the likelihood of future failures for the more likely failure modes. Based on the low probability of risk to the project, a recommendation was made that MCO \#63 should not be opened, unloaded, and reprocessed.

Performance of stochastic modeling to esablish safe and flex ible criteria to store SN F sludges in L arge D iameter C ontainers (L D C s). Sludges from K East basin canisters contain reactive metals, and will be combined with floor sludge to maintain an acceptably low concentration of these problematic metals. In an effort to broaden the acceptable sludge loading criteria, PNNL used a stochastic modeling technique in which values for the volumes of floor and canister sludge, as well as the concentrations of the materials of interest, were allowed to vary. This approach created the technical foundation for the sludge ratio used for nominal and safety basis calculations, and allowed removal of excessive and operationally restrictive conservatism.

D esign and fabrication of nondestructive evaluation tools to measure contamination levels of $\mathrm{K}$ E ast Basin walls and floors. PNNL designed and built two new systems to survey the $\mathrm{K}$ East Basin for radionuclide contamination on and in the concrete walls and floors using non-destructive examination (NDE) methods. The resulting data will support basin disposition decisions, e.g., establishing basin covers or concrete removal techniques.

\section{Partners in Success for DOE}

PNNL has successfully partnered with the Project Hanford Management Contractor, FH, since O ctober, 1996. PNNL's contributions to the partnership include the delivery of key science and technology solutions necessary to process spent nuclear fuel, and to stabilize and store plutonium. This partnership has led to significant breakthroughs in methods to chemically separate plutonium from solutions and to safely convert spent nuclear fuel from wet to dry storage.

O ur partnership with FH is implemented through a formal Memorandum of Agreement (MOA) that assigns the technology function to PNNL and includes:

- Providing D irect Technical Support to Projects

- Coordinating External R\&D Interfaces

- Planning, Analysis, and Risk Management

- Establishing the Scientific Basis for Closure
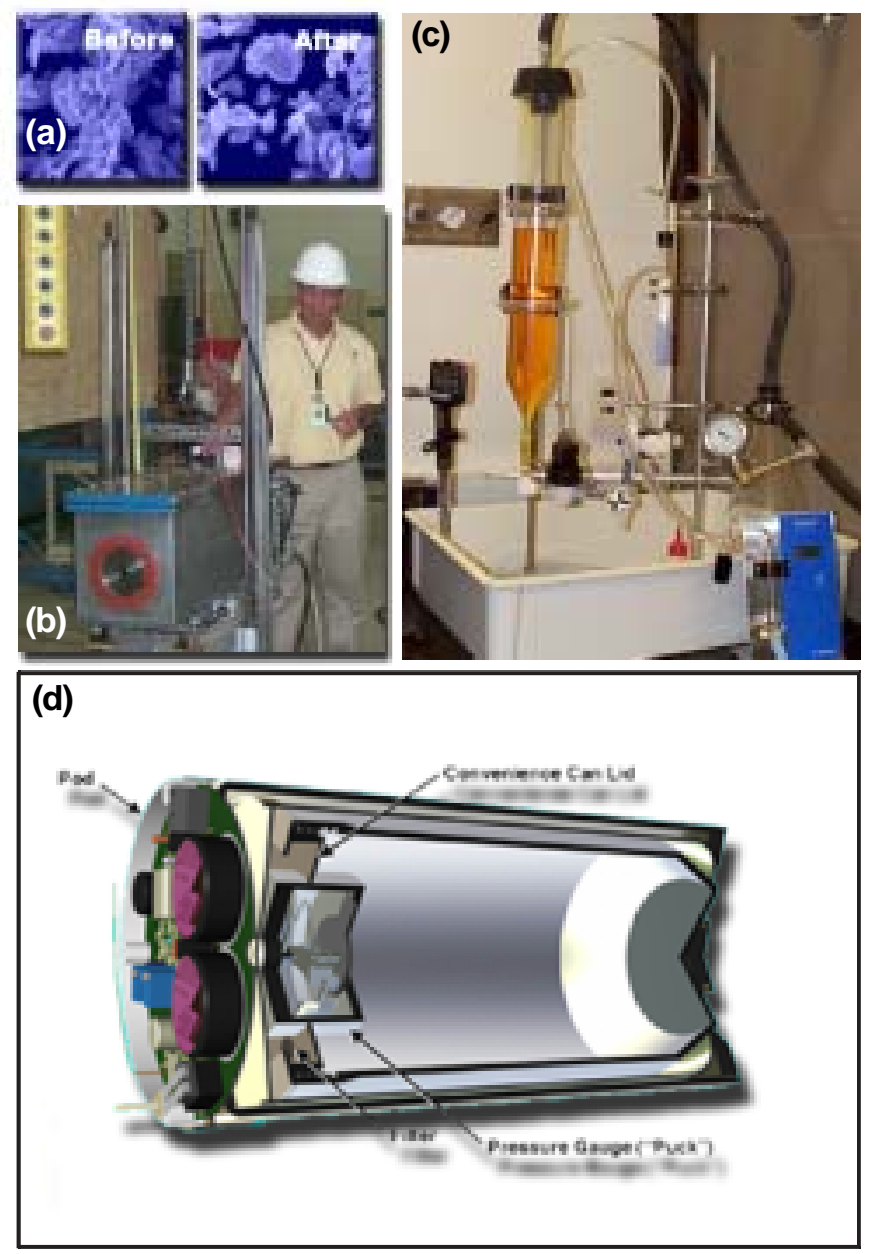

Figure 1.2.6, a) Before and after Scanning Electron Microscope photos show the reduction of uranium following thermal stabilization; b) Nondestructive Evaluation system developed to measure contamination levels on walls of K-Basins; c) Scaled testing of a new process to precipitate Pu from solutions; d) Cutaway of an advanced, wireless canister monitoring system for long-term storage of Pu. 


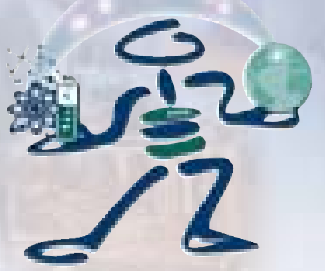

1.2.7 PNNL's Site-Wide Planning and
Integration Support to DOE-RL

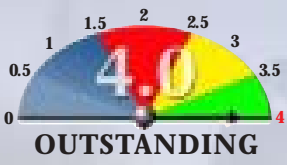

PNNL provides DOE-RL with the technical basis, analysis, and planning for accelerated Hanford clean-up and supports implementation of the Accelerated Clean-up Plan through RL office-level projects, and the integration of these projects throughout RL and with ORP.

\section{DOE-RL Can Count on PNNL}

PNNL staff support the DOE-RL Assistant Manager for Integration (AMI) as the "technical arm" in D OERL commitments to accelerate mission completion and reduce the lifecycle cost of the $\mathrm{EM}$ cleanup. O ur unique combination of local expertise at Hanford, capability in decision analysis, and participation in the Cleanup Constraints and Challenges Team (C3T) process make our product offerings technically robust. The C3T, an interagency collaboration to identify, characterize, and remove barriers to environmental cleanup progress at the Hanford Site, is designed to rebuild trust and improve the working relationships among DOE, EPA, and the Washington State Department of Ecology.

Throughout the past fiscal year, technical information related to the constraints and barriers to environmental cleanup at Hanford were presented at a series of facilitated workshops from a neutral perspective to catalyze meaningful open dialogue toward resolving these constraints. The high-quality efforts of the C3T team were validated by the key regulators and D OE Offices in the March 5, 2002 Letter of Intent between the various agencies and DOE-HQ. The PNNL-led C3T process is called out specifically as one of the key reasons for Hanford being allocated $\$ 433 \mathrm{M}$ of the $\$ 800 \mathrm{M}$ out of the new Cleanup Reform Account for FY 2003, to begin the acceleration of Hanford Cleanup.

\section{Praise for PNNL's C3T Leadership}

PNNL has received wide acclaim for its leadership and participation in the C3T effort. According to a Letter of Intent signed by Jessie Roberson, EM, documenting how the results of the C3T, the Top-to-Bottom Review, and other improvements will be used to accelerate Hanford cleanup, "this represents a transformation in Hanford Site cleanup...." Washington State Governor,
G ary Locke, hailed the announcement of faster cleanup at Hanford, the direct result of C3T efforts, as " the best news for Hanford since the signing of the original cleanup agreement."

Specific products generated by the C3T team in support of RL's Hanford Site planning and integration efforts during FY 2002 include:

- The Central Plateau Project Execution Plan

- The River Corridor Justification of Mission Need

- Columbia River Corridor Project Execution Plan

- Technology; A Strategic Assessment

- RL GFI/ S Status Report

- Performance Management Plan for the Accelerated Cleanup of the Hanford Site.

\section{Helping To Synergize DOE-RL and DOE-ORP}

PNNL's work in support of the AMI is focused on and directly relevant to critical problems associated with D OE's cleanup of the Hanford Site. Hanford has two DOE field offices (DOE-RL and DOE-ORP). The project work overseen by DOE intersects geographically on Hanford's Central Plateau as depicted in Figure 1.2.7a.

Because of the geographical and logical connectedness of the work required to cleanup both the Columbia River Corridor and the Central Plateau, and because of the separateness of the field offices, PNNL has been working with RL for the past year via the C3T process to find technically defensible methods to accelerate the cleanup and reduce overall cleanup costs. This problem of an EM cleanup at Hanford that "takes too long" and "costs too much" is represented in Figure 1.2.7b. 
PNNL's C3T Team provided effective and efficient programmatic management when it played a pivotal role in the development of targets of opportunity to help accelerate mission completion. In addition, their

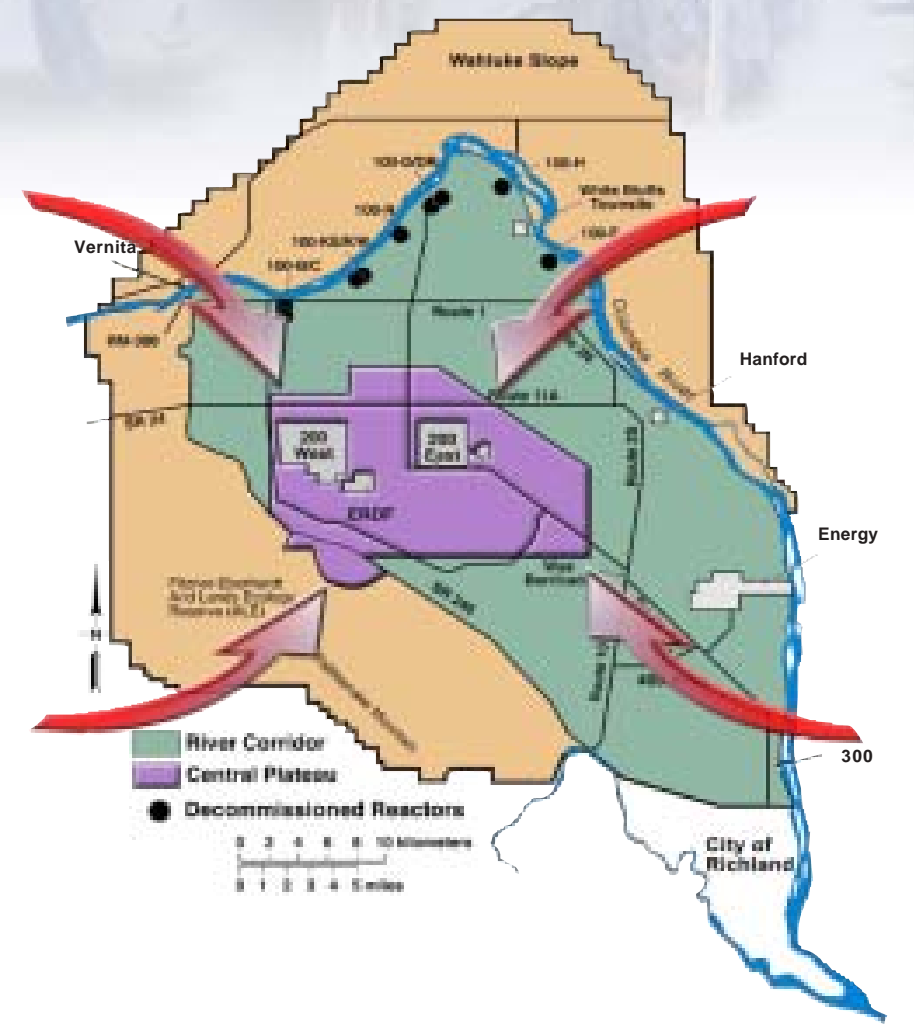

Figure 1.2.7a. DOE's goal is to confine its active cleanup efforts to the Central Plateau region, as noted on the map. PNNL is providing unique technical assistance support to DOE to develop the integrating plans that will accelerate the EM cleanup at Hanford. work to bring the regulators and stakeholders into the decision making process was lauded as a key ingredient in the early allocation of over $50 \%$ of DOE's Accelerated Cleanup Reform Account.

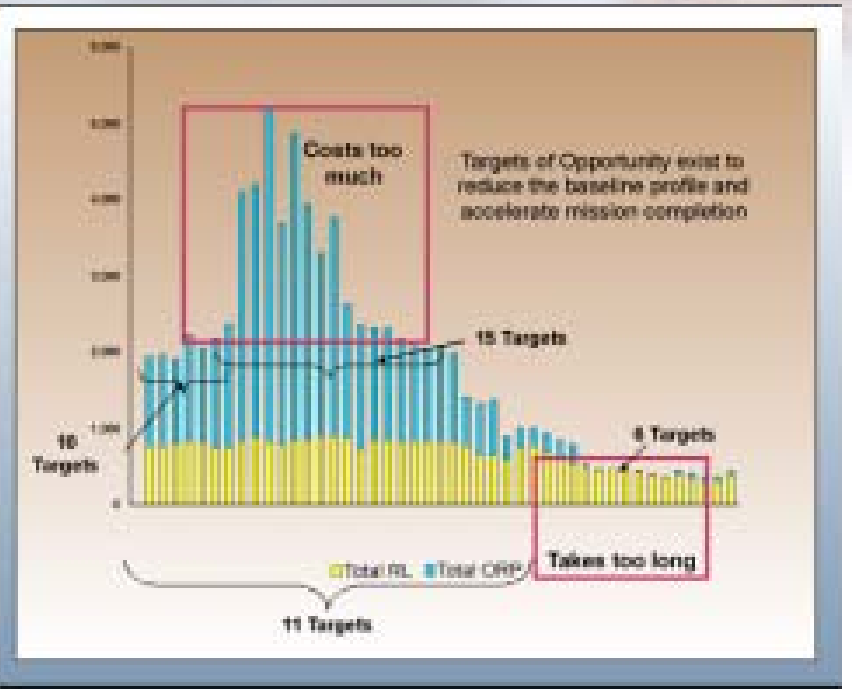

Figure 1.2.7b. This chart shows the budget profile over time, necessary to clean up the Hanford Site. To reduce overall costs and to shorten the schedule will require significant near-term commitment while integrating improvements to the current cleanup baseline and/or modifying the baseline, as necessary. 


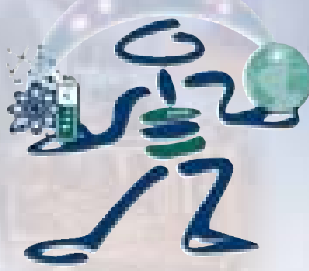

\subsubsection{PNNL's Site-Wide Dosimetry Services Support for DOE-RL}

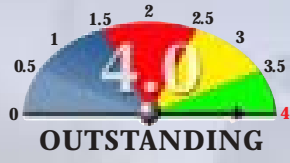

\section{PNNL provides RL with state-of-the-art, cost-effective radiation measurement services necessary to protect Hanford Site workers and the general public.}

\section{Protecting Workers Through Radiation Measurement}

PNNL's work in providing dosimetry services to the Hanford Site supports one of DOE's most critical missions. The measurement of worker dose through immediate methods (instrumentation), passive methods (dosimetry and radiobioassay) and the maintenance of records of dose measurements is necessary to support the maintenance of a safe worker environment as the site clean up work is performed. Measurement of residual radioactive material in soils and materials is critical to releasing property and real estate from D OE control. PNNL supports both the measurement of occupational dose (through dosimetry and bioassay) and the measurement of residual radioactive material through non-destructive assay and radiation measurement instruments.

PNNL continues to play a critical role in ensuring the health and safety of Hanford Site workers. Through nearly 40 years of providing radiation measurement services, PNNL has developed the technical expertise and understanding of customer needs and regulatory drivers to provide high quality radiation measurement services to DOE-RL and the Hanford Site. DOE-RL recognizes the exceptional quality of PNNL radiation measurement services and wants for PNNL to continue providing these services for the life of the Hanford Site. Services include dosimetry and occupational dose record management; radiological instrumentation and calibration; radiobioassay; and non-destructive analysis.

\section{PNNL Services Responsive to Changing Needs}

During FY2002, PNNL continued to provide Department of Energy Laboratory Accreditation Program (D O ELAP) accredited dosimetry services that rapidly respond to changes in Hanford Site requirements for dosimetry measurements. The dosimetry program main- tains a detailed technical basis for measuring worker radiation doses in difficult environments such as the mixed neutron/ photon fields at the Plutonium Finishing Plant and the high energy beta fields in the tank farms. Intimate knowledge of the Hanford Site's dosimetry needs allows the dosimetry program to develop new measurement techniques as necessary to measure the changing radiation fields introduced as the site cleanup progresses. New measurement techniques include accredited "head" dosimetry for unique tank farms geometries, finger dosimetry with greater accuracy for high energy beta fields for use at the 324 building, and special dosimeter designs for analyzing challenging radiation fields such as mixed energy beta and neutron fields.

\section{Plenty of Good Instruments}

PNNL maintains a calibrated pool of radiation detection instruments with sufficient inventory to respond to changing site requirements for radiation detection instruments. Nearly 15,000 instruments calibrations were performed in FY2002. The calibration program is staffed by radiation detection experts who can assist Hanford Site staff in identifying and deploying instruments appropriate to measure the complex and challenging radiation fields on the Hanford Site. Staff maintain current knowledge of radiation measurement techniques and DOE regulations which, coupled with their knowledge of the changing Hanford mission, allows PNNL to advise Hanford staff and DOE-RL on appropriate tools and methods to perform radiation measurements required to support site cleanup. Maintenance of the instrument pool allows Hanford Site facilities to adjust their instrument needs, as dictated by facility conditions, in a cost-effective manner because spare instruments from decommissioned facilities are redeployed at facilities with increasing instrumentation needs. 


\section{Tally of FY2002 Measurements}

During FY 2002, PNNL processed more than 55,000 external dosimetry and in vivo measurements. The processing of nearly 48,000 external dosimeters included:

- 19,951 standard dosimeters,

- 7,026 neutron combination dosimeters,

- 17,404 finger rings,

- 2,381 Area dosimeters,

- 1,310 environmental dosimeters,

- 67 nuclear accidents dosimeters, and

- 3,120 expedited processings.

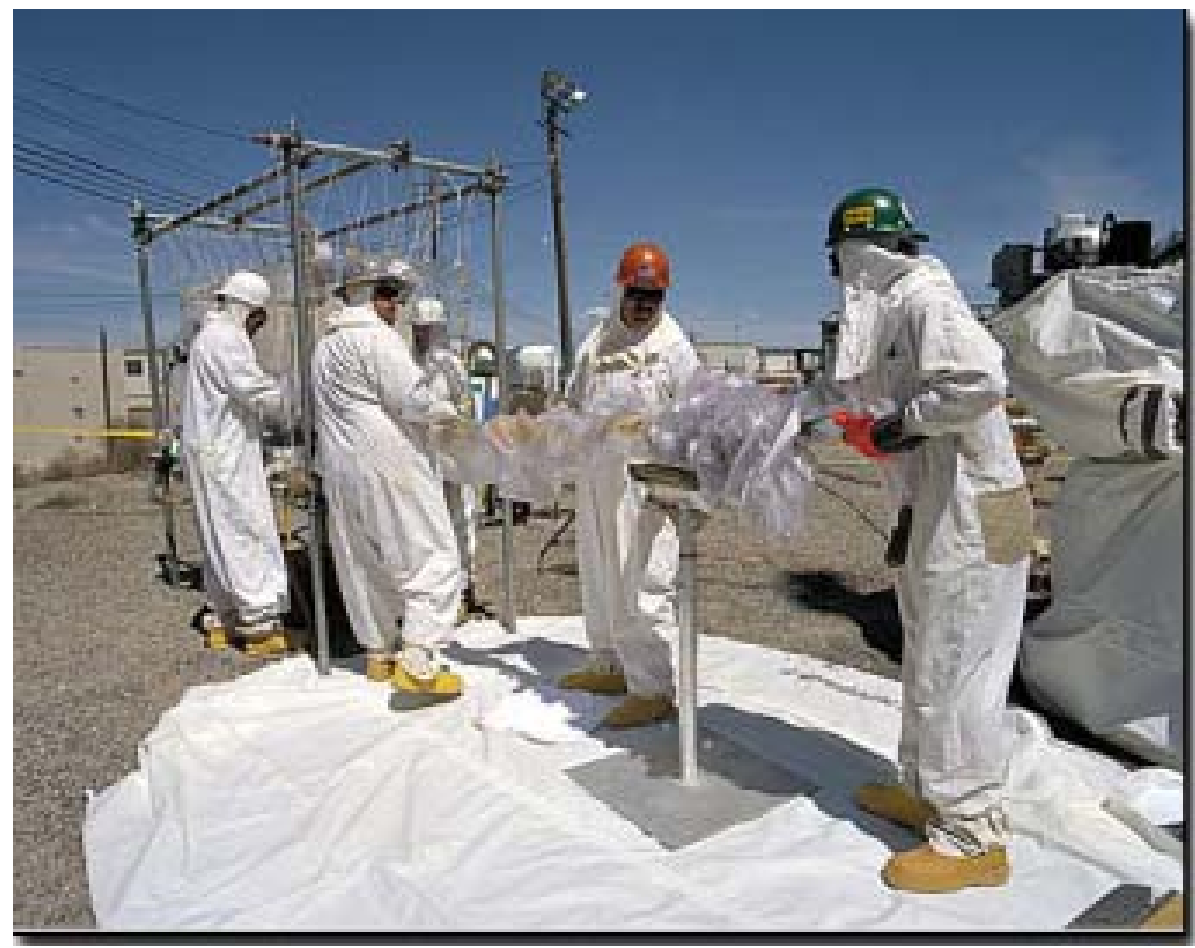

Figure 1.2.8. The Hanford Site contains 177 underground radioactive waste tanks, contents of which are routinely monitored. PNNL provides radiation measurement tools to protect Hanford Site workers by monitoring their exposure to radiation.
In addition to 219 intake evaluations, FY2002 saw some 6,900 in vivo measurements, including:

- 5,638 whole body counts,

- 1,230 chest counts, and

- 15 miscellaneous counts.

\section{Employee Dose Records Management}

PNNL maintains radiological dose records for present and former Hanford employees (except Du Pont employees), records that have been critical as DOE implements the Energy Employee O ccupational Illness Compensation Program Act (EEOICPA). PNNL's records management program for radiological dose records is a robust program that responds quickly to changes in records storage technology to ensure that records continue to be retrievable in the coming decades. These records are made available to Hanford staff through the Radiological Exposure (REX) database, a state-of-the art dose tracking database developed and implemented at PNNL. 


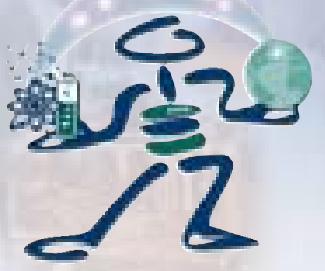

\subsubsection{Support to DOE's Office of River Protection}

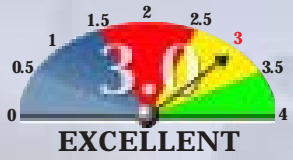

\section{PNNL provided the Office of River Protection with strategic planning and risk analysis to help ensure the quality of the tank waste cleanup baseline and to accelerate the safe retrieval, immobilization, and storage of Hanford tank wastes.}

D uring FY 2002, PNNL provided high-quality programmatic risk and decision analysis to the $\mathrm{O}$ ffice of River Protection (ORP). PNNL melded the scopes of work of the three key players in Hanford's River Protection Project (RPP) - the O RP, Bechtel National Inc. (BNI), and CH2M HILL (CHG) - to develop a single Integrated Risk Baseline for cleanup activities. This had not been done before and resulted in ORP's ability to analyze and evaluate alternative cleanup scenarios and technologies to accelerate Hanford Site cleanup activities, while reducing costs and programmatic risk.

\section{Acceleration and Risk}

Understanding risks associated with accelerated cleanup schedules and identifying specific technologies for cleanup activities lets D OE develop mitigation plans if problems occur. D oing things faster reduces costs, but also increases risk. PNNL developed several key products to help ORP understand the risks associated with various cleanup alternatives and technologies. During FY2002 PNNL developed:

- The Life Cycle Model (LCM) to analyze RPP scope and schedule. This model allows ORP to develop alternative cleanup approaches and to understand the net cost and schedule effect of the proposed approaches.

- The Integrated Technical Plan (ITP). PNNL staff analyzed vulnerabilities in the original baseline, allowing ORP to make current mission acceleration investments in tank closures and in supplemental waste processing capabilities.

- The Topographical Risk Assessment (TRA) Tool. This interactive visualization tool allows the user to manipulate cleanup activity duration to examine the net effect to programmatic risk.

\section{More Understanding, More Confidence}

PNNL efforts have resulted in increased DOE confidence in the Integrated Technical Baseline and the probability of meeting cleanup goals with the timeline allotted by D OE's accelerated cleanup schedule. PNNL's efforts also decreased the likelihood of cost and schedule overruns. PNNL staff also reviewed the ORP subcontractor's Risk Mitigation Plans to ensure the adequacy of activities and/ or technologies to mitigate the consequences of potential realized risk. PNNL staff helped DOE understand the vulnerabilities in the River Corridor baseline cleanup plan and the technologies necessary to accomplish the Hanford Site Environmental Restoration work in accordance with the accelerated cleanup schedule.

At Hanford, the acceleration of the legacy tank waste cleanup, including the pressure to shorten the schedule and contain cost, has created new project risks. PNNL's work in FY2002 resulted in the identification of mitigation strategies in the following areas:

- Close Coupled Design/ Construction of the Waste Treatment Plant (WTP) - To maintain an acceptable schedule, the primary processing facility for the tank waste must be built at an extremely ambitious pace, thus increasing overall risk.

- Technologies for Supplemental Immobilization Capacity - The WTP will not have the capacity to process all the waste on the accelerated schedule. Alternative immobilization technologies for the less threatening waste that meet the needs for possible land based disposal must be identified, tested, and deployed. 
- Cost-Effective Waste Retrieval Technologies - One of the major program costs is the cost to retrieve the waste from 177 tanks and feed it to the WTP and supplemental processing lines. New, cost-effective technologies will need to be proven and deployed.
- National HLW Repository Complete - To avoid the cost of interim storage facilities at Hanford, a major cost-cutting strategy is to ship the immobilized highlevel waste to the national high-level waste repository on a just-in-time basis. There is no assurance however, that the repository will be open.

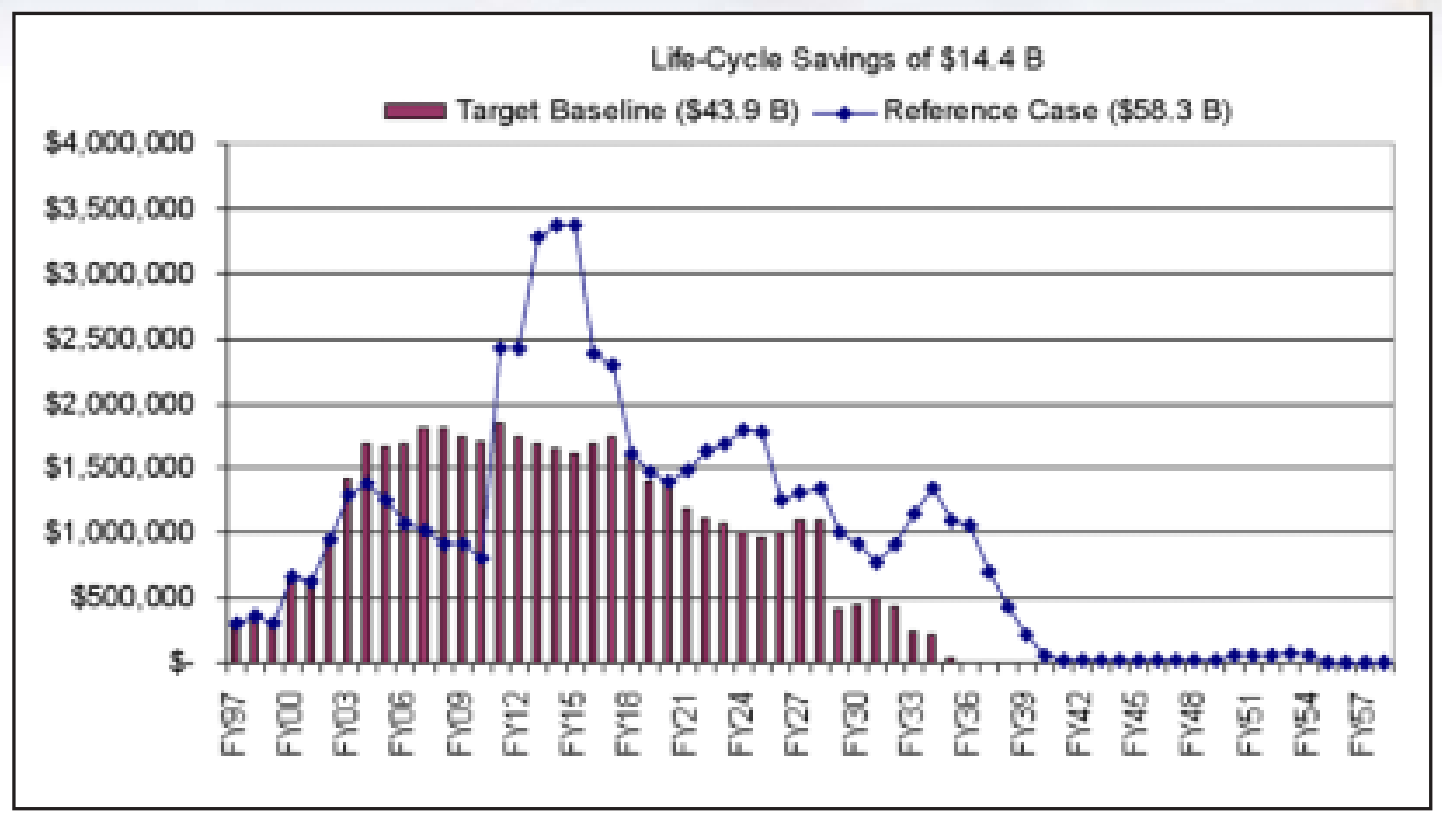

Figure 1.2.9 Life cycle cost comparison of the original River Protection Project (RPP) cleanup baseline to the proposed accelerated cleanup baseline (Target Baseline). PNNL developed the Life Cycle Cost Model (LCM) that enabled the Office of River Protection (ORP) to analyze alternative cleanup approaches and technologies, to forecast a life cycle cost savings of $\$ 14.4$ Billion. 


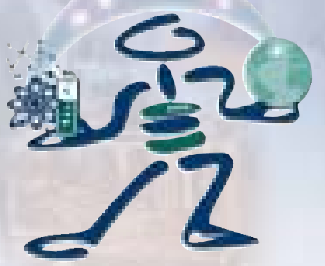

\title{
1.2.10 PNNL's Science and Technology Contributions to Hanford Site Environmental Restoration
}

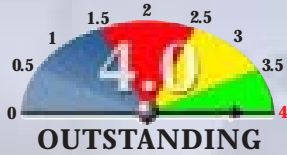

\author{
PNNL develops and delivers key scientific and technical \\ knowledge to enable more effective Hanford Site restoration.
}

Throughout FY2002, PNNL provided high quality support to Environmental Restoration activities both on the Hanford Site and across the D OE Complex. The impact of the contribution of science and technology to all aspects of Hanford Site restoration was noted by Jane Hedges, Washington State Department of Ecology, this year. Hedges commented: "The focused S\&T program contributed valuable information on the processes involved in the fate and transport of contaminants, notably cesium-37 through the Vadose Zone, and provides a better basis for planning, investigating, modeling, and ultimately, closure of these two tank farms...."

\section{Noteworthy FY2002 Events}

- Updating the Scienœ and Technology (S\& T) Roadmap. This update addresses comments by the National Academy of Sciences and the National Research Council, adds the soil and groundwater remediation technical element, and shifts the science and technology project from understanding fate and transport to developing the science and technology needed for remediation.

- Completion of the scientific input to the 0 ffice of River Protection's B-BX -BY Field Investigation Report, including the results of laboratory experiments and numerical modeling. Completion of this work provides experimental laboratory data generated by field investigations at representative sites, and numerical modeling to evaluate conceptual and numerical models of water and waste migration in the vadose zone at the B-BX-BY Tank Farm complex. This work makes significant progress toward understanding the effects of tank leakage on the Hanford Site groundwater. It will be used to determine the need for interim remedial actions and impacts to Tank Farm closure.

- Providing the critical technical information neoessary to document the technology options for treatment of a mix ed waste, uranium metal in ontaminated oil, ex humed from the
618-4 Burial G round. This information is currently being used by Hanford's Environmental Restoration Contractor to determine the best treatment path forward for this difficult waste mixture. No standard treatment path is currently available. Treatment of this waste mixture must be accomplished within the next 30 months.

\section{Why This Work Is Important}

O ur support of Hanford's Environmental Restoration activities supports one of D OE's most important missions on the Hanford Site and a pressing national need. The S\&T Roadmap is the planning tool for the Science and Technology Project. The addition of the remediation technical element identified research and technology development activities that are needed to accelerate cleanup at the Hanford Site and implement final remedial actions.

Research reported in the B-BX-BY Field Investigation Report focused on three areas: 1) strontium geochemistry and transport at B-110, 2) uranium speciation and dissolution from BX-102 sediments, and 3) fluid flow and transport. The scientific input by the S\&T Project to the ORP Field Investigation Report for the B-BX-BY tank farm complex represents a specific milestone in the S\&T Roadmap. The research addresses important scientific issues associated with transport of tank wastes and features of the vadose zone that control waste migration. The research results explain attenuation mechanisms of strontium-90 and uranium in the subsurface and allow development of geochemical models to predict future behavior of these contaminants.

In addition to providing significant support to Hanford Site science and technology issues, we have also provided complex-wide support by interfacing between Hanford and other DOE sites to define a prioritized set of DOE Complex-wide science and technology environmental restoration issues. 


\section{Managing Effectiveness and Efficiency}

The efficiency and effectiveness of PNNL's programmatic leadership of this work is evidenced by the fact that the S\&T Roadmap update included input from stakeholders, regulators, Tribal Nations and other D OE National Laboratories.

In addition, the input to the B-BX-BY Field Investigation Report included contributions from several D OE National Laboratories, the Environmental Management
Science Program, and D OE user facilities. PNNL also provided technical and programmatic leadership for prioritizing science and technology needs and defining the EM-50 Alternative Projects for carbon tetrachloride characterization and remediation as well as remediation of leaked high-level waste into the vadose zone. Finally, PNNL made significant contributions to the development of Strategic Initiative 6 for Groundwater Protection in the DOE Hanford Performance Management Plan.

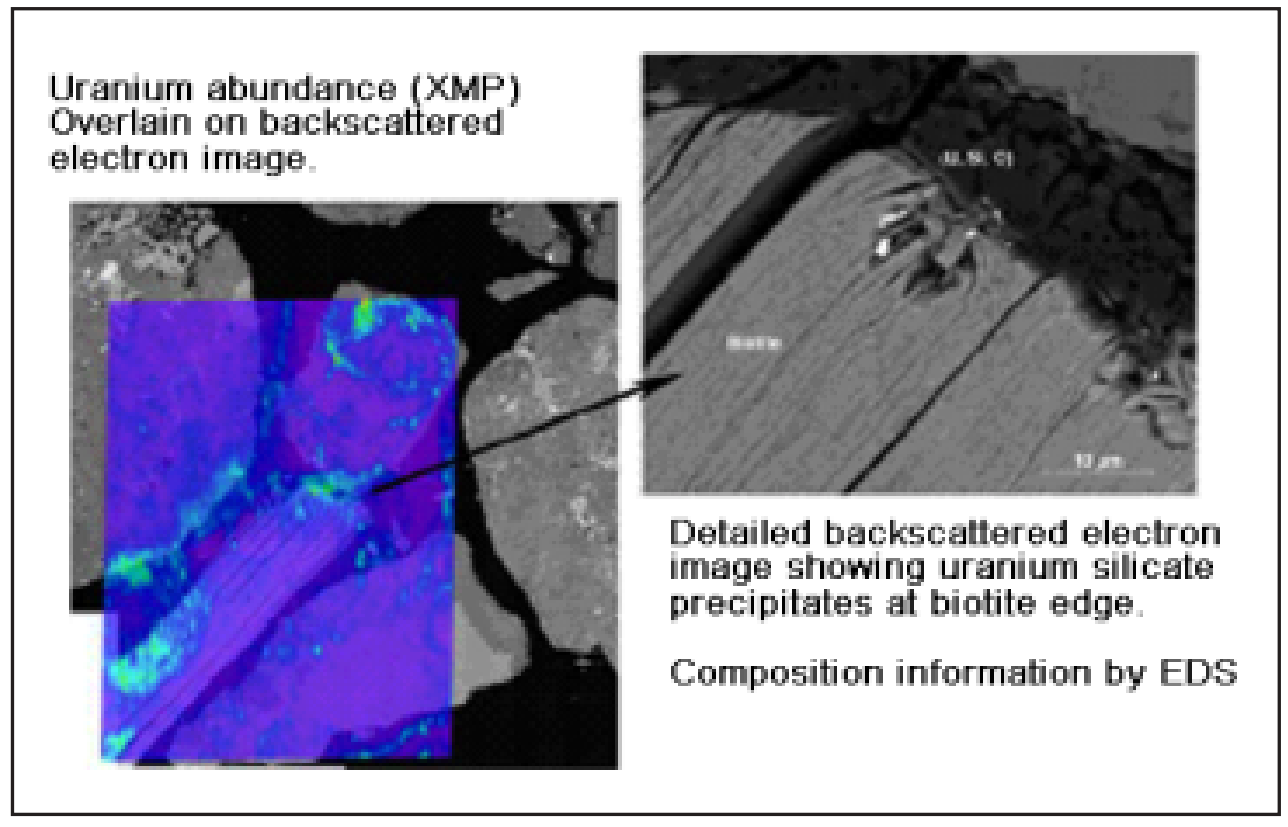

Figure 1.2.10. Information from PNNL Science and technology efforts helps make remediation decisions at Hanford. PNNL staff photomicrographically identified the chemical form of uranium contamination below the Hanford tank farms, critical in determining potential impact to groundwater and for selecting appropriate remedial actions. 


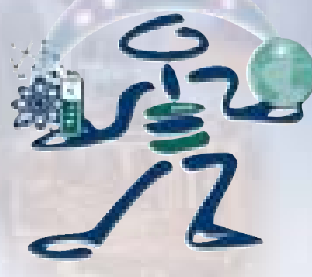

1.3.1 National Security Mission

PNNL's National Security Directorate develops and

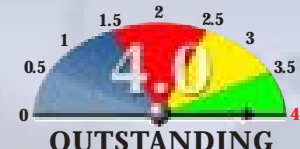

deploys innovative solutions to the country's most critical security challenges in the areas of Global Security, National Defense, Homeland Security, and Special Programs. (For more detailed information, see Appendix B.)

\section{Global Security}

Global security, which is the work we perform in proliferation prevention, arms control, and treaty verification, is the cornerstone of our national security business. We develop technology as well as support arms control and nonproliferation policy. We are a significant contributor to NNSA's Materials Protection Control and Accountability Program that is securing nuclear material throughout the former Soviet Union. We are also helping prevent the transfer of nuclear, chemical, and biological warfare knowledge and technology to rogue nations that support terrorism. PNNL has led the safety upgrades at Soviet-designed reactors throughout the Former Soviet Union for the past 10 years, and we are a contributor to the design, construction, and installation of the new confinement shelter at the Chernobyl

Nuclear Power Plant. In a local partnership with D OE's HAMMER facility located at the Hanford Site, we have trained both international and domestic border guards in preventing the smuggling of nuclear, biological and chemical materials.

\section{National Defense}

National Defense is our support to the protectors of our country, the D epartment of D efense (DoD). D rawing upon our expertise in physical and chemical sensing, we are developing and deploying diagnostic and prognostic systems on aging weapons systems to assure a high likelihood of mission readiness and effectiveness. We are also helping DoD define its logistics systems and processes as it transforms from a forward deployed force positioned for the Cold War to a highly mobile and responsive force for the $21^{\text {st }}$ century threat environment. The D oD faces significant environmental restoration challenges as it reduces the size of its infrastructure and support complex. PNNL is applying environmental restoration technologies deployed for the D OE complex to similar challenges at $\mathrm{D} 0 \mathrm{D}$ sites.

\section{Homeland Security}

Long before September $11^{\text {th }}$, PNNL was developing technology to help combat terrorism and to protect our nation's critical infrastructures for the law enforcement community, first responders, U.S. Customs, State, and Commerce departments, as well as DOE, NNSA and D oD. O ur homeland security business has developed technology for detecting attempts to smuggle Weapons of Mass D estruction (WMD) materials and has helped equip and train first responders who will have to respond to WMD terrorist incidents. Several technologies have been fully commercialized. Attention is now being turned to the longer-term science and technology agenda needed to provide continuous and evolving improvements to the security of our homeland.

\section{Special Programs}

Special Programs is our work for the intelligence community - DOE's Office of Intelligence (D OE-IN) plus the armed services and national intelligence agencies. We are major supporters of DOE-IN, primarily supporting nuclear intelligence. O ur signatures are nuclear intelligence and nuclear forensics, drawing upon nuclear fuel cycle expertise developed during the plutonium production days of Hanford. Expanding on this role, we are currently leading a new effort in D OE-IN addressing offshore non-nuclear energy intelligence.

O ur support to the national agencies in the areas of remote sensing, Measurement and Signals Intelligence (MASINT), and analysis of massive data sets is growing rapidly. O ur expertise in robotics, small power supplies, and wireless communication has provided technology and systems to the intelligence community that supports covert and unattended operations. PNNL was selected by the intelligence community to lead the Western Regional Information Science Research Center. 


\section{Core Science Base Applied to Mission Requirements}

PNNL is making significant S\&T investments in systems biology, computational sciences, and molecular science to strengthen the core science base of PNNL. The National Security D irectorate draws upon this core science base in its continuing mission as contributor to national efforts to prevent the proliferation of WMD and to improve Homeland Security.

\begin{tabular}{|c|c|}
\hline $\begin{array}{l}\text { Actinide \& } \\
\text { Analytical } \\
\text { Chemistry }\end{array}$ & $\begin{array}{l}\text { - D etecting and Preventing WMD Proliferation } \\
\text { - Treaty Monitoring and Verification Technologies }\end{array}$ \\
\hline $\begin{array}{l}\text { Biomolecular } \\
\text { Science }\end{array}$ & $\begin{array}{l}\text { - Countering Bioterrorism } \\
\text { - Bio Warfare D efense }\end{array}$ \\
\hline $\begin{array}{l}\text { Computational } \\
\text { and Information } \\
\text { Science }\end{array}$ & $\begin{array}{l}\text { - Intelligence From Massive D ata Sets } \\
\text { - Network Centric Warfare } \\
\text { - Image Processing }\end{array}$ \\
\hline $\begin{array}{l}\text { Chemical and } \\
\text { Physical Sensing }\end{array}$ & $\begin{array}{l}\text { - In Situ Diagnostics and Prognostics } \\
\text { - NBC D etection, Monitoring, Characterization }\end{array}$ \\
\hline $\begin{array}{l}\text { Nuclear Science } \\
\text { and Engineering }\end{array}$ & $\begin{array}{l}\text { - Nuclear Intelligence and Nuclear Reactor Safety } \\
\text { - Fissile Material Protection, Control, D isposition } \\
\text { - Tritium Production }\end{array}$ \\
\hline
\end{tabular}

\section{National Security Represents $45 \%$ of the Overall Laboratory Business Portfolio}

The growth of our national security portfolio is due to our ability to apply the core science and technology base that supported plutonium production and environmental cleanup to address a broad set of contemporary national security challenges.

- More than half our work is for NNSA in the areas of nuclear nonproliferation, nuclear safety, and treaty verification. We also are using our nuclear science expertise to develop technology and processes for producing tritium for the weapons stockpile in commencial light water reactors.

- DOE's O ffice of Counterintelligence (DOE-CN) has relied on PNNL to develop and deploy cyber security tools throughout the DOE complex, drawing upon our strengths in information visualization and mining massive data sets.
- O ur Work for Other Federal Agencies spans the Customs, State, and Commerce D epartments, as well as the IRS and the FBI. The vast majority of this work is directly related to homeland security and countering terrorism.

\section{FY2002 Performance}

A description of accomplishments and evaluation of PNNL's performance supporting DOE's national security mission was developed and reviewed with key sponsors in NNSA prior to the production of this report. To preserve the integrity of that document, we have included it in its entirely in Appendix B and refer the reader there for more detail on FY 2002 performance.

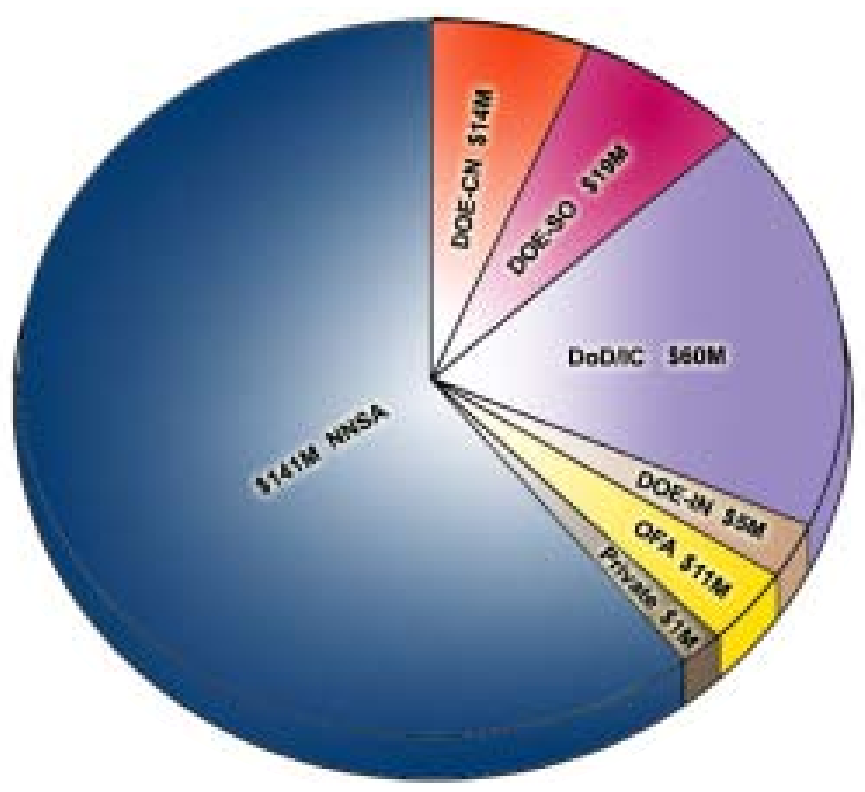

Figure 1.3.1. National Security revenue of $\$ 251$ million represents $45 \%$ of the overall Laboratory business portfolio. 


\title{
1.4.1 Improving the Nation's Energy Systems to Provide Secure, Clean, O0UTSTANDING Affordable Energy: Distributed Energy and Energy Systems
}

\begin{abstract}
PNNL provides leadership in the development of advanced communication and control technologies to benefit a highly connected electricity grid and distributed energy systems.
\end{abstract}

The Laboratory is providing the leadership and technology development to enable a transformation in the reliability, capacity, and efficiency of the nation's electricity grid through the application of information science and technology to electricity transmission, distribution, and end-use. Key technology developments needed to transform the nation's electricity grid will include network based control systems, distributed intelligence control, autonomous agent systems, energy diagnostics and controls and building dynamics.

\section{Leadership and Technology Developments in Transmission Reliability}

The Laboratory supports the D OE Transmission Reliability Program and the President's National Energy Plan through participation and leadership in the Consortium for Electric Reliability Solutions (CERTS). In support of the National Energy Plan call for a review of the national transmission system, PNNL staff wrote the advanced technology options chapter in the National Transmission G rid Study released by Secretary Abraham in May 2002. These findings have played a significant role in the Federal Energy Regulatory Commission (FERC) and administration's development of new energy market policy.

PNNL's research efforts in support of the DOE Transmission Reliability Program include real-time power system monitoring and control, analysis of load as a reliability resource, and a study of distributed energy resource impacts on the transmission system's dynamic performance. PNNL received an E nergy 100 award in 2001 for the Wide Area Measurement System (WAMS), a network of synchronized monitors collecting highspeed data from strategic locations throughout the power grid, jointly developed over the past 10 years with DOE, the Bonneville Power Administration (BPA), Electric Power Research Institute, and other utility company support. The Western Systems Coordinating Coun- cil (WSCC) has nearly doubled the number of monitors in the network in the last year, due in large part to PNNL facilitation and assistance. Tools developed by PNNL provide the virtual instrumentation necessary to measure electric power system performance, analyze the dynamic response from system disturbances or tests, and validate planning models against measured system behavior. A WAMS disturbance analysis workstation was supported by PNNL at the California ISO with cofunding from the California Energy Commission. With leadership and facilitation by PNNL, WAMS now is being adopted in the Eastern Interconnect, which includes the Eastern U.S. and Canada. PNNL staff actively support the Modeling and Validation Work G roup of the WSCC, including supporting system tests and drawing together data and tools needed to calibrate planning models using data collected from these tests.

\section{Leadership in Advanced Communications and Controls}

The Laboratory was a principal thought leader and developer of a new vision for the nation's electric energy system, one that uses telecommunications and information technology to access and empower distributed energy technology to dramatically improve the economic and operational performance of electric services. Collaboration with major industrial firms such as IBM, ALSTOM, and utilities such as BPA and American Electric Power, as well as broad industry groups including the CEO Coalition, in addressing technical needs and policy opportunities (specifically through meetings with the FE RC Chairman) has helped fuel desire for this transformational concept.

PNNL helped organize and lead a DOE Communications and Controls Workshop in May 2002 in Reston, Virginia. This workshop brought together more than 75 participants from 50 different organizations to create an R\&D roadmap for this new DE\&ER program. 
PNNL will help organize and lead a larger Industry Workshop, O ctober 24-25, at Skamania Lodge near Portland, Oregon. This workshop will be co-sponsored by BPA and is focused on showcasing the industry in the Northwest.

\section{Buildings-Cooling-Heating-Power}

PNNL has taken a lead in developing and deploying diagnostic and control technologies for the BuildingsCooling-Heating-Power demonstration at the University of Maryland. PNNL developed a diagnostic system for absorption chillers that will be demonstrated at the University of Maryland in FY2003. Additionally, PNNL developed and transferred two diagnostic platforms to the University of Maryland. O ne platform provides the basis for application to a wide variety of energy devices and will be used by students for research, development, and demonstration of diagnostic technology. The other platform includes the diagnostics for outside air economizers, a major energy efficiency device in modern buildings. Since it is estimated that $25 \%$ of all economizers are operationally defective (which wastes substantial energy), these developments set the stage for wide adoption of diagnostic technology in buildings, particularly for emerging technology such as building-level combined heat and power, which can save enormous amounts of energy nationwide.

In addition, the PNNL D ecision Support for O perations and Maintenance (D SO M) system has been developed and installed at multiple US Marine Corp bases resulting in significant energy saving and improved self-sufficiency. The system has been extended to Public Housing Authorities with a pilot installation for the New York City Housing Authority which resulted in a $\$ 400 \mathrm{~K}$ savings during the first year of operation.

\section{Leadership and Support of Regional Energy Issues}

PNNL staff supported DOE-RL in developing a site strategy to enhance Hanfords contribution to National Energy Plan goals and regional energy issues, consistent with Secretary Abraham's Memorandum of Understanding with the Western G overnor's Association. PNNL organized regional stakeholders, including the D OE Seattle Regional Office, BPA, regional utilities, and others to support the effort. This resulted in approval in May of DOE-RL's "Energy to Assets" strategic plan, targeting three key outcomes.

PNNL's management was also instrumental in creating the new Northwest Energy Technology Collaborative this year. Governor G ary Locke of Washington State announced this new organization on August 21, 2002, with the goal of making Washington, and the entire NW, leaders in clean energy technologies. Energy technology related companies and organizations will work together to accelerate the development and adoption of new innovative energy technologies. They will specifically leverage technology innovation at PNNL to invest in commercial ventures, accelerate deployment, and create jobs.

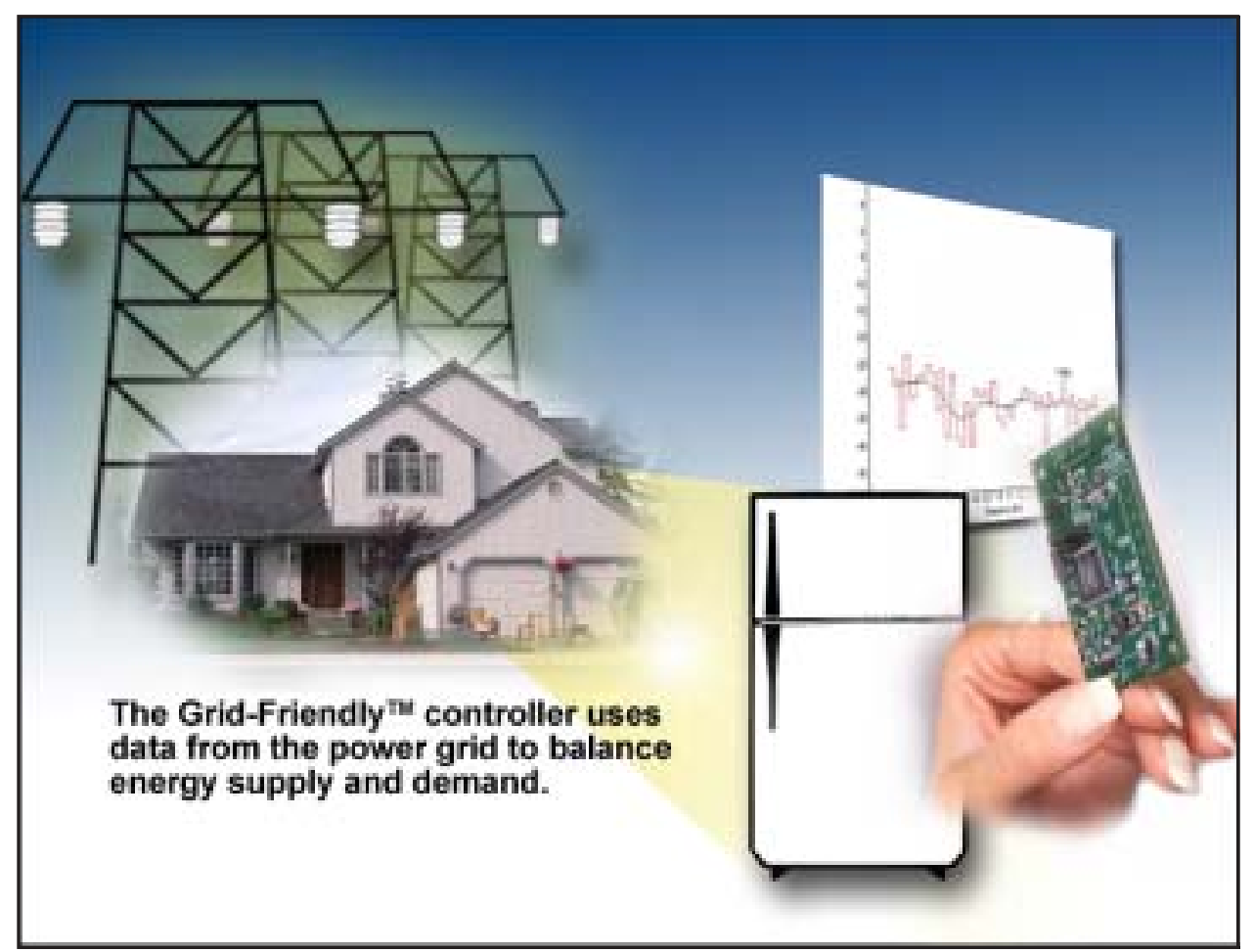

Figure 1.4.1. The Grid Friendly ${ }^{\mathrm{TM}}$ controller uses data from the power grid to balance energy supply and demand. 


\subsubsection{Improving the Nation's Energy Systems to Provide Secure, Clean, Affordable Energy: High-Efficiency Transportation Systems

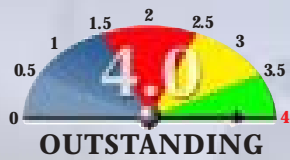

\section{PNNL is developing advanced transportation technologies for essential power systems, lightweight materials, and emissions control.}

The PNNL projects developing advanced transportation technologies are all cost shared with industry partners such as Ford, G M, D aimlerChrysler, D elphi Corporation, ALCOA, Freightliner, PACCAR, Caterpillar, Cummins, and D etroit Diesel. PNNL technical contributions include the development of processes that enable lightweight materials to reduce automotive and heavy-vehicle weight, leading to increased vehicle fuel efficiency; the development of advanced fuel cell technologies to reduce fuel consumed by parasitic loads; and the development of advanced after-treatment technologies to reduce diesel emissions, an essential step toward highly efficient diesel engines for trucks and cars.

\section{Leading the Essential Power System Program Area with DOE}

The vision of the Essential Power System (EPS) Program is to increase heavy vehicle fuel efficiency by $10-15 \%$ during realistic drive cycles and to eliminate heavy truck idling needed to provide energy for electric needs other than propulsion. PNNL supported the EPS industry workshop held in D ecember 2001 (attended by more than 80 industry and government participants), the multi-year program plan, and the competitive solicitation. PNNL leveraged activities with the $21^{\text {st }}$ Century Truck Partnership, Hydrogen and Fuel Cell programs, and Fossil Energy's Solid Energy Conversion Alliance (SECA) program.

PNNL, in collaboration with the National Energy Technology Laboratory (NETL), and technology development and program managers for the Hydrogen Program, defined a technical program that deals with essential power systems (EPS) based upon solid oxide fuel cells (SOFC) for heavy trucks. EPS could provide power for any function on the truck not involved in moving the truck, but requiring electrical or mechanical energy- lights, hotel loads (HVAC, computers, appliances, lighting, entertainment systems), pumps, starters, compressors, fans, trailer refrigeration, engine and fuel heating. An EPS would enable the transition from "belt and gear driven" generation to auxiliary power generation of electricity. Benefits of an EPS include reduction of emission during idle, the potential for $10 \%$ increased fuel efficiency during a long-haul drive cycle, and increased engine life by about 100,000 miles over five years. PNNL efforts in FY2003 will focus on development of auxiliary power unit controls and system thermal/ electrical models for transportation, and dynamic modeling for packaging shock and vibration.

PNNL staff consistently contributed to the mission of Hydrogen, Fuel Cells, and Infrastructure Program by participating in the 2002 U.S. D OE Hydrogen and Fuel Cells Annual Program and laboratory research and development reviews, and the Hydrogen Storage Roadmap Meeting.

\section{Technology for Emissions Control}

O ne of the distinctive signatures in applied catalysis developed over the past decade lies in the area of emissions chemistry. With increased emissions standards on the horizon, particularly those for diesel engines, PNNL has an excellent opportunity to grow a coupled applied/ fundamental catalysis program. In FY2002, PNNL hired a key staff member to support both D OE Combustion and Emission Control programs and to lead PNNL's diesel emissions reduction projects. This staff member was funded with laboratory research and development funds to develop modeling tools and capabilities that will support aftertreatment technologies. This work was presented at the 2002 D OE Diesel Engine Emissions Reduction Conference.

PNNL initiated three new projects with Caterpillar, Cummins and Detroit Diesel in support of the multilaboratory aftertreatment technology roadmap and in meeting 2007 emission standards. 


\section{Supporting DOE's FreedomCAR Program}

PNNL was successful in developing R\&D 100 awardwinning microchannel technologies that address the critical issue of a rapid start gasoline reformer. This novel system includes a compact steam reformation-based fuel processing system for the onboard reformation of hydrocarbon fuels that meets FreedomCAR performance targets for energy density, efficiency, residual carbon monoxide content, durability, rapid start-up, and transient response. Highly effective reactors, fuel and water vaporizers, recuperative heat exchangers, and condensers that are broadly applicable to fuel processing and fuel cell systems also are being developed. Endothermic steam reformation is emphasized in this effort to take best advantage of unique heat and mass transfer benefits available in engineered microstructures.

Researchers have achieved significant progress toward meeting performance targets established by

FreedomCAR. Targets for fuel flexibility, warm transient response, energy density, and residual carbon monoxide concentrations have been met or exceeded. A new design for reactors, heat exchangers, and vaporizers operates with exceptionally low pressure losses that are critically needed to meet rapid start-up requirements for transportation applications. Full-scale microchannel steam generators have been provided to industrial partners for testing and evaluation, including McD ermott Technology Inc. Finally, PNNL has partnered with Argonne National Laboratory, Los Alamos National Laboratory, and Oak Ridge National Laboratory to develop and demonstrate a rapid-start autothermal fuel processing system for on-board transportation applications.

PNNL technical contributions included the development of materials processes and manufacturing technologies that enabled increased use of lightweight materials to reduce automotive and heavy vehicle weight, leading to an increase in vehicle fuel efficiency. Significant accomplishments during FY2002 included the completion of a lightweight vehicle frame for a popular sport utility vehicle, and demonstration of unique glazing systems that reduce the weight of the glass by 30 percent while still retaining safety and durability.

\section{Helping DOE Leadership in the $21^{\text {st }}$ Century Truck Partnership}

PNNL, in addition to our role as technology developer with both industry and government partners, directly support D OE's lead role in the $21^{\text {st }}$ Century Truck Partnership, including one person in Washington D.C. during the summer of 2002.

PNNL staff consistently contributed to the Office of Freedom Car and Vehicle Technologies (OFCVT) mission by participating in the $21^{\text {st }}$ Century Truck Technical Roadmap, the Office of Advanced Automotive Technologies (OAAT) Annual Offsite Workshop, the OHVT Annual O ffsite, the D iesel Engine Exhaust Reduction Workshop, DOE Non-carbon Based Fuels Workshop, G PRA Review, the Annual CIDI Review and the 21 ${ }^{\text {st }}$ Century Truck Materials Roadmap.

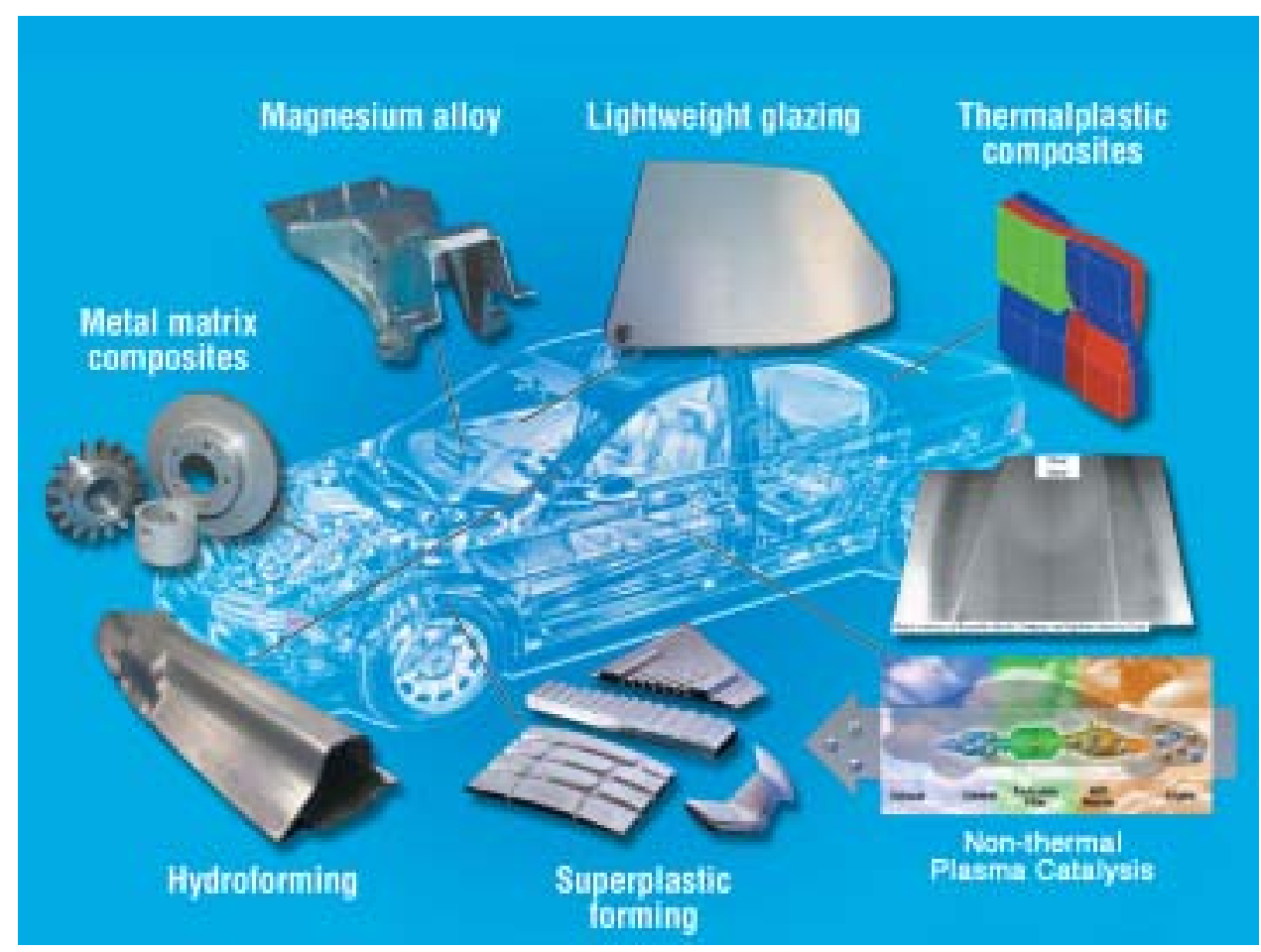

Figure 1.4.2. PNNL has developed a non-thermal catalyst for emissions reduction and is working with major vehicle manufacturers to reduce the weight of transportation vehicles by 20 percent. 


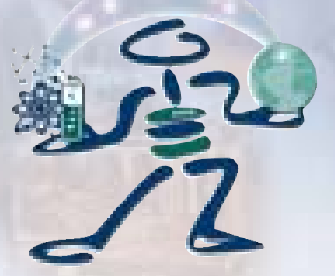

\subsubsection{Improving the Nation's Energy Systems to Provide Secure, Clean, Affordable Energy: Bio-based Products and Processes}

\section{PNNL is developing bio-based products and processes to displace imported petroleum and assist with the implementation of integrated biorefineries.}

The newly reorganized Office of Biomass Programs consolidated biomass R\&D efforts previously sponsored through the O ffices of Industrial, Transportation, and Power Technologies. The major goals of the new program include: 1) reducing dependence on imported petroleum, and 2) helping establish integrated biorefineries that produce a combination of products, fuels, and power. The Laboratory is involved in research that assists the Office of Biomass Programs in meeting these goals. PNNL has been very successful in identifying opportunities to include major agricultural industries in the research. These partners provide cost sharing to leverage D OE investments and their involvement ensures the research meets the needs of industry. In FY2002 PNNL conducted projects for the Office of Biomass Programs that totaled approximately $\$ 2.2$ million.

\section{Strong R\&D Capabilities in Catalysis and Advanced Biomolecular Processing}

In FY 2002, PNNL further strengthened its scientific $\mathrm{R} \& \mathrm{D}$ capabilities in the area of biomass catalysis and biomolecular technology. The catalysis research involves a range of approaches to create bio-based products, fuels, and energy from biomass. The biomolecular technology involves the use of innovative fungal fermentation to more effectively convert biomass. As a result of advances in these areas, PNNL was successful in partnering with industry on several proposals submitted in response to a D OE solicitation issued in mid2002. PNNL will be a partner on two of the seven proposals funded directly by DOE and two others from the same solicitation to be funded by the U.S. D epartment of Agriculture (USDA), participating in a total of four of the nine funded projects. Industry partners include Cargill, National Corn Growers Association, and Iowa Corn Promotion Board. This research is expected to lead to the near-term implementation of these technologies into commercial processes.

\section{Value Recognized by Industry}

Industry is recognizing the value of PNNL's work on competitively awarded projects dealing with bio-based products. In late FY2001, PNNL was awarded four competitively-based projects with industry partners, including the National Corn G rowers Association, the Iowa Corn Promotion Board, Archer D aniels Midland Corporation (ADM), and the Grain Processing Corporation. These projects include production of higher value products such as polyols, iso-sorbide, and other polymer building blocks. Strong technical progress in FY 2002 generated increased industrial interest in these products, and ADM presented PNNL with a plaque in appreciation for the Laboratory's work on the project. PNNL views active industry interest in these bioproducts as a critical part of the goal of establishing economic, integrated biorefineries.

\section{Advances in Catalysis to Reduce Environmental Impacts}

PNNL began research on an innovative thermal catalytic technology to efficiently gasify wet biomass feedstocks, which is important because most biorefineries will produce wet wastes. Examples of wet biomass include fermentation wastes and manure. Initial results in 2002 showed these feedstocks can be converted rapidly and completely to fuel gas without the formation of sludge. D epending on the catalysts and conditions, the wet biomass can either be converted to a hydrogen-rich gas or a gas containing mostly methane. The ability to rapidly convert more than $99 \%$ of whole cattle manure to hydrogen or methane is a major technical accomplishment. This technology is important in meeting DOE's goals of reducing environmental emissions from biomass systems. 
The Northwest Bioproducts Research Institute

PNNL made significant progress in its continued efforts to build partnerships of regional universities, national laboratories, and industries. PNNL and its partners began a DOE project to evaluate the capabilities of regional institutions and to evaluate how those resources can effectively be used to support D OE. The collaboration includes the Idaho National Engineering and Environmental Laboratory (INEEL), Washington State University (WSU), University of Idaho (UI), University of California-Davis, and the USDA Western Regional Agricultural Center. Four participants- PNNL, INEEL, WSU, and UI- have completed a Memorandum of Understanding establishing the Northwest Bioproducts Research Institute, a regional center of excellence for bio-based products. Its goal is to bring together the $R \& D$ capabilities of these institutions and work with industry to develop new products.

\section{Creating Intellectual Property for PNNL and DOE}

PNNL bio-based projects generated eight patents in FY2001, and some of the CRADA partners are currently negotiating for rights to the technologies. In FY2002, PNNL received one new patent and submitted eight new patent applications for bio-based products and processes. The development of this type of intellectual property is crucial to industry to provide a basis for investment in new bio-based technologies on a commercial scale.

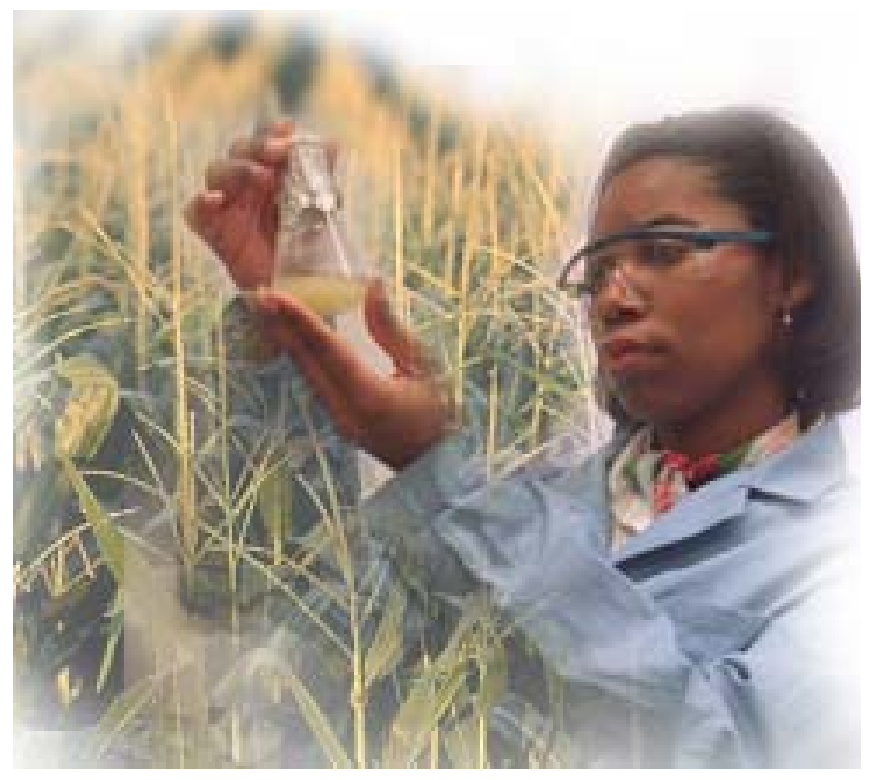

Figure 1.4.3. PNNL scientists are taking biomass conversion processes from the laboratory to industrial applications. 


\title{
1.4.4 Vision 21 Goals Advanced Through Zero-Emissions Fossil Energy Conversion Technologies: Fuel Cell Technology
}

\begin{abstract}
PNNL continues its leadership toward achieving the goals of the Solid-state Energy Conversion Alliance and expanding the development of fuel cells.
\end{abstract}

PNNL supports the Office of Coal and Power Systems through its efforts in the Advanced Fuel Cell program and in support of the next generation of coal-based near-zero emission central power generation. The Laboratory demonstrated its leadership and technical contributions in the development and implementation of the Solid-state Energy Conversion Alliance (SECA) and the High Temperature Electrochemistry Center (HiTEC), both accomplished in partnership with the National Energy Technology Laboratory (NETL).

\section{Leadership and Support for the SECA Program}

In FY2002, PNNL provided leadership and technical assistance to SECA and contributed to the creation of HiTEC, laying the groundwork for expansion of SECA to scale fuel cells to the size needed for central power stations and to incorporate coal as a fuel. The Laboratory also helped plan and lead a large industry coordinated carbon sequestration project in support of the Office of Coal and Power's mission and goals.

SECA is directed to accelerate the commercialization of low-cost solid oxide fuel cells (SOFC) as quickly as possible during the next decade. It is a collaborative effort led by NETL and PNNL and is supported by DOE's Office of Fossil Energy and NETL's Strategic Center for Natural G as. This alliance of U.S. industry, universities and other research organizations, represents a new model for joint government and private industry technology development.

SECA's goal to create a solid oxide fuel cell (3-10 kW) that can be mass-produced in modular form at a cost of $\$ 400$ per kilowatt requires major breakthroughs in the design and manufacture of SOFC systems.

PNNL coordinates the Core Technology component of SECA, and NETL coordinates the industrial teams. There are currently four industrial teams with up to two more scheduled to start in FY2003.
SECA's success includes large numbers of industries wanting to participate in the development of rapid technological advances. The level of excitement is very high, both in the U.S. and in Europe. If SECA meets its goals, it will revolutionize power generation.

The Laboratory is helping expand SECA by clustering modules to accommodate central power station sizes up to 100 megawatts. These large fuel cell clusters must be capable of operating on gasified coal. System optimization is one of the goals of the SECA expansion, which is necessary to meet the goals of Vision 21.

\section{Technology Supporting SECA}

Selected technical accomplishments for the SECA Core Technology Program include:

- advanced doped perovskite cathode electrode materials for improved electrical performance of cells and stacks at 750 degrees $C$;

- ceramic anode electrode formulations for red-ox, sulfur and carbon tolerance;

- a composite ceramic seal configuration for improved gas tightness;

- computational thermal, stress and electrochemical models for better understanding of fuel cell processes and the optimization of the cell and stack designs;

- high-performance computing modeling tools for detailed microstructured electrochemistry to enable optimization of electrode microstructure and understand causes of performance degradation;

- thermal flow and electrical system level modeling tools for design and controls of SOFC auxiliary power units; 
- high-performance computing modeling tools for detailed microstructured electrochemistry to enable optimization of electrode microstructure and understand causes of performance degradation;

- thermal flow and electrical system level modeling tools for design and controls of SOFC auxiliary power units; and

- compilation of materials database for SOFC current collector application.

PNNL participated in university, industry and government agency outreach activities, including:

- Invited presentations to the Boeing Corporation, United Technologies Research Center and Allegheny Ludlum Corporation

- Invited technical presentations at meetings sponsored by American Society for Metals, American Ceramic Society, and The Metallurgical Society

- Technical presentations at University of Pittsburgh, Montana State University

- Potential technology collaboration with Rolls Royce

- Technology exchange with Julich

- Participation in Indo-US fuel cell workshop

- Coordination meetings with U.S. Army Communications-Electronics Command (US CECOM)

- D efense Advanced Research Projects Agency "Palm Power" development

- NASA/DOE/DoD workshop for aerospace applications of SOFC

- O hio Fuel Cell Coalition meeting and workshop

\section{High Temperature Electrochemistry Center (HiTEC)}

The High Temperature Electrochemistry Center was initiated in FY2002 to address the underpinning technical issues that need to be addressed before Vision 21 can be realized. These technology barriers cover a wide spectrum of issues from coal gasification to interfaces between fuel cells and turbines. PNNL leads the hub center and universities make up the satellite center. Each university will focus on a different technology area. PNNL, along with NETL, will coordinate the university activities, so that all major technology barriers are being addressed. The HiTEC currently has one university satellite center (Montana State University) and plans to add two per year until all technology areas are covered, with a total of approximately seven anticipated.

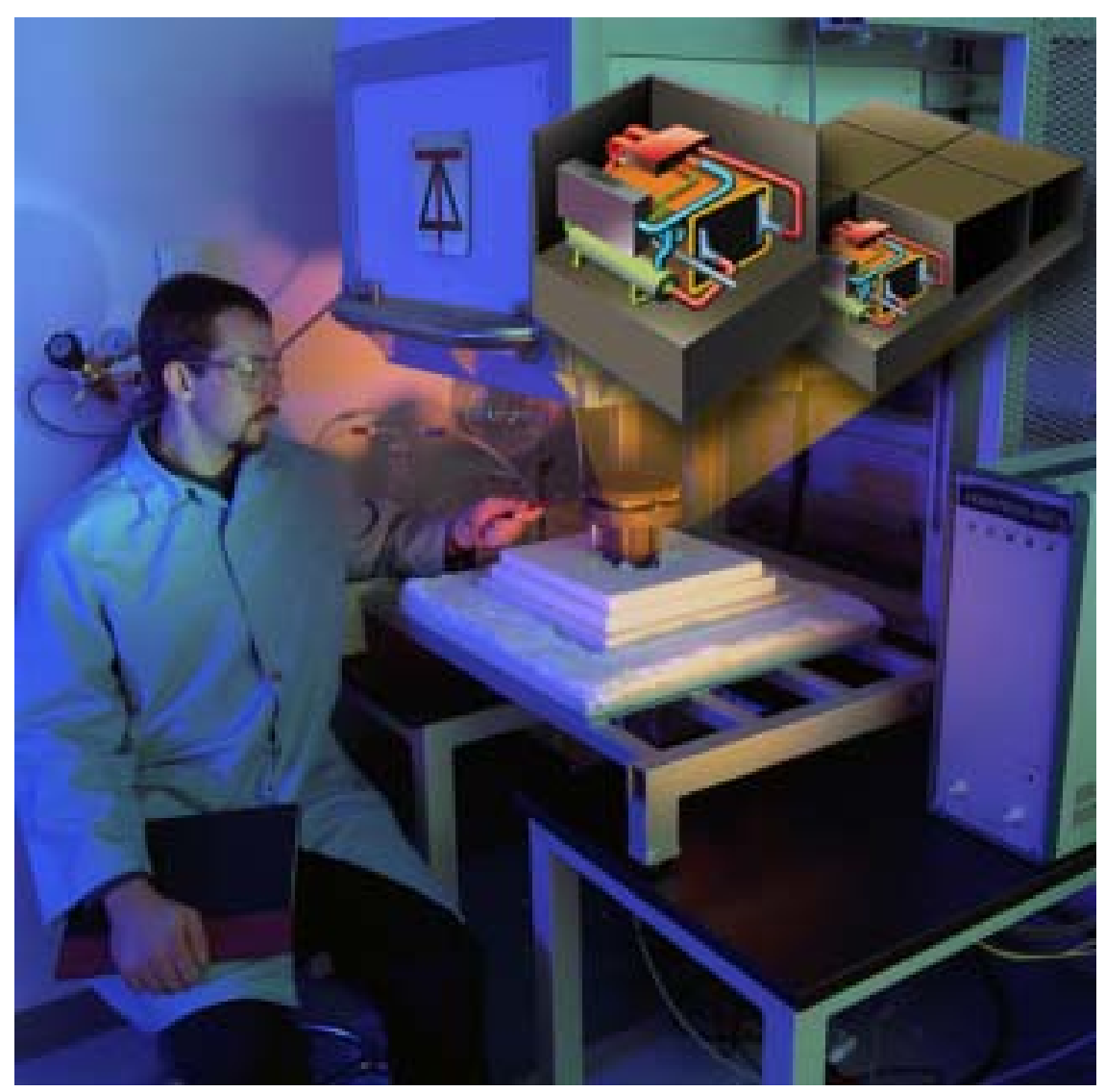

Figure 1.4.4. PNNL researchers are working to solve the technical challenges required for the widespread use of fuel cells in vehicles and other applications. 


\subsubsection{Vision 21 Goals Advanced Through Zero-Emissions Fossil Energy Conversion Technologies: Carbon Management}

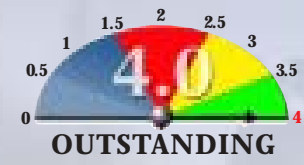

\section{PNNL's understanding of climate change science allows the development of technologies for carbon sequestration and capture in support of a presidential initiative for a voluntary $17.5 \%$ reduction in carbon dioxide emissions.}

In FY2001, collaborative analysis and workshops focused on understanding the role for coal in a carbonconstrained world has been the signature of the PNNL, Fossil Energy, and NETL relationship. In FY 2002, the Laboratory took several important steps with NETL to solidify the analysis-related aspects of the partnership and build a technology component.

\section{Strategic Investments in Carbon Management Technical Capabilities}

The Laboratory significantly expanded its internal discretionary investments in the area of carbon sequestration in order to better support Fossil Energy. Areas of focus include: reservoir modeling, sequestration in saline formations, sequestration in hydrate-bearing formations, and in-situ mineralization of $\mathrm{CO}_{2}$ in basalt formations. FY 2003 investments will also include monitoring and novel carbon capture technologies.

\section{Support to DOE Carbon Management Programs}

The Laboratory partnered with American Electric Power, BP, Schlumberger, the Ohio Coal D evelopment O ffice, and Battelle to start a $\$ 4$ million, 18-month project to characterize the suitability of O hio River Valley formations for carbon sequestration. PNNL will provide monitoring, reservoir modeling, and integrated risk assessment support to the team. Participating in the nation's largest individual sequestration project, PNNL and NETL also initiated a joint analytical effort on sequestration/ carbon management that is expected to expand in FY 2003.

\section{Outreach and Collaboration with Industry and Government}

PNNL initiated an outreach effort focused on the coal industry to begin building consensus around the issue of carbon management and simultaneously build support for D OE-FE programs. Important engagements and presentations include interactions with the companies of the World Coal Institute, the National Mining Association, and the Washington Coal Club.

PNNL conducted more than two dozen senior government briefings for various agencies, the Vice President's office, the Council on Environmental Quality, state agencies, and the Environmental Protection Agency on the importance of carbon capture and sequestration, as well as the importance of moving toward the construction of large-scale experimental facilities that would enable an expanded scientific understanding of sequestration. The intention of these briefings is to build a broad base of support in government for D OE-FE's sequestration program.

Because the President's agenda includes expanded cooperation on climate change R\&D, PNNL has invested considerably in Japanese and Australian R\&D partnerships, as well as more modestly in European and Canadian partnerships, with the intention of using these partnerships to help position D OE-FE for success in FY 2003. 


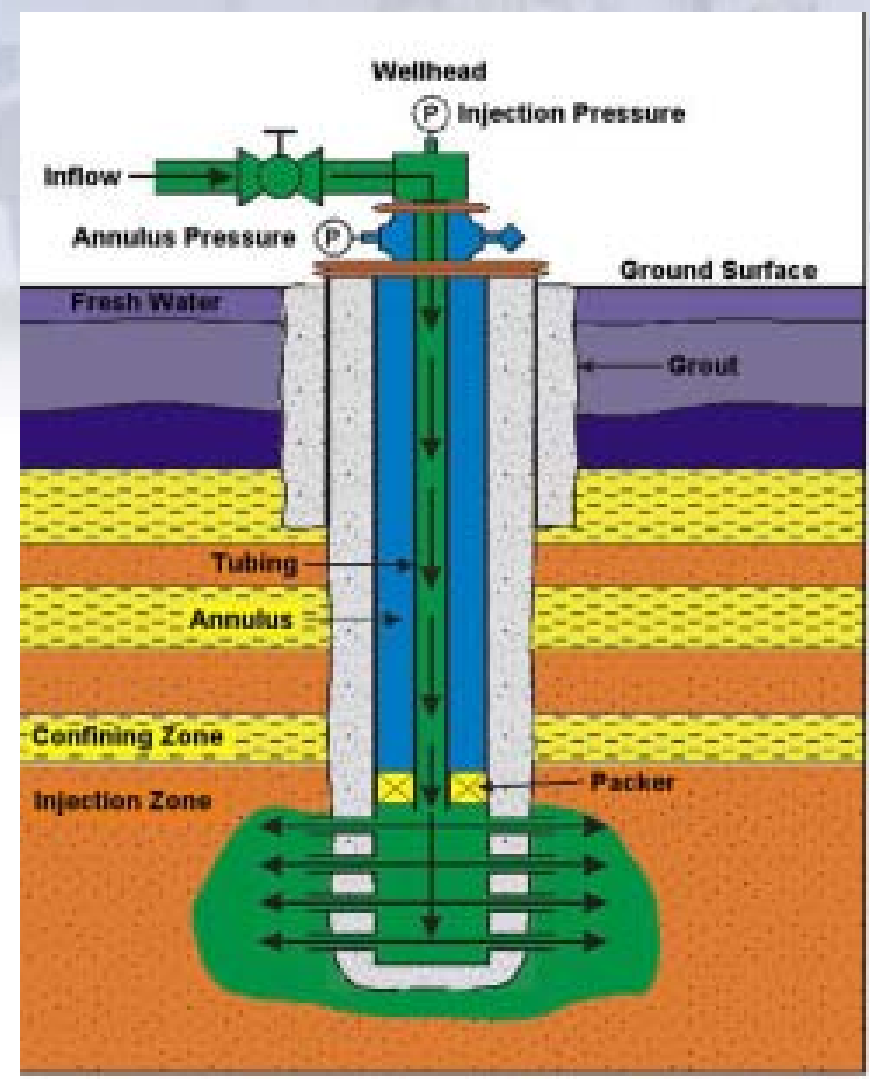

Figure 1.4.5. PNNL scientists are studying the flow and chemical reaction processes of $\mathrm{CO}_{2}$ at high pressure in basalt and sedimentary rock formations to assess the potential of these formations to permanently sequester $\mathrm{CO}_{2}$. 


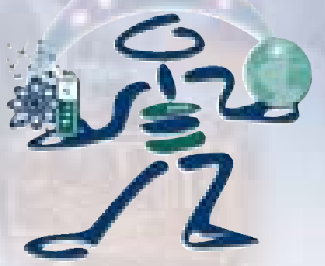

\subsubsection{Nuclear Science and Technology in Support of DOE Nuclear Energy

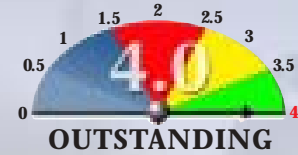 and Other National Security Missions}

\section{PNNL is sustaining and building national capabilities in nuclear science and engineering in support of both DOE 2010 new nuclear plant and Generation IV goals.}

O ur nuclear energy, science, and technology capabilities give us unique strengths in advanced materials, processes and diagnostics critical to the development of next-generation nuclear reactors and securing a safe and viable nuclear energy option.

\section{Science \& Technology to Support DOE Nuclear Energy Strategy}

We are focusing our nuclear science and technology business strategy on the major new D OE initiatives led by the Office of Nuclear Energy. In parallel, the Laboratory is working with other Battelle and PNNL sectors to sustain and grow the Laboratory's overall business portfolio related to nuclear science and technology.

\section{New Staff and Capabilities}

In July 2002, the Laboratory hired Alan Waltar as D irector of Nuclear Energy, Science and Technology. As a strategic hire, Dr. Waltar is responsible for the Laboratory's relationships with the Office of Nuclear Energy, Science and Technology. He also leads PNNL's relationship development with potential partners for new initiatives under the auspices of the Office of Nuclear Energy for the G eneration IV Nuclear Energy Systems initiative. In addition, Dr. Waltar will work with Battelle and PNNL sector leaders in developing the broader relationships necessary to sustain and grow the Laboratory's overall nuclear S\&T- business portfolio.

\section{Leadership and Teaming Support}

The Laboratory collaborated with universities, industry, and other national laboratories on three successful proposals submitted under D OE-NE's Nuclear Energy Research Initiative (NERI). We are the lead organization on two projects, "Innovative Approach to Establish Root Causes for Cracking in Aggressive Reactor Environments" (collaborator is GE Global Research Center) and "Innovative Low-Cost Approaches to Automating QA/ QC of Fuel Particle Production Using On-line Nondestructive Methods for Higher Reliability" (General A tomics, Iowa State University, O ak Ridge National Laboratory are collaborators). In addition, PNNL is a collaborator on the ANL West-lead project, "D esign of Radiation-Tolerant Structural Alloys for G eneration IV Nuclear Energy Systems." Total value of the new projects is about $\$ 4 \mathrm{M}$ over three years.

Under our continuing role as the Executive Agent for the D OE-NE International Nuclear Research Initiative (I-NERI), PNNL participated in meetings in Korea and France to review ongoing collaborative projects and to coordinate agreement on next steps for new projects. Crafted by PNNL, the second solicitation for collaborative U.S/ Republic of Korea (ROK) proposals in nuclear energy R\&D was issued by D OE-RL on July 8, 2002. The Laboratory also conducted peer reviews of US/ ROK proposals in the areas of next generation reactor and fuel cycle technology; innovative nuclear plant design, manufacturing, construction, operation, and maintenance technologies; and advanced nuclear fuels and materials. We will continue to support the $\mathrm{O}$ ffice of Nuclear Energy as it secures new bilateral agreements with Canada and South Africa.

In FY2003, we will establish mutually beneficial linkages and strengthen existing ties with industry, academia, and other national laboratories. We will team on collaborative $R \& D$ as well as pursue possible organizational teaming in response to complex marketing opportunities that may emerge from major new DOE initiatives. 


\section{Highlights of FY2002 Activities}

- In January 2002, PNNL entered into a teaming agreement with MPR Associates, a well-established, premiere engineering firm that serves the commercial nuclear industry as well as U.S. government and international clients. PNNL and MPR Associates are seeking opportunities to collaborate on joint proposals.

- The Laboratory was named as a collaborator in the successful proposal submitted by the Western Nuclear Science Alliance (WNSA) in response to Nuclear Energy's new Innovations in Nuclear Infrastructure and Education (INIE) program. The Alliance is led by Oregon State University's Nuclear Engineering D epartment. Alan Waltar, PNNL, will serve on the WNSA Advisory Committee.
- PNNL has made important discoveries in how cracks propagate in nuclear reactor components. The Lab's unique ability to characterize and understand this cracking behavior will be used to support the Nuclear Regulatory Commission and the nuclear power industry by helping identify root causes for the reactor vessel head degradation at the Davis Besse nuclear power plant in O hio.

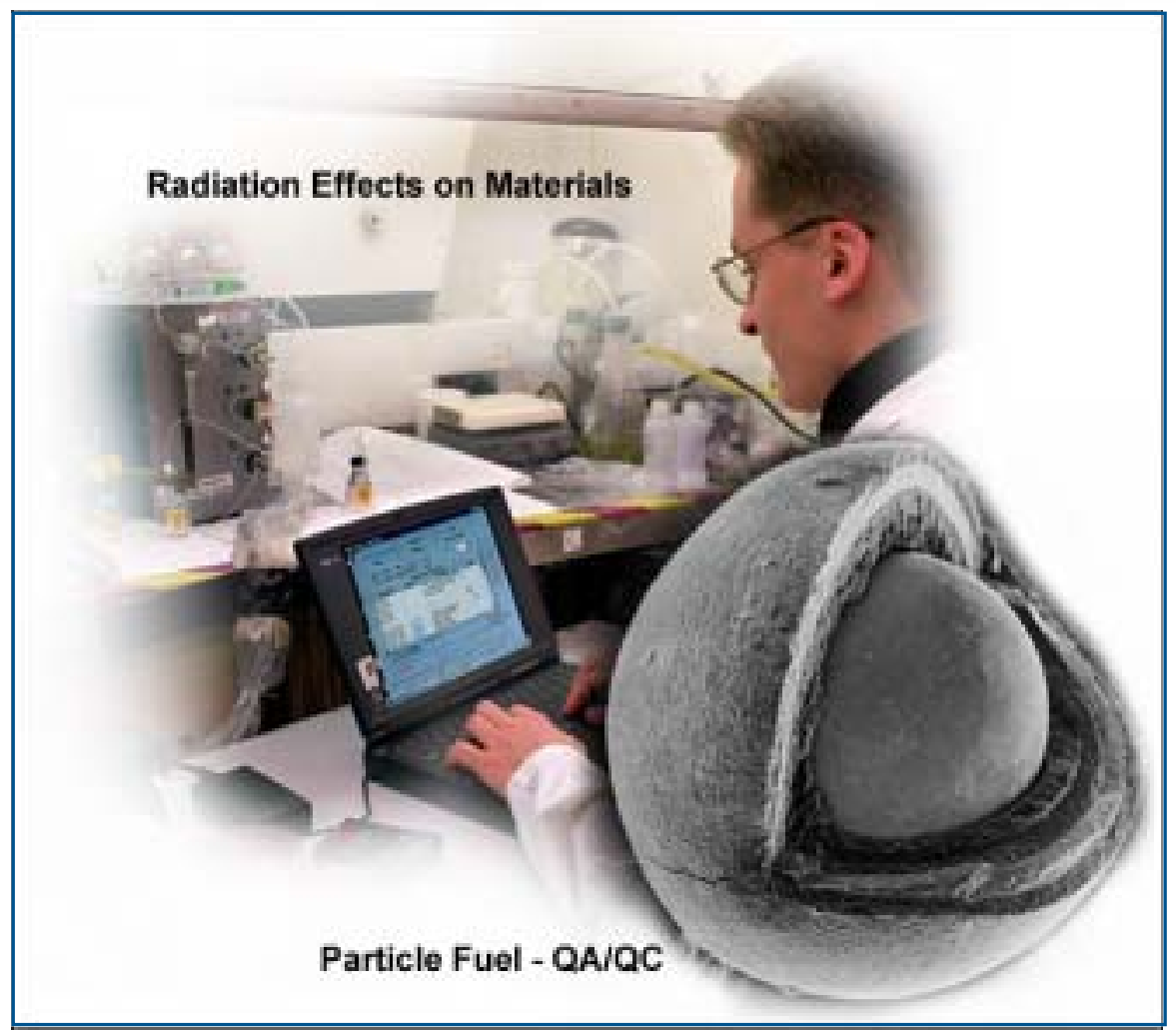

Figure 1.4.6. Applying nearly 40 years of material science and reactor operations expertise, PNNL is working with the nuclear industry to extend the life of existing reactors and developing new advanced reactor designs. 


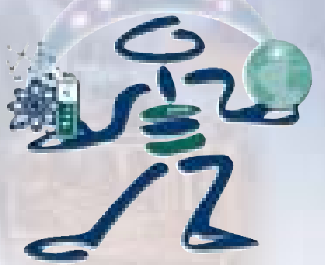

\subsection{1a Building a Multidisciplinary Research Program in Systems Biology}

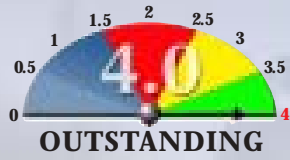

\section{PNNL built substantial capability in systems biology by assembling the expertise (people), developing the technology, and strengthen- ing the constituency to underpin BSI success.}

The Biomolecular Systems Initiative (BSI) continues to make outstanding progress building a multidisciplinary program in Systems Biology. D uring FY2002, it met or exceeded all its targets in the Performance Evaluation and Fee Agreement.

\section{The Right People}

Through the BSI, PNNL extended offers to one senior biologist specifically focused on systems biology, two mid-level biologists, and one computational biologist. The senior hire is Weiwen Zhang from Paradigm G enetics, whose expertise is in metabolic regulation and integrated genomics. Biologists Liang Shi, from Case Western, and Alex Beliaev, from ORNL, were hired for their considerable expertise in gene expression, microarrays, bacterial signaling networks, and phosphatases. An offer was also extended to one computational biologist. Additionally, we have hired four entry-level staff, S\&E Associates, to support the increased volume of work resulting from our recent awards.

\section{The Right Business}

The initiative sought to build the external business base with continued focus on DOE/ OBER and NIH. The goal was \$17M worth of high quality proposals submitted to DOE and NIH for calls with a focus on proteomics, computational biology and visualization, and microbial research. The initiative submitted proposals for multi-year funding valued at over $\$ 60 \mathrm{M}$, far in excess of its target.

\section{The Right Relationships}

The initiative also sought to strengthen existing institutional relationships with OHSU, UW and WSU Tri-Cities to collaborate on joint proposals and benchmarking projects. In particular, BSI proposed to

- demonstrate progress in building a national resource for bioinformatics through the OHSU collaboration by submitting one or more major NIH proposals jointly with OHSU, and
- establish a cost-shared position at WSU Tri-Cities slated for a future tenured position (Diana Bigelow) and to work with Dr. Bigelow to begin establishing a new multi-disciplinary program in systems biology at WSU Tri-Cities.

In addition to submitting two joint proposals with OHSU, a sound institutional relationship between OHSU and PNNL supports collaborations at a working level. O ne example includes Brian D ruker, MD, who is working with Karin Rodland on tyrosine phosphorylation detection methods. Another is D r. Chris Dubay, who is working with PNNL's George Chin to begin participatory analysis and pre-conceptual design of novel biosciences collaboratories.

A joint graduate program in biotechnology and systems biology with WSU is developing. An announcement is planned for November to begin recruiting students for fall 2003 class registration. Implementation planning is nearly complete. WSU budget request identifies funding for a tenured position for the 2003-04 school year.

\section{The Right Publications}

BSI set a target of submitting 20 articles for publication in peer-reviewed journals. Cell signaling, proteomics, and microbiology research were specified as target subjects. More than 50 papers were submitted since September 2001 and over 35 articles have been accepted for publication. Notable journals include Nature Biotechnology, Journal of Cell Biology, Molecular Cell Endocrinology, Science, Nature, Applied Magnetic Resonance, Traffic, Journal of the American Chemical Society, Analytical Chemistry, Applied and Environmental Microbiology, Journal of the American Society for Mass Spectrometry, Proteomics, Journal of Physical Chemistry, and Toxicological Sciences.

\section{The Right Approach}

Systems biology with a multidisciplinary approach is critical to the study of biological problems in the postgenomic era. PNNL is specifically qualified for systems 
biology because of its unique strength in proteomics and imaging technologies. The sophisticated technologies available at PNNL can be applied to a wide range of biological problems.

The BSI is currently developing along two parallel systems, mammalian cell biology and microbial biology. The leadership position in systems biology will be gained by several important results published in highprofile scientific journals. If important contributions can be made faster in microbial biology, then BSI should focus on it in the next 1 to 2 years. In the mammalian cell biology area, collaboration with outside investigators on a sharply focused area may help to push important discoveries that can bring PNNL into the limelight. The most successful development programs in biology are those that are pulled by the biology, not pushed by the technology.

\section{The Right Advisory Review}

The BSI External Advisory Panel conducted a review of the initiative in August, providing feedback and guidance on specific focus areas and scientific-technical content, alignment with DOE's missions, future activities, collaboration, business strategy, and resource and investment needs.

The panel had the following key observations and recommendations for the BSI, followed by more detailed discussion:

- The BSI is continuing to make significant progress. Last year's recommendations were noted and appropriate actions taken.

- The BSI has strong technical leadership. Several key hires have been placed during the last year.

- The Systems Biology approach is the right approach, and PNNL's niche is the tools and equipment.

- The BSI is well positioned to capture solid funding and make significant scientific impact in the G TL program.

- The ongoing LD RD projects represent solid technical proposals and fit within the framework of the BSI's strategy.
- The new LD RD proposals are technically excellent and some are clearly strategically in line with the direction of BSI and are critical to its continued progress.

- The BSI needs to strengthen its position to capture significant NIH funding.

- More attention is needed to the business case (other than GTL).

- The BSI needs to publish in high-visibility journals.

- Intellectual property issues/ opportunities need to be a focus of the BSI.

The BSI leadership agreed with most of the assessments made by the committee, but disagreed with respect to intellectual property issues and the business case. The initiative currently works with the Intellectual Property Office of the PNNL Legal Department to identify intellectual property and feels this is the correct approach. Furthermore, the committee was apparently unaware of many of the marketing studies done by the initiative to support our business case. However, we have implemented many of the suggestions of the committee, such as increasing our investment in the microbiology area and pushing for publications in higher-visibility journals.

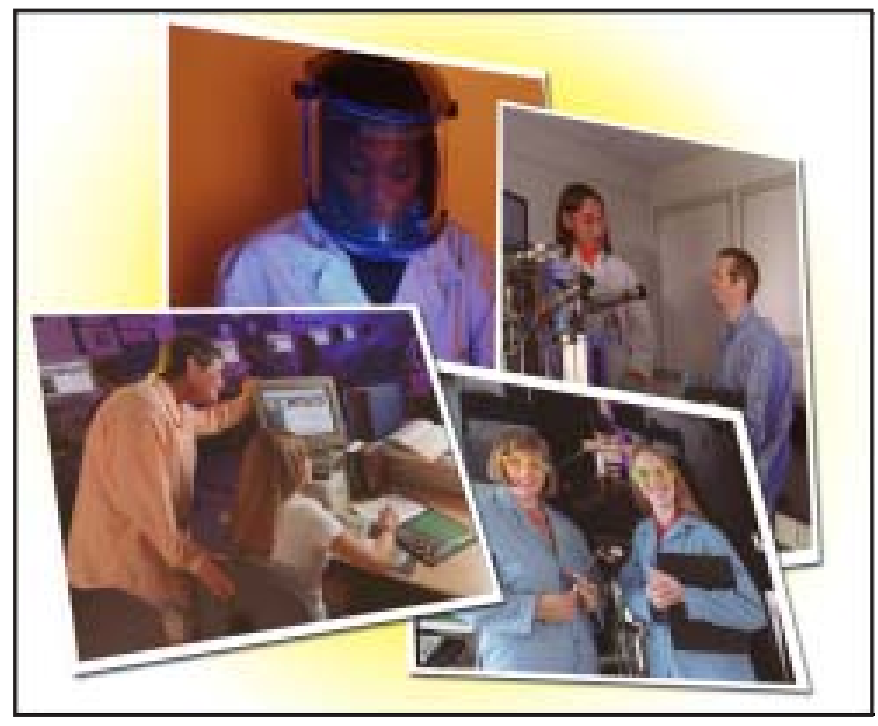

Figure 1.5.1a. Students in Research - WSU Tri-Cities and PNNL will be launching a new joint graduate program in Systems Biology offering students research opportunities with the advanced technologies and scientific expertise available at the Lab. 


\subsection{1b Importance of the DOE Genomes \\ to Life Proposal Win and \\ Advancements in Single Chain Antibody Generation}

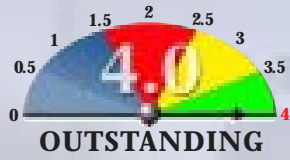

In collaboration with ORNL, PNNL will participate fully in the DOE GTL initiative, a program that will help move biology from genome to proteome the next frontier. A Single-Chain Antibody breakthrough generates significant interest in the scientific community for its potential protein and pathogen detection system applications.

Building on the success of the Human Genome Project, this program is designed to deliver new knowledge on the biological mechanisms enabling organisms to develop, survive, carry out functions, and reproduce. Knowledge gleaned through GTL will help society achieve the most far-reaching of all biological goals: a fundamental, comprehensive, and systematic understanding of life. The successful proposal (\$10.6M over 3 years) will help establish PNNL as a primary player in GTL and should position the Lab for a leadership role in systems biology. This, in turn, will enable us to compete for future facilities, solidify key partnerships, support DOE mission areas, and realize our capability investments in people and science. DOE anticipates that to build a major proteome program, funding for facilities and facility operations may require approximately $\$ 200 \mathrm{M} /$ year, and funding for R\&D approximately $\$ 150 \mathrm{M} /$ year. When it is fully operational, they expect a $\$ 350 \mathrm{M} /$ year of steady-state funding.

\section{Responding to the GTL Call}

D OE received $\$ 19 \mathrm{M}$ from Congress to begin the GTL in FY 2002 and in response to the first call, PNNL submitted two separate proposals. PNNL teamed with ORNL and other collaborators to respond to GTL Goal 1 (Identification and characterization of the molecular machines of life) to investigate multi-protein complexes that execute cellular functions and govern cell behavior. The second proposal was directed at Goal 3 (Characterize the functional repertoire of complex microbial communities in their natural environments at the molecular level) and was led by PNNL with collaborators from other national laboratories, companies, and academic institutions. The overarching goals of both proposals were to define a scientific vision and help create the technological infrastructure for understanding communities of microorganisms at a systems level. This strategy was intended to play upon our strengths in high throughput proteomics while maximizing our chances of winning participation in at least one award.

\section{The Center for Molecular and Cellular Systems}

Established as a consequence of the successful Goal 1 proposal, the Center is designed to anticipate the longterm growth of the entire GTL program, its framework modified as new knowledge is acquired and new biological, analytical, and computational capabilities develop. The three main phases of work for the Center are: (1) identify the complement of protein complexes and their components; (2) elucidate function and dynamics of complexes - intermediates, nature of interactions, cellular location, kinetics; and (3) establish how changes arising from environmental stress affect complex formation and function. The near-term goals are to: (1) complete characterization and comparison of initial set of protein complexes, (2) evaluate new approaches for high-throughput identification and opportunities for automation, and (3) develop and implement new technologies to permit characterization of $80 \%$ of protein complexes in a single organism per year. The longer term goals are to: (1) incorporate additional tools and data to characterize complexes, and (2) establish techniques for assessing location of complexes in cells, tools to identify cell interaction interfaces and dynamics. Achieving these goals should lead to a molecular-level understanding of protein complexes and, ultimately, networks. This will allow scientists to predict/ change behavior of organisms and cell communities, as well as predict the function of biological pathways. 


\section{GTL Goal 3}

While D OE awarded no Goal 3 funding to the national laboratories in the first round, the D epartment anticipates a second call this fall, as it remains a high priority. O ur proposal received very high rankings; D OE has encouraged us to re-submit for the next round.

\section{Breakthroughs in Single-Chain Antibody Generation}

In addition to the GTL award, the BSI has achieved notable success in single-chain antibody research. The project, initiated as a "bridging technology" effort, has demonstrated significant breakthroughs, including: (1) successful cloning of small artificial fragments of human antibodies into yeast; (2) creation of a "library" with over $10^{9}$ distinct types of single-chain antibodies; and (3) ability to select antibodies, on a high-speed flow cytometer. O ur scientists have been able to rapidly create high affinity-probes suitable for detecting pathogens and cancer-associated proteins, and have obtained previously "impossible" antibodies by circumventing the restraints of the normal immune system. They are now in position to generate an unlimited supply of specific antibodies far more rapidly than with any previous techniques. The success of generating single-chain antibodies provides; a unique advantage that will allow us to form valuable collaborations, be competitive for "big science" funding, and maximize our LD RD investment for fundamental science. This single chain antibody capability has generated enormous interest from scientific partners and funding agencies, particularly NIH. The National Cancer Institute is working with us to obtain direct, noncompetitive funding to develop single-chain antibodies against a panel of 100 biomarkers for early detection of cancer, with the eventual goal of developing a "cancer chip" for diagnostic use. Additional applications of interest to NIH include detection of pathogens and early responses to infection, particularly in relation to potential agents of bioterrorism.

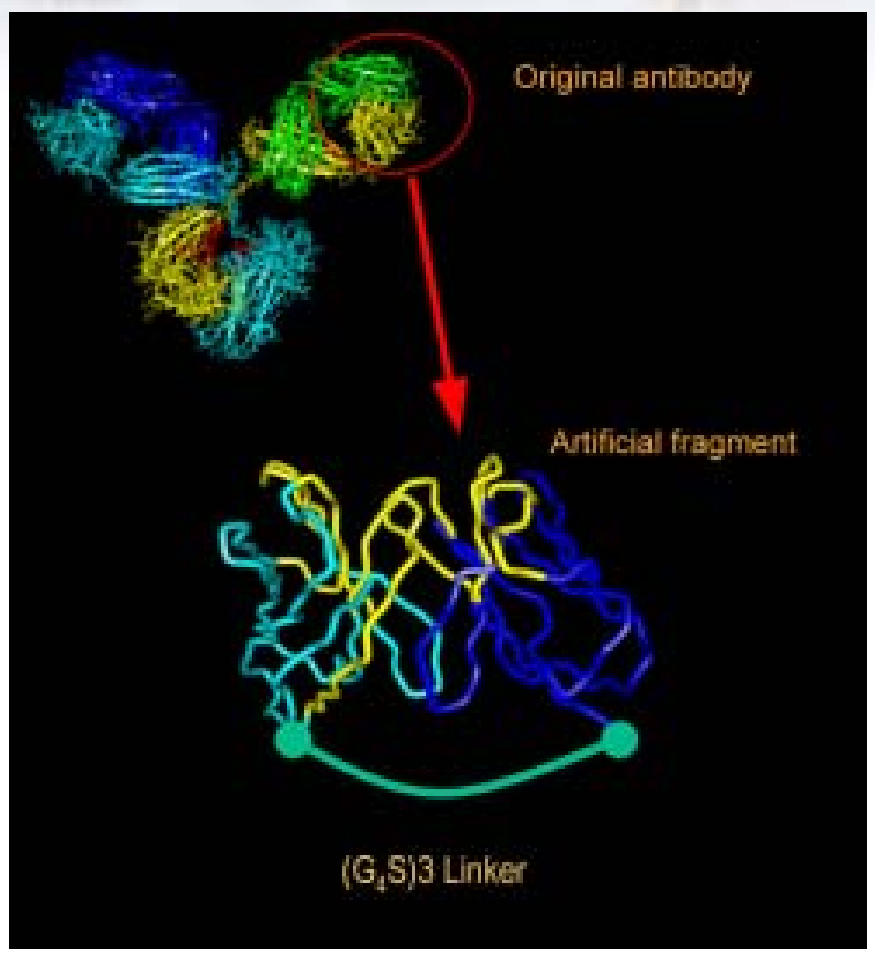

Figure 1.5.1b. New Single Chain Antibody technique developed by BSI researchers enables creation of high affinity-probes suitable for detecting pathogens and cancer-associated proteins. 


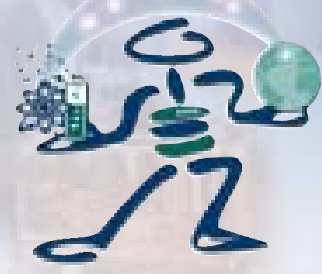

1.5.2 CS\&EI Accomplishments and
Advisory Panel Implementation

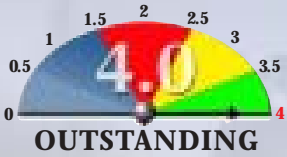

\section{CS\&EI achieved six of its seven technical goals to establish computational capabilities in different scientific disciplines while simultaneously building a multidisciplinary advisory committee to help set new direction and review progress.}

As goals for FY 2002 the Computational Science \& Engineering Initiative (CS\&EI) targeted performance in seven project areas and establishment of an Advisory Committee . CS\&EI achieved six of its seven technical goals to establish computational capabilities in different scientific disciplines while simultaneously building a multidisciplinary advisory committee to help set new direction and review progress.

\section{Goals and Progress Status}

G oal 1 In environmental scieno, develop new parallel numerical approaches for solving the non-linear governing onservation equations for coupled flow of multifluid systems in porous media, and demonstrate on a $\mathrm{H}$ anford Site simulation. Completed: Routine parallel computing of multifluid flow and transport through the subsurface has been developed and demonstrated around a cluster of million-gallon underground storage tanks on the Hanford Site. See "Advanced Simulation Software for Subsurface Science," FY 2002-4, PI: S.B. Yabusaki.

Goal 2 In computer scieno, the initiative will develop a global index ing facility for unstructured data on distributed shared memory computers. Completed: D eveloped scalable communications middleware for massively parallel, distributed memory computers; developed a new distributed, dynamic tree data structure, based on exponential trees. See "Practical Sub-logarithmic Searching and Sorting for Computational Science Applications," FY20012, PI: J.M. Malard.

G oal 3 In engineering science, the initiative will develop computational models for hydroforming aluminum alloy and damage models for the design of short fiber thermoplastic composite structures. Completed: Developed an inverse approach to hydroforming and tested for an efficient and rapid analysis of flat sheet and tube hydroforming. Formulated a damage model for continuum damage analysis of misoriented short-fiber composites subject to matrix cracking. See "D evelopment of Modeling Tools for Joining of Hydroformed MultiComponent Lightweight Structures," FY2000-2, PI: BN Nguyen; "D evelopment of Damage and Optimization Tools for the Design of Short-Fiber Thermoplastic Hybrid Composite Structures," FY 2002-4, PI: M.H. Khaleel.

G oal 4 In atmospheric science, the initiative will develop computational tools to interface calculation of rate constants for atmospheric radical reactions with electronic structure calculations in N W Chem. Partially completed: D eveloped computational tools that enable the utilization of electronic structure codes, such as NWChem, on high performance parallel computers toward the accurate calculation of rate constants. Capabilities developed in this project enabled the most comprehensive and accurate study to date of the kinetics for the oxidation of ethylene $\left(\mathrm{OH} \cdot+\mathrm{C}_{2} \mathrm{H}_{4}->\mathrm{C}_{2} \mathrm{H}_{4} \mathrm{OH} \cdot\right)$ reaction. A previous investigation of this reaction by others missed both the 2nd complex and 2nd transition state. However, not all of the integration of these new capabilities with NWChem was achieved. The final POLYRATE computation is still a separate step. See "Tools for Computations of Chemical Reaction Rates Relevant to Atmospheric Chemistry Models," FY2000-2, PIs: S.M. Kathmann, M. D upuis.

Goal 5 In computer science, the initiative will develop the capability to run large ( >1M mesh elements) N W G rid problems on parallel machines, by applying the $G$ lobal A rrays (GA) and Fortran 90 programming models. Completed: Developed the capability to run large NWG rid (adaptive mesh) problems on parallel machines, employing a newly developed set of sparse matrix Global Array (GA) communication routines to support unstructured mesh data structures on a Linux cluster of several hundred computing nodes. Also rewrote the physics part of the solver, NWPhys, in For- 
tran 90. Several calculations were successfully run with more than 1 million mesh elements on parallel computing platforms. (See cover image produced by NWGrid/ NWPhys, for the Federal computing R\&D "Blue Book," on line at http:/ / www.hpcc.gov/ pubs/ blue03/ 03BBfinal.pdf. See "Code D evelopment and Tools for NWG rid/ NWPhys," FY2000-2, PI: H.E. Trease.

Goal 6 In imaging scienœ, the initiative will design and build an image processing work bench that integrates multiple image formats/ data sets, in-core and out-of-ore numa parallel processing methodologies and visualization. Completed: Prototyped a parallel environment with an extensible toolbox for processing images using Commercial Off The Shelf (COTS) computing, called PiCEIS, that is portable to PC-Linux clusters, IBM SP and SG I parallel computers and that achieves speedup factors of 75 in some runs (i.e., 1 hour processing times reduced to less than 1 minute); developed software to display moderately sized images $(<$ 300 Mbytes) in real-time using the IBM Scalable Graphics Engine and IBM 9.2 Mpixel display, at 208 dpi. See "D evelopment of a Parallel Computational Environment for Imaging Science (PiCEIS)," FY2001-3, PIs: D.R. Jones, G.I. Fann.

Goal 7 In computational geochemistry, the initiative will ex pand the Plane W ave methods in N W C hem by inorporating an embedded model for lattice ions. Completed:

Designed and developed a new implementation of the self-consistent charge density functional tight-binding method in the context of NWChem suite of codes. See "Mixed Hamiltonian (PW/ MM) Methods for G eochemical Electronic Structure Studies," FY2000-2, PI: E.J. Bylaska.

\section{Advisory Committee Established}

Completed: CS\&EI established an advisory committee of four internal and five external technical experts to guide the initiative in charting a course to its most important thrusts. The committee includes members spanning all the R\&D Directorates commensurate with the CS\&EI's lab-wide efforts. Seven members or their delegates attended the first annual review meeting which was held on August 1-2, 2002. Consultation with internal advisors will continue during appropriate times in the Laboratory Directed Research and D evelopment (LD RD ) cycle to fine tune plans and address specific issues.

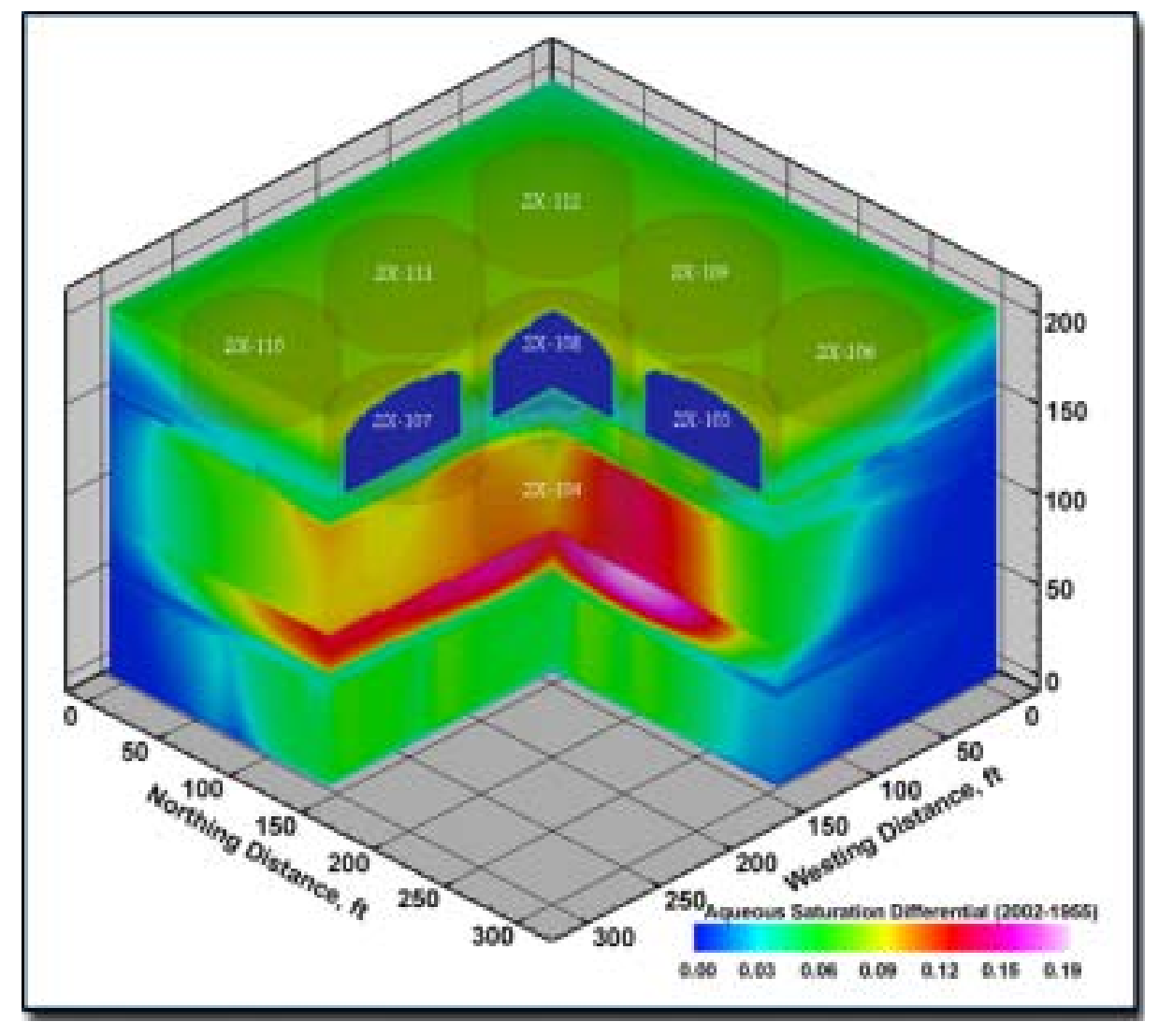

Figure 1.5.2. New parallel processing simulation uniquely incorporates the complex chemistry, physics, and highly variable subsurface conditions under Hanford tanks to strengthen long term risk assessment. 


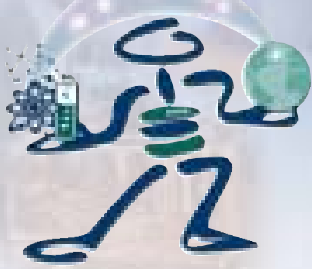

\subsubsection{Nanoscience \& Nanotechnology Efforts at PNNL}

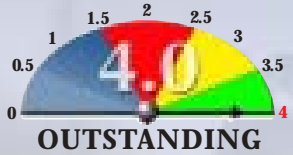

\section{PNNL's Nanoscience \& Nanotechnology Initiative produced excellent science and increased its internal and external visibility while simultaneously improving program focus and used peer review to establish direction and check progress.}

\section{Increased Visibility}

NSTI increased visibility of Nanoscience and Nanotechnology activities at PNNL by exceeding its goals for publishing in peer-reviewed journals, presenting papers at national and international meetings, establishing and hosting seminars and maintaining information on its website. The initiative, which sought to submit at least six new papers for publication in peerreviewed journals, submitted 11, of which two were featured on journal covers. In addition, the initiative proposed to present at least five technical papers at national or international meetings and presented 10 , several of which were invited presentations. Further, the initiative established a seminar series and hosted five seminars (beating the target of four), with distinguished speakers from University of Washington, Montana State University, Stanford and Seagate. Finally, NSTI maintained its website up-to-date with visible work.

\section{Programmed Project Development}

\section{NSTI increased focus on Nanoscience and}

Nanotechnology activities within the Laboratory by exceeding its goal to prepare two proposals (it prepared three) in response to the FY 2002 BES NSET call, one of which was funded at the $\$ 900 \mathrm{k} /$ year level. In addition, DARPA invested in Scott Chambers' spintronics work to the tune of $\$ 300 \mathrm{k} / \mathrm{yr}$, which is expected to increase; we also got a $\$ 100 \mathrm{k}$ commitment from BES for development of basic science in spintronic materials. O ther activities included setting up the External Advisory Board (EAB) to provide direction, hiring two new staff, and setting up a specific set of plans and responsibilities for relating nanoscience opportunities relevant to agencies outside of BES. In particular, the Initiative created a strong focus area in High Specificity D etection, including nanobiological methods, to support the area of Homeland Security. Three new proposals for FY2003 funding under NSTI were selected based on inter-initiative meetings with the Homeland Security Initiative.

\section{Advisory Board Validates \\ NSTI Management and Impact}

NSTI received valuable feedback from the EAB, which met in August. The Board noted that NS\&T is completely compatible with national and federal $R \& D$ priorities and has excellent management. The Board reported several indications that the National Nanotechnology Initiative (NNI) would proceed on course. They noted that "NNI holds great promise broadly across many scientific fields and most sectors of the economy and that the nanoscale R\&D agenda includes a balance of basic and applied research, nanoscale instrumentation and metrology, manufacturing, and the dissemination of new technical capabilities to industry. Nanoscale R\&D priority areas include material science, biotechnology, and research relevant to medical care and homeland security. Of particular importance are nanostructures that more effectively collect and deliver samples to sophisticated sensors (chemical, biological, radiological, electromagnetic, photonic, acoustic, or magnetic). The D OE Office of Science has been and will continue as a major participating agency in NNI and other priority areas maintaining and expanding exciting and diverse research activities performed in universities, national laboratories, and the private sector.

"In addition to being well aligned with these priorities, the PNNL NS\&T takes advantage of existing strengths in molecular, theoretical and computational sciences and can both support and take advantage of the larger investments being made in the computational and biological sciences initiatives. The existing infrastructure at PNNL can, by and large, support the NS\&T, and the emphasis on expanding the research effort seems both appropriate and highly likely to succeed. The initiative directly supports each of the primary mission areas of the D OE: advancement of basic science, enhancement of national security, provision for a secure energy future, and cleaning up the production complex. 
"This initiative has already provided significant return on investment with awards from DOE-SC and DARPA. It is severely resource limited but well positioned to expand and to leverage complementary investments in the molecular, computational and biological sciences. Since funds to support the Joint Institute will not come out of the initiative budget next fiscal year, more LDRD research can be done at PNNL while retaining the technical relationship between the University of Washington and PNNL. This is a very positive action.

"Focusing the initiative to better use the limited resources has been a tremendous improvement in the initiative. Also the initiative has formed strategic relationships with regional partners University of Washington (e.g., joint institute) and University of O regon that builds regional advocacy."

\section{New Thin Film Technique May Lead to Quantum Computing}

PNNL scientists developed a technique to synthesize a thin anatase titanium dioxide film infused with cobalt that retains its magnetic properties at room temperature. This could open the door to harnessing an electron's spin (spintronics) to carry information rather than its charge, potentially enabling on-chip integration of magnetic storage and processing and quantum computing. The result would be far greater data storage and faster processing.

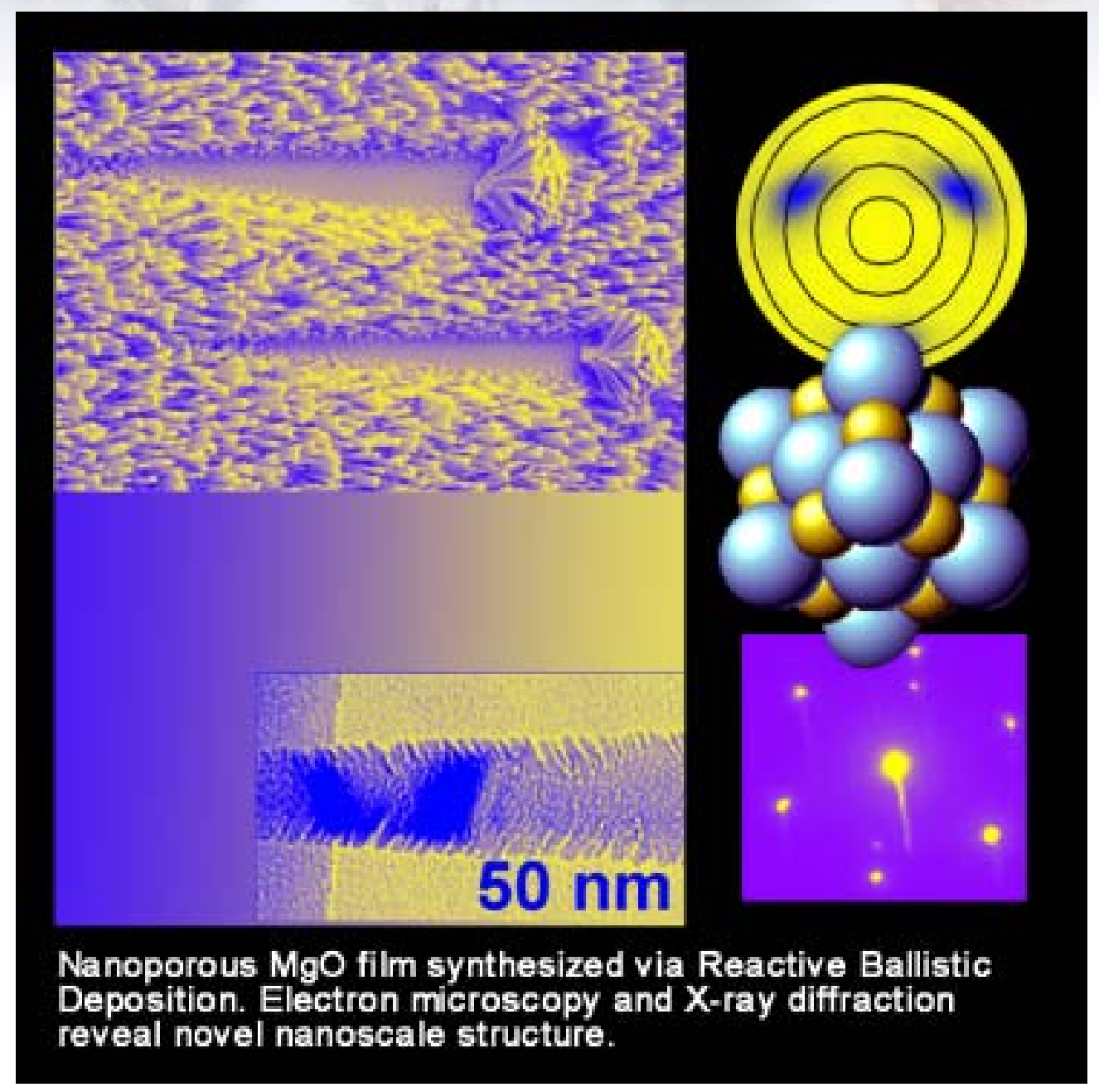

Figure 1.5.3. PNNL's novel technique for growing tailored nanoporous $\mathrm{MgO}$ films results in extra fine structure with extremely high surface area that's readily accessible to reagents. This advance in material science has potential applications in heterogeneous catalysis, sensors, and other areas important to DOE missions. 
1.6.1 Impact of Joint Global Change Research Institute with University of Maryland

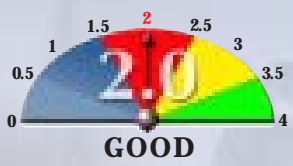

Despite a less than expected level of joint proposals, PNNL's partnership with the University of Maryland resulted in significant accomplishments, which neither institution would have achieved alone.

Formed in March 2001 by PNNL and the University of Maryland, the Joint G lobal Change Research Institute (JGCRI) has made significant progress in developing collaborative relationships between PNNL and the faculty and students of University of Maryland. The institute was formed to bring together a critical mass of interdisciplinary experts in broad science topic areas as well as economics, technology and policy to address global change challenges. The strong global ties and network of the Joint Institute connect its efforts in climate change to national and international policy communities. The Institute's mission also includes training university students to carry on this important work in future.

For FY2002, three areas were highlighted for measurement as part of the Performance Evaluation and Fee Agreement: publication, growth of faculty and student involvement, and submission of joint proposals.

\section{Articles in Prestigious Journals}

The commitment in the performance agreement was to submit at least six articles to prestigious journals.

The journals targeted included:

- Nature

- Science

- Climatic Change

- Environment

- Energy Policy

In addition, if staff members were invited authors, the following journals were deemed to meet the definition of prestigious:

- Annual Reviews of Energy

- Foreign Affairs
- Scientific American

- Issues in Science and Technology

JGCRI staff members submitted a total of nine articles to the above journals. Further, a Special Issue of Climatic Change was edited by Norm Rosenberg and Cesar Izaurralde. Climatic $\mathrm{C}$ hange also invited Rosenberg and Izaurralde to edit another special issue this year.

Richard Benedick was invited to submit an article to Issues in Science and Technology, and G erry Stokes was invited to submit a letter. Both were published in the winter edition. Clearly JG CRI exceeded its target for publications.

\section{Faculty and Student Involvement}

From a level of two faculty members, no graduates, and one undergraduate in FY 2001, JGCRI set a target to grow involvement with five faculty members, three graduate and three undergraduate students affiliated with the JGCRI research program. The institute exceeded their goal with five adjunct appointments of JG CRI staff, a special program of affiliate faculty designation including five faculty members (which is being implemented during the fall semester), and involvement of seven graduate and six undergraduate students.

In addition, the Lab's first Fulbright Fellow completed a three-month visit at the Institute, and four Chernoff Fellows were also visitors during this time. JG CRI exceeded its targets in the area of faculty and student involvement. 


\section{Joint proposals}

JGCRI set an ambitious goal of \$1M worth of joint proposals with University of Maryland for FY2002. \$245K worth of joint proposals was submitted, with $\$ 120 \mathrm{~K}$ funded, thus meeting only about $25 \%$ of the goal.

For the future, several areas look promising. The most important future proposal is on climate negotiations involving work with the University of Maryland School of Engineering. This has the potential to be quite large (perhaps as much as $\$ 1 \mathrm{M}$ over the life of the project). JGCRI is also developing work with the Agriculture and Natural Resources D ivision and preparing for an anticipated large NSF solicitation expected this Fall (\$1-1.5M for each of five years).

\section{Additional Accomplishments and Future Direction}

Invited presentations were high this year with presentations at the American Association for the Advancement of Science.(AAAS) and a broad range of other venues including the Aspen Energy Forum. O ur symposium in the Fall involved students and faculty from the University, and we supported the University's World Energy Policy Forum with two invited presentations. There were several invitations to testify before Congress. The JG CRI staff has been heavily involved in the creation of the President's Climate Change Research Initiative and the National Climate Change Technology initiative.

The JGCRI is building toward a broadly funded program of research in integrated assessment and climate change technology analysis. In the coming two years we expect to have funding from NSF, NOAA, and an expansion of USDA and NASA funding. The aspiration is to be D OE's leading institution for analysis of longrange energy policy.

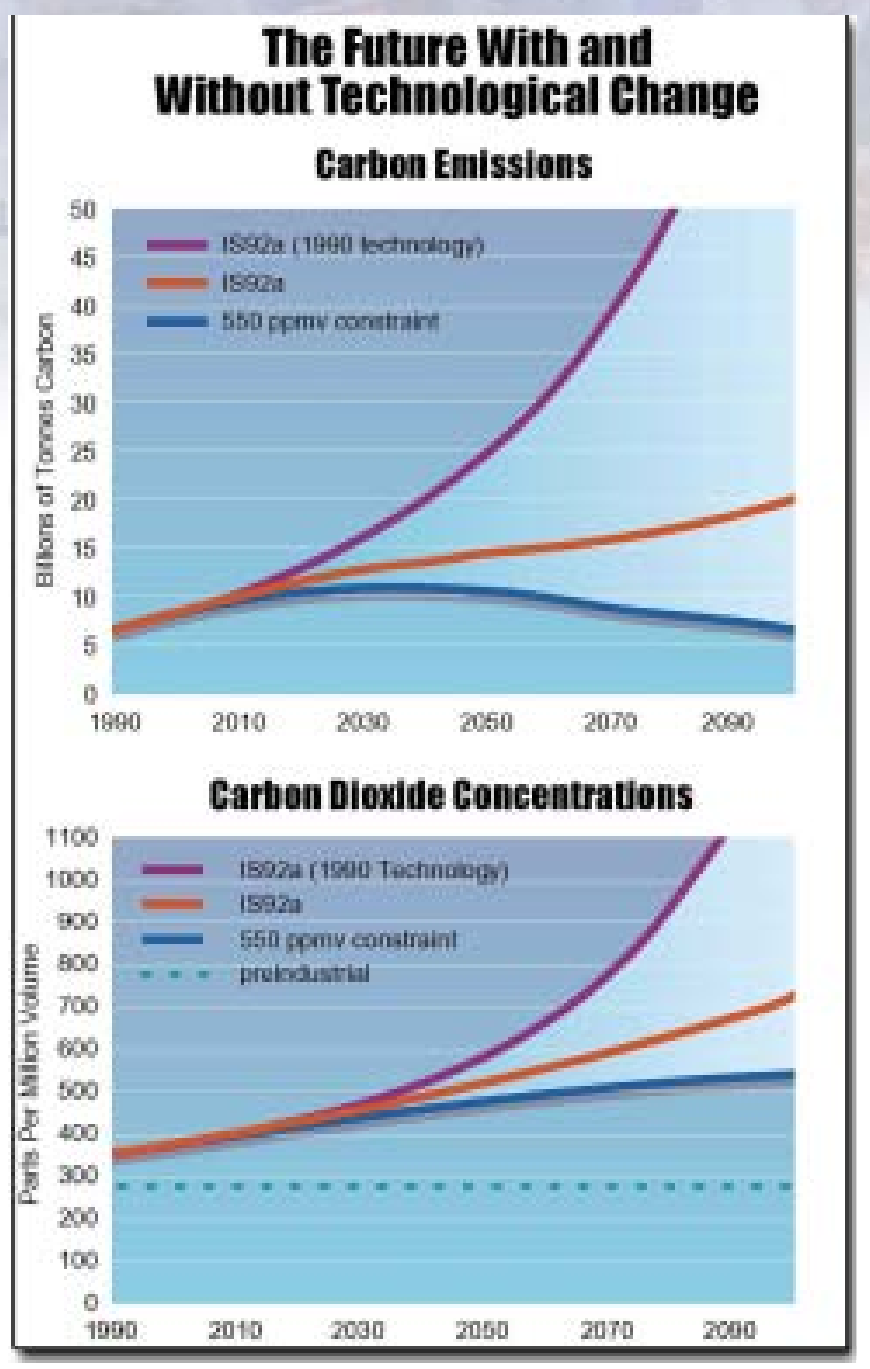

Figure 1.6.1. The JGCRI is providing the research for future climate change policy. 


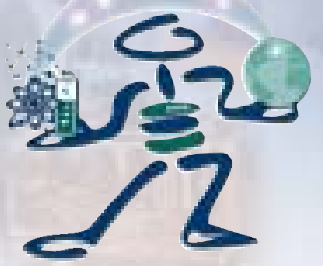

\subsubsection{Impact of Joint Research Institute with University of Washington}

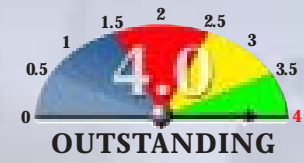

\section{PNNL's collaboration with the University of Washington in Nanoscience and Cell Signaling expanded the horizons of both institutions and is helping to develop the next generation of researchers.}

\section{Indicators Fully Met}

PNNL's collaboration in the area of nanoscience and nanotechnology, the Joint Institute for Nanoscience (JIN), exceeded all of its FY2002 goals.

- Submitting two joint proposals - The Institute met its proposal goal by submitting 2 joint proposals of which 2 were funded.

- E ngaging five full time or full time equivalent graduate/ postgraduatel faculty research positions in JIN projects - Eight full time equivalent graduate/ post-graduate/ faculty research positions were engaged in the Institute's projects, exceeding its goal of five.

- Submitting at least four joint publications/ presentations - The Institute submitted 15 joint publications/ presentations, exceeding its target of four, and

- Co-hosting one work shop to establish future collaborative efforts between PN N L, UW and industry partners in the $\mathrm{N}$ anotechnology area - Two workshops were co-hosted (at Richland in February and Seattle in September) and a technology forum, Nanotechnology meets Business, was held at UW on September 17.

\section{JIN Steering Committee}

The JIN Steering Committee met for the fifth time in September. Overall it concluded that the JIN was off to a good start and had been quite productive, but to make things really work and take best advantage of complementary institutional strengths and developing collaborations, some specific actions need to be undertaken beyond the written scope of the JI and JIN agreements. The Steering Committee recommended the following actions:

- Explore joint appointment models at other labs (ORNL/ UT, LBNL/ UC) with a goal to establish mechanisms for joint PNNL/ UW appointments;
- Identify large project targets and coordinate that with the next call for Awards; and

- Explore the possibility of a regional nano-alliance.

JIN also established a joint website. JIN activities have been cross-linked on the UW and PNNL Nanoscience websites. The approximate 25 JIN awards given to date have been listed on the joint website.

\section{Joint Program and Partnerships}

PNNL's Joint Program in Cell Signaling with UW exceeded its goals to:

- Engage at least one graduate student fellowship and one postdoctoral fellowship position in support of Cell Signaling research;

- Submit at least two joint grant applications or other proposals to third parties; and

- D evelop a joint project in modeling the cell and initiate design of the Computational Cell Environment.

We had successes with Mike Kellen and John Keane in graduate student fellowships and Anamika Sakar in a post-doctoral fellowship. We have three joint proposals submitted: one to NSF- not funded but very good reviews and resubmission planned; two to $\mathrm{NIH}$ - one in review now, and one to be reviewed in early 2003 by a special study section under direction of the NIBIB BRP guidelines. Michel Kellen, Anamika Sakar, Peter Divalentin (a UW undergraduate student who also works on the program) and Haluk Resat (PNNL) are working on joint manuscripts. Peter and Michel have written a substantial stochasitic simulation software package, SigTran, and a Java G UI, and it has been distributed to Haluk and others at PNNL (as well as made available on the CSI web site for download). Haluk's signal transduction "models" have been 
successfully simulated using SigTran. We are now integrating SigTran within the first version of a general purpose research planning, modeling and experiment management system, the "Biologist's D ashboard."

In preparation for FY2003, we have developed a jointly managed web site (http:/ / www.biomolecular.org/ students/ index.html) to advertise and facilitate applications to the Joint Program. The Fall program has started with two successful applicants (a graduate student and a postdoctoral fellow). After additional advertisement of the program at UW, we are expecting a larger response to the call for fellowships that begins in January. The UW and PNNL staff members managing this Joint Program share an objective for the Joint Program to become self sustaining through external grant support and will continue to foster joint responses to program calls from D OE and NIH in FY2003. This association may lead to our scientific involvement in a futuristic ExploreLife initiative being sponsored by UW, the city of Renton, and local industry.

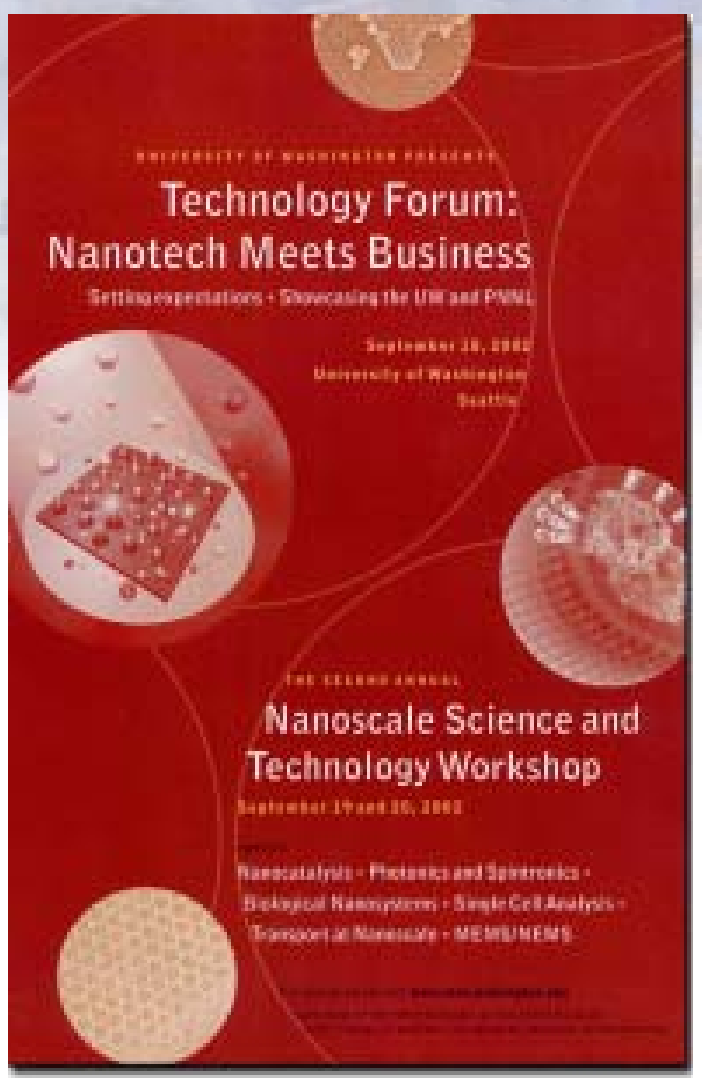

Figure 1.6.2. PNNL and UW's complimentary strengths in materials science, nanobiology, and nanoeducation combined with unique EMSL instrumentation result in a powerful collaboration to meet research challenges. 


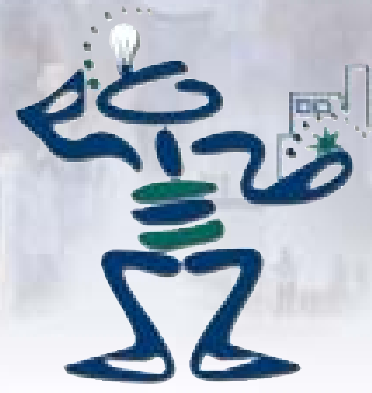

Part I

\section{Status of Performance Against Critical Outcomes 2.0 Management and Operational Excellence}

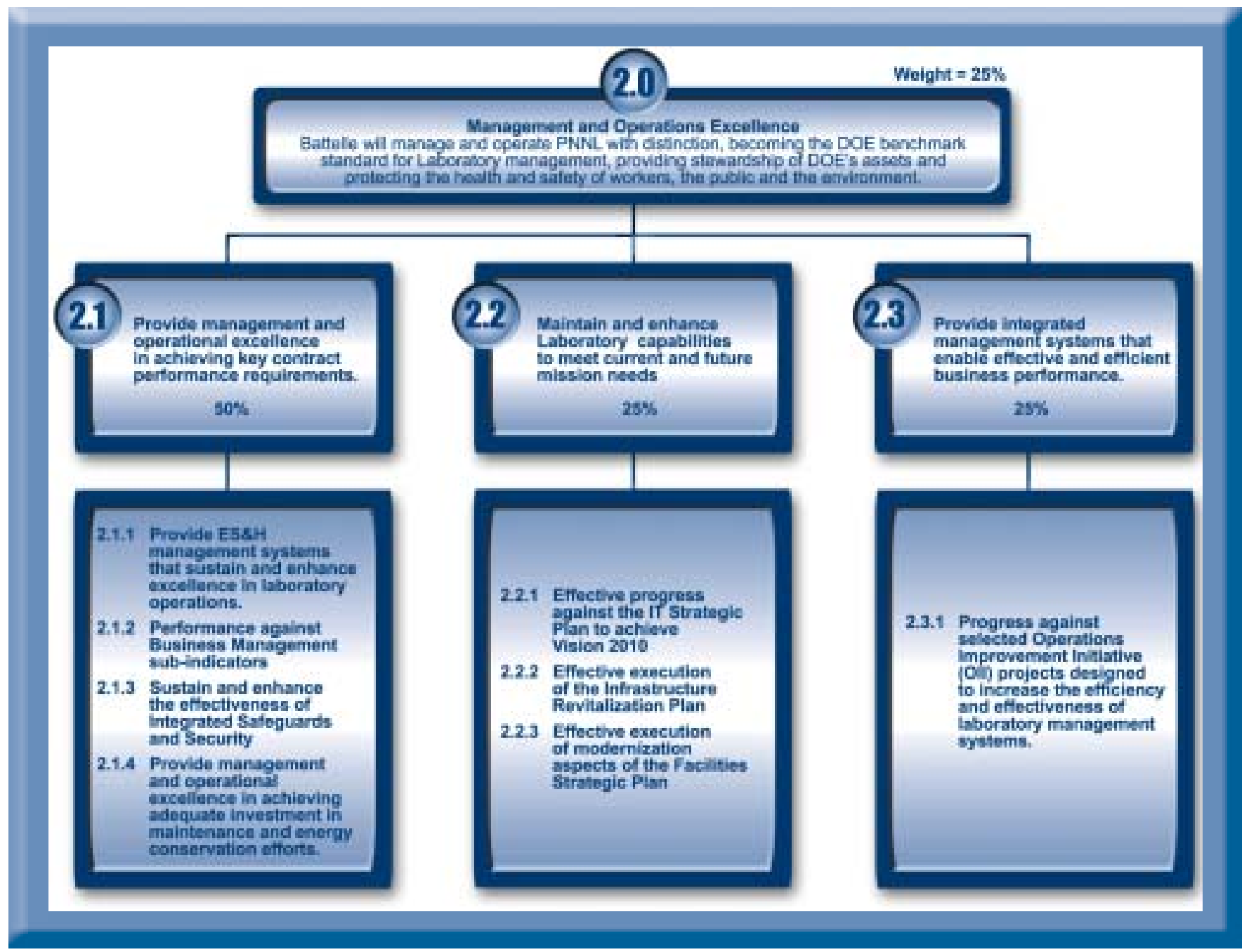




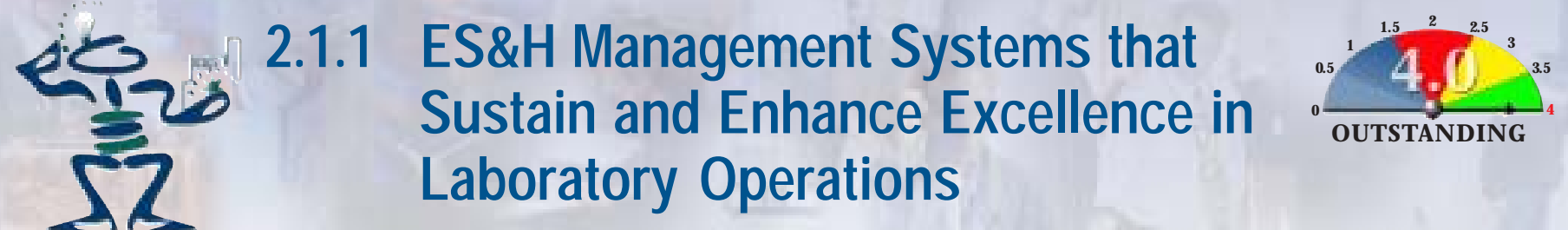

In FY2002, PNNL continued to operate at a level consistent with
achieving an "outstanding" rating for ESH \& Q performance,
demonstrating the continued effectiveness of our integrated
ESH \&Q systems, processes, and tools.

\section{Performance Against Indicators}

The performance indicators in Table 2.1.1 identify the eight ESH\&Q measures and target values that formulate a portion of the Laboratory's picture for demonstrating operational excellence for FY 2002. As evident in the table, all of the performance measures are within statistical control and/ or are within the agreed upon target values.

We continued to observe favorable results in the Total Recordable Case Rate (TRCR), Lost Workday Case Rates (LWCR), and in a couple of sub-tiered measures. For example, PNNL's total lost workdays (includes days away from work and restricted workdays) for FY2002 are $46 \%$ of last year's figures (1334 in 2001 vs 613 days in 2002).

We have developed a favorable trend in the TRCR numbers because of 1) more focused attention by PNNL management toward preventing worker injuries, 2) increased use of Hanford site occupational medical work conditioning services 3) changes in OSHA reporting requirements taking effect in January 2002, and 4) less severe injuries occurring. As stipulated in the FY 2001 A nnual Self-E valuation Report, we partnered with Facilities \& O perations to focus management attention on this issue and work to reduce staff injuries. The change in OSHA reporting requirements affecting the rate numbers appears to be substantiated by other Hanford Site contractors experiencing favorable rate changes during the same time period.

Figure 2.1.1 shows a historical view of the Laboratory TRCR from Jan 1994 to mid CY2002. The Laboratory has continually improved by reducing the injury rates over time. The rates show fewer staff members getting injured, and, for those that are hurt, the injuries are less severe. PNNL's TRCR is better than the industry average (Bureau of Labor Statistics, SIC \#873) for the counterpart business entity (industry: 2.6, vs.

PNNL's: 1.6).
We concluded this year with no environmental releases and/ or related fines. This year's environmental events performance equaled the Laboratory's efforts in fiscal year 2001.

Staff training goals were met early this year, meeting the target value of $>95 \%$ by May, the earliest completion of this goal since tracking began in 1998. As of September, the composite score for the Laboratory was $99.7 \%$ of staff completing their assigned ESH\&Q training.

Two items warrant specific mention, the first being an uptake of radioactive material (depleted uranium) by a staff member in the 306W building. The uptake did not meet reporting thresholds. Positive bioassay results combined with elevated work place air samples prompted PNNL to investigate work activities in the 306W machine shop. The investigation, performed by PNNL's Independent O versight group, identified that a 306-W machinist received an internal exposure of 96 millirem from depleted uranium when the machinist used a contaminated grinder to sharpen a milling tool. The investigation also concluded that planning and carrying out work in Shop 132 did not have sufficient discipline to identify and control hazards associated with project tasks. Corrective actions are in progress.

The second item involved an explosion-proof refrigerator/ freezer that had low levels of beryllium on the top exterior surface. The amount of contamination was slightly above the release criteria in 10 CFR 850.31 ( 0.262 vs 0.2 micrograms $/ 100 \mathrm{~cm}^{2}$ ). When we bought a new refrigerator, and loaned this refrigerator to Columbia Basin College (CBC), there were no compliance issues with EPA, OSHA or WISHA. But, the appropriate D OE, Lab, and CBC personnel were notified as soon as the problem was identified and the refrigerator was immediately retrieved from $\mathrm{CBC}$. Because the refrigerator had not been placed in service and was located in a trailer with few occupants, public contact was minimal. Five workers that handled the refrigerator accepted 
PNNL's offer of medical screening. PNNL made a media release to the local newspaper (Tri-City Herald) to notify the public. Steps are being taken at the Lab to prevent recurrence.

Making Improvements, Getting Awards

We have continued to make improvements to the management systems, processes, and tools under the ESH\&Q Directorate purview. D etails about these enhancements may be found in module 2.3.1a.

Awards received this year include the "White House Closing the Circle" award, and the DOE "National Pollution Prevention" award, both for pollution prevention efforts by the Laboratory. PNNL was also recommended for ISO 14001 Environmental Management System registration. These awards and registrations pro- vide independent third-party confirmation of PNNL's operational excellence.
Table 2.1.1. ESH\&Q Performance Continues to Meet Target Values and Demonstrates the Laboratory's Commitment to Staff Safety, Health and the Protection of the Environment.

\begin{tabular}{|c|c|c|}
\hline $\begin{array}{l}\text { Performance } \\
\text { Measures }\end{array}$ & Target Goals & FY2002 Actuals \\
\hline Total Recordable Case Rate & $\begin{array}{l}<2.2 \text { cases } / 200,000 \\
\text { work hours }\end{array}$ & 1.6 \\
\hline Lost Workday Case Incident Rate & $\begin{array}{c}<1.1 \text { cases } / 200,000 \\
\text { work hours }\end{array}$ & 0.8 \\
\hline Releases to the Environment & $<2$ events & 0 events \\
\hline $\begin{array}{l}\text { Percent of Employees with } \\
\text { Required Training }\end{array}$ & $>95 \%$ & $99.7 \%$ \\
\hline Unplanned Radiation Dose & 0 events & 0 events \\
\hline $\begin{array}{l}\text { Spread of Radioactive } \\
\text { Contamination }\end{array}$ & $<3$ events & 0 events \\
\hline $\begin{array}{l}\text { Loss of Control of Radioactive } \\
\text { Material }\end{array}$ & $<1$ loss & 0 \\
\hline $\begin{array}{l}\text { Violations of U.S. DOT Hazardous } \\
\text { Materials Shipping Regulations }\end{array}$ & $\begin{array}{l}0 \text { events for major } \\
\text { incidents } \\
<1 \text { events for minor } \\
\text { incidents }\end{array}$ & $\begin{array}{l}0 \text { events } \\
0 \text { events }\end{array}$ \\
\hline
\end{tabular}

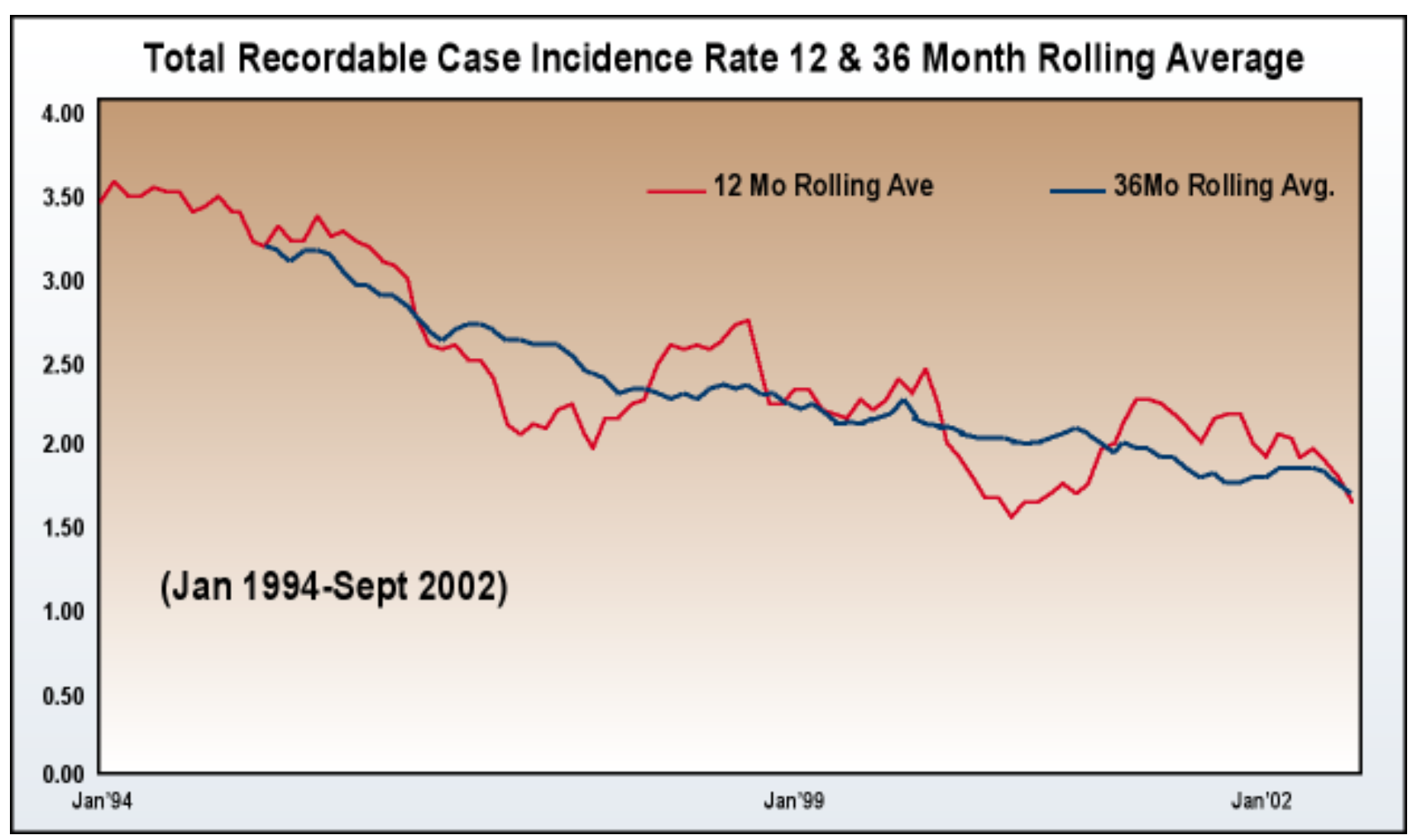

Figure 2.1.1. Declining "Total Recordable Case Rate" shows fewer staff members are getting hurt at PNNL. 


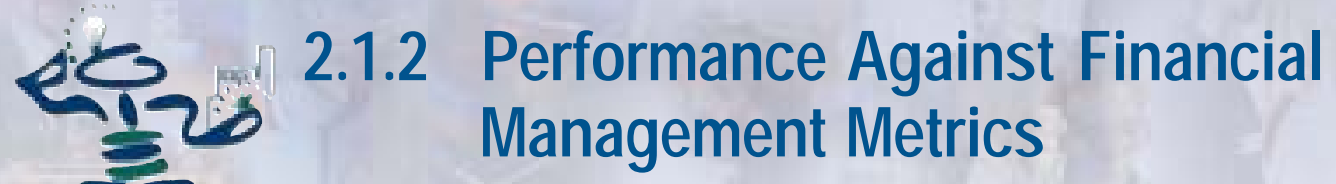

\begin{abstract}
PNNL's improving business performance overall reflects its successful attention to cost management; a shift in business mix between labor and $3^{\text {rd }}$ party costs highlighted the sensitivity of one cost metric.
\end{abstract}

PNNL is committed to providing high quality science and technology at a competitive cost. By focusing on continued cost improvement and establishing business indicators in our performance agreement with the DOE, PNNL has continued to improve its cost performance over the past decade. PNNL's overhead cost savings of \$81M from FY1994 to FY 2002 in constant FY02 dollars has translated to decreasing overhead rates and cost to our clients.

Business indicators provide measures that drive the pricing and investment decisions of PNNL's leadership team. Use of business metrics is an effective tool in benchmarking with other National Laboratories as well as other non-profit laboratories. Three primary business metrics form the basis for PNNL's ongoing efforts to improve cost efficiency through business growth and optimizing overhead cost.

\section{Overhead Cost as a Percentage of Charge-Out Rate}

The percent of the Laboratory's average 1830 fully burdened direct charge out rate that is overhead versus salary and fringe is a key metric for managing overhead rates. It is the goal of the Laboratory to optimize the amount of labor cost charged to customers compared to overhead costs applied to that labor. By monitoring the average 1830 fully burdened direct charge out rate in the two components, overhead vs. salary and fringe, management can demonstrate the impact of pricing and rate decisions on costs charged to customers. PNNL's long-term goal is a burdened charge out rate comprised of less than 50\% overheads. See Figure 2.1.2a.

\section{Direct FTEs as a Percent of Laboratory Total FTEs}

Direct FTEs represent the primary indicator of resource deployment to customers. It also represents the primary source of overhead recovery. Monitoring the level of direct FTEs is an institutionalized management practice at the Laboratory. Evaluating direct FTEs relative to the total FTEs available in the Laboratory indicates a measure of the Contractor's resource management. See Figure 2.1.2b.

\section{Total Overhead Cost Expressed as a Multiplier}

For every dollar of directly charged cost to a client, an overhead amount is applied. Reducing the multiplier in simple terms is achieved by either increasing the amount of direct costs charged to clients (i.e. grow the business) or by reducing the actual amount of overhead costs incurred. See Figure 2.1.2c.

As PNNL has consciously shifted its business mix toward more labor-intensive projects, we have realized that reducing the multiplier is in fact more complex than our simple statement above. In fact, as labor becomes a larger component of our business, despite a favorable trend on both our labor and non-labor multipliers, the composite multiplier does not reflect an improvement. PNNL believes this is a useful measure but is proposing to add the other multipliers to the performance indicator as well. By monitoring the individual variables that drive the composite multiplier, we will better reveal PNNL's efforts to reduce overhead rates. The individual multipliers are directly within PNNL's management influence while the composite multiplier is determined by the weighting of the individual multipliers and not directly within management's control. The view of the multipliers in Figure 2.1.2c reveals the favorable downward trend of the individual multipliers without a similar effect on the composite.

\section{Two Items Warrant Mention}

First is the chain of events surrounding the Elimination of Weapons G rade Plutonium Program (EWG PP). BMI billed DOE \$850,000 for work performed before funds were transferred between government agencies and without a formally approved work authorization. D OE Order 412.1, April 20, 1999, invoked by Pacific 
Northwest National Laboratory Contract DE-AC0676RL01830, requires that no work start without a scope of work, identified funding source, and a contract funding modification. PNNL has a long-term, trusting relationship with the client, D efense Nuclear Nonproliferation and the Office of International Nuclear Safety and Cooperation within D O E's National Nuclear Security Administration (NNSA). When requested by D efense Nuclear Nonproliferation to support the EWGPP Program, PNNL agreed to accept this challenge at BMI's risk. Both DOE and PNNL management realized that the funds transfer would take some time, but felt that it would probably happen over about four months. EWG PP Project Management believed the long-standing PNNL "Anticipatory/ Overrun Authorization" process could be used to support the need to start work on a time critical project. The project manager believed the anticipatory process used Battelle Memorial Institute funds and that these funds were at risk should the funding not arrive. He recommended that BMI accept the risk, and senior PNNL National Security Directorate management accepted the risk for BMI. The project manager's perception was subsequently communicated to the client, and the project was begun under the Anticipatory/O verrun Authorization process. PNNL and NNSA management coordinated all aspects of the EWG PP program deliberations and the use of the anticipatory authorization funding process with D OE's Richland Operations Office (D OE-RL). When Congress raised concerns about funding, PNNL stopped work and BMI repaid D OE the overrun plus interest.

Second, as a result of the system accommodations surrounding PNNL's anticipatory policy, D OE-RL reviewed PNNL's practice relative to control point funds control. PNNL's system was automatically closing any control point overruns to 1830 suspense. A review of the past year showed that control point violations had occurred and been moved to suspense on 12 control points; six of these occurrences were resolved within the 30 day suspense accounting guidelines. PNNL has changed its system and will no longer clear overrun cost to suspense. Automated reports are being developed to alert management further in advance of potential funds control issues. outstanding result.

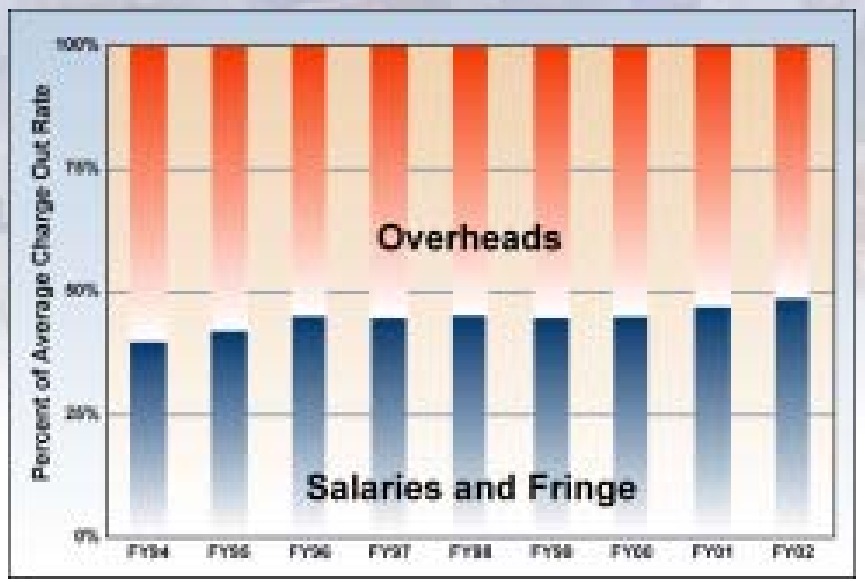

Figure 2.1.2a. PNNL's overhead rates were reduced such that overheads were less than $52 \%$ of an average 1830 charge out rate; an outstanding rating and impressive trend.

Figure 2.1.2b. PNNL increased the number of staff funded directly by clients while limiting growth of indirect funded staff count resulting in just over $50 \%$ of total direct FTEs being direct; an

Direct FTE's as a Percent of Total FTE's

$\begin{array}{llllll}\text { FY97 FY98 } & \text { FY99 FY00 } & \text { FY01 FY02 }\end{array}$

Fiscal Year

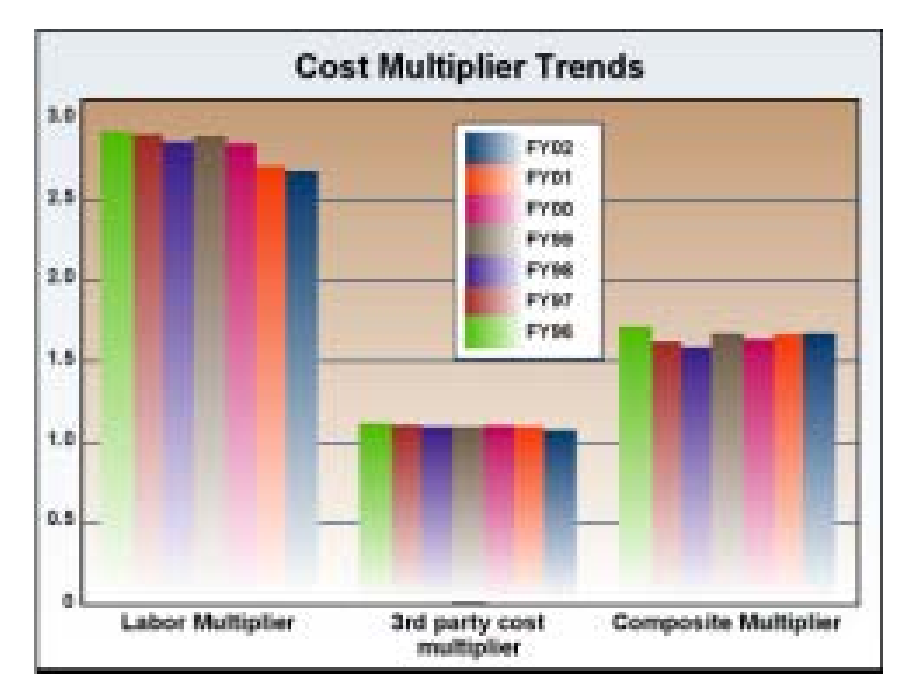

Figure 2.1.2c. PNNL continues to make progress in reducing each of its independent multipliers. A shift in business mix away from $3^{\text {rd }}$ party costs results in a composite multiplier of 1.668 and a rating of marginal. 


\subsection{3a Permeation of Safeguards and Security (SAS) Integration and Training Throughout the PNNL Organization}

\section{SAS is integrated into the PNNL culture, and staff have the knowledge and training to carry out their responsibilities.}

\section{Importance of Integrated Safeguards and Security Management}

PNNL has implemented an Integrated Safeguards and Security Management (ISSM) Program, one of the first within the complex. The Laboratory strongly believes that it is possible and necessary to integrate science and security. O ne reason for early implementation of an ISSM system was the breadth of research activities PNNL conducts. The spectrum ranges from very open, in the EMSL User Facility, to compartmentalized work in some of the classified programs. Building a system that met the protection needs for both environments was essential, and the Laboratory has nurtured and evolved the ISSM system to accommodate both effectively.

D uring the past year, an ISSM Program action plan was completed to document actions necessary to further mature the ISSM Program. Actions noted in this plan were completed in accordance with the schedules; D irectorates were educated on SAS expectations, assessments, and lessons learned. Feedback from Directorates was obtained and used by the SAS program to improve and expand the SAS Awareness program.

\section{Role of the Senior Management Council}

The Integrated Safeguards and Security Senior Management Council was established and chartered to provide a senior forum for:

- The review of new and changing SAS conditions that affect the Laboratory,

- The identification of policy issues that should be raised to the leadership team, and

- The identification and/ or endorsement of action plans as conditions warrant.

The "conditions" addressed by the council are wide ranging and include such factors as new policy/ directives from DOE or other regulatory agencies, evolving business activities, emergency conditions, cyber threats and security incident reports from across the DOE complex. The council is comprised of the D eputy Laboratory Director for O perations, the Director of Facilities and Operations, the Manager of Safeguards and Security Services, the Chief Information O fficer, the Senior Counterintelligence O fficer, the Computer Protection Program Manager, and a representative from the Environmental Technology; National Security; Energy, Science and Technology, and Fundamental Sciences research directorates. This representative group makes sure that all equity stockholders are represented when integrated safeguards and security related issues are addressed.

\section{How PNNL Protects Assets}

The Laboratory employs a graded system for the protection of property, facilities and assets that includes the use of security areas, access controls and accountability systems. Asset Protection Agreements (APAs) are developed to document the identification of the security interest activities and associated protection measures by facility location. APAs are established on a graded fashion and take into account the nature of the security interest; protection requirements identified in appropriate directives, threat potentials and countermeasures, and assign a defense or safeguards priority position based on a composite evaluation of these factors. The APA serves as the security plan for the individual facilities. Line management assisted by Safeguards and Security Services determine the protection plans. The APA is an automated system that receives input directly from other applicable Laboratory systems involving different security interests/ assets on a near real-time basis. This information is then reviewed to ensure appropriate security measures have been put into place.

\section{Managing and Measuring SAS Effectiveness}

To ensure compliant SAS integration and the effective deployment of the management system, SAS require- 
ments were defined and disseminated to Laboratory staff through regular reviews of SBMS materials and Records of Decision (ROD s). $100 \%$ of the SAS SBMS materials were reviewed and updated (in accordance with schedule). ROD s and associated actions were completed in conjunction with D ivision representatives; 12 ROD s and associated actions were prepared/ completed during FY 2002. Four additional ROD s were prepared and ongoing actions are on track.

The effectiveness of the SAS Program would also be measured through evaluations of performance in SAS programmatic areas. The SAS self-assessment program and resulting corrective actions were conducted in accordance with applicable requirements and expectations and reflected an appropriate compliance program. The outcome of these assessments confirmed that the SAS Program was achieving all objectives.

The degree to which Line organization staff and management are current with Safeguards and Security training requirements was continually assessed and met or exceeded expectations (98.4\%). Line organization training records for 2002 reflect an upward trend and improvement in compliance with SAS training requirements. This reflects the Laboratory's commitment to SAS - ensuring training and knowledge are commensurate with assigned responsibilities.

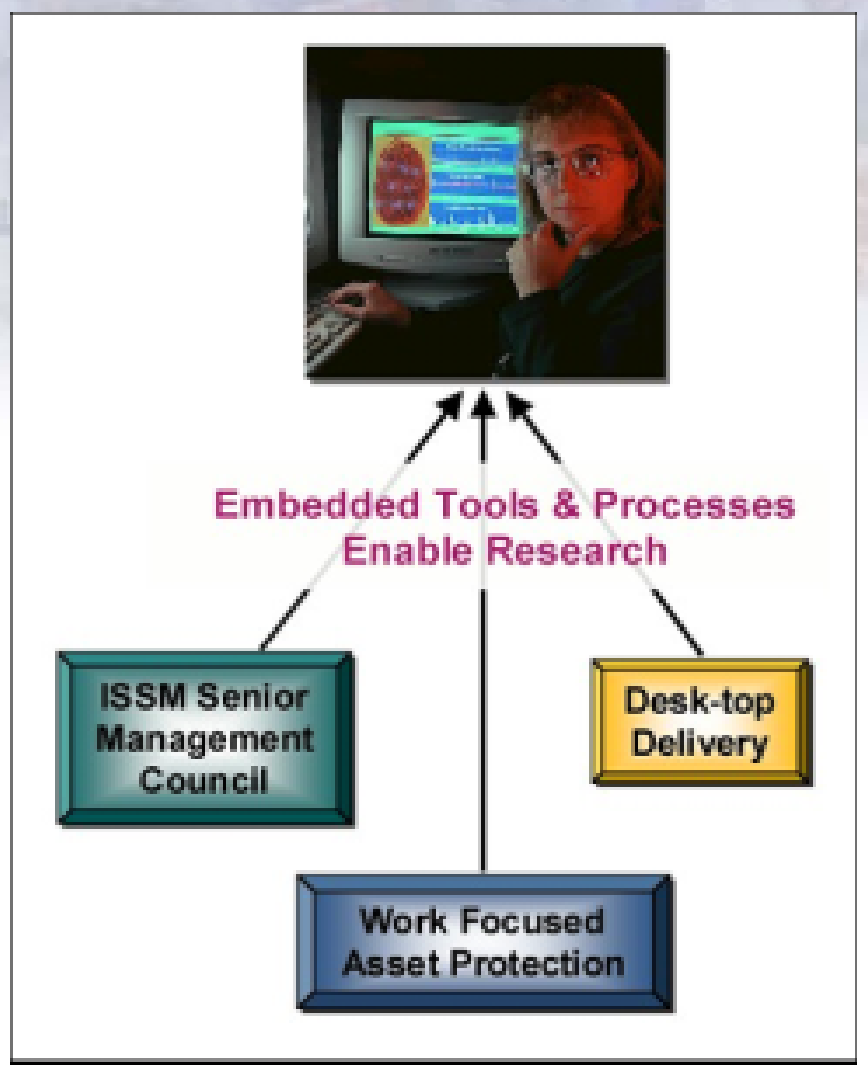

Figure 2.1.3a1. Two examples of integrated processes we have introduced as part of the ISSM program are a Senior Management Council and Asset Protection Agreements.

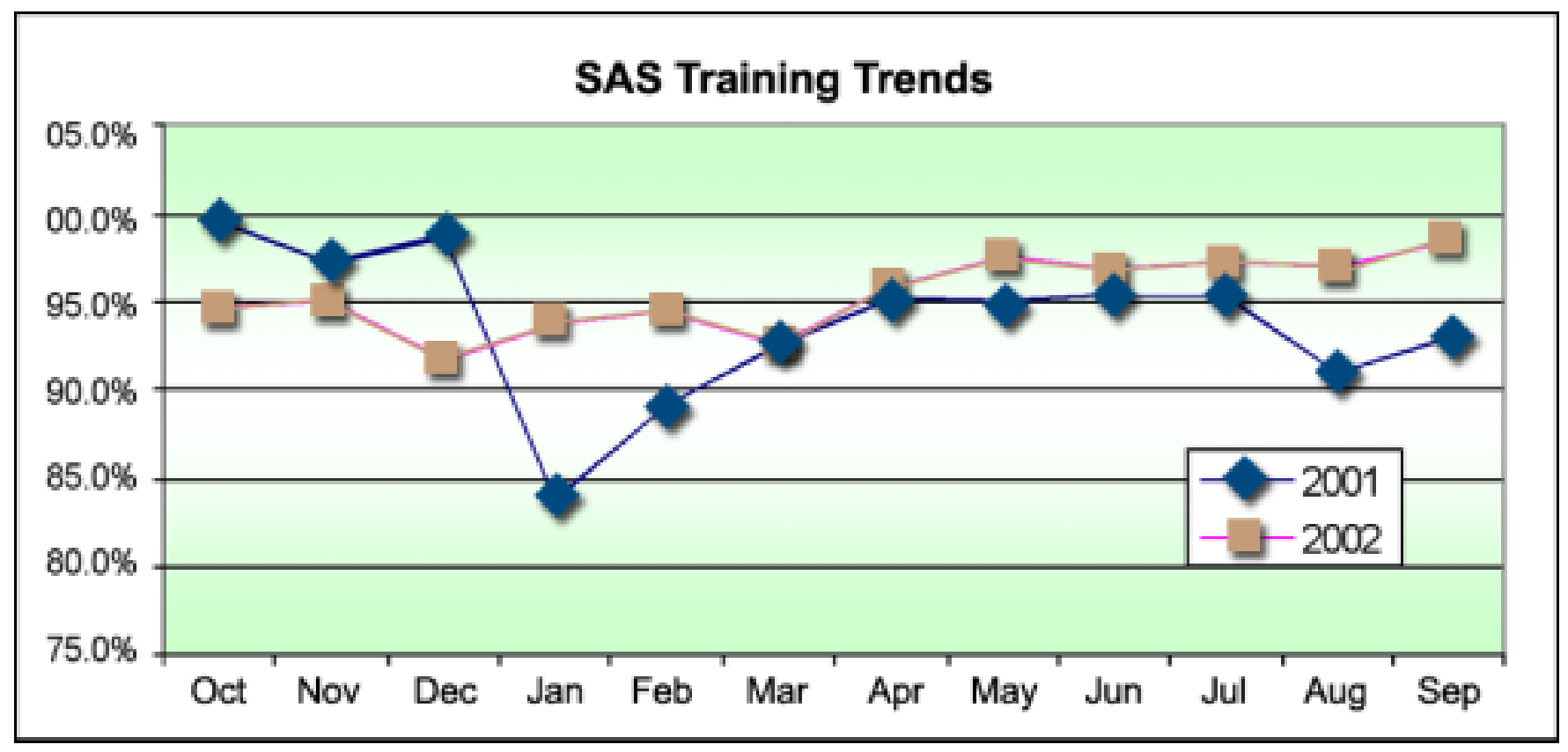

Figure 2.1.3.a2 The upward trend and improvement in compliance with SAS training requirements demonstrates the Laboratory's commitment to SAS. 


\subsection{3b Congruence of High External Evaluations of SAS Performance \\ with Actual Identification, Reporting, and Mitigation of Threats}
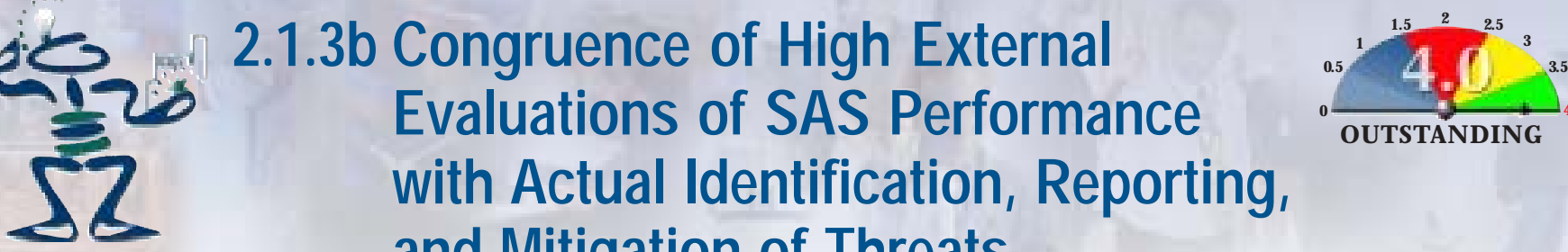

External reviews confirmed that PNNL's SAS performance is outstanding.

\section{Positive External Evaluation}

The Laboratory's performance in Safeguards and Security programmatic areas at protecting assets and compliance, as measured by external evaluations and performance against agreed upon corrective action plans, met all expectations. All external evaluations of SAS resulted in satisfactory or greater composite ratings.

The review by the DOE 0 ffice of Independent 0 versight and Performanœ A ssurance (OA ) [SAS Program] was completed in 2001, resulting in a "Satisfactory" rating. Actions associated with this review were approved and completed in 2002 in accordance with schedules and plans.

The bi-annual inspection of the Counterintelligence Program by the Office of Counterintelligence (external evaluation) was very "flattering" to its staff and their accomplishments. The Lead Inspector described the Program as a "mature, integrated program, with high morale, very productive, dedicated, and committed staff, with strong management and some best practices identified." The Program was rated as "excellent," the highest evaluation possible according to their unique, but rigid, standards. The PNNL Counterintelligence Program has received outstanding ratings from the D OE Office of Counterintelligence in each of the last three fiscal years.

\section{Performance Matches Reputation}

The Laboratory has demonstrated its ability to identify, report and mitigate, as necessary, any emerging threats. Line organizations ensured the number of significant incidents of a Security Concern within the control of Battelle with impacts upon the national security, defense, or foreign relations of the United States were minimized and mitigated. Corrective actions for identified threats or issues are developed and implemented by the line organizations in a timely manner. Figure 2.1.3b shows, the trend for significant incidents of a Security Concern has shown a definite reduction since implementation of the ISSM Program.

In addition, the proactive incident reporting program ensured security events were reported in a timely manner and managed as required resulting in the identification and renovation of weaknesses in procedures and policies designed to protect government interests.

O ther activities associated with the reduction of threats and the integration of SA S include reassignment and renaming of the National Security Building to match its mission. Classified activities and Limited Areas had been previously consolidated into this single location. Co-locating similar work activities helps to streamline and invoke the appropriate controls tailored to the work.

O ther accomplishments after the incidents surrounding September 11, 2001, include:

- Vulnerability assessment for one of our facilities using newer threat criteria,

- Clear Zone for the perimeter of a designated facility,

- Random explosive detection by K-9s at mailrooms,

- Enhanced communications with local lawenforcement agencies,

- Training (suspicious packages, mail) for mail handlers,

- Enhanced automatic access control systems allowing for immediate closure of buildings during emergencies,

- Increased staff awareness activities, and

- Rewards/ recognition for staff vigilance. 


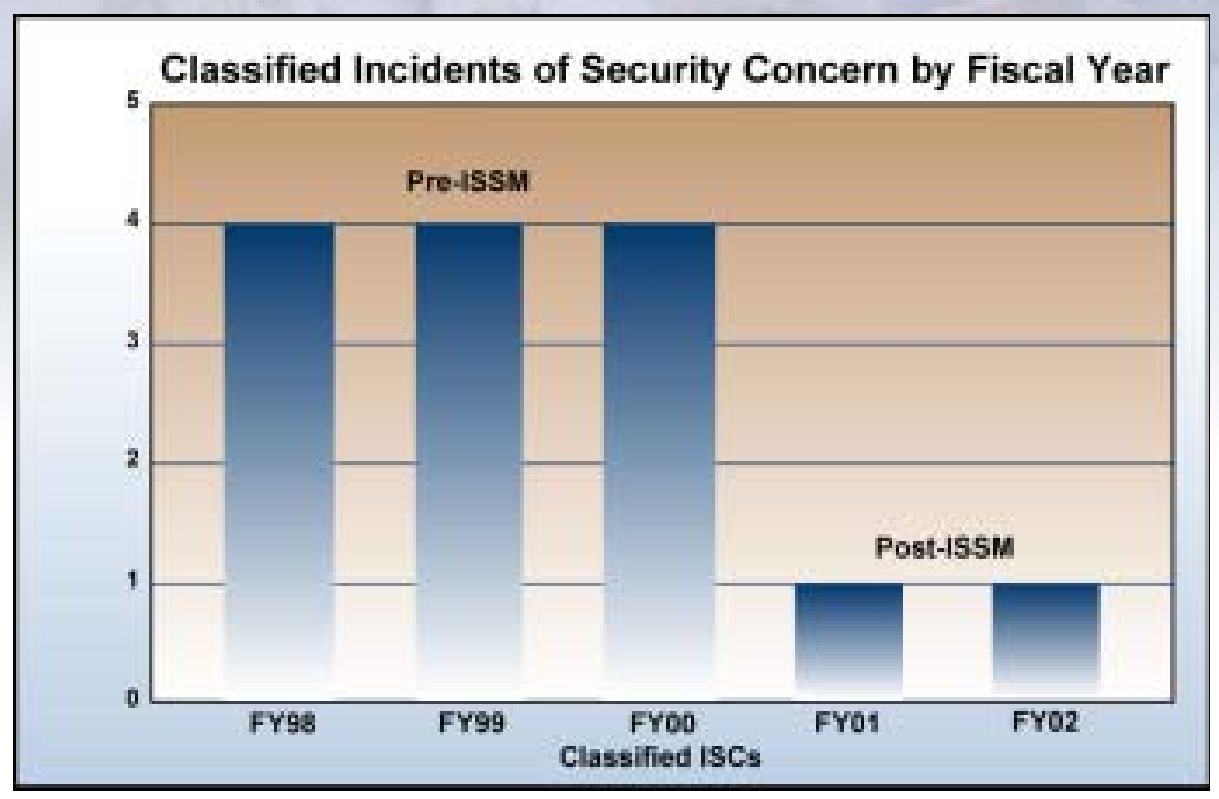

Figure 2.1.3b. ISSM has had an order-of-magnitude improvement effect on incidents of Security Concern. 


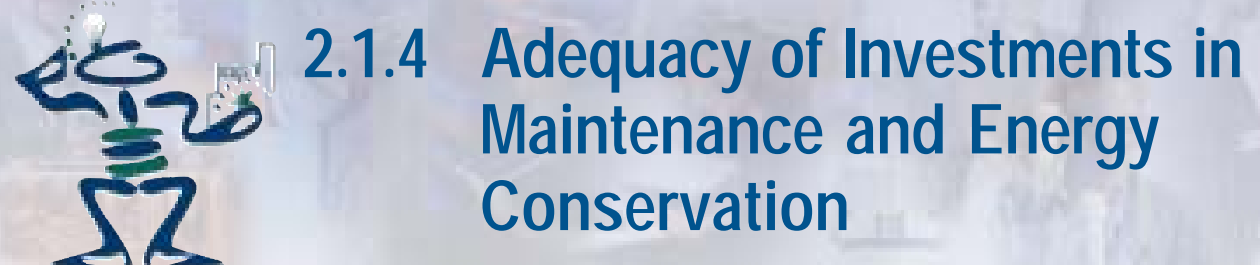

PNNL is an effective and efficient steward of facility assets, keeping
the physical plant in reliable operating condition for its present use
while continually looking at strategies to reduce energy and water
consumption.

FY 2002 was a challenging but successful year in facility operations. Facility operations was tested by higher expectations for operational performance, as well as the impact of managing the most complicated set of facility outages in recent years. O ur staff and systems responded remarkably to these challenges, allowing us to outperform last year by the widest margin in recent memory. By all indicators, we achieved our goals for FY2002 representing a second consecutive year of consistently strong operational and service performance and enhanced customer value. We also won the International Facility Management Association Golden Circles Award, arguably one of the most prestigious awards given in the field of facility management. For the second year in a row, we also won Federal Energy Management Program and D OE D epartmental awards for our efforts to conserve energy and water. Finally, we were also recipients of a White House Closing the Circle pollution prevention award for using "Green" custodial chemicals in our facilities.

\section{Maintenance}

By all indicators, maintenance and work control outperformed last year. Through September 2002: (1) actual cycle time for dispatch work fell $17 \%$ from 2.84 to 2.35, (2) we met the planned need date $93.5 \%$ of the time compared to $85.5 \%$ the previous year, (3) we completed preventive maintenance on schedule $99.6 \%$ of the time- this compares favorably to an industry benchmark of 95\% and last years' $98.4 \%$, and (4) the expected level of maintenance investment will exceed 3.4\% (RPV) for the Consolidated Laboratory.

\section{Energy Conservation}

By all indicators, PNNL's efforts in energy conservation exceeded the critical outcomes and outperformed last year, an achievement highlighted by the recognition of two Federal Energy Management Program awards and two DOE Departmental Awards. In 2002, PNNL reconstructed the 1985 (office) and 1990 (laboratory) energy use baseline (BTU/ sf). O ur energy reduction of $30.2 \%$ in laboratory facilities exceeded D O E's 2010 goal of $25 \%$ - the result of investments in infrastructure upgrades (Energy Savings Performance Contracts, third party financing, Bonneville Power Administration grants, and Battelle and DOE capital), innovative recommissioning programs, and positive staff behavior to conserve energy. In 2002, we expect to reduce overall PNNL energy consumption by $6 \%$ compared to the annual goal of $2 \%$. O ther accomplishments included the qualification of Sigma 5 as an Energy Star Building. If the facility remains qualified for a period of twelve months, it will be awarded with the Energy Star label. We completed a number of energy audits, including major facilities like EMSL and 331, 326 and 329 buildings. These audits identified additional opportunities for investment in energy conservation measures. O ur water conservation efforts also continued to pay dividends. In 2002, we were able to put an additional 20 million gallons of river water to beneficial use in surrounding farmlands.

In addition, the Laboratory signed an agreement to purchase and use 8.8 million kilowatt hours of power produced by a wind-generated energy project in FY 2003. The purchase covers more than 10 percent of the Laboratory's energy needs, and it means the Laboratory will be one of the federal government's leaders in the use of Green energy, with 13.7 percent of its energy coming from renewable resources. This level of usage surpasses goals set earlier in FY2002 by DOE for national laboratories and other sites to purchase three percent of their power from $\mathrm{G}$ reen sources by 2005 and 7.5 percent by 2010. The PNNL purchase also will diversify the region's electricity portfolio and stimulate a new energy economy in the Pacific Northwest. 


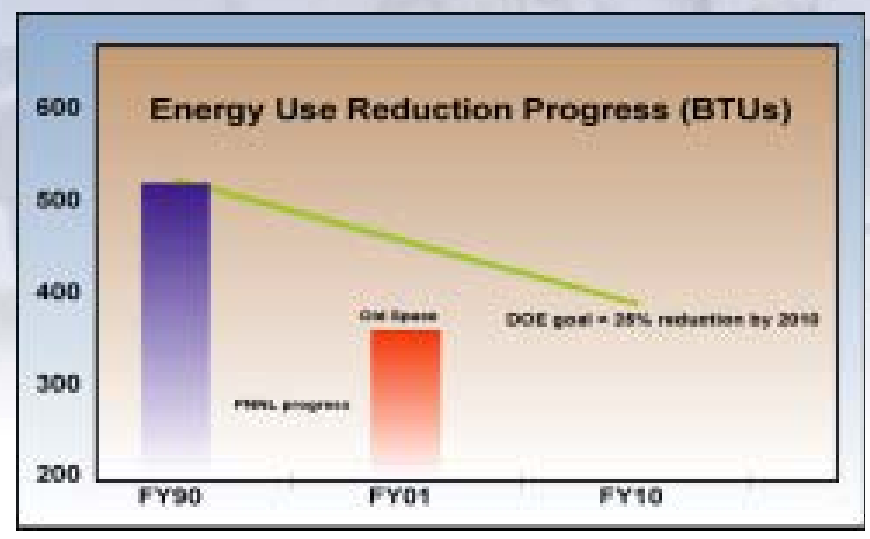

Figure 2.1.4a. Our energy reduction of $30.2 \%$ in laboratory facilities has already exceeded DOE's 2010 goal of $25 \%$.

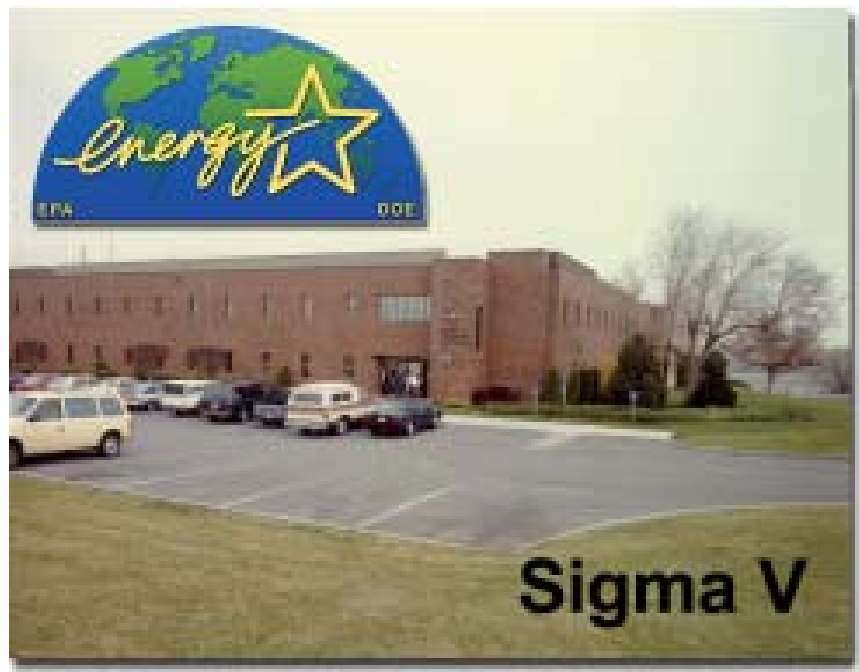

Figure 2.1.4b. Sigma 5 qualified as an Energy Star Building; the first PNNL building to qualify for this noteworthy achievement.

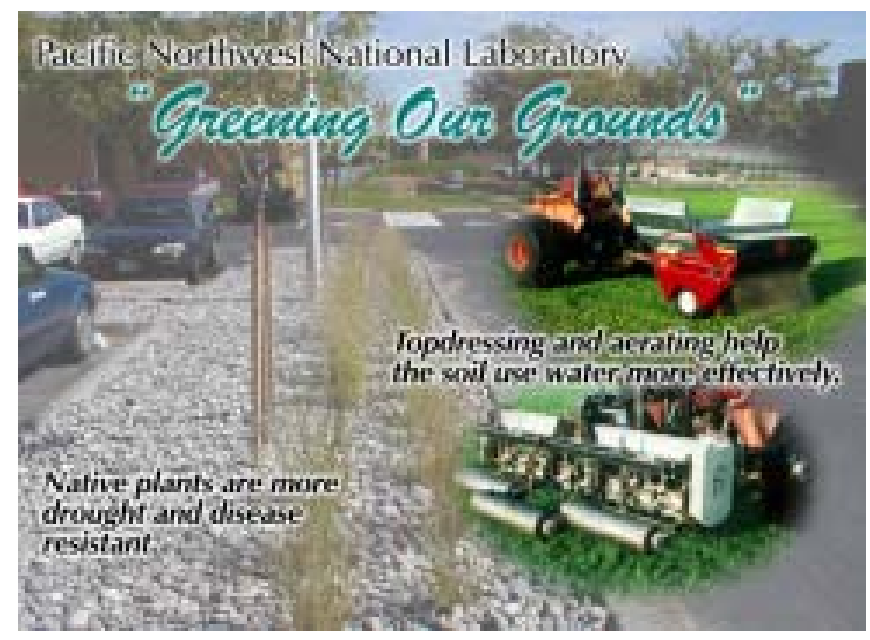

Figure 2.1.4c. PNNL's “Greening Our Grounds" program resulted in greater than $30 \%$ water reduction for our campus. 


\subsubsection{Effective Execution of the Information Technology (IT) Infrastructure Strategic Plan to Achieve the 2010 Vision of the Laboratory}

\section{PNNL made significant progress in delivering the information technology environment staff need to address challenges in science, energy, environmental quality, and national security.}

\section{Why an IT Strategic Plan?}

In this decade, research projects will be more computer and data intensive, involve researchers from many disciplines, and employ an array of widely distributed resources. Information technology is critical to PNNL's effectiveness as a contributor to solving the nation's most critical challenges in science, energy, environmental quality, and national security.

The PNNL IT Infrastructure Strategic Plan, updated annually, describes the vision and strategy for information technology that guide investment decisions in support of the Laboratory's mission and vision. It describes the long-term vision for the Laboratory's IT environment, the key strategies or approaches we have chosen to achieve that vision, the desired business outcomes resulting from those strategies, and key near-term actions or milestones.

\section{Five of Six Milestones Were Fully Achieved}

This indicator measures Battelle's ability to provide the IT infrastructure needed to achieve the 2010 Vision of the Laboratory by measuring progress towards the IT Infrastructure Strategic Plan. PNNL fully achieved five and partly achieved one of the six key milestones chosen to represent progress against the plan during FY2002. Those milestones and the status of progress at the end of the fiscal year are described in the following.

Milestone 1. Increase deployment of infrastructure for high-speed (100 Mb) network connectivity to the greatest extent practical (approximately 98\% of all PNNL desktop systems) to accommodate interaction with research data sets of increasing complexity and size.
Status - Completed. Currently, 97.6\% of PNNL desktop systems are connected via high-speed connections of $100 \mathrm{Mb}$.

Milestone 2. Increase wireless network infrastructure to $65 \%$ of staff in buildings that are part of PNNL's Richland North (RCHN) or 300 Area network to support mobile computing within PNNL facilities.

Status - Exceeded. Currently, wireless coverage extends to $75 \%$ of staff in RCHN and 300 Area buildings.

Milestone 3. D eploy Public Key Infrastructure (PKI) certificates to PNNL employees to enhance protection of information with an enterprise capability to encrypt sensitive information.

Status - Completed. Currently, over 3100 staff are using the capability for digital signatures or encryption of sensitive information.

Milestone 4. D evelop business model and project management plan to upgrade PNNL's Internet connection to OC-12 to support collaborative simulation and engineering initiatives.

Status - Partially completed. Funding has been secured and a project management plan is in place to upgrade PNNL's Internet connection to regional university collaborators (via the Seattle Gigapop) to OC-12 by mid-FY2003. PNNL has engaged the NSF-funded LIGO facility located on the Hanford site to help fund this upgrade.

Funding for upgrade of the ESnet link to the Seattle Gigapop has not yet been identified. However, 
PNNL is activity engaged with the O ffice of Science and other National Laboratories to reestablish U.S. leadership in high performance computing. The proposed Ultrascale Scientific Simulation Computer Capability (USSCC) will demand a corresponding high performance wide area network capability that includes connecting PNNL at bandwidth far exceeding $0 \mathrm{C}$-12 (see Figure 2.2.1).

Milestone 5. D eploy a collaborative work environment that integrates shared team workspaces including CollabraSuite, Electronic Lab Notebook, and multimedia support that includes pre-recorded, live, and on-demand audio, video, and 3-D modeling to facilitate enhanced collaboration among multidisciplinary and geographically dispersed teams.
Status - Completed. PNNL's collaboration environment now includes CollabraSuite (shared group workspaces), Electronic Lab Notebook, WebEx (web conferencing), live and pre-recorded/ ondemand streaming-video services, and both roombased and mobile video conferencing capabilities.

Milestone 6. Expand common scientific toolkit for PNNL-wide use in support of information discovery, analysis, visualization, and/ or data management (minimum of one new commonly available scientific tool).

Status - Completed. Three products were added to the scientific toolkit during FY 2002.

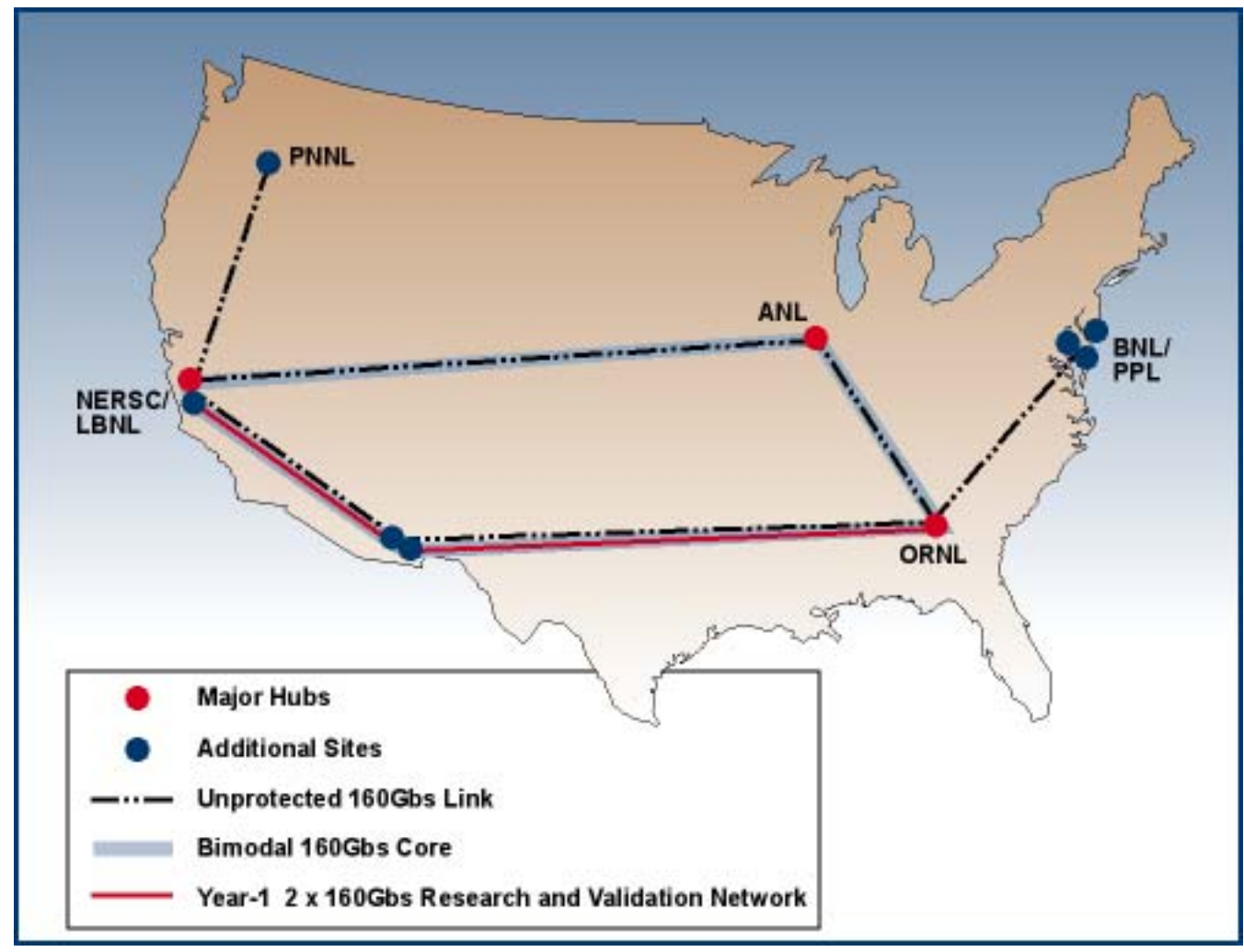

Figure 2.2.1. Concept diagram of Wide Area Network supporting the Ultrascale Scientific Simulation Computer Capability (USSCC), which if completed, will provide a high performance wide area network capability at bandwidth far exceeding OC-12. 

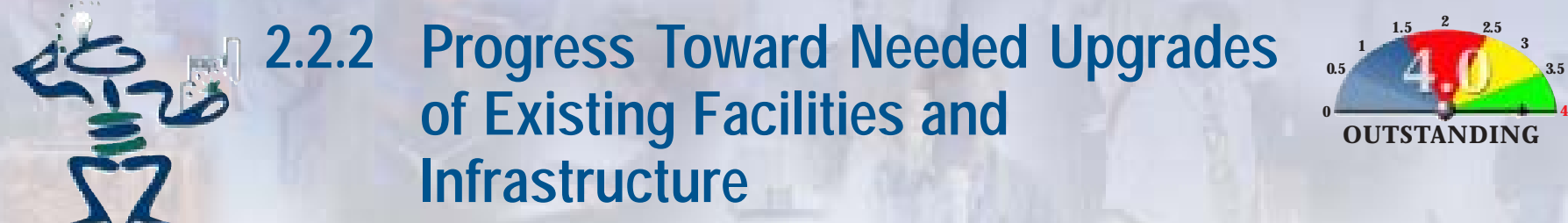

PNNL revitalized existing facilities and infrastructure, providing
additional capabilities and space essential to support R\&D the Lab's
S\&T mission, but progress on 300 Area transition stalled.

Five Milestones Met

1. CD -2 approval obtained for the FY2002 DOE Office of Science Line Item, Project D -494, Laboratory Systems Upgrade. Project increases energy efficiency of buildings and enables continued building operations.

2. Upgrades to two safety significant systems within RPL building; replacement of the HVAC Controllers and Switchgear were completed ahead of schedule and under the authorized budget without disruption to ongoing $R \& D$ work within the facility.

3. FE MP funded project completed retrofitting (approximately 1,500) fluorescent light fixtures with more efficient electronic ballasts and lamps in the 318, 320, and 350 Buildings.

4. E SPC Phase II implemented to install energy savings upgrades in Battelle buildings.

5. E limination of L egacy Waste and Contamination from PN N L A ssigned Facilities. Removed, packaged, and transferred the remaining PNNL-managed 300 Area Special Case Waste (SCW) and materials from PNNL-assigned facilities, completing all PNNL deliverables under the TPA M-92 series milestones nearly four years ahead of schedule.

\section{One Milestone Not Met-300 Area Transition}

Following the development of the Flour Hanford (FH) study for accelerating cleanup of the Hanford site in July 2000 and PNNL's supplemental study completed in June 2001, a measure of progress was identified to create a project team to omplete an implementation plan for D OE -RL's 300 A rea 0 ptions Study decision. This measure was established on the basis of PNNL's and AMT's expectation that DOE-RL would approve the expendi- ture of EM funds to construct a multi-purpose laboratory facility capable of supporting dislocated $R \& D$ operations within the cleanup zones. At the time the indicator was established it was not foreseen that EM-1 and RL would modify their support for the preferred alternative established in both studies. As evidenced by the following, PNNL has continued to provide support in establishing acceptable alternatives to resolve this critical interface between EM and SC mission objectives.

Following the DOE decision in November to no longer support constructing a single replacement facility, AMT requested that PNNL explore less visible alternatives that could be accomplished locally. A PNNL project team was formed without supplemental funding to evaluate feasible options.

Solutions involving the modification of existing core facilities to accept the displaced work were formulated. $R \& D$ organizations trimmed their original requests and an evaluation for the relocation of 3720 Bldg. activities to RPL was completed, resulting in a favorable cost reduction of more than $\$ 4 \mathrm{M}$ over previous alternatives.

In April 2002, RL counterparts in AMT and AMRC were briefed on the alternatives, but EM's focus on cleanup was increased and RL did not embrace a plan that required any expenditure of cleanup dollars for relocating $R \& D$ operations.

Recognizing the need to resolve this critical interface, RL formally signed a PNNL Baseline Change Request on 0 ctober 1, 2002, which includes developing an exit strategy from the 300 Area. This work is anticipated to be coordinated in conjunction with the newly formed SC site office, RL and the River Corridor Cleanup (RCC) contractor. 


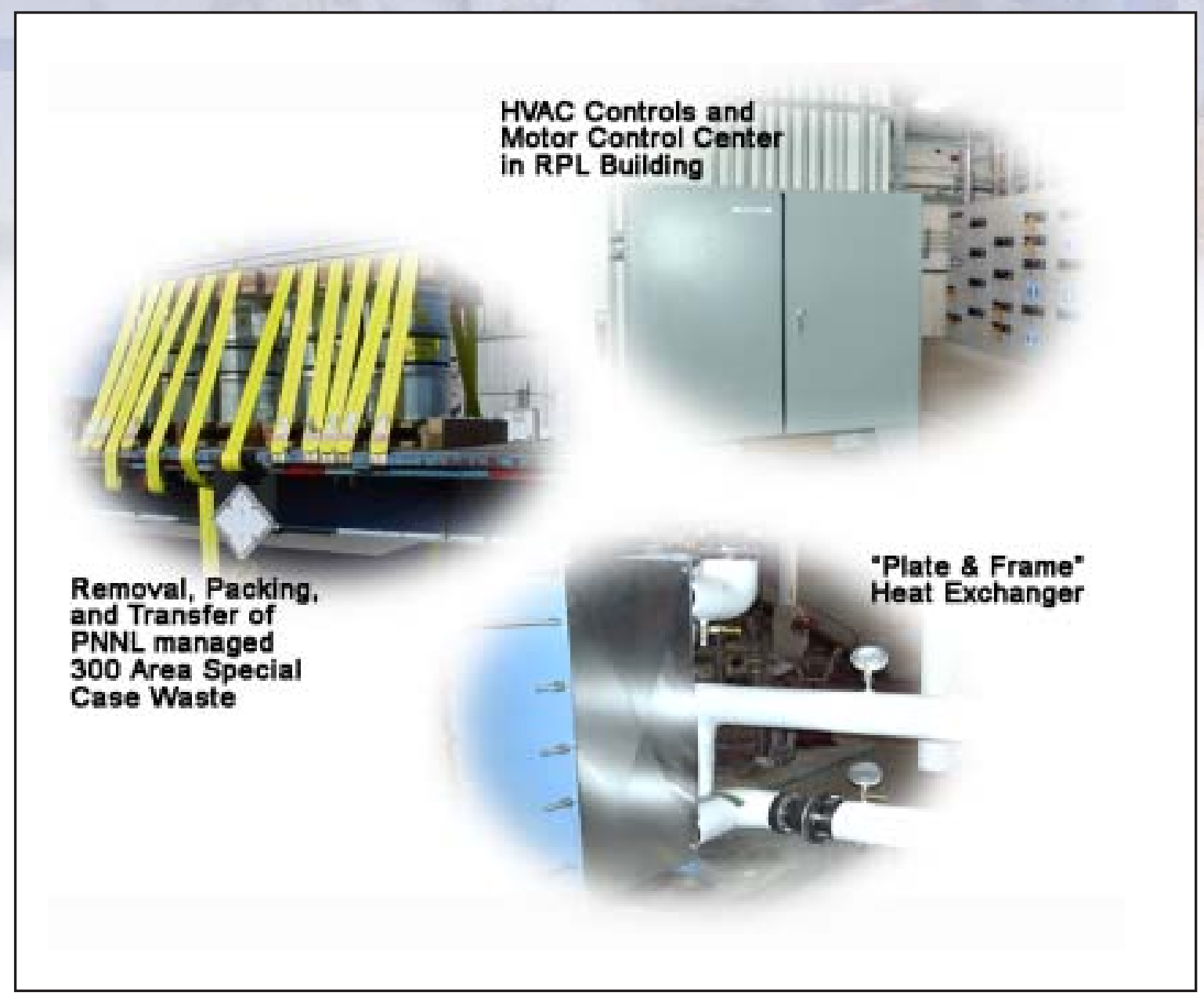

Figure 2.2.2. Modernization and augmentation of major facility systems set in motion the resurgence and support for the R\&D missions of the future within PNNL facilities. 


\subsubsection{Progress Toward Building Needed New Facilities and Infrastructure}

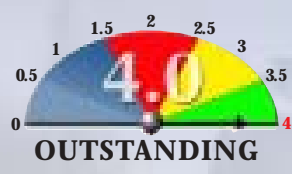

\section{PNNL met eight of nine FY2002 new construction-related milestones.}

\section{Milestones Met}

1. Completed construction and turnover to operations of the 331 Building - $3^{\text {rd }}$ floor south laboratories in support of the Biomolecular Systems Initiative.

2. Completed construction of LSL II Laboratories in support of the Biomolecular Systems Initiative. Planned use as a pilot Proteomics Facility is important to meet the long-term DOE Genomes to Life Program facility needs.

3. Completed acquisition plan for Phase 2 of interim systems biology space requirements.

4. Completed revitalization of the expanded facilities in the National Security Building (NSB), formerly EESB, to accommodate projections for growth in National Security mission.

5. Completed the systems biology research centers preconceptual plan. A critical element of the plan is DOE-BER's G enomes to Life Program facility planning.

6. Constructed space to house the high performance computational capabilities at EMSL.

7. Completed White Paper and developed strategy that accommodates National Security's current and future needs within the existing portfolio of facilities. EESB designated as National Security Building (NSB).
8. Completed Phase 2 of the PNNL Site Master Plan. D ocument updates utility capacity and site configuration information needed to design and construct new research facilities.

\section{Milestone Not Met}

Computational \& Analytical Sciences Building milestone

- PNNL has made progress towards the issuance of a Request for Proposal (RFP) for the Computational \& Analytical Sciences Building (CASB). All documentation (Performance Specifications, Room Data Sheets, SEPA, Biological/ Cultural Review, etc.) required to issue the RFP has been developed and is ready for release. Completion of the Battelle Site Master Plan allowed the siting of the facility and location for utility services. Financing alternatives are being explored to provide the best value for D OE and Battelle. An external web site has been developed to expedite communication to potential bidders where they can get the necessary documentation for responding to the RFP. DOE programmatic support has been well received, and D OE Market Sector and BMI support is on the way. DOE-RL approval will be sought once Battelle approves. 


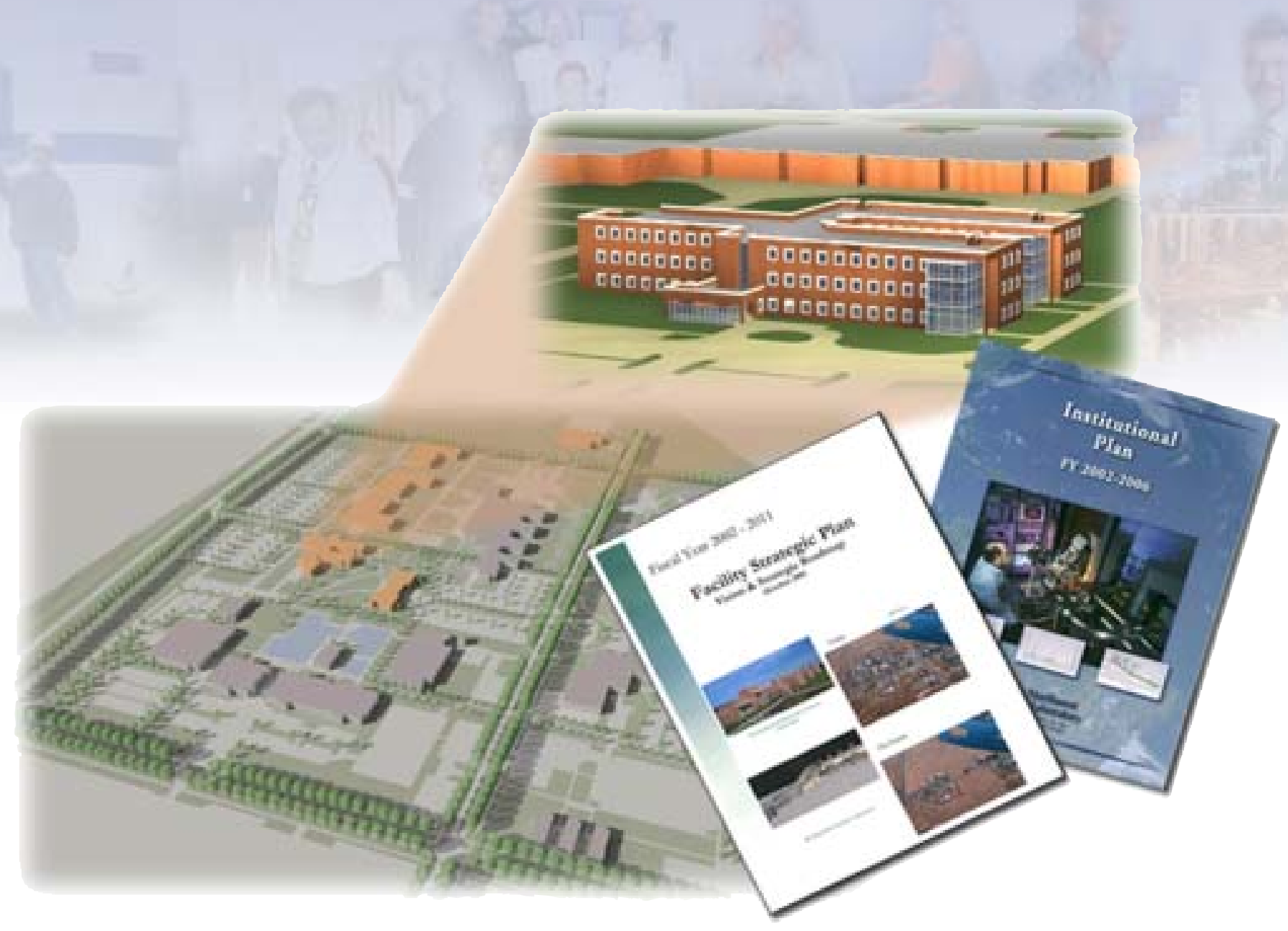

Figure 2.2.3. Facility, Strategic, and Institutional Plans have been developed, transforming the 2010 Vision into tangible steps towards achieving the various elements on our planning horizon. 


\subsection{1a Commitments to Improve the Effectiveness and Efficiency of Integrated ES\&H Management Systems}

The successful completion of all agreed-upon FY2002 ES\&H Management System improvement milestones, plus the resolution of an additional important emerging issue, shows PNNL's long-term commitment to making our set of integrated ES\&H systems, processes, and tools measurably better.

\section{We Did What We Agreed To...}

- We completed on-going enhancements to our PNNL Environmental Management System and were recommended for official ISO 14001 registration. The effort is the latest achievement over the last five years to measurably demonstrate the improvement of our Integrated Safety Management System through external third-party verification.

- We completed a three-year effort to deploy the Integrated Operations System (IOPS) to all PNNL's lab-intensive Richland facilities in order to better establish and communicate safe laboratory practices, identify and control workspace hazards, identify and obtain appropriate training, and control access to workspaces for an efficient and productive laboratory.

- We completed the initial system development for the Hazard Analysis Initiative, which will integrate the proposal planning risk management decisions of Electronic Prep \& Risk (EPR) with the IO PS benchlevel capabilities for identifying, evaluating, and mitigating hazards. This improvement, to be deployed in FY2003, provides an efficient mechanism to close the loop between proposal risk identification and ultimately mitigating the identified hazards of funded projects.

- We confirmed that the FY2001 improvements we made to our process for providing for the safety and security of staff who work off-site had met our performance improvement expectations.
- We made three focused improvements in our radiological control program to better meet the needs of our research staff:

- We developed and implemented a mapping tool that completely and concisely provides "one stop shopping" in SBMS for the requirements and tools associated with the use of radioactive materials.

- We developed and implemented a web-based Radioactive Material Tracking (RMT) database tool within the RPL to ensure reliable, cost-effective, fully-compliant tracking of RPL's radioactive materials.

- We implemented an innovative risk-based radiological control program for work with low level radioactive tracers with the intent of improving the Laboratory's ability to attract scientific talent and advance research in the areas of biological sciences, proteomics, and toxicology mission areas. (Note that this initiative was not included as a milestone in indicator 2.3.1.)

\section{...And More}

In addition to the above contractually agreed-upon improvements, we developed for FY2003 implementation a Variable Waste Chargeback system to resolve emerging issues associated with the planned loss of direct funding for Waste Management and Environmental Compliance activities at PNNL. The solution establishes PNNL as the D OE O ffice of Science leader in proactively addressing this complex-wide issue. 


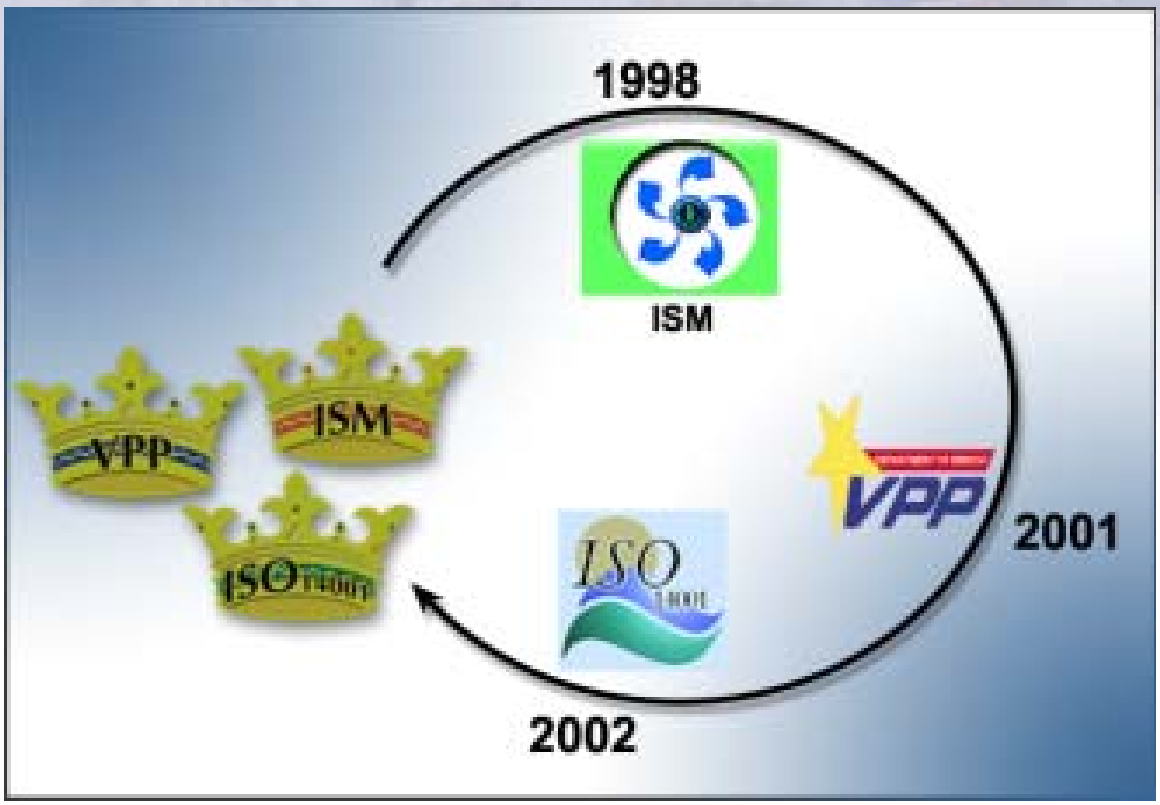

Figure 2.3.1. The "Triple Crown" of ISM certification along with VPP Star status and the recently obtained ISO 14001 registration combine to signify ES\&H excellence. 


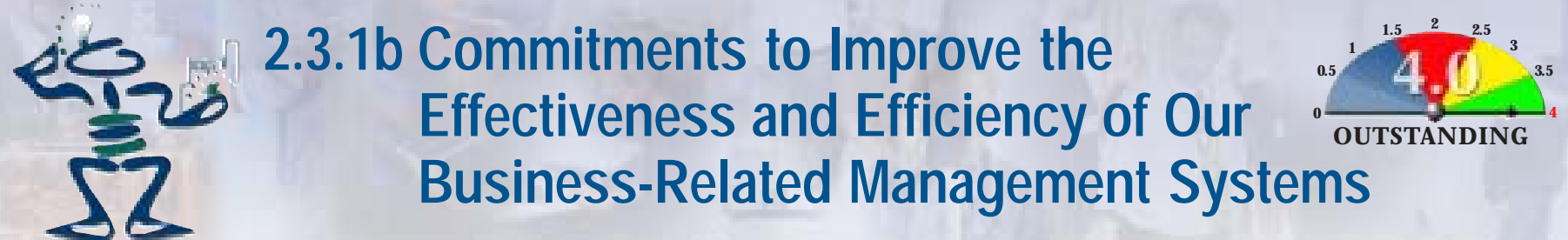

By fulfilling all DOE expectations-and more-in FY2002, we continue to develop innovative approaches to Laboratory business operations that enable outstanding research, maximize value per research dollar, maintain forefront facilities and equipment, and protect DOE's information assets.

\section{Indicator Fully Met}

In FY2002, DOE expected PNNL to make business operations improvements in three areas specified in indicator 2.3.1 of the Fee Agreement. In response to this, we accomplished the following:

1 Combined Integrated Planning and Integrated Assessment into a single management system, which reduced overhead costs and improved decision making by providing a more holistic approach to a performance-based management. The $\$ 215,000$ in savings was accomplished by reducing management and administrative costs and streamlining and integrating processes. The improved decision making was accomplished by delivering more strategic information during business planning (e.g., sector budget targets and reviews that explicitly accounted for business forecasts and performance) and streamlined information across system documents and deliverables. Reengineering the management system description to make it more useful both as an assessment tool and as input to planning and decisions associated with the FY 2003 Lab Agenda, is one example of improved decision making as a result of integrating these systems.

2. Developed a program description of the Laboratory's current practices for corrective action management, which has provided a clearer understanding of our graded approach and will enable us to better identify needed improvements to the program in the future. We have now documented the processes for handling each distinctive condition that requires a corrective action on some level. For example, we have a very prescriptive corrective action process for radiological problems that is distinct and different in terms of the rigor and documentation from that used for Off-Normal Occurrences. Now that we have documented our current approach and process, we will be able to continue to assess our performance and identify future improvement opportunities.

3. Identified implementation issues and recommendations concerning the Laboratory's Customer Service Model which will serve key input into improvements planned for FY 2003.

\section{Accomplishments Above and Beyond}

In addition to the initiatives specified in 2.3.1 of the Fee Agreement, we also accomplished many other improvements demonstrating that continual improvement is ingrained in our culture and imbedded in the way we manage operations.

These improvements included savings of over $\$ 2,400,000$ from the following:

- Implementing a new system for purchasing, receiving, and accounts payable, which will reduce transaction costs by an estimated $\$ 300,000$ while also improving functionality.

- Achieving $\$ 400,000$ in cost savings by renegotiating travel agreements.

- Reducing energy and water use through various conservation and efficiency initiatives leading to the following savings and awards:

- Avoiding over $\$ 380,000$ in utility costs

- Reducing irrigation water use by 35\% (114 million gallons) since 1999.

- Achieving the D OE order 430.2A goal of 30\% reduction In BTU/ft 2

- Receiving the Federal Energy Management Program 2001 Energy Efficiency/ Energy Management Award

- Receiving the D OE-HQ 2001 Departmental Energy Management Award 
- Working with the State of Washington D epartment of Revenue Auditor to identify key characteristic of Battelle's and DOE's research that would allow it to qualify for tax credits on a number of previously unclaimed projects. To date, Battelle has received tax credits plus interest of over $\$ 1,330,000$.

Additional examples of operational improvements include:

- Becoming the first national laboratory to extend its specialized technical library resources to the public and private sectors. The library enhanced access for all customers by making its web-based catalog available via its external web page. Through the catalog, local, state, and regional customers at colleges and universities, local and state libraries, plus other national laboratories, can view information about the Library's collection of over 45,000 print and electronic books, standards, journals, and a growing number of technical reports.

- Enhancing the Electronic Records and Information Capture Architecture (ERICA) system to deliver improved capabilities for managing and reporting PNNL publications and associated information and to enable staff to access, analyze, and leverage the results of PNNL research activities.
- Implementing Electronic Records using the new TRIM (Total Records Information Management) server. The new system provides instant retrieval of records and eliminates the cost/ time required to retrieve boxes of records from storage.

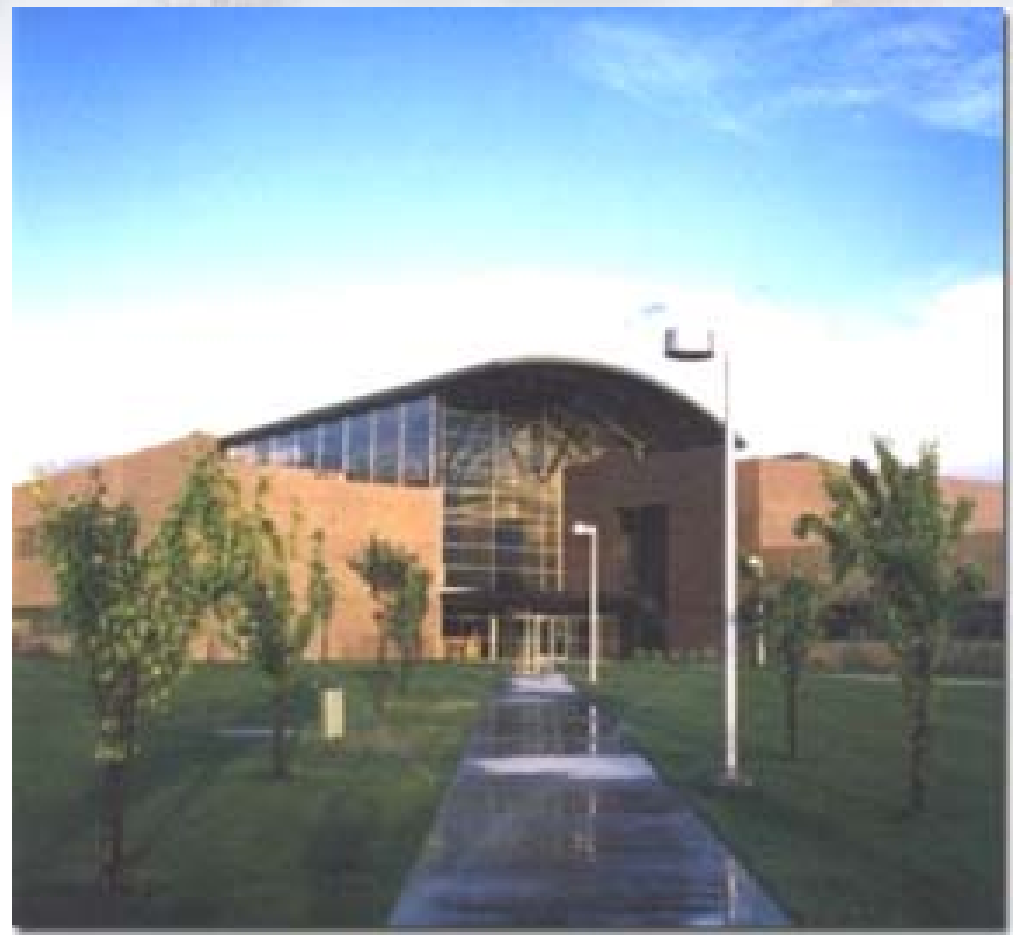

Figure 2.3.1b. In FY2002, the technical library became the first in the national laboratory system to extend its specialized resources to the public and private sectors. This is one example of the many operational improvements implemented by the Laboratory in FY2002. 


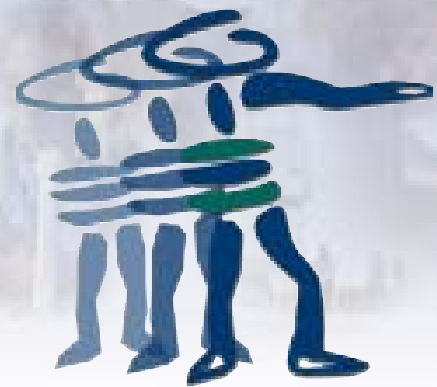

\section{Part I}

\section{Status of Performance Against Critical Outcomes 3.0 Leadership Excellence}

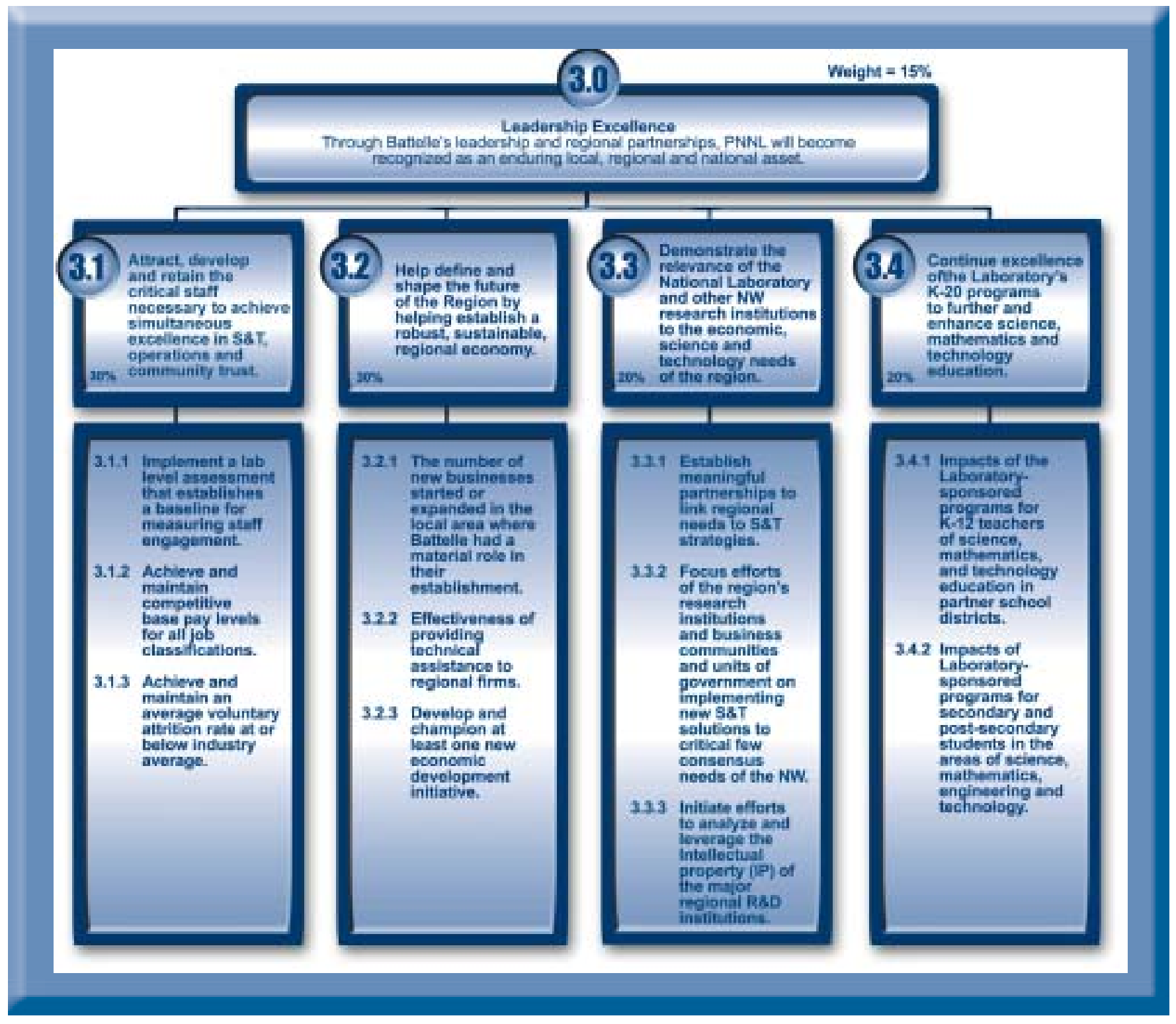




\section{Competitive Pay}

PNNL offers an attractive total compensation package comprised of a competitive base pay, comprehensive benefits, and flexible variable compensation programs. Providing competitive base pay is essential to attract and retain high-caliber staff that can achieve the level of excellence sought through DOE missions and critical outcomes. A compa-ratio (CR) is the compensation ratio that measures the relationship of a staff member's monthly base salary to the established job grade midpoint(s) of approved salary ranges. Ranges are reviewed annually for competitiveness and become effective January $1^{\text {st }}$. O ne can find a CR by dividing actual base salaries into grade midpoints, and then combining average grade CRs into a derived total lab CR.

PNNL achieved an average CR for all job families of 0.97 during all of FY 2002, which is within the optimum range of 0.95 to 1.05 (see Figure 3.1.1/ 3.1.2a). This is on track with our projected goal to achieve and maintain competitive base pay levels for all job classifications. Achieving this goal will help us stay competitive and move toward being the "employer of choice."

\section{Engaged Staff}

The Laboratory's strategic success depends on leaders' and managers' ability to attract, motivate, and retain staff members who are committed to the objectives of the organization. According to research conducted by the Gallup Organization, a high level of staff engagement is linked to higher productivity and safety, lower turnover, and customer satisfaction. Gallup defines an "engaged" employee as one who is in the right role, is consistently productive in that role, and is psychologically fully committed to bringing out the best efforts to bear to that role. In FY2002, we conducted a Workplace Engagement Assessment (WEA) with two goals in mind: (1)better understand to what extent our staff are engaged in the workplace, and use this information to evaluate how staff engagement impacts our business outcomes such as productivity, profitability, and customer satisfaction

(2)build a stronger workplace where staff can grow and develop in their careers and where talents and strengths of front-line managers are fully developed and deployed.

In FY2002, PNNL fulfilled all four performance requirements related to measuring staff engagement. Specifically,

- Over $95 \%$ of all managers who received a workplace engagement survey attended a Q 12 manager orientation.

- Each scorecard has been compared to industry "Best in Class." Best in Class is defined as any workgroup that scores in the $75^{\text {th }}$ percentile of $G$ allup's database. Thirty-three percent of PNNL workgroups were rated best in class by their staff (see Figure 3.1.1/ 3.1.2b).

- PNNL completed an analysis to identify internal top performing workgroups.

- D uring the $4^{\text {th }}$ quarter, PNNL conducted focus groups with those internal top-performing workgroups to determine specific best practice strategies that can be shared with the rest of the organization.

In FY2003, the Lab will complete its second workplace engagement survey and will continue to build on the results from the analysis of the best in class workgroups. "Best Practice" strategies will continue to be analyzed and shared throughout the Lab.

In addition, PNNL will examine the internal correlation between workgroups' productivity and high engagement scores. 


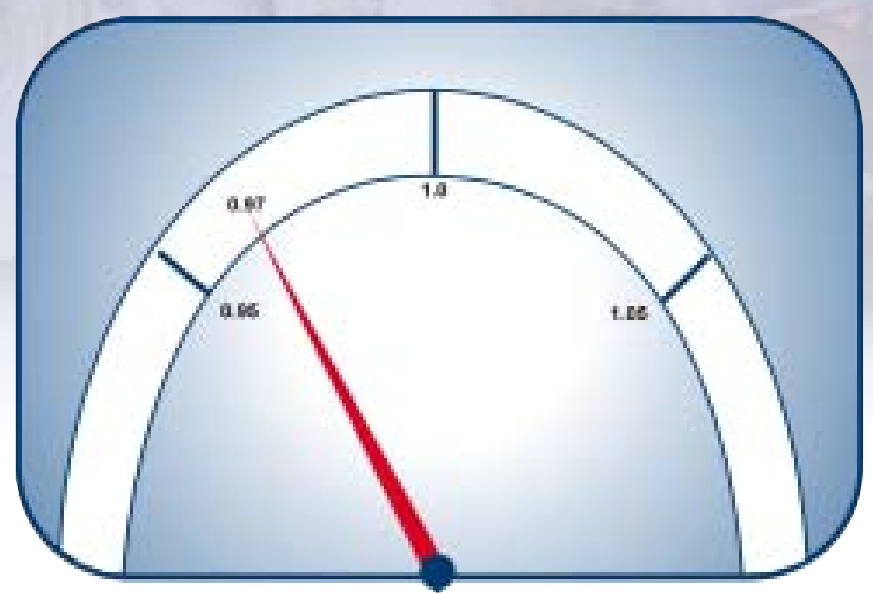

Figure 3.1.1/3.1.2a. PNNL is able to maintain its compa-ratios within the industry-average range of $0.95-1.05$

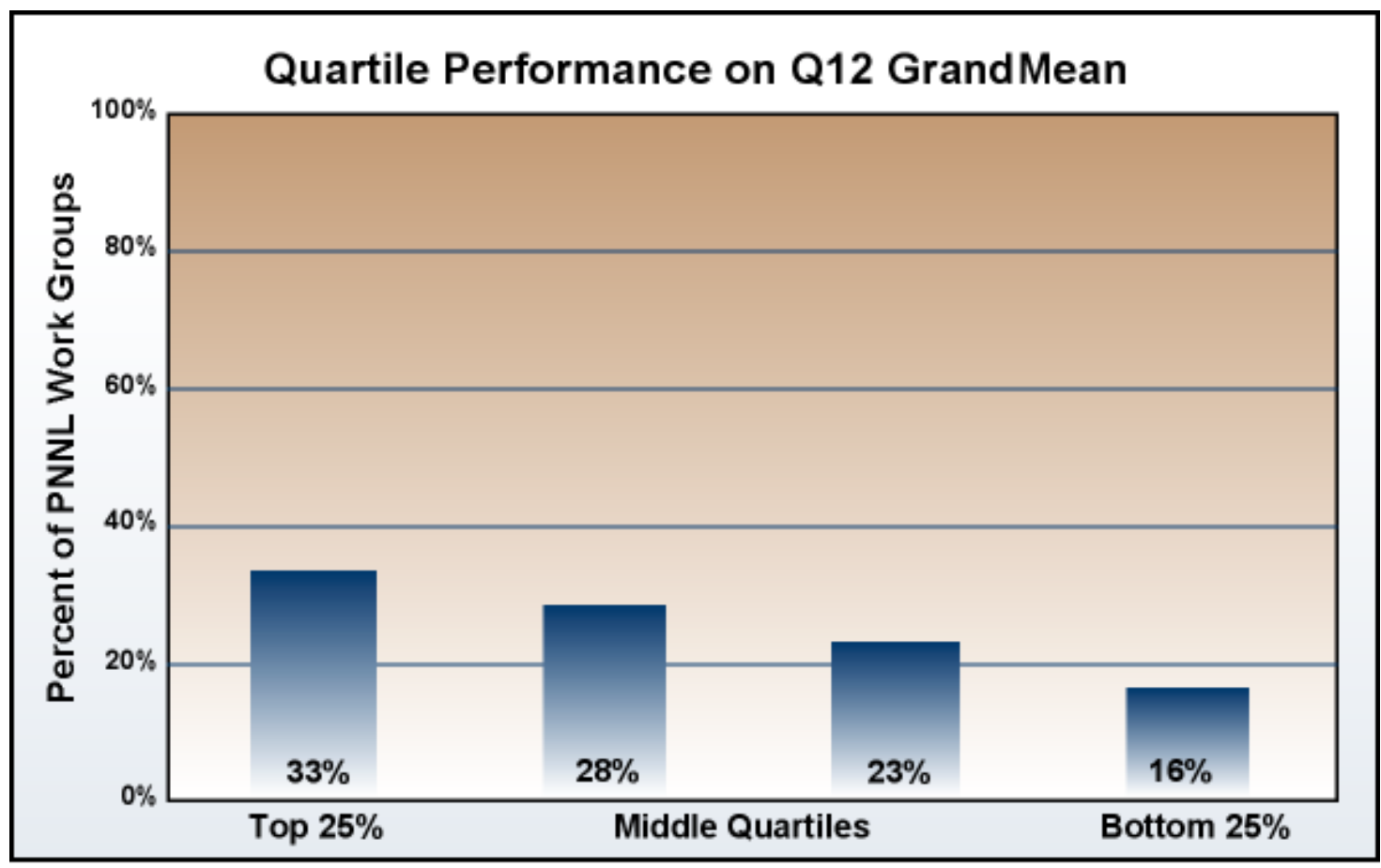

Figure 3.1.1/3.1.2b. One-third of PNNL's workgroups are in Gallup's Best Practice group, which is defined as the top $25 \%$ ( $75^{\text {th }}$ percentile). 

first-class facilities and equipment, and engaged workgroups make people who come to PNNL want to stay.

Human Resources continually monitors the rate at which staff are leaving the Lab voluntarily (called the voluntary separation rate, or VSR), and evaluates the VSR against industry norms to ensure that it is not adversely impacting the Lab. In FY2002, PNNL achieved a VSR of $5.5 \%$, which is well below the industry average of $7.6 \%$ for the same timeframe (see Figure 3.1.3). The increase in the VSR from FY2001 to FY2002 is due to inclusion of limited-term employees in our data set. Many factors contribute to PNNL's low VSR.

\section{Growth Opportunities}

PNNL provides opportunities and resources necessary for staff to perform quality work and continue to be challenged in their chosen fields. PNNL fosters an environment that provides access to technical and non-technical training and development opportunities. Some specific examples include:

- Management Skills D evelopment Program (MSDP) - This program is part of an overall strategy for achieving PNNL's vision of developing outstanding managers. Well-equipped managers can more effectively enable staff to achieve individual and organizational goals. The MSD P is a three-year program designed to enhance the participants' knowledge, skills, and abilities to manage and develop staff. The core curriculum of the MSDP provides participants with an opportunity to learn basic management principles and skills, become familiar with BMI and PNNL strategies and business objectives, and network with their peers across the Laboratory.

- M entoring Program - The Laboratory's Mentoring Program offers assistance to staff members in expanding or enhancing their careers and professional development. The program provides the framework for designing a mentoring relationship through the development of a written mentoring agreement. It involves the deliberate pairing of a more skilled and experienced person with a lesser skilled or experienced person and establishes goals.
- Invitation to E x œllenœ (ITE ) - G etting to Know PN N L This program is designed to help new staff become more fully integrated into the organization during their first year of employment and better understand the Laboratory's overall culture, work environment, and operations. It also provides opportunities for new staff to meet peers and coworkers, as well as members of the leadership team, management, and senior staff.

\section{Salary and Benefits}

PNNL has competitive salaries, excellent benefits, and a flexible work environment that enables us to attract and retain high-caliber staff. A robust recruiting and retention toolkit enables us to attract, retain, and enhance technical, support, and leadership capabilities. O ur Benefits package is ranked high compared to Fortune 500 companies. A flexible total compensation strategy allows us to incent and reward excellent performance of individuals and teams. O ur flexible work environment allows staff to customize their working hours to best suit their needs.

\section{Facilities and Equipment}

PNNL's facilities and equipment are first-class, and our employees enjoy the experience of our close-knit, campus environment. We have almost two million square feet of facilities and equipment valued at more than one-half billion dollars. In addition, our User Housing Facility (UHF) makes it easier for visiting scientists, students, or researchers to visit the Lab for extended periods of time.

O ur employees have the materials and equipment they need to succeed in doing quality work. Some of our equipment is one-of-a-kind. This past year, PNNL acquired a 900-megahertz Nuclear Magnetic Resonance (NMR) spectrometer. The most powerful and largest spectrometer of its type ever built, it weighs 16 tons and contains $180+$ miles of specially formulated superconducting wire. 


\section{High Levels of Engagement}

The results of our Gallup Organization $\mathrm{Q}^{12}{ }^{\mathrm{Tm}}$ survey show that PNNL's overall performance in employee engagement falls into the $59^{\text {th }}$ percentile. This excellent rating means that our employees are more engaged than $41 \%$ of the other companies that are rated by The $\mathrm{G}$ allup O rganization. High levels of engagement correlate to high levels of staff retention.

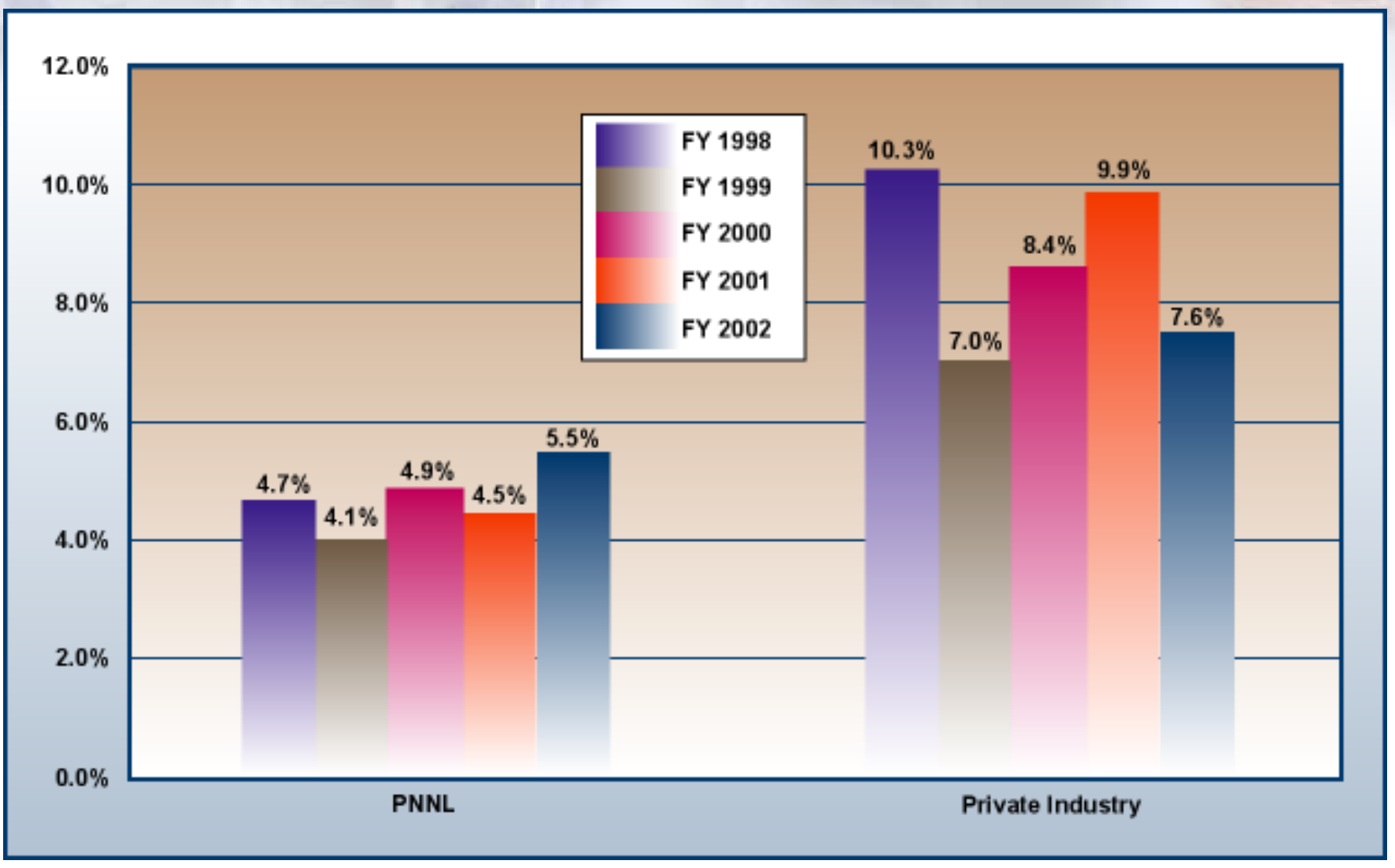

Figure 3.1.3. PNNL Voluntary Separations Rate (VSR) continues to be well below industry norms. 


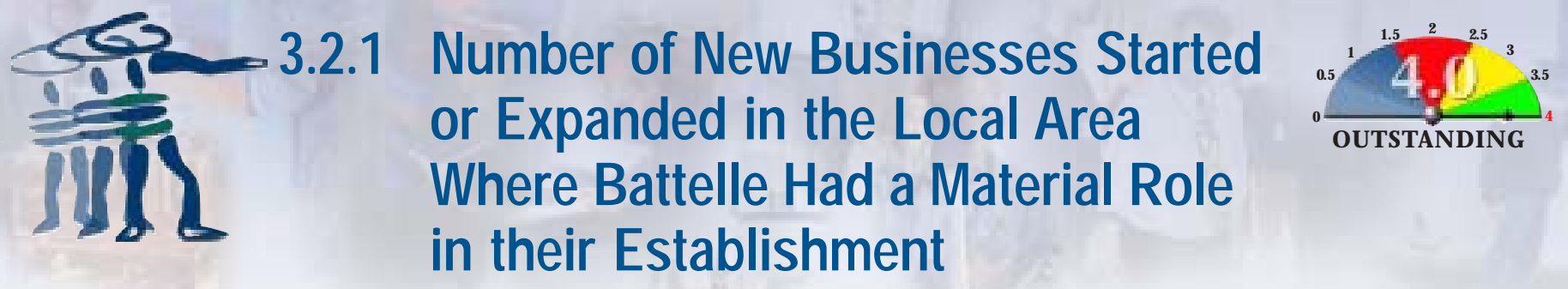

\section{In FY2002, PNNL technology, technological assistance, and entrepreneurial support played a significant part in the establishment, relocation, and expansion of six local businesses.}

Table 3.2.1. PNNL assistance helped start and expand six local companies in FY2002, meeting out FY2002 goal.

\begin{tabular}{|c|c|c|c|c|}
\hline Company Helped & $\begin{array}{l}\text { Startup of } \\
\text { Expansion }\end{array}$ & Type of Business & $\begin{array}{l}\text { Nature of PNNL } \\
\text { Assistance }\end{array}$ & Impact \\
\hline $\begin{array}{l}\text { Meier Enterprises, Inc. } \\
\text { (Kennewick, WA) } \\
\text { www.meierinc.com }\end{array}$ & Expansion & $\begin{array}{l}\text { Engineering, design, } \\
\text { consulting, IT and Web } \\
\text { services }\end{array}$ & $\begin{array}{l}\text { Technology assistance for } \\
\text { a new Web-based } \\
\text { educational product, } \\
\text { Learning to Write }\end{array}$ & $\begin{array}{l}\text { PNNL usability evaluation and } \\
\text { recommendations contributed to } \\
\text { improved product design }\end{array}$ \\
\hline $\begin{array}{l}\text { Visual Editor Consultants } \\
\text { (Richland, WA) } \\
\text { www.mcnpvised.com }\end{array}$ & Startup & $\begin{array}{l}\text { Offers a visualization } \\
\text { software tool, called the } \\
\text { Visual Editor, for a } \\
\text { computer code widely } \\
\text { used in the nuclear } \\
\text { industry; offers training } \\
\text { on Visual Editor }\end{array}$ & $\begin{array}{l}\text { 1. Entrepreneurial Leave } \\
\text { of Absence Program } \\
\text { 2. SBIR Alerting Service, } \\
\text { a PNNL-developed } \\
\text { information tool } \\
\text { 3. Equipment rental from } \\
\text { PNNL }\end{array}$ & $\begin{array}{l}\text { - Leave of absence enabled the } \\
\text { founder to start the company } \\
\text { - Founder won a } \$ 64,000 \text { DOE grant } \\
\text { he found in the SBIR Alerting } \\
\text { Service } \\
\text { - Battelle-excessed computers and } \\
\text { monitors are used in training }\end{array}$ \\
\hline $\begin{array}{l}\text { RainTech International } \\
\text { Corp. (Richland, WA) } \\
\text { www.electropurification.com }\end{array}$ & Relocation & $\begin{array}{l}\text { Water purification } \\
\text { technology/ equipment }\end{array}$ & $\begin{array}{l}\text { 1. Recruitment to the } \\
\text { Tri-Cites } \\
\text { 2.Entreneruaial assistance }\end{array}$ & $\begin{array}{l}\text { - Company moved from LaGrande, } \\
\text { Oregon in part to access PNNL } \\
\text { expertise } \\
\text { - Business planning assistance led to } \\
\text { investor presentations to begin } \\
\text { raising equity capital } \\
\text { - WSU MBA students are conducting } \\
\text { a PNNL-supported marketing study } \\
\text { that will help RainTech identify and } \\
\text { reach customers }\end{array}$ \\
\hline $\begin{array}{l}\text { Belhaven Applied } \\
\text { Technologies } \\
\text { (Kennewick, WA) } \\
\text { www.belhaven.com/ } \\
\text { company.html }\end{array}$ & Expansion & $\begin{array}{l}\text { Custom-built equipment } \\
\text { and engineering services }\end{array}$ & $\begin{array}{l}\text { 1.Technology assistance } \\
\text { 2.License to PNNL } \\
\text { technology, "Lab in a Box" } \\
\text { 3.Leads for business } \\
\text { expansion }\end{array}$ & $\begin{array}{l}\text { - Belhaven now offers a new product } \\
\text { that analyzes engine oil before } \\
\text { problems occur } \\
\text { - Contract work with PNNL has } \\
\text { accounted for } 70 \% \text { of Belhaven's } \\
\text { income for the past } 2 \text { years }\end{array}$ \\
\hline $\begin{array}{l}\text { Surgical Implant } \\
\text { G eneration Network } \\
\text { (Richland, WA) } \\
\text { www.sign-post.org }\end{array}$ & $\begin{array}{l}\text { Startup and } \\
\text { expansion }\end{array}$ & $\begin{array}{l}\text { Orthopedic treatment of } \\
\text { fractures to economically } \\
\text { disadvantaged populations } \\
\text { worldwide }\end{array}$ & $\begin{array}{l}\text { 1.Technology assistance } \\
\text { for mechanical testing and } \\
\text { computer visualization } \\
\text { 2. Business contacts } \\
\text { 3. Permission from } \\
\text { commercial software } \\
\text { company for SIGN's free } \\
\text { use of visualization } \\
\text { software }\end{array}$ & $\begin{array}{l}\text { - Technology assistance contributed } \\
\text { to improved design of orthopedic } \\
\text { devices } \\
\text { - PNNL's "endorsement" helped } \\
\text { SIGN get a grant from a state } \\
\text { technology commercialization } \\
\text { organization } \\
\text { - Legal assistance, business contacts, } \\
\text { and humanitarian organization } \\
\text { contacts (e.g., Mercy Core) are } \\
\text { helping SIGN achieve its technical } \\
\text { and business goals }\end{array}$ \\
\hline $\begin{array}{l}\text { InStar Corporation } \\
\text { (Kennewick, WA) } \\
\text { www.instarcorp.com/ } \\
\text { index.html }\end{array}$ & Expansion & $\begin{array}{l}\text { Software for insurance } \\
\text { agency management }\end{array}$ & $\begin{array}{l}\text { 1. Entrepreneurial } \\
\text { assistance } \\
\text { 2. Attended PNNL } \\
\text {-sponsored "Rainmaking } \\
\text { in a Capital D rought" } \\
\text { workshop on raising } \\
\text { equity capital }\end{array}$ & $\begin{array}{l}\text { - Business strategy assistance and } \\
\text { facilitation of a stock ownership plan } \\
\text { have helped InStar increase revenues } \\
\text { and attract employees } \\
\text { - Introduction to potential investors, } \\
\text { advisors, and partners are positioning } \\
\text { InStar to expand its markets } \\
\text { and funding sources }\end{array}$ \\
\hline
\end{tabular}




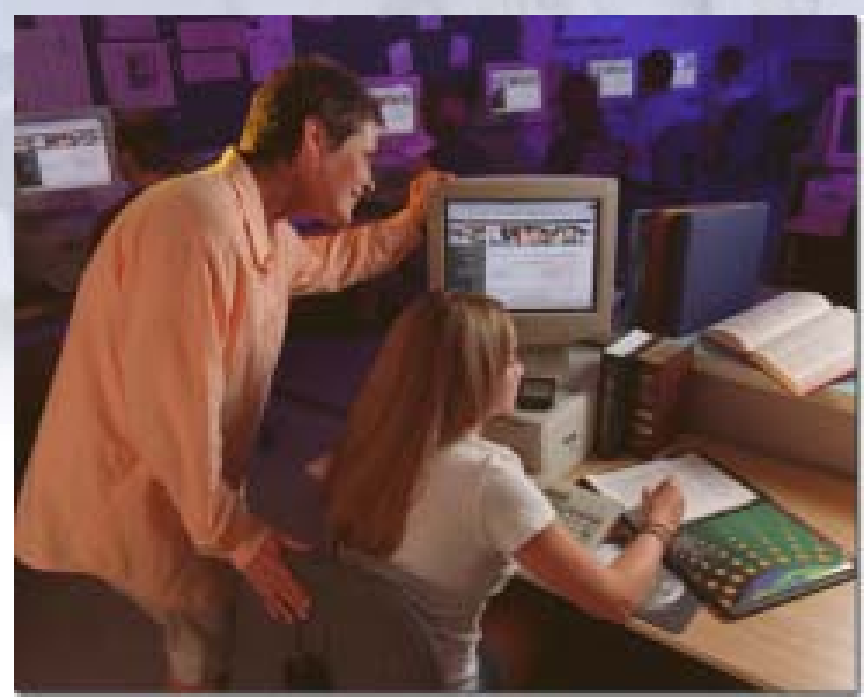

Figure 3.2.1a. Write on! Students are finding it easier to handle writing complexities with the Web-based Learning to Write ${ }^{\mathrm{TM}}$ software by Meier Enterprises, Inc., Kennewick. Teachers can add customized content and track student progress online. PNNL staff conducted a usability evaluation for the new software product and made recommendations on design, marketing, and quality.

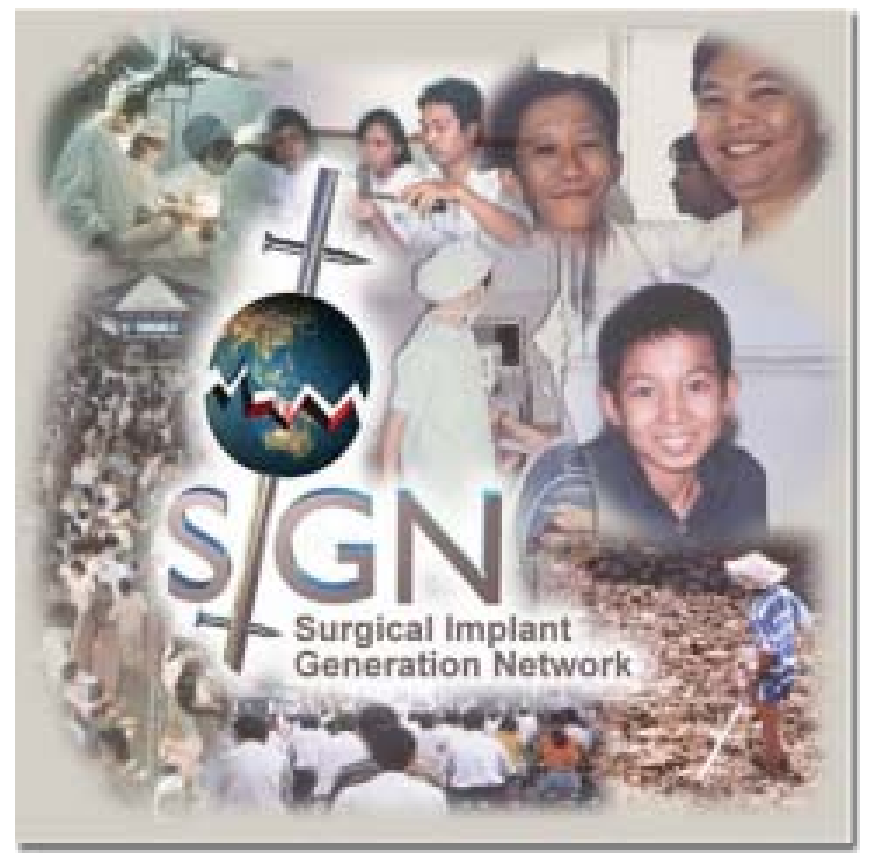

Figure 3.2.1b. SIGNs of life. The Surgical Implant Generation Network (SIGN), Richland, provides surgical implants and training to treat fractures in economically disadvantaged countries. PNNL provided technology assistance and business contacts to help the company get started and grow.

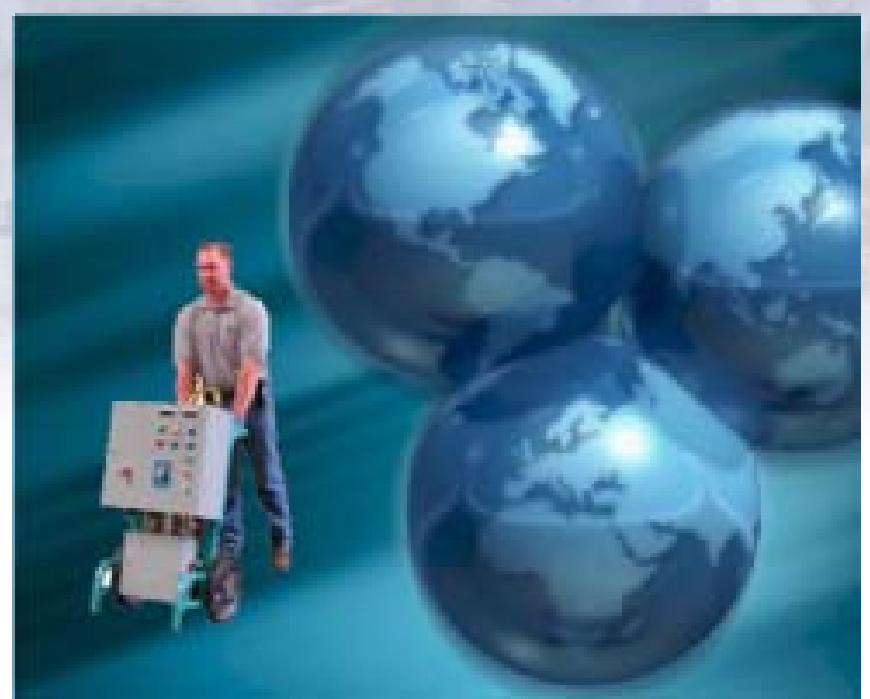

Figure 3.2.1c. Water wonder. RainTech International's electrical coagulation process removes contaminants such as heavy metals, bacteria, silicon, and oils from water without using chemicals, heat, ion resins, or membranes. PNNL helped recruit the company to locate in the Tri-Cities and is supporting business and entrepreneurial assistance to help it grow. 


\subsubsection{Effectiveness in Providing Technical Assistance to Regional Firms}

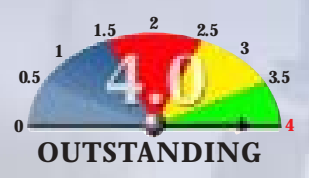

\section{In FY2002, PNNL's technology assistance to 52 firms in the Pacific Northwest earned 93\% satisfaction ratings from the recipients.}

Under the Technology Assistance Program, PNNL engineers and scientists offer technology assistance at no cost to qualifying commercial businesses. Firms can get up to five days of free assistance annually.

Examples of assistance are product development, materials testing, and resolution of technical problems.
In FY2002, PNNL's technology assistance to 52 firms in the Pacific Northwest earned 93\% satisfaction ratings from the recipients. The survey used a five-category scale, ranging from "very dissatisfied" to "very satisfied," with $93 \%$ of respondents stating that they were "satisfied" or "very satisfied." 
"Cost savings are realized with inclusion of Night ballast upgrades, Iighting improvements. Exhaust fan upgrades are being made to ... reduce power consumption by $50 \%$." - James Gaines, Severn Trent Labs

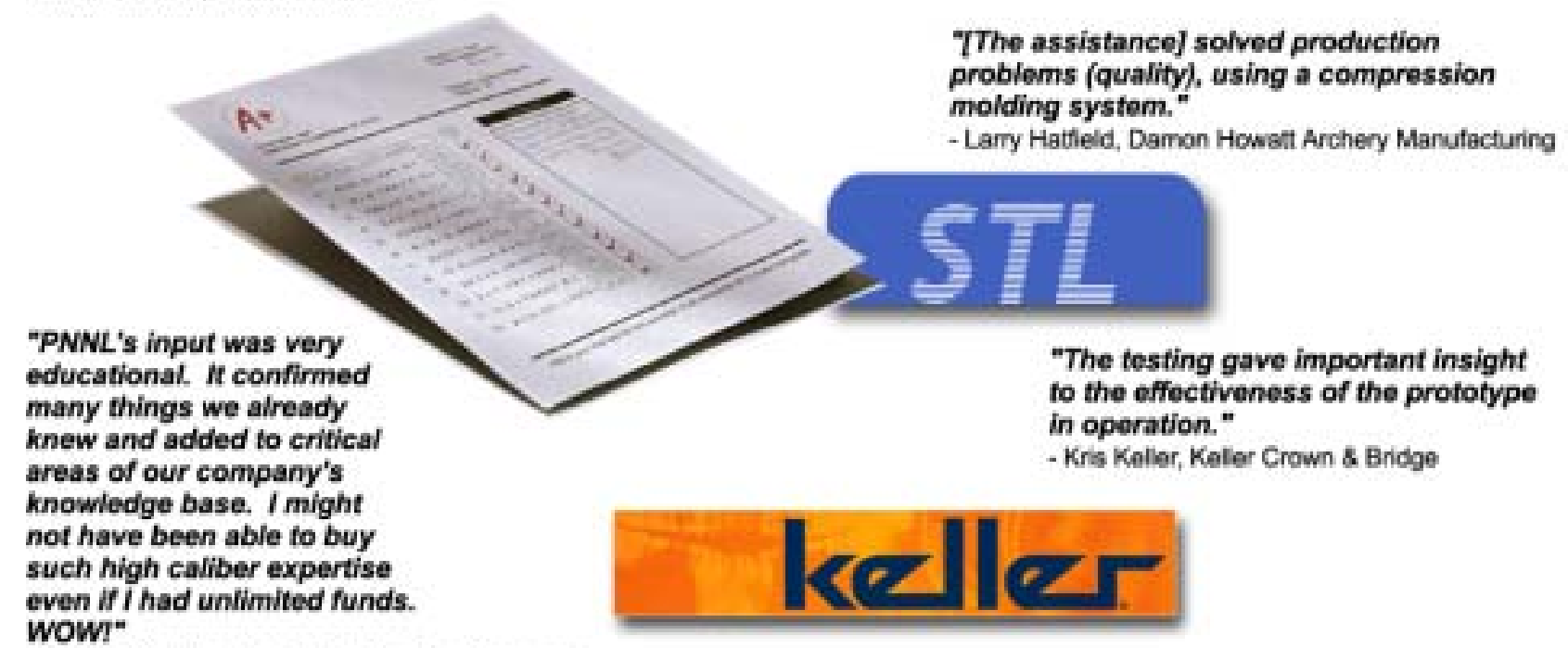

- Richard Schilling, National Informatics Compary

The assistance I received has been a great help in introducing my technology to the utility industry, to state regulators, and to legislators."

-Fred Beierie, Beierle Energy Associates

"The technical assistance allowed us access to Rattlesnake Mountain wind data and the meteorological site.

This onabled us to better understand the wind local regime for our proposed Maiden Wind Projoct noarby."

- Wiliam Damon, Washingion Winds

\section{We have been implementing design recommendations made from our PNNL-provided [assistance.] \\ - Erin Thomton, Mundo Communications Network}

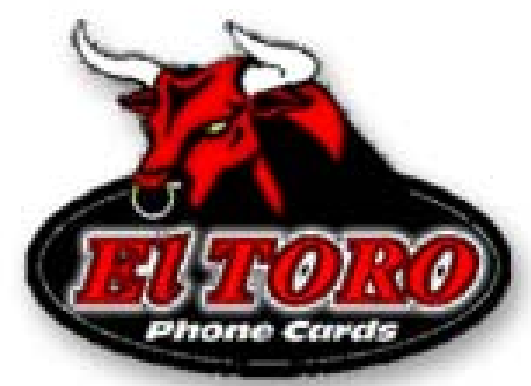

"[PNNL] provided technical analysis of data, provided assistance in setting up our data collection efforts, and other analysis that has led to several meteorological towers in place and collecting wind data throughout the Northwest and California. As a startup organization [Last Mile Co-Op], the assistance provided by PNNL was essential to our early success."

- Charles Dawsey, Benton Rural Electric Asscciation

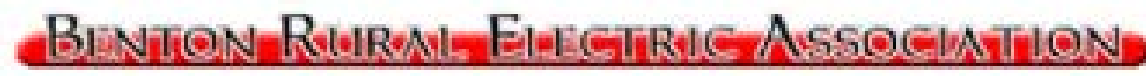

"[The assistance resulted in] a new product for lowering soll pH via irrigation water applications." - Robert Venable, Tri-Chem, Inc.

Figure 3.2.2. Regional companies confirm the value of PNNL technical assistance in FY2002. 


\subsubsection{Developing and Championing New Economic Development Initiatives}

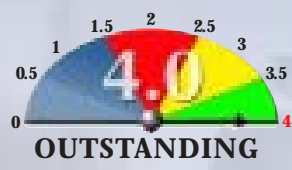

\section{In FY2002, PNNL helped fund and implement three new economic development initiatives designed to help small tech-based businesses find funding and attract key staff.}

\section{WaFAST program}

PNNL partnered with the Washington Technology Center and five other partners to launch the Washington State Federal and State Technology Partnership (WaFAST) Program. WaFAST helps Washington State small businesses and entrepreneurs compete for federal funding of technology research and product development under the Small Business Innovation Research (SBIR) Program. WaFAST provides information, regional conferences and mentoring groups, and direct assistance to people interested in this funding. PNNL helped write the proposal that led to WaFAST being funded by the U.S. Small Business Administration, helped lead the Pacific Northwest SBIR conference that WaFAST hosted, and publicized WaFAST events to Eastern Washington entrepreneurs. Figure 3.2.3a shows the WaFAST web site that describes the services offered.

\section{Tech Job Connection}

PNNL launched a new Web-based tool, Tech Job Connection, at http:/ / www.pnl.gov/ edo/ jobs.stm (Figure 3.2.3b). Tech Job Connection is a free online source of resumes and job postings for the Mid-Columbia Area of Washington and Oregon. It's a way to find qualified employees for tech companies that are within a 50-mile radius of the Tri-Cities, Washington, and that are not Hanford contractors. The underlying purpose is to make experienced, serial entrepreneurs from throughout the Northwest available to local technology-based firms. Anyone can browse the listings and contact people or companies of interest. Since the service began in February 2002, 40 people have listed their resumes and 10 jobs have been posted.

\section{Northwest Technology Investor Network}

PNNL, with the support of six Washington partner organizations, led the effort to launch a new Web-based tool: Northwest Technology Investor Network, at http:/ / www.pnl.gov/ edo/ technetwork.stm. It's an online forum that links investors and entrepreneurs in the high-tech sector (Figure 3.2.3c). Technology-based businesses and manufacturers from throughout the Northwest can post their business plans on the website, connecting them to a large network of accredited investors. Investors have one-stop access to quality business plans that will help them identify investment opportunities in the high-tech sector. To date, 12 Northwest organizations have become outreach partners of the Network, telling their members about the new resource.

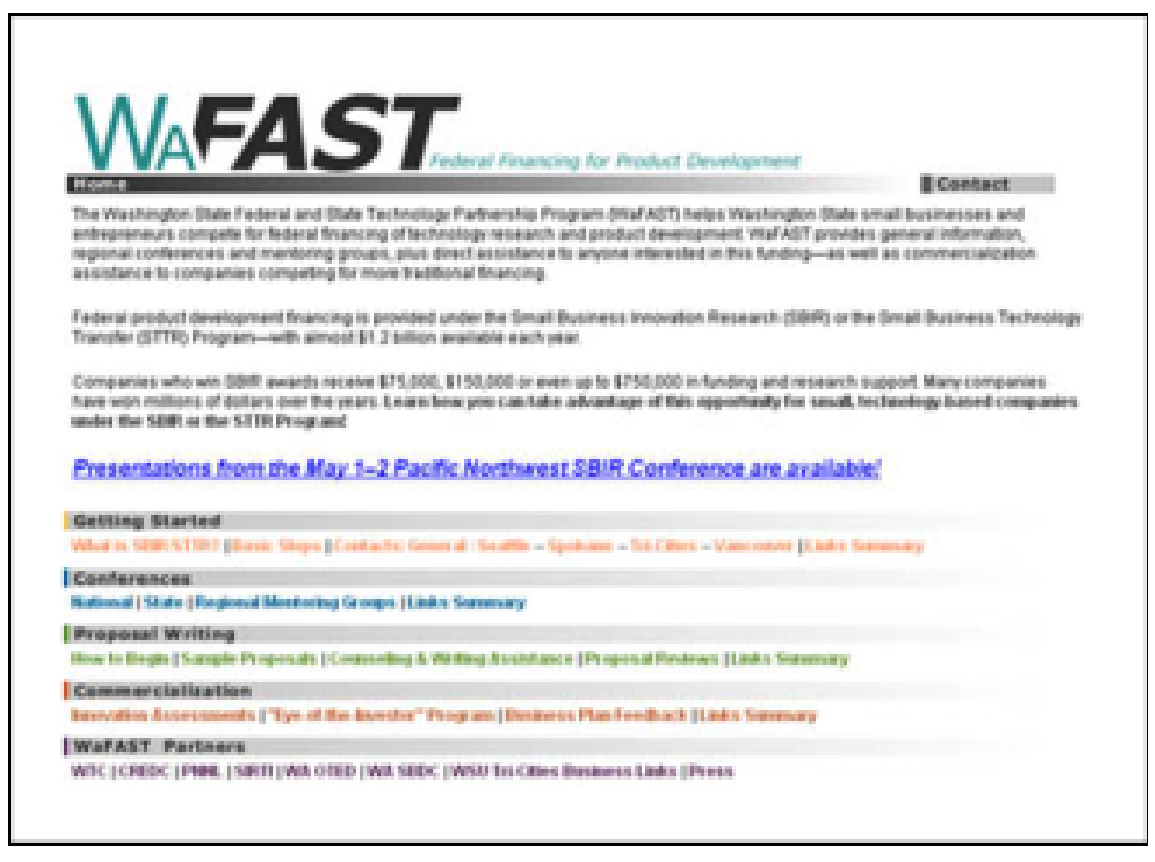

Figure 3.2.3a. Under a new program called WaFAST, PNNL participated with other partners in activities designed to increase the number and quality of proposals submitted by Washington small businesses for federal SBIR funding. 


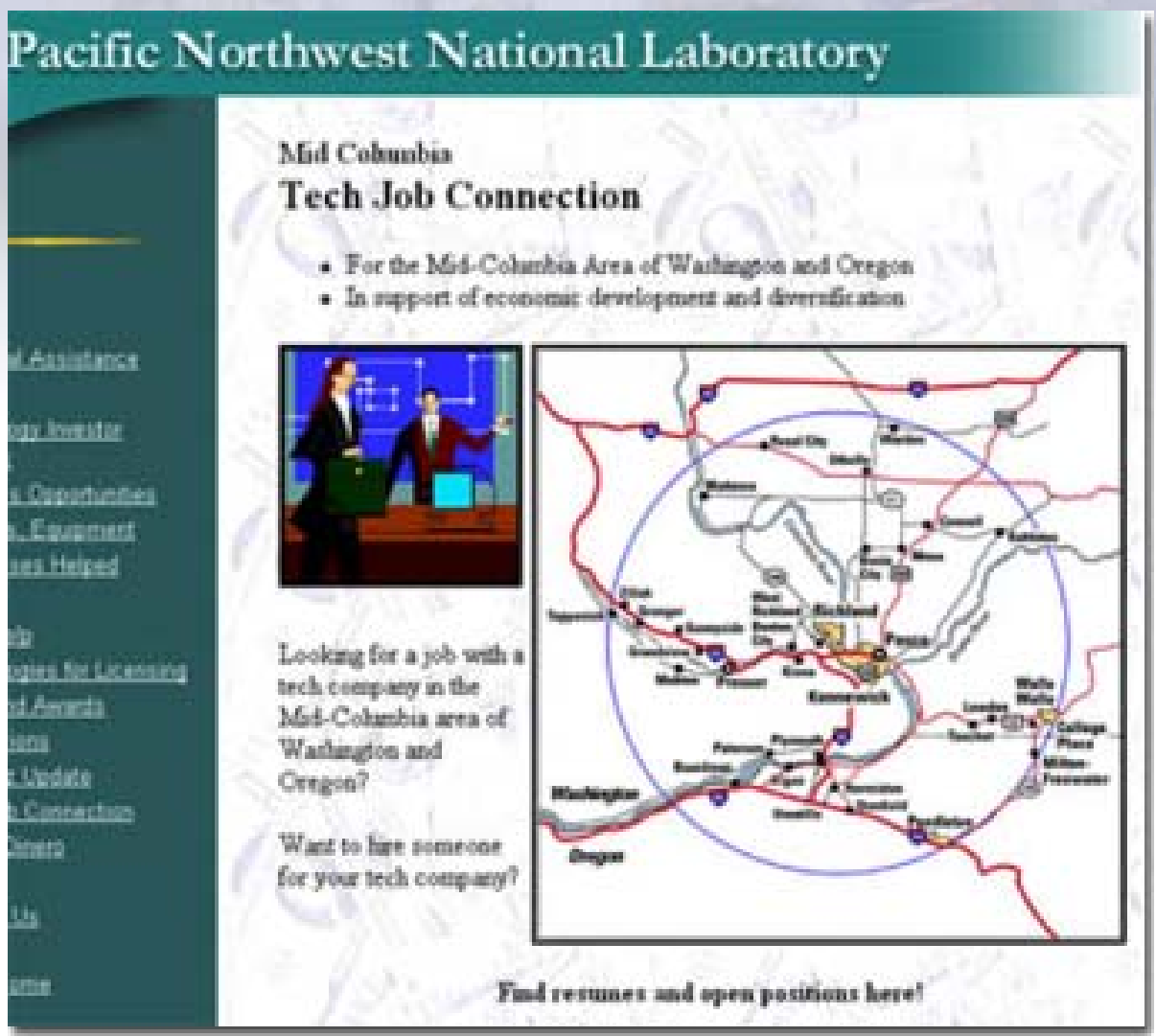

Figure 3.2.3b. The Tech Job Connection displays resumes and job postings for Mid-Columbia tech firms.

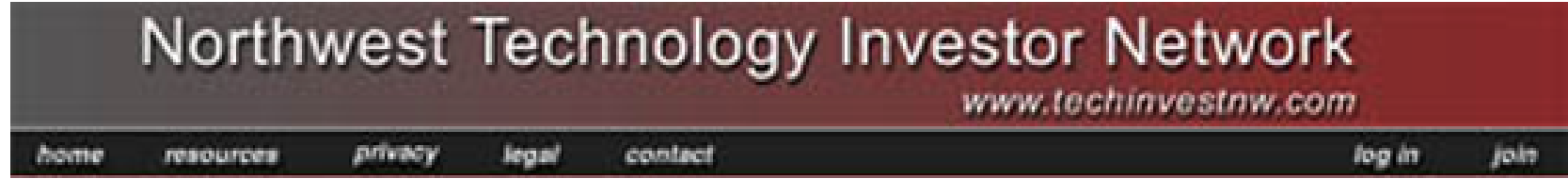

\section{bridging the gap between entrepreneurs and investors}
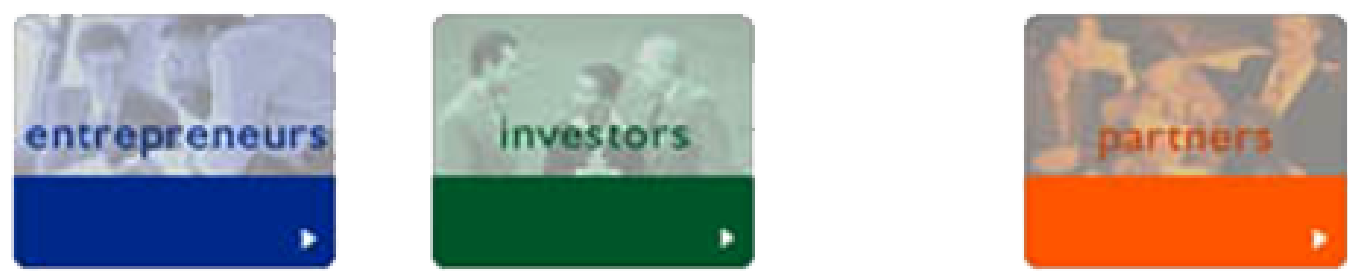

Figure 3.2.3c. PNNL launched a new Web-based tool, the Northwest Technology Investor Network, to link investors and entrepreneurs in high-tech sectors. 


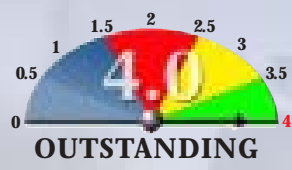
Economic, Science, and Technology Needs of the Region

\section{PNNL leads an effort focusing the S\&T of the region's major public R\&D institutions on solving the critical needs of the Northwest.}

\section{Establishing meaningful partnerships}

PNNL recently reconvened the Linking Regional Resources (LRR) group to identify needs held in common by the states of the Northwest that may, in part, be amenable to S\&T solutions available through the region's major research institutions. The members of the LRR group are Idaho National Energy and Engineering Laboratory, Pacific Northwest National Laboratory, The O regon University System (O regon State University and University of O regon), The Inland Northwest Research Alliance (Washington State University, Idaho State University, and University of Idaho), The O regon Health and Sciences University, and University of Washington

O ther organizations including the Washington Technology Center, Senator Murray's office, and Senator Cantwell's office are included in the LRR group to provide input on regional needs and represent their perspective on market interests.

\section{Identifying Regional Needs}

The first step in this process was to identify a set of critical needs that may be amenable to science and technology solutions. A draft list of needs was first prepared from the needs identified by the Offices of Science and Technology in Washington and Idaho. A consensus-driven process was then pursued to add specificity to these needs by working with the members of the LRR and others representing governmental and non-governmental organizations in the Northwest. The consensus-driven process has resulted in targeting needs related to (1) the generation, transmission and distribution of energy; (2) the use of remote sensing and other technologies to better manage the region's water resources and provide for its security; and (3) the promotion of the region's strong bio-technology capabilities among new and existing firms in this industry.
The LRR is now focusing on these common needs of the three states by finding technologies and technical resources within the states' multiple research entities that, if made commercially available, would both address those needs and stimulate new business and economic activity in the Northwest.

\section{Using new methods for identifying and implementing S\&T solutions}

The group agreed to adopt the following process for finding and implementing S\&T solutions. Intellectual property (in the form of patents) was harvested from the US Patent and Trademark Office (USPTO) or D erwent, (an online data acquisition tool), for each of NW entities. Over 800 patents issued between 1995 and 2001 were loaded into a PNNL developed data visualization and analysis tool called Starlight. Starlight indicates "clusters" of like technology based on the patent abstracts, titles, and claims. The IP from each institution was coded to allow analyses determining what technology clusters were represented by each institution.

O nce bundles of technologies were identified, the group agreed to form subgroups with technology and business representatives from the participating institutions. These subgroups will work with industrial partners and trade organizations to move the technology from research to a marketable product or process. At present, the LRR is working with the Washington Technology Center (WTC). The WTC has recently formed the Northwest Energy Technology Collaboration to, among other things; work with the firms of the energy industry in the Northwest to identify their needs for and interests in innovations in energy science and technology. The institutions of the LRR will use these needs to identify individual or bundled technologies and technical resources that might address these needs. When these resources are found, the WTC will take the responsibility for bringing the appropriate institutions together with the firms seeking technology solutions. 


\section{Additional Partnerships}

Additional partnerships were developed or strengthened during FY2002, significantly enhancing PNNL's ability to address specific capability needs.

- Northwest Water Research Partnership - A Memorandum of Understanding was finalized in May between PNNL; Idaho Water Resources Research Institute; University of Idaho; Oregon State University; O regon Center for Water \& Environmental Sustainability \& Institute for Natural Resources; and State of Washington Water Research Center to productively pursue "Research and Technology D evelopment Contributing to Optimal Water Resources Utilization for Fish and Wildlife Recovery in the Pacific Northwest."

- 0 regon Universities System/ 0 regon Health \& Sciences University Collaborative Working Group - D uring FY2002, PNNL continued to engage in and strengthen this cooperative relationship for research and educational activities among O regon's higher education institutions (E astern O regon University, O regon Institute of Technology, O regon State University, Portland State University, Southern O regon University, University of O regon,
Western O regon University, and the O regon Health and Science University).

- Micro-products Breakthrough Institute - Oregon State University and the Pacific Northwest Traditional Laboratory have teamed to establish the Microproducts Breakthrough Institute in order to accelerate the development and application of science and technology to transform chemical, energy and biological systems by employing micro and mesoscale processes.

- PNNL, with the Washington Technology Center, led the development of the Northwest Energy Technology Collaborative, a regional organization to accelerate the emergence and growth of the energy technology industry in the Pacific Northwest. The Collaborative is a joint, voluntary effort of business, government, non profit, industry and educational institutions in the Pacific Northwest who share the common goal to position the Pacific Northwest region of the United States as a recognized leader for innovative research, education and product development for energy technology markets around the world.

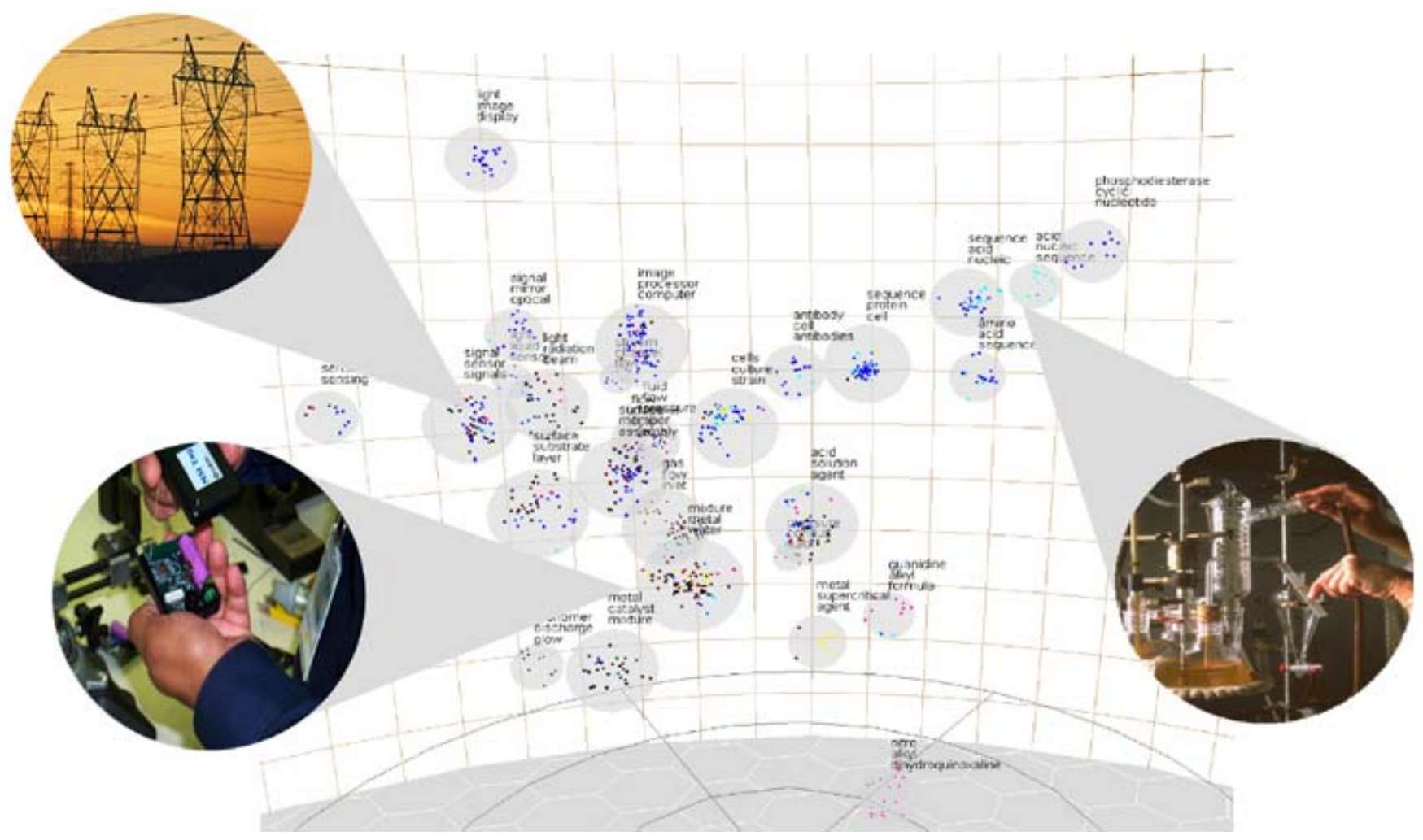

Figure 3.3.1/3.3.2. PNNL identifies bundles of IP from NW Research Institutions and is exploring commercial opportunities to meet regional needs. 


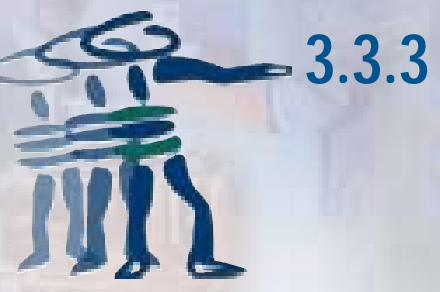

Relevance of PNNL and Other
National Research Institutions to the
Economic, Science, and Technology
Needs of the Region

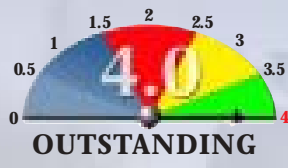

wh

\begin{abstract}
The Linking Regional Resources (LRR) group has found four technologies from the region's cooperating research institutions that could be used to address regional needs.
\end{abstract}

\section{Discovering technology bundles}

The LRR Group agreed to focus its initial effort on identifying bundles of technologies that might address regional energy needs. Initially, patents from all entities were analyzed. Early analysis indicated that none of the region's major public research and development institutions are patenting significant numbers of inventions related to energy generation, distribution, or transmission. Based on this, the Linking Regional Resources (LRR) group is finding other ways to identify appropriate technologies and technical resources. First, each institution took on the responsibility to identify and contact its staff who are working in this area and to probe for new innovations and discoveries. Secondly, PNNL gathered data on the technical publications produced by these institutions between 1995 and 2001. We assembled and fed into Starlight, a PNNL-developed data visualization and analysis tool, abstracts on approximately 68,000 refereed articles from our regional institutions, and initiated a search for articles (and the names of authors) related to energy. We are currently using both methods to generate lists of potential technologies and technical resources that will address the needs and interests of the region's energy firms.

In addition to its continued focus on energy, the LRR group requested that we also try to find technologies and bundles from the participating research and development institutions that can address regional needs in remote sensing (image acquisition and processing), the development of bio-based products, and the management of water resources. The group also agreed that it would like to find data from the Starlight analyses of both the patent and technical literature databases that support a broad regional claim to pre-eminence in funded research in the field of human biotechnology. Using key words that defined the needs, we were able to identify patents from across the research base that could potentially impact these needs.

After reviewing the results, the team agreed to make finding water resource management technologies and technical resources their priority. Several specific patents were identified as a starting point for investigation. The four patents shown in Table 3.3.3 are representative of that group. The LRR group is establishing a subgroup to investigate the best mechanism for taking this bundle of water treatment technologies forward.

The LRR group also agreed to pursue, as its second priority, the investigation of the biotechnology area in an effort to develop a more coordinated and collaborative $R \& D$ base and to gain broader recognition of the collective capability of the Northwest. Analysis similar to that performed on the water treatment technologies is underway.

\section{Analyzing technology bundles}

To uncover a more thorough representation of the full capabilities of the institutions and to reflect the most recent additions to their technologies and technical resources, PNNL is adding still more data to the Starlight data analysis and visualization tool. New databases under development include identifying all current grants and contracts in place at each institution and all US PTO patent applications applied for by these institutions. The data from the grants and contracts in force at these institutions will permit us to identify not the research done in the past but the research underway today. Data on patent applications will allow us to find inventions that are typically less than a year old. Because patents are often not filed before a year from the date of invention and typically take between two and three years before they issue, data from this source often is at least three years out of date. 


\section{Continuing Efforts}

The LRR group plans to bring the appropriate commercialization resources together to move the identified bundles of technologies forward. This will be done in part with the use of the Entrepreneurial Centers at the University of Washington and the University of O regon.

Table 3.3.3. These four similar water resource technologies come from three distinctly different institutions.

\begin{tabular}{|lccc|}
\multicolumn{1}{|c}{ Patent Title } & Patent \# (US) & Inventors & Entity \\
\hline $\begin{array}{l}\text { Surface funtionalized mesoporous } \\
\text { material and method of making same }\end{array}$ & $6,326,326$ & Feng, Liu, Fryxell & PNNL \\
$\begin{array}{l}\text { Method for removing contaminants from } \\
\text { water using membrane filtration in } \\
\text { combination with particle adsorption to }\end{array}$ & $6,113,792$ & Benjamin, Chang & UW \\
$\begin{array}{l}\text { reduce fouling } \\
\begin{array}{l}\text { Method for detecting organic } \\
\text { contaminants in water supplies }\end{array}\end{array}$ & $5,942,440$ & Dooley, Barrier, Buttner & INEEL \\
$\begin{array}{l}\text { Removing contaminants from water using } \\
\text { iron oxide coated mineral having olivine } \\
\text { structure }\end{array}$ & $5,911,882$ & Benjamin, Chang, McMeen & UW \\
\hline
\end{tabular}



Math Teachers and Students

\section{For the 3rd straight year, surveys confirm that PNNL enhanced science education by exposing both teachers and students to research at the Laboratory.}

\section{Survey Results Illustrate Program Effectiveness}

Two FY 2002 surveys, measuring 1) the impact of Laboratory-sponsored programs for K-12 teachers; and 2) the impact of Laboratory-sponsored programs for secondary and post secondary students, form part of a broad set of evidence that serves to illustrate the overall effectiveness of Science \& Engineering Education at the Laboratory.

Two cohorts of teachers in the Partnership for Arid Lands Stewardship (PALS) Teacher Project and one cohort of "teachers in training" in the D OE Pre-Service Teacher (PST) Project rated their experience as O utstanding. Teachers participating in the Teacher Research Participation (TRP) Program rated it Excellent. In each case, the survey participants rated development of their scientific content knowledge and new skills, as well as transferability of this content and skills to the classroom. O verall, more than $88 \%$ of the 62 participants in these programs gave them $\mathrm{O}$ utstanding ratings.

Secondary and post-secondary students in the Community College Institute (CCI), Faculty and Student Teams (FaST) Program, Student Research Apprenticeship Program (SRAP), Student Research Intern (SRI) Program, Science Undergraduate Laboratory Internship (SULIformerly ERULF) Program, and Young Women in Science (YWiS) Program all rated their experience as O utstanding. Survey participants rated their research experience on science content knowledge, skill development, and impact on their choice to pursue a career in science and technology. Overall, more than $92 \%$ of the 112 participants in these programs gave them an O utstanding rating.

\section{FY2002 Science \& Engineering Education Highlights}

- Conducted a comprehensive outreach effort to approximately 250 universities to increase the visibility of DOE and PNNL science and engineering education programs for faculty and students.
- Convened an Academic Review Panel to help improve PNNL's student application procedures, including the design of a student selection tool that promises better student/ mentor matches.

- Expanded the Leadership and Assistance for Science Education Reform (LASER) Project, which now reaches over 166,000 students in Washington State.

- Enhanced the quality of mentoring students receive from PNNL staff by creating "toolkits" that better prepared staff and students for their appointments.

- Increased the minority participation in all PNNL Fellowships (e.g., D OE- and PNNL-sponsored Fellows) by 23\% (includes Asians) over FY 2001 and by almost 36\% over FY 2001 for students historically underrepresented in Science, Technology, Engineering and Mathematics (STEM).

- Conducted two new programs for underrepresented students, including a program for high-school age women and a DOE-FE sponsored program (Mickey Leland) for undergraduate/ graduate students from Historically Black Colleges and Universities (HBCUS), Hispanic students and students in tribal schools.

- Significantly improved the quality and quantity of student applications for PNNL's Student Research Apprenticeship Program (SRAP), a program that provides underrepresented high school students with summer research appointments to the Laboratory.

- Generated public recognition of DOE's and PNNL's efforts in science and engineering education by placing articles in seven publications (both electronic and print); making seventeen presentations at various conferences, meetings and symposia; and visiting various universities and national conferences for the purpose of communicating the breath of opportunities at PNNL to students and faculty.

For our primary client, the DOE Office of Science, Office of Workforce Development for Teachers and Scientists, Science \& Engineering Education: 
- Provided research appointments for students and faculty from 18 states designed to train the next generation of scientists and engineers and math/ science teachers. Ninety-six students and faculty participated in 81 PNNL research projects in FY 2002 as part of the CCI, FaST, PST and SULI undergraduate programs.

- Provided DOE-SC with high-quality on-line products and services, including ApplicationLink and EducationLink that enhanced the efforts of the O ffice of Workforce D evelopment for Teachers and Scientists. The resulting undergraduate science and engineering education programs support D OE's goal to "provide the scientific work force that ensures sucess of D O E 's science mission and supports our $\mathrm{N}$ ation's leadership in science and technology."

- Supported D OE's education and diversity goals by emphasizing the appointment of a diverse set of students (e.g., gender, ethnicity, and geographical distribution).

- Promoted national visibility of DOE-SC sponsored programs by conducting a widespread communication effort that included providing information at 27 separate recruiting venues (e.g. university visits, conferences, symposia) as well as direct contact with community college and university faculty.

- Continued its strong focus on enrichment programs to complement the Laboratory research experience, including technical seminars; sessions on science ethics, selecting a graduate school, and technical writing; tours, guest speakers and social events designed for students.
- Established an excellent program for initial orientation and follow-up for students and mentors, including online training, student and mentor information packets, signed agreement forms by both student and mentor before the appointments were finalized, completion of DOE program deliverables, and efforts to create an "alumni website" as a way to sustain contact with students.

- Leveraged DOE's resources using PNNL project funds to add five additional CCI appointments. Additionally, SULI was able to support the 48 students with DOE-SC providing 55\% of the costs and PNNL staff providing $45 \%$. This is an improvement over FY2001 where the split was $66 \%$ for D OE and 34\% for PNNL staff.

- Recruited NSF-supported participants into CCI (2) and FaST (9).

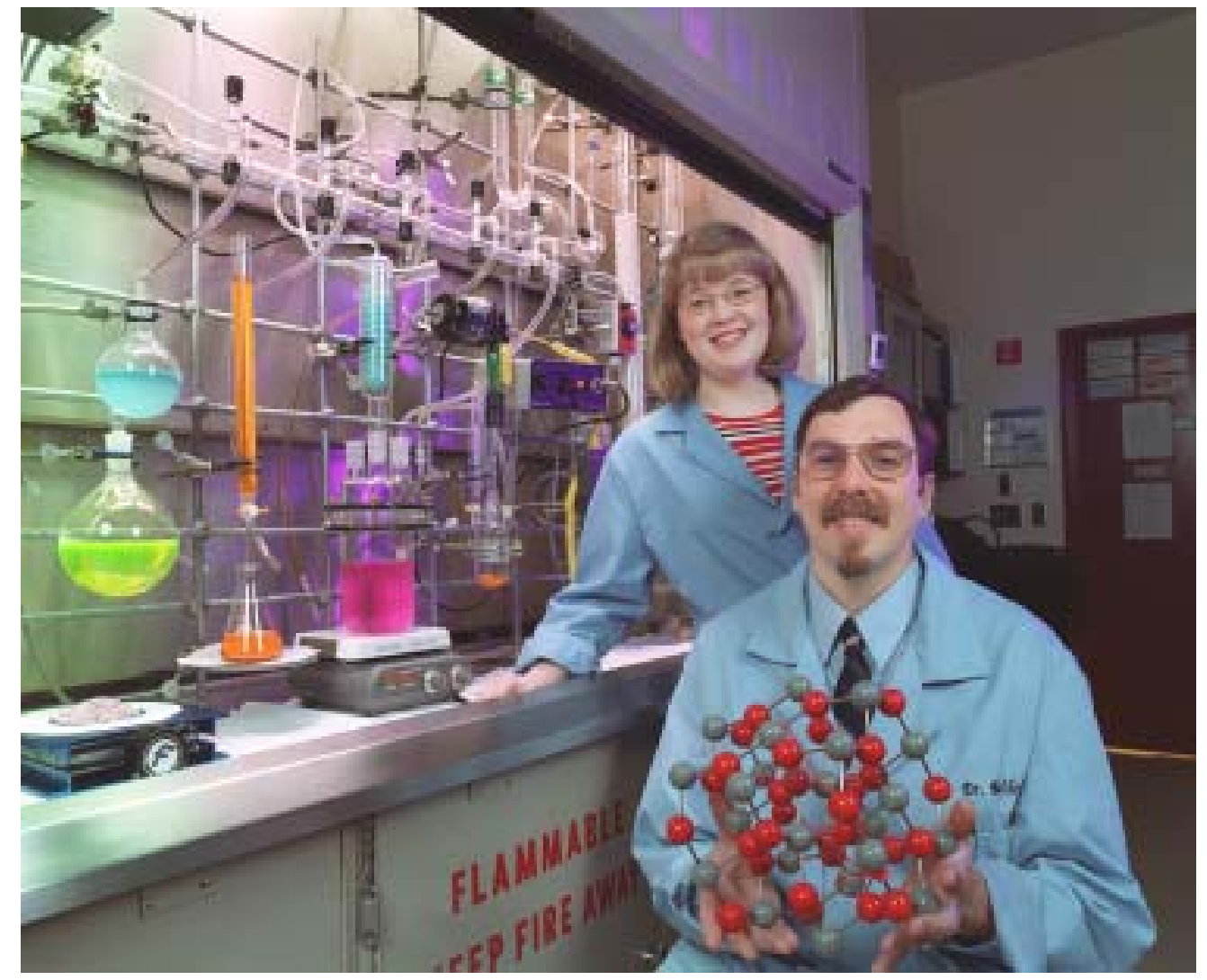

Figure 3.4.1/3.4.2. Heather Brown, a student at Columbia Basin College, is working with mentor Tim Hubler to learn how to synthesize and characterize materials for separating complex waste components and for developing smart material coatings for highly selective sensors. 


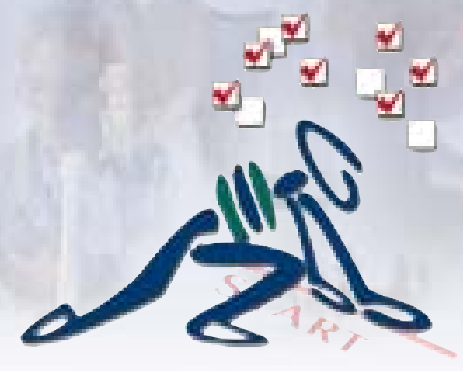

Part II

Readiness to Achieve PNNL 2010 Vision 


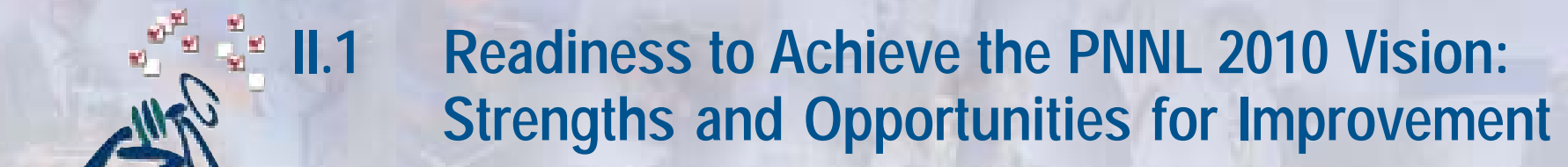

\section{PNNL's vision and strategy provide the focus for determining, through self-assessment, our strategic strengths and opportunities for improvement so we can prioritize them for action.}

PNNL uses a tool called the Laboratory Agenda (Figure II.la) to plan, communicate, and implement the vision and strategy for PNNL. The Laboratory Agenda is composed of five strategic objectives that support our vision. Underlying the objectives are key outcomes that define our aims, dictate our focus, and direct the actions of our business units (directorates). Key outcomes include high-priority strategic improvement opportunities as well as other outcomes needed to accomplish our strategic objectives. We then develop tactical action plans to accomplish the key outcomes and, ultimately, the strategic objectives of our vision. A subset of our key outcomes and current year actions are used as critical outcomes in our Performance Evaluation and Fee Agreement (PEFA).

PNNL's management council uses the self assessment process to assess strengths and opportunities for improving and executing the Laboratory Agenda (Figure II.lb). We decide what capabilities to retain, enhance, acquire, or phase out, and then adjust our action plans accordingly. This flexible process allows us to remain nimble in a world of rapidly changing priorities.

\section{PNNL's Strategic Objectives}

1. Science and technology excellence is central to PNNL's agenda. PNNL exists primarily to create new, scientific knowledge and then rapidly translate that knowledge into solutions for D OE, the nation, and the world.

2. Outstanding managers and staff are the key to our scientific accomplishments, stewardship of national resources, and operational innovations. Success in achieving our vision is directly tied to our ability to retain, attract, and develop outstanding staff and managers, and to create an environment where staff members can apply their talents and skills. Ultimately we strive to make PNNL the employer of choice by developing a highly engaged workforce- a workforce characterized by staff members who are challenged by their work and who are in roles that best suit their talents.

3. As a leader in research management and operations we provide the tools and infrastructure for modern research, remain good stewards of DOE's assets, and protect ourstaff, the public, and the environment. By optimizing Lab maintenance and operations to facilitate excellence in research we will be recognized as abenchmark for providing long-term stewardship as measured against other D OE national laboratories.

4. Deployment of highly beneficial technologies results in rapid translation of scientific discoveries into technologies that provide high value to DOE and substantial social and economic benefits to the region and the nation. We strive to increase the number and impact of our technology deployments and create innovative ways these deployments can benefit D OE and PNNL. By increasing available financial returns there is opportunity to reinvest and renew this national laboratory.

5. As a valued regional and community asset we help enengize the region's economy and advance the quality of life. We contribute to the region's prosperity through innovative initiatives and alliances with industry, government, universities, and other research and economic development organizations. 


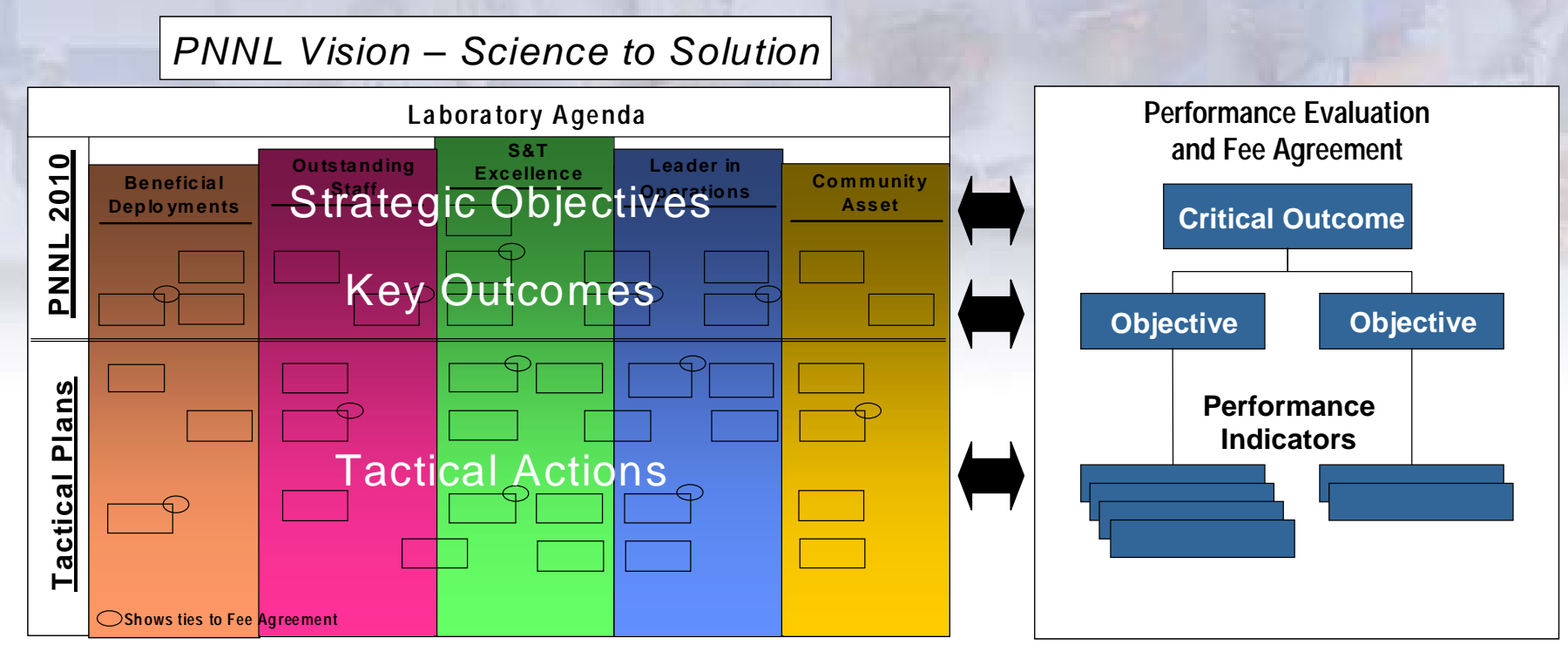

Figure II.1a. The Lab Agenda and PEFA are closely aligned at all levels.

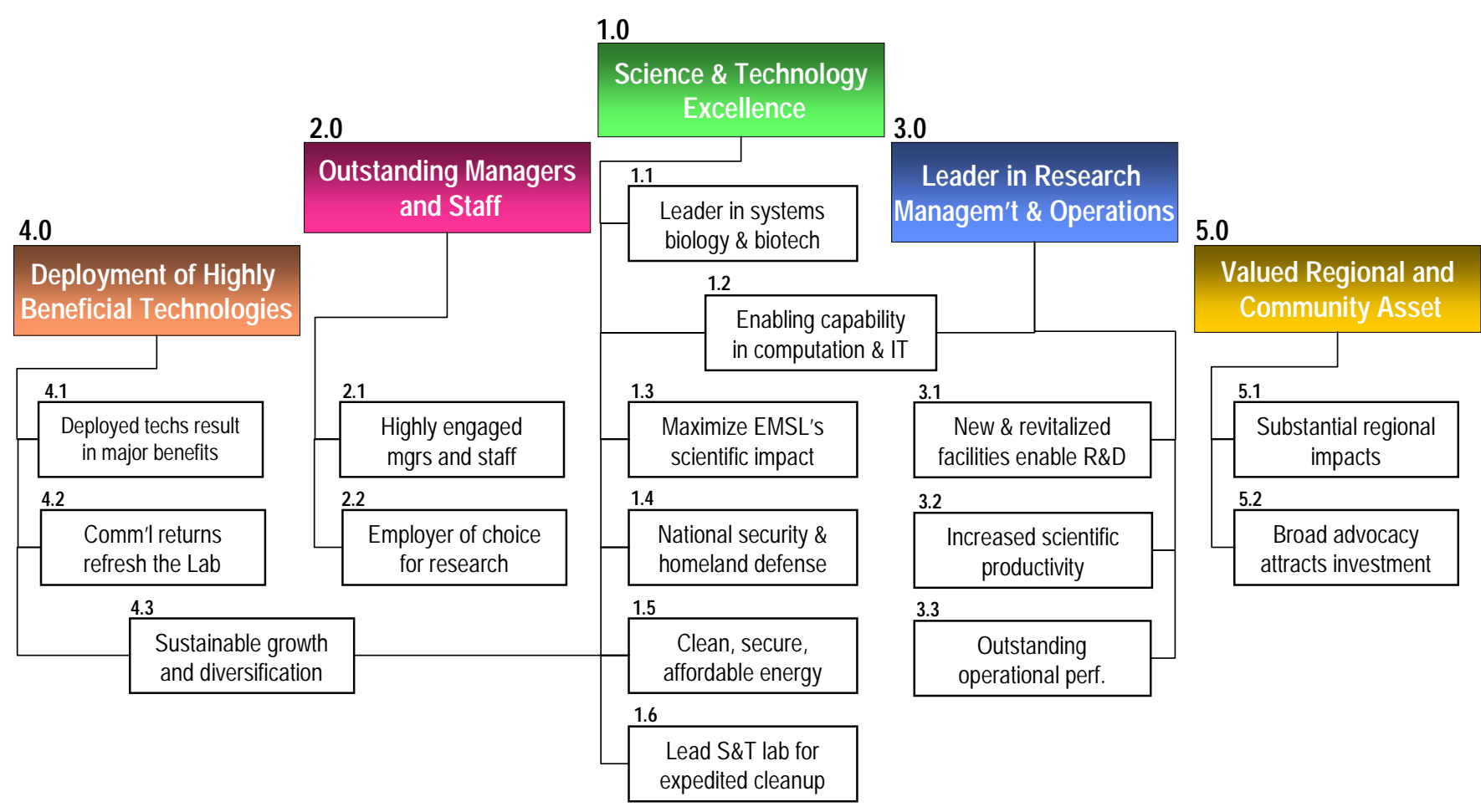

* Numbers denote sections in PNNL 2010 Action Plan

Figure II.1b. The five strategic objectives and key outcomes from the core of our PNNL 2010 strategy. 


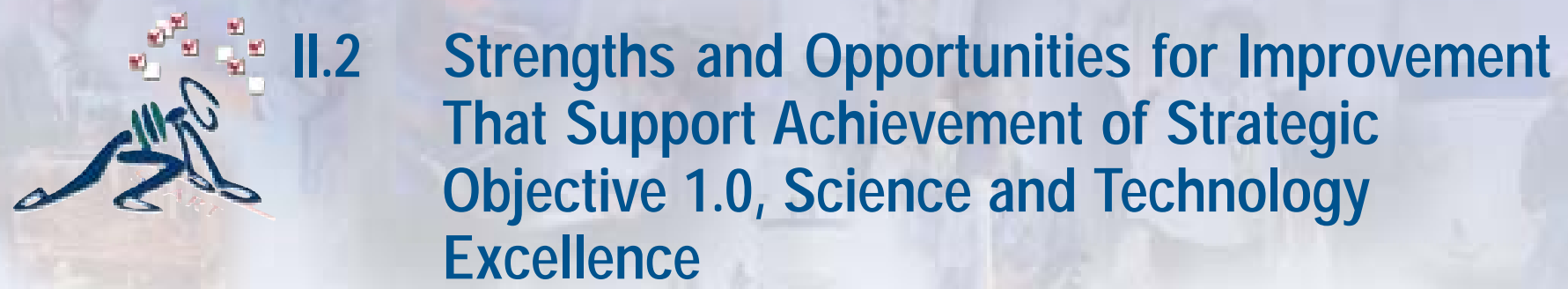

0 ur strengths in generating new capabilities and providing thought-leadership to national research agendas highlight the need to increase communication of the scientific contributions of our multi-program laboratory and gain consensus of the scientific community, advisory bodies, and/ or clients on strategies to meet our evolving infrastructure and capability needs.

\section{Strengths}

We are known for deliverying high-quality results that advance DOE missions. Our abilities to understand and conceive science and technology solutions that address our D OE missions and to consistently deliver high-quality results are key to our success. Here are just a few examples:

- The efforts of the PNNL-led Cleanup Constraints, and Challenges Team (C3T) resulted in the Hanford Site being awarded \$433M for Accelerated Clean-up.

- PNNL, in conjunction with the Savannah River Technology Center, developed a new formula for vitrifying radioactive waste that is likely to result in $\$ 1$ billion in life-cycle savings with lower operational risk.

- 0 ur leading role in proliferation prevention is helping to secure weapons grade materials throughout the Former Soviet Union and to prevent the transfer of nuclear, chemical, and biological warfare knowledge and technology to rogue nations that support terrorism.

Our ability to generate new science and technology capabilities supports our delivery of high-quality, relevant results to our customers. O ur ability to establish new capabilities is a notable strength. O ur capability development initiatives (see Sections 1.5.1-1.5.3) are based on D OE mission needs, comprehensively planned, and subjected to external peer review. We must absolutely maintain this ability to continue serving our D OE customers and other clients with break-through science and technology solutions. O ur new capabilities include:

- Increasing selectivity and sensitivity of sensors;
- Modeling and simulation of high-temperature materials and processes to support efforts such as solid-oxide fuel cell developments;

- Regional climate modeling;

- Procurement of the world's largest Linux-based supercomputer to use for systems biology, genomics, and proteomics research;

- Procurement of the world's largest and highest performing NMR to enable the study of molecules individually and in group interactions; and

- Analysis of massive data sets and disparate information.

We are invited by DOE and other clients to participate as thought-leaders in directing national research agendas. We have had notable impact on the national agenda in the following areas:

- integrated assessment of carbon on global climate change,

- transformation of energy systems, such as nationalscale grid systems,

- debt-for-nonproliferation concepts and approaches,

- elements of DOE's Genomes-to-Life program,

- advanced fuel cell development,

- high-performance computational chemistry, and

- information analytics.

Finally, our proactive commitment to peer review and validation of our scientific accomplishments ensures high-quality science and enhances our competitive success. (See Appendix A for further detail.) 


\section{Opportunities for Improvement}

We need to better clarify and more broadly communicate the extent of the value received by all of our customers from the multi-program nature of our work. PNNL has played substantial roles in all of D OE's missions for the last several years. The resulting synergies have led to the translation of several scientific discoveries to applications in multiple missions and translation of applications from one mission area to another. In addition, multiple programs enable us to support highly specialized capabilities and provide internal resources that can be used to refresh Lab capabilities broadly. $\mathrm{O}$ ur ability to support multiple missions is at risk if we are unable to generate active stewardship of our broad resources across D OE sponsors. We neeed to expand our efforts toward this goal.

\section{To provide the infrastructure and capabilities} needed for the future, we must improve our ability to anticipate the changing needs of DOE programs and gain consensus of the scientific community, advisory bodies, and/ or clients on our responses to those needs. Because of the leadingedge nature and broad benefit of many of facilities, instruments, and other capabilities that will be needed in the future, the Lab needs to engage D OE program managers, regional delegates, and experts in the scientific community early to build consensus for and effectively manage a response that ensures we have the facilities, staff, and equipment to support future mission needs. The need for agility in this area is leading us to explore new, more flexible funding options for facility and infrastructure needs with D O E. Internally, this highlights the need to improve our strategic infrastructure planning process by doing more comprehensive analysis and business case development to support change decisions.

The FY 2002 external review of our EMSL programs identified needed enhancements in the management of our user facility. This is described in detail in Section 1.1.5.

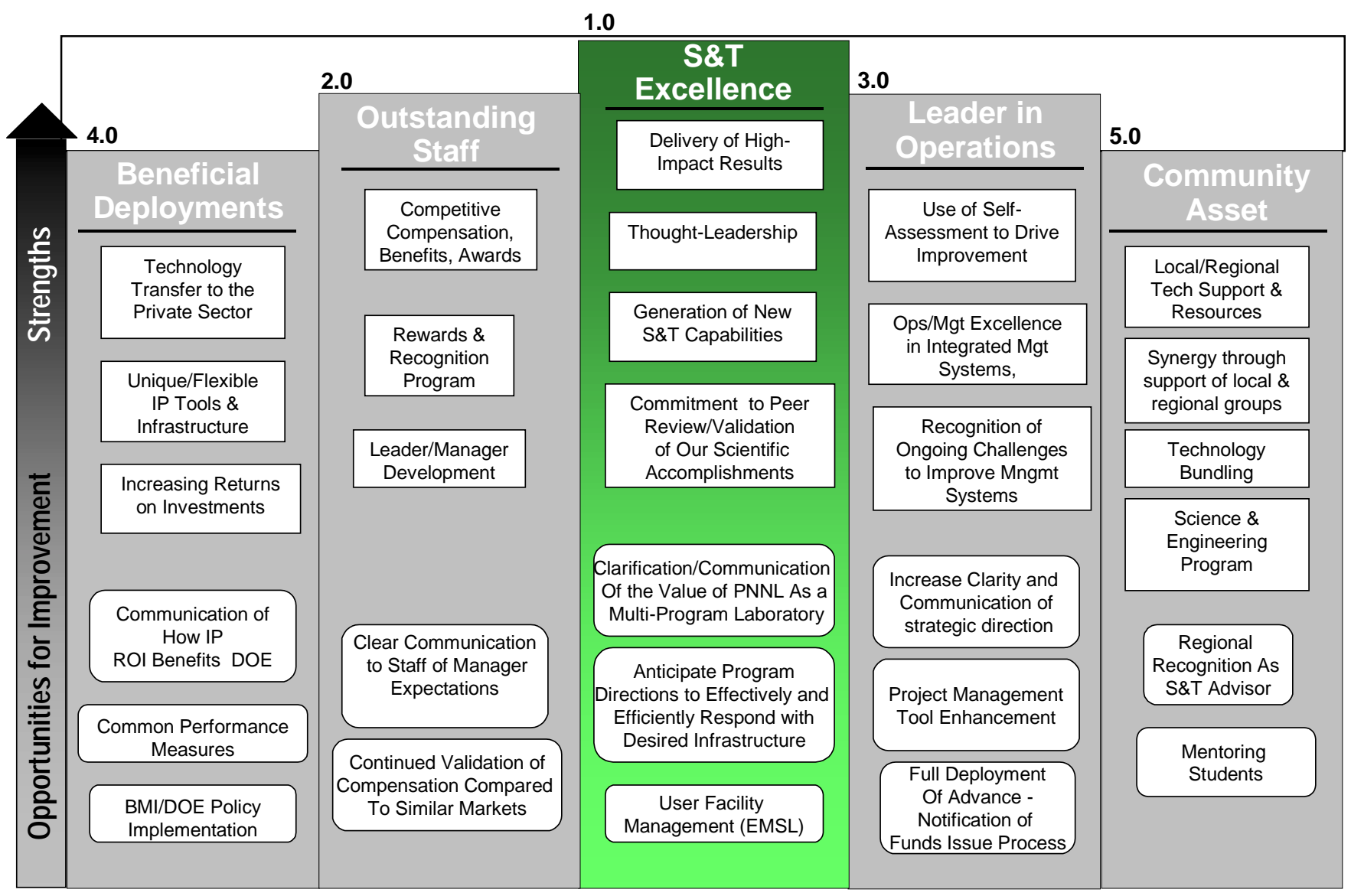

Figure II.2. Strategic strengths and opportunities for improvement identified through self-assessment: Strategic Objective 1.0, Science and Technology Excellence. 


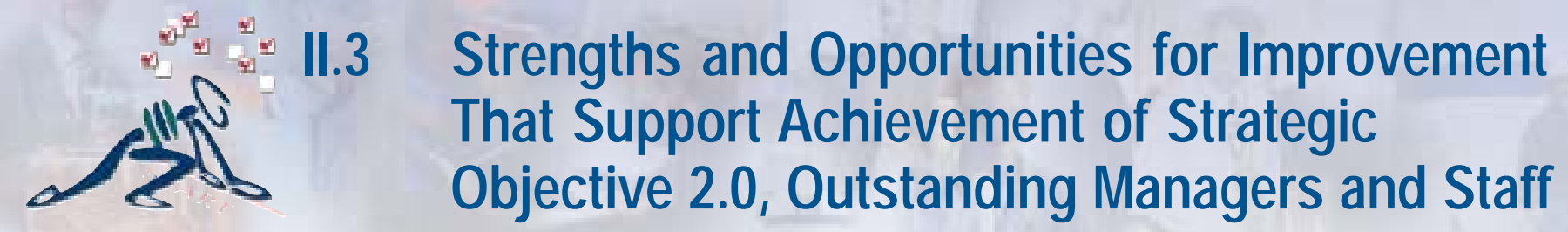

PNNL acknowledges the critical importance of our staff through our efforts to develop a highly engaged work force led by talented managers. This continued focus on staff engagement is necessary but we must also assure that staff are compensated at levels competitive with the market.

\section{Strengths}

We compensate our staff with competitive salaries and a high quality benefits package for all employees, and have increased our use of variable pay mechanisms to provide flexible compensation capabilities in addition to base pay (e.g., O utstanding Performance Awards, O utstanding Team Performance Awards). Consequently, our attrition rate is low compared to other similar organizations.

We have a strong Rewards and Recognition Program that includes O utstanding Performance Awards (OPAs) and several other rewards programs focused on Lab objectives (e.g., intellectual property, commercialization). We are developing a Rewards and Recognition philosophy for PNNL that will integrate existing Directorate-level programs under one umbrella and articulate objectives/ links to the overall Lab strategy and their applicability to all staff.

We focus energy on developing outstanding managers and staff. The commitment of our senior managers is demonstrated by their active support, participation, and implementation of leader/ manager development programs, including the Management Skills D evelopment Program, Workplace Engagement Assessment (Gallup), Leader/ manager strength finder assess- ments (best practices and talents), and the movement of R\&D / S\&T leaders across Battelle-managed labs for the benefit of staff and DOE.

\section{Opportunities for Improvement}

We must help staff better understand what is expected of them at work. As identified in our Gallup Q -12 survey evaluation, this is a key component of engaged, highly productive staff. Although we score relatively high compared to the Gallup R\&D $50^{\text {th }}$ percentile we desire continued improvement. This will require improved communication between staff and managers to clarify expectations; increased opportunities for staff to do what they do best and excel in their role; and regular feedback to staff on the progress they are making in their work. This should include clear communication about how staff fit into the mission of their directorate and the Laboratory.

We need to assure we have the right external markets identified and appropriate compensation validation to those markets completed for each of our disciplines. We continue to validate our salary data against established market survey and are always looking for new sources of benchmark data in the hightech industry. 


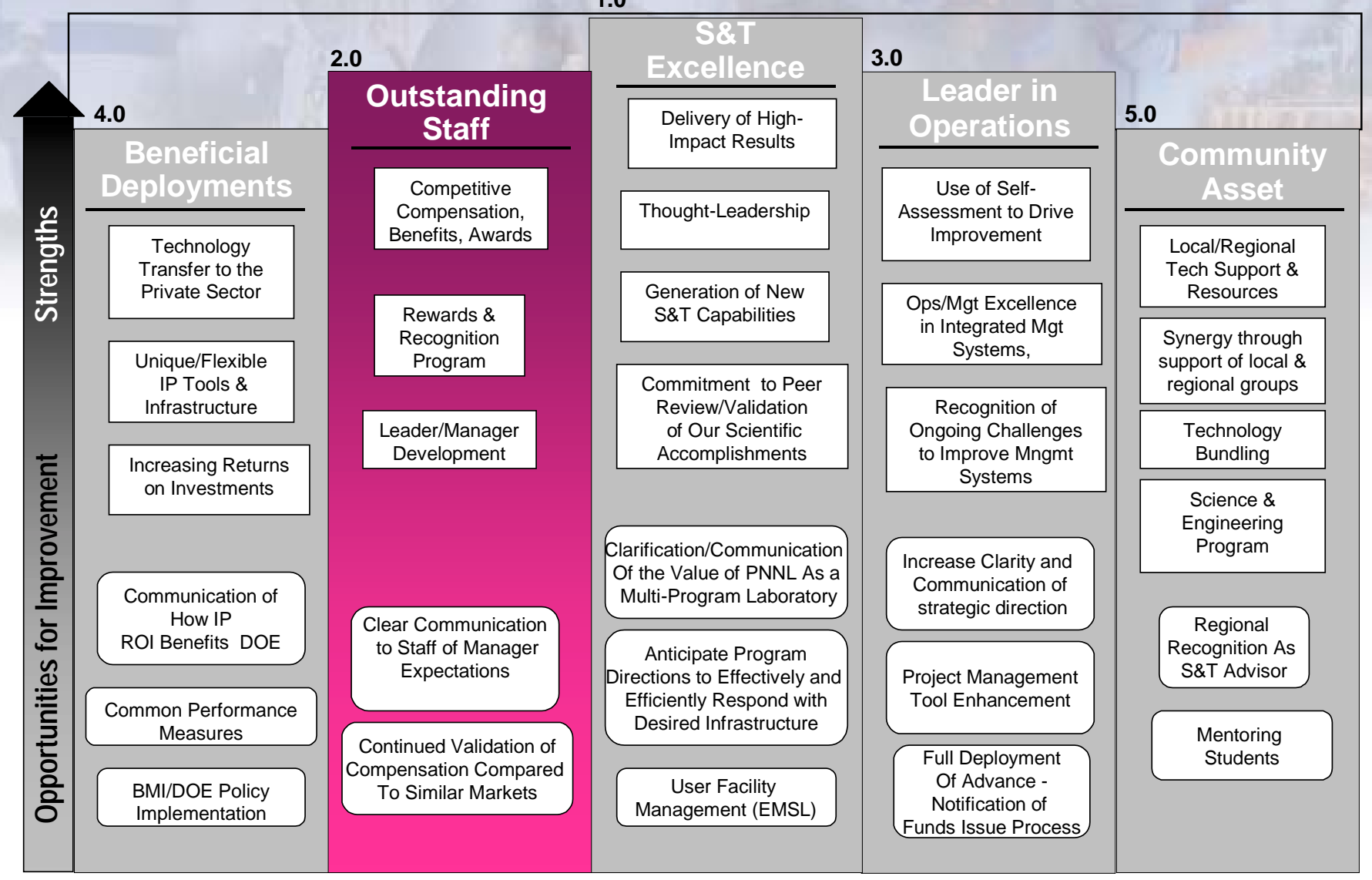

Figure II.3. Strategic strengths and opportunities for improvement identified through self-assessment: Strategic Objective 2.0, Outstanding Managers and Staff. 


\section{II.4 Strengths and Opportunities for Improvement That Support Achievement of Strategic Objective 3.0, Leader in R\&D Management and Operations}

Continual improvement of our management processes through self-assessment allows us to maintain high overall performance and to deal quickly and effectively with problems and challenges when they arise; however, we need to enhance tools our project managers use to assist in their delivery of products and services.

\section{Strengths}

\begin{abstract}
A hallmark of our successful R\&D operations management at the Laboratory is our philosophy and practice of self-assessment in search of continual improvement opportunities. We have been successful at building a culture that uses self-assessment to identify opportunities for improvement and then propose, develop, and implement strategies for optimizing existing or developing new or replacement processes. We use selfevaluation tools (lessons learned/ root cause analysis and corrective action, and risk-based reviews including internal audits) to identify issues and prevent their recurrence. Although we are not always successful (e.g., we did not fully incorporate all requirements of DOE Order 412.1, Work Authorization, into our policies and processes), we have established a culture that drives us to question and evaluate our approach to work and how we implement effective corrective actions.
\end{abstract}

We recognize an ongoing challenge exists to continue optimal rigor in assessments of our business operations and management systems and identify areas for improvement. We continually seek more mature measures to assess our processes, products, and services. Some of the ongoing challenges include:

- new contract implementation including defining our governance and assurance processes. This includes senior management more clearly defining and communicating strategic direction and acceptable levels of risk and determining a graded approach to management system certification;

- establishment of the RPL "nuclear island" concept in the 300 Area;

- rigorously protecting sensitive-unclassified information and export control;

- re-implementing the ROD (Record of D ecision) on D OE Order 412.1 and developing new Work Authorization rules (with RL/ AMT concurrence);

- revisiting our Material Control System requirements;
- completing an effectiveness assessment of the Integrated Operations System (IOPS) Hazards Analysis Initiative, and

- defining a long-term strategy for 300 Area facilities/ capabilities in support of the planning/ acquisition/ divestiture of needed capabilities, facilities, and equipment.

We have outstanding leadership and performance in the following key areas:

\section{Integrated Management Systems}

Examples of excellence in PNNL's integration of management systems include Environmental Management System; the Safety and Health Management System; the Integrated Safeguards and Security Management System; and the Integrated Planning and Assessment Management System.

\section{Environment, Safety, Health \& Quality (ESH\&Q)}

Indicators of PNNL's leadership and operational performance excellence include the recent recommendation for PNNL's registration to the ISO 14001 Environmental Management System standard, Voluntary Protection Program (VPP) G old Star status, the VPP Superior Star award, Integrated Safety Management (ISM) validation, our track record this year of no Reportable Occurrences of release to the environment, and our sustained high performance with regard to environmental events. The Lab consistently exceeds D O E's pollution prevention expectations for low-level waste, and continues to achieve sustained environmental compliance. This year, the Laboratory received the Department of Energy "National Pollution Prevention" award.

\section{Facility and Equipment Management}

The Lab continues to garner recognition as a leader in energy management, receiving Federal Energy Management Program (FEMP) Awards, a White House Closing the Circle Award, and a commendation for being a leader in green power purchases. Also, PNNL received the Inter- 
national Facility Management Association's (IFMA) coveted Golden Circles Award as outstanding facility management organization of the year. Internal and external customer feedback continues to indicate a high level of satisfaction. The Facilities \& O perations (F\&O) Directorate continues to implement innovative practices (e.g., energy and operations cost avoidance/ reduction initiatives) and a number of F\&O staff have been awarded national certifications in Facility Management technical specialties.

\section{Business management systems and processes}

The Lab's Cost Management Program balances reinvesting in the Lab's infrastructure and maintaining our cost competitiveness. It also uses the Battelle-managed labs' collective buying power to realize discounts and other financial advantages (e.g., securing a second airline in the Tri-Cities, airline fare reductions, P-Card agreement, and rental car agreements.) We also have an Operations Improvement Initiative (OII) that sets aside overhead funds for improvement investments that demonstrate a positive payback in reduced operating costs.

\section{Counterintelligence}

For each of the last three fiscal years, the Counterintelligence (CI) Program has had the highest rating possible from the DOE Office of Counterintelligence during their biannual audit of the program. During the last audit, CI was described as a mature, integrated program, with high morale, very productive, dedicated and committed staff with strong management, and implementing some best practices. This program recognizes the ongoing challenge to maintain a high level of performance and implements strategies and a strong assessment program to assure this outcome.

\section{Opportunities for Improvement}

We need to implement the new contract to ensure that we improve our effectiveness and efficient management and operations of PNNL. By improving our definition of our governance and assurance processes and implementing new risk management approaches we will optimize our systems to meet this challenge.

We will continue improvement of the communication of our Lab-level strategic direction and performance expectations. This is discussed in detail in Section III.3.

We need to enhance tools for project managers to assist in their delivery of products and services. In FY2003 we will fully deploy the Hazards Analysis tool that will provide reasonable assurance that hazards are identified during the project planning stages. A cross-functional team was used to develop this tool so that our research project managers' specifications were addressed in its development. Commitment to lower rates will allow project managers to be more competitive and conduct more work on each project. We also need to find other ways to assist managers to obtain and then deliver workscope that energizes and builds staff capability while meeting important client needs. Tools such as these need to be identified, developed and existing tools (e.g. SBMS user interfaces) optimized to better assist our project managers in the pursuit of research activities.

\section{We will increase our management focus on funds} control in the coming year. O ur emphasis will be in providing for proper implementation of DOE O rder 412.1, advanced notification of funding issues and control points status analysis. Automated management reports highlighting the potential funding issues will be developed. Close communication with DOE budget staff will be maintained to work potential funding issues prior to any overrun situation. Enhancements to expedite the authorization and receipt by projects of funding will be implemented to offset the selected loss of anticipatory authorization mechanism.

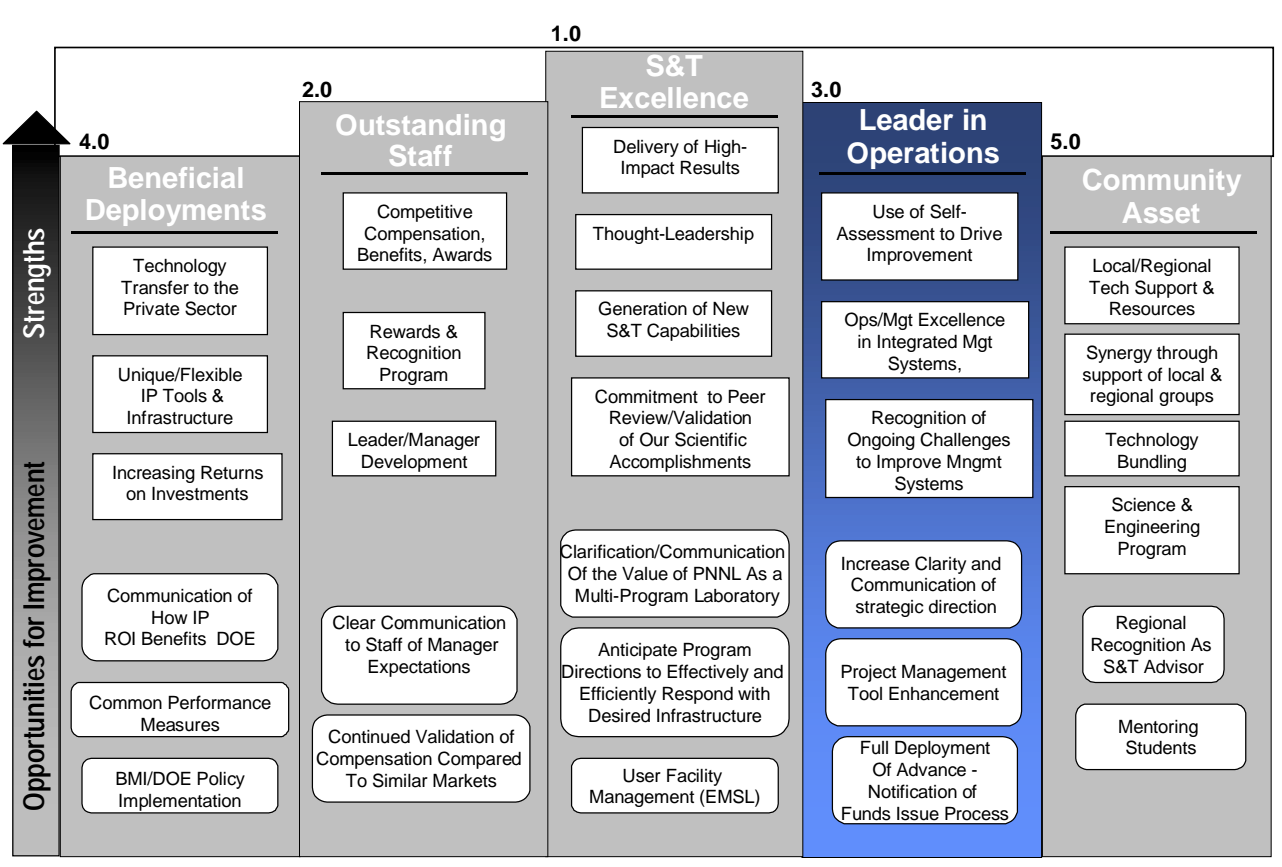

Figure II.4. Strategic strengths and opportunities for improvement identified through self-assessment: Strategic Objective 3.0, Leader in Research \& Development Management \& Operations. 


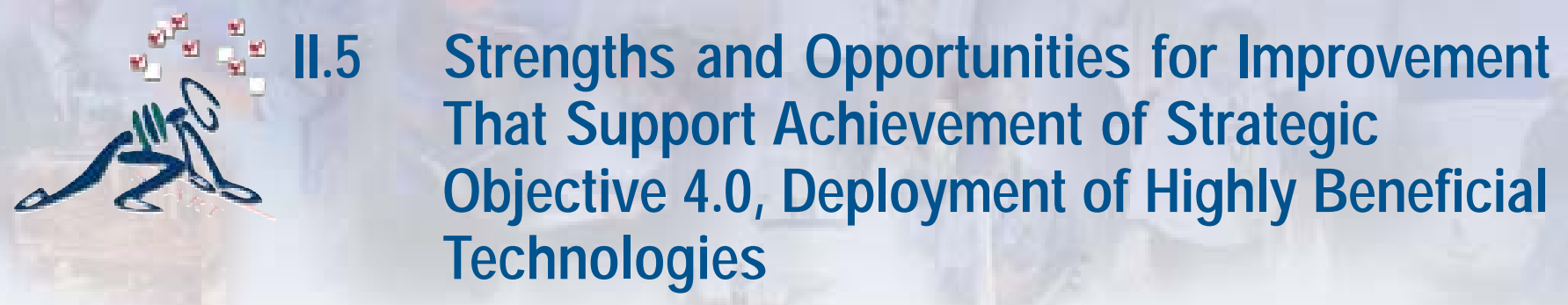

O ur ability to successfully transfer technologies using PNNL's unique and flexible IP infrastructure underscores the need to better communicate the reinvestment potential and related strategies to our DOE customer.

\section{Strengths}

We excel at transferring technologies to the private sector. In FY2002, more than 30 technologies were licensed to private sector companies. For example, the PNNL-developed techniques for sample concentration have been licensed to five major manufacturers of mass spectrometers and have been incorporated in numerous products sold by these manufacturers. The Acoustic Inspection D evice, a technology that relies on ultrasound to examine and identify contents of sealed containers, was licensed to a private company for potential use in customs inspections and could be used in homeland security applications.

In early 2002, the Federal Laboratory Consortium recognized the Laboratory with three Excellence in Technology Transfer Awards. O ne award recognized the creation of a new company, Vitex Systems Inc., which is bringing two products to market that are based on PNNL's ultrabarrier coating technology. These technologies could allow plastic to replace glass in electronic displays and help advance next-generation display devices. The second FLC award focused on our work with Motorola on the transfer of PNNL's capabilities in molecular beam epitaxy and its applications to semi-conductor manufacturing. Lastly, the FLC pointed to the creation of Wave ID, a new company created to manufacture, market and distribute the radio frequency tag technology developed at PNNL. Wave ID was recently purchased by Alien Technology, a fast-growing California-based company.

PNNL also transfers technologies through its alliances with industry. For example, PNNL and the National Energy Technology Laboratory coordinate the Solid State Energy Conversion Alliance (SECA). PNNL manages SECA's Core Technology Program, with responsibility for developing and transferring solid oxide fuel cell technology to industrial teams for commercialization.
The SECA program is widely acclaimed as an effective and successful technology development and transfer program.

Unique and flexible tools and IP infrastructure position us to excel at IP development, investment, and partnering/ licensing, and have enhanced our ability to capture industry interest. In addition to the traditional national lab tools (e.g., Collaborative Research And D evelopment Agreements), we also have tools that the other national labs don't have (e.g., Use Permit, Contractor-funded Tech Transfer). This gives us greater flexibility and increases our ability to respond more quickly and creatively to industry. Additionally, we use DOE and BMI funding to leverage opportunities.

We continue to increase our reinvestment in the Laboroatory through increased licensing revenues (300\% increase since 1998), and rewards to staff for their technology development contributions (more than a six fold increase since 1998). In return for licensing, we have been able to increase our equipment inventory at no additional cost.

\section{Opportunities for Improvement}

O ur strategy for providing substantial returns for reinvestment in the laboratory from IP revenues, and the subsequent benefit DOE receives needs to be better communicated to our customer. The opportunity for this improvement to positively impact refreshment of Laboratory capabilities and infrastructure needs such as equipment is high and all options should be carefully explored and successful strategies employed.

We need to develop a common set of performance measures that capture more than just revenues and will give us an accurate picture of our strengths and areas for improvement in our IP commercialization process. Management must implement these measures 
consistently across the Lab. This will help us realize even greater levels of success in this area. We must also clarify the link for our staff between our IP potential/ client interest and our ability to secure R\&D projects, and we need to encourage greater staff participation in IP development through performance incentives/ rewards/ recognition.

1.0

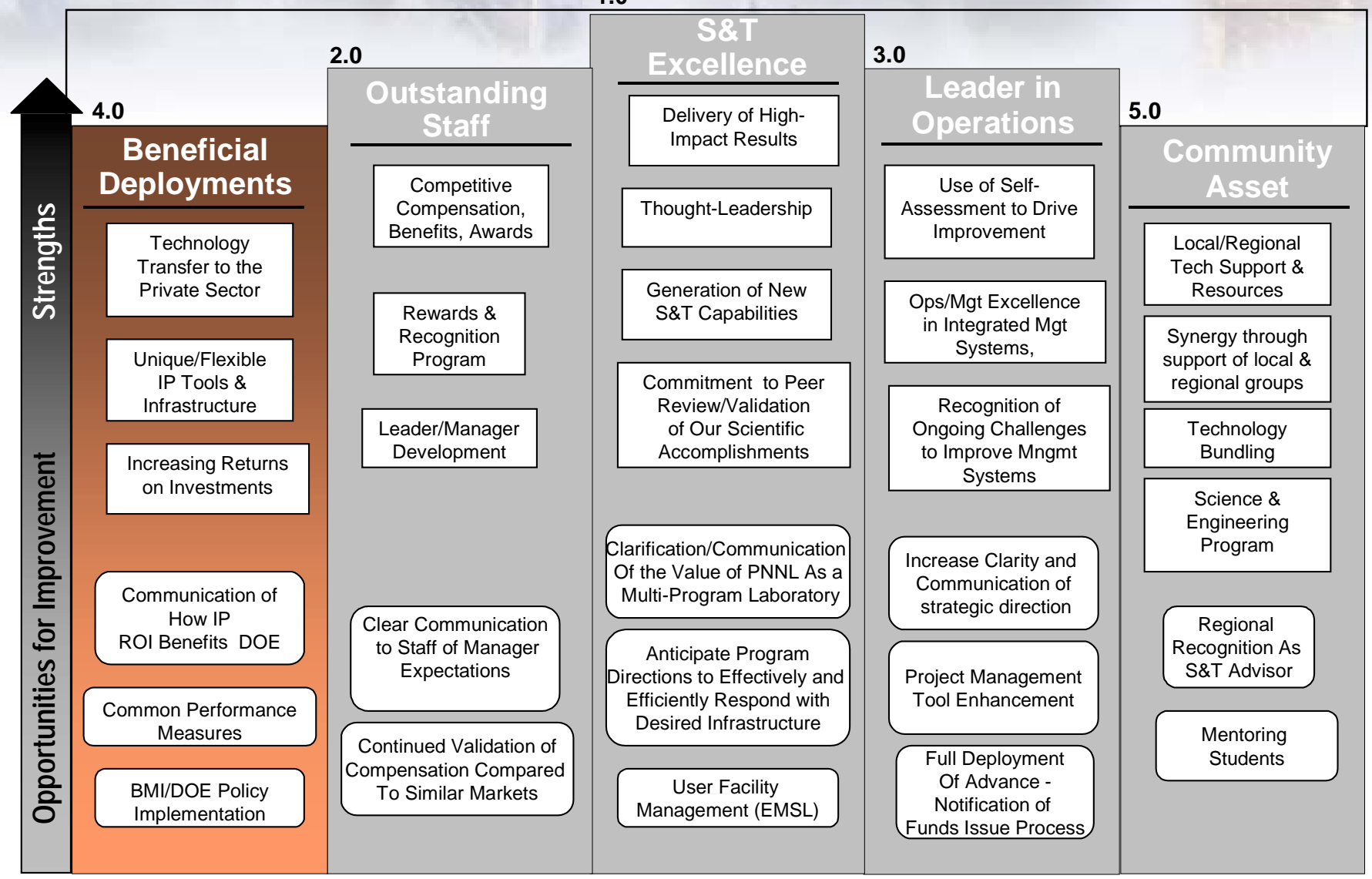

Figure II.5. Strategic strengths and opportunities for improvement identified through self-assessment: Strategic Objective 4.0, Deployment of Highly Beneficial Technologies. 


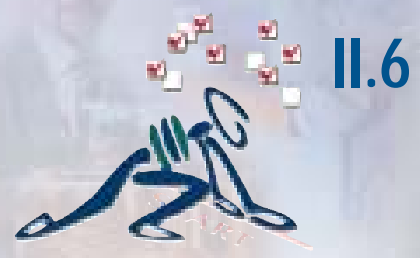

\section{Strengths and Opportunities for Improvement That Support Achievement of Strategic Objective 5.0, Valued Regional \& Community Asset}

PNNL provides significant impetus and support for local and regional economic growth by bringing together the region's major research institutions in focused efforts to find solutions to significant regional issues, by building new technology-based enterprises to broaden and diversify the region's economy, and by contributing substantively to the region's science and engineering education.

\section{Strengths}

We provide technical support and business guidance to new and existing businesses in the northwest region. To be a valued community asset and promote economic development in our region is fundamental to our strategy. During the last year, we provided technology assistance to 52 firms and 8 new business starts or expansions. We also initiated and are implementing three new economic development programs: Northwest Technology Investors Network, Technology Job Connection, and the Community Roundtable.

We are linking the resources of the region's major research and development institutions to meet Northwest needs and provide dispersed economic opportunities. We succeeded in involving representatives from each of the region's major research institutions in our Linking Regional Resources Program. This is a long-term, committed, collaborative effort to link technologies and technical resources in ways that will solve Northwest problems and contribute substantively to the creation of new technology-based economic activities. We are also working with four centers of entrepreneurship at three of the region's major universities to evaluate and make available to the public the products of bundled technologies from the major research and development institutions. The program is currently assembling bundles of technologies and technical resources on energy supply alternatives and methods for managing the region's water resources. At present, the Lundquist Center for Entrepreneurship and the Center for Law and Entrepreneurship, both at the
University of Oregon, are evaluating the business feasibility of and market interests in PNNL energy management and water purification technologies to promote their commercialization and adoption by the public in the Northwest.

We support other organizations in our community and region that represent a wide variety of economic development activities of mutual importance. O ur support runs the gamut from Board and Committee membership (e.g., Tech Alliance, Chamber of Commerce, Washington Biotechnology \& Biomedical Association), to labor-hours invested in many activities and various corporate donations. We continue to compare and contrast the missions of these organizations to the Lab's strategic objectives, and furnish guidance to involved PNNL staff as to where their efforts might best be made.

We have developed and continue to maintain a strong science and engineering education program that fosters the scientific content knowledge and skills of elementary, secondary and post-secondary teachers and faculty. Through our technical staff, we have a direct role in educating and mentoring future scientists and engineers, and are recognized as a leader in the region's business sector for science and technology education reform (e.g., Washington Leadership and Assistance for Science Education Reform Project). We promote diversity in the science and engineering track by conducting programs focused on students historically underrepresented in the Science, Technology, Engineering and Math pipeline (e.g., African American, Hispanic, Native American and women). 


\section{Opportunities for Improvement}

We need to improve our level of recognition as an S\& $\mathbf{T}$ advisor in the region and as a valuable catalyst for economic development, technology commercialization, and science and engineering education reform. Pursuit and capture of new funding sources (e.g., grants, contracts) will help us realize the goal of establishing regional offices or outposts that will promote our presence as the leading authority for the industries, universities, and state and local governments in our region. Recognition by venture capitalists as a fertile source for investment in commercially viable technologies is critical if economic development is to flourish. This in turn will result in more opportunities to use our business tools (e.g., Starlight, a data analysis and visualization tool) to help match the right technical solutions to our regional problems. We also need to be recognized for the connectivity we establish between the corporate world and science and engineering education, and use our reputation as a corporate benefactor and proponent of education as a marketing strategy.

We need to increase mentoring expectations among our technical staff in order to improve our educational contributions to K-12 science education leaders (e.g. teachers, administrators, scientists/ engineers, and community leaders). By increasing the mentoring expectations of PNNL technical staff, particularly as they relate to working with culturally diverse students and faculty, we will be better equipped to help the anticipated increased number of these students and faculty in PNNL's science and engineering education program.

1.0

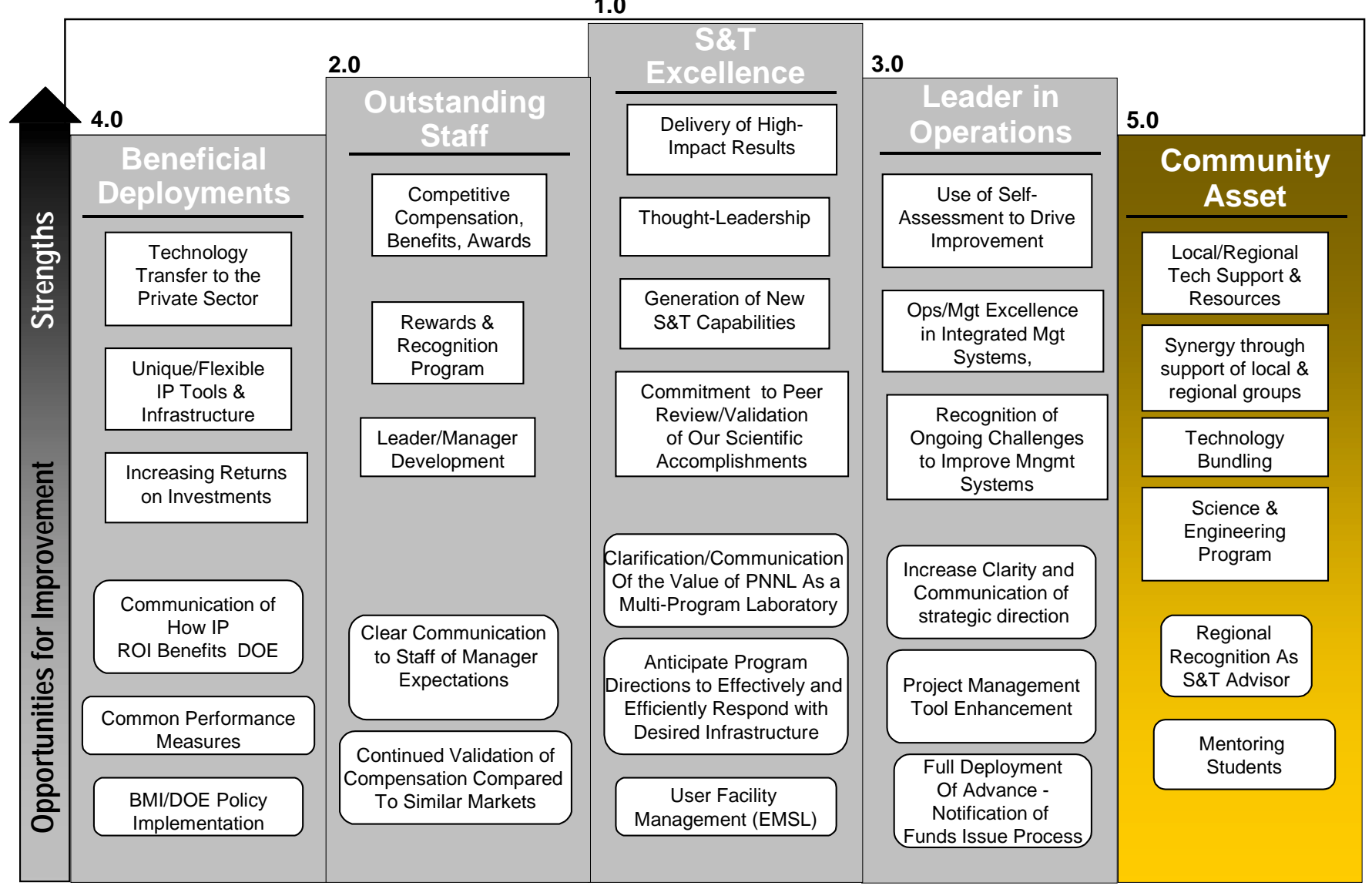

Figure II.6. Strategic strengths and opportunities for improvement identified through self-assessment: Strategic Objective 5.0, Valued Regional and Community Asset. 


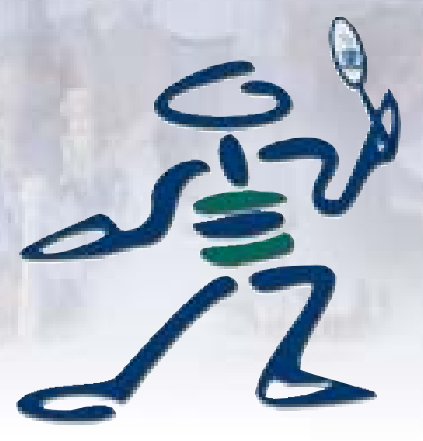

Part III

Adequacy of PNNL's Self-Assessment Process 


\section{霓 \\ III.1 DOE-RL's Satisfaction with PNNL's Self- Assessment Processes and Use of Results to Improve Performance \\ D0E RL confirms the continuing improvement of PNNL's self- assessment processes and the usefulness of the results to drive performance improvement.}

\section{Background}

For the last five years, an annual survey of the health of PNNL's self-assessment processes as seen through the eyes of our customer, DOE RL, and the relationship with our RL self-assessment counterparts has been part of PNNL's self-evaluation. Survey results provide us with opportunities to improve the processes and increase our ability to meet our counterparts' needs and expectations.

\section{Satisfaction with the Process}

In FY 2002, RL and PNNL staff agreed that the annual satisfaction survey needed to place more emphasis on self-assessment process maturation along the lines of performance based management. As a result, four new process measures were added to the FY 2002 survey: willingness to accept challenges/ stretch goals; degree of performance based management concepts implemented; ability to manage performance through self-assessment; and the willingness to accept a risk-based approach to achievement of objectives. RL's evaluation of these self-assessment process measures indicates a high level of confidence in PNNL's ability to manage performance through self-assessment. See Figure III.1a.

PNNL's self-assessment processes continue to increase in maturity as indicated by RL survey responses. Degree of alignment between directorate performance goals and Laboratory-level goals also shows an increase over the previous year's survey results. See Figure III.1b.

Supportive remarks in the survey Comments section round out another positive evaluation of PNNL's selfassessment processes, and reflects D OE RL's confidence in the Lab's ability to manage performance through selfassessment and use of assessment results. This year, $53 \%$ of the respondents provided comments. With the exception of three responses that took issue with the survey questions, all comments were complimentary of their counterparts' efforts to implement self-assessment and manage performance.
In FY2003, PNNL will continue to work with RL staff to improve the survey questions so that we learn what is most important about our self-assessment processes and our relationships with our RL counterparts.

\section{Satisfaction with the Results}

DOE RL's level of satisfaction with PNNL's use of self-assessment results to drive performance improvements remains at a high level. The four percentage point drop from FY2001 survey results is not statistically significant, and may be an artifact of the $22 \%$ replacement/ turnover of RL self-assessment counterparts. No respondents indicated a "not satisfied" response. See Figure III.1c.

RL's satisfaction with their level of involvement in PNNL self-assessment activities increased by one percentage point over last year, indicating that $83 \%$ of our D OE RL counterparts are satisfied or more than satisfied.

In response to the question (new this year) regarding the level of their oversight of PNNL activities, 92\% of our RL counterparts responded that it was "Just right."

However, 8\% (6 respondents) indicated that the level of their oversight was "too little." These responses warrant investigation as to the individual causes that may be driving these responses.

The survey population size and response rate continue to grow, increasing the validity of survey results. The survey population increased by $25 \%$ over last year, and the response rate remained in the $90 \%$ range.

As in past years, individual survey results were sent to all PNNL counterparts to enable discussion and resolution of any issues, and confirmation of things that are working well. 


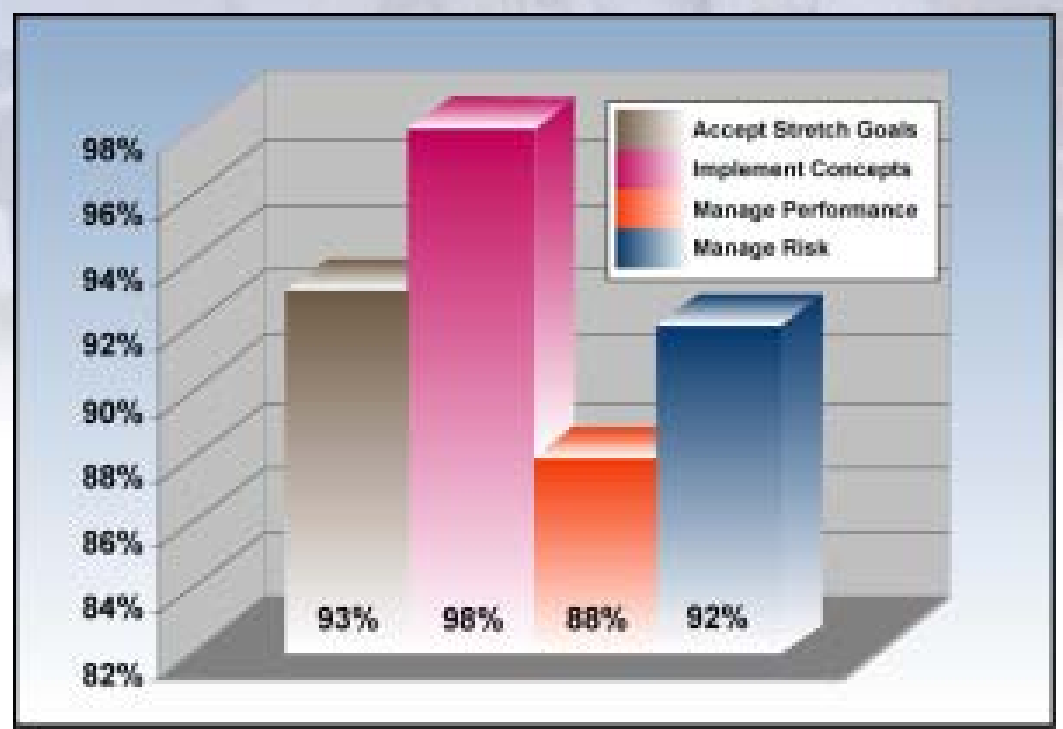

Figure III.1a. RL indicates that PNNL is doing well in four critical areas.

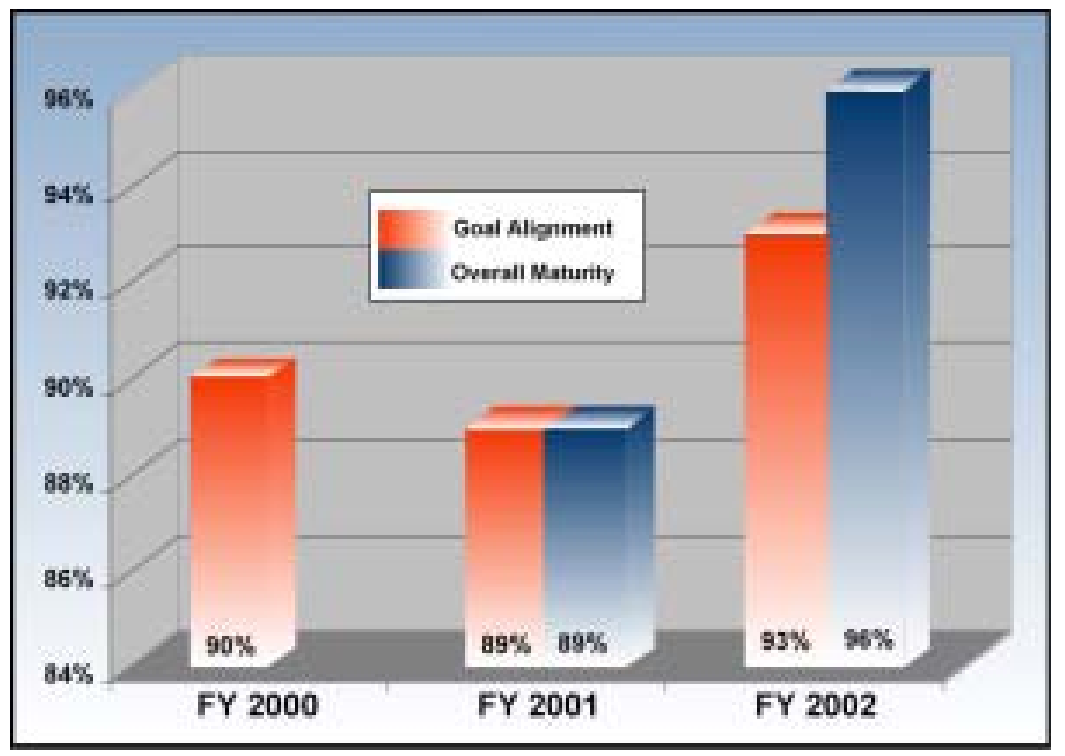

Figure III.1b. RL confirms that PNNL self-assessment processes continue to mature.

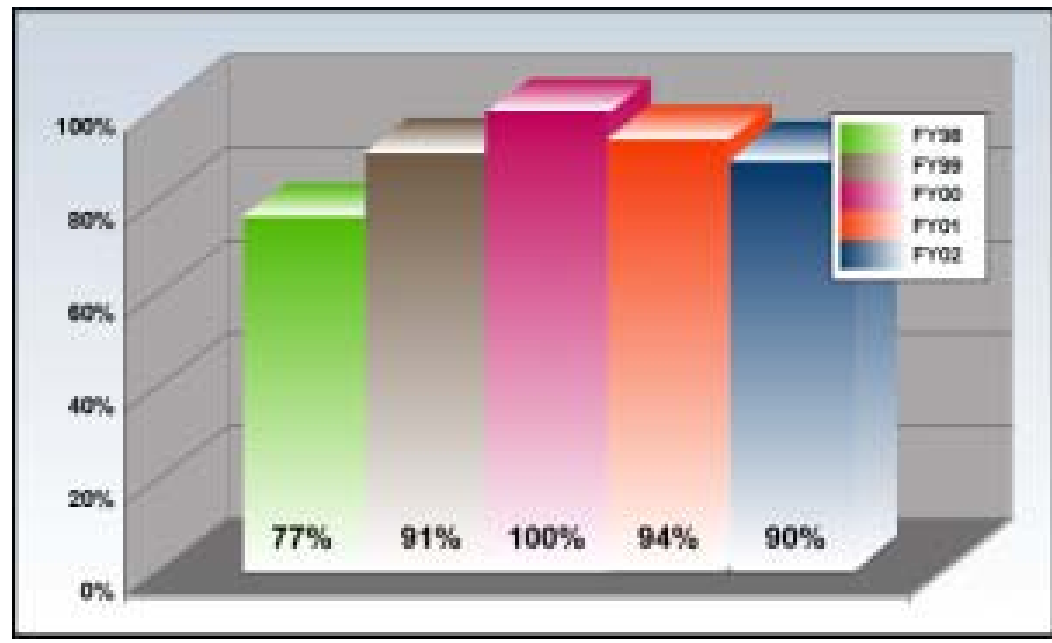

Figure III.1C. RL finds that PNNL's use of assessment results to drive improvements remains high. 


\section{Adequacy of the Performance-Based
Self-Assessment Process \\ Managers value PNNL's performance-based self assessment pro- cess as a management tool.}

PNNL's approach to self-assessment is sound and the process is robust. Level 1 managers say that selfassessment is helping us achieve the vision and strategy goals in our Laboratory Agenda. The directorates have a framework to connect their tactical business plans to the D OE critical outcomes within the agenda. The Laboratory self-assessment approach helps align organizations with the strategy and builds ownership for performance. O ur DOE customer has rated our performance outstanding for the past four years.

\section{Our managers have taken initiative to improve} their local self-assessment processes. Level 1 managers are using self-assessment results to make strategic and tactical decisions during the annual business planning and throughout the year. The directorates create performance measures for their dashboards that are meaningful and aligned with the managers' performance goals. While all the directorates are selecting self-assessment based on information received from previous self-assessments and needs identified during business planning, two directorates have taken the initiative to document their decision process for selecting self-assessment topics.

\section{Managers aspire to achieve even greater levels of effectiveness in the self-assessment process.}

Although the results being achieved demonstrate that self-assessment is robust, the Level 1 managers have even higher expectations for self-assessment in the future. In Figure III.2 they have given their own opinion of the characteristics of an ideal self-assessment process and how important each characteristic is to achieving the ideal. O ur managers concluded that the greatest improvement in the Laboratory self-assessment process would be realized when greater clarity on Laboratorylevel direction is achieved. They believe this can best be achieved through an increase in the consistent communication of the Laboratory Agenda key outcomes during the strategic business planning process. The specific recommendations are discussed in module III.3.
PNNL managers identify top five characteristics they believe comprise an ideal self-assessment process. The following summarizes the characteristics they identified.

Self-assessment focuses on what's important. Self-assessment uses a graded approach that is strategy and riskbased, focusing on measuring performance that is key to the strategic and tactical goals of the organization. Its results are used to make decisions related to improving performance relative to these goals. Managers know what to measure, how to measure, and how to use the results to manage their performance. $\mathrm{O}$ ur managers considered this characteristic most important. It has an average weighted importance of $38 \%$.

The $\mathrm{L}$ aboratory has the right self-assessment process. The purpose of self-assessment is constant over time and our self-assessment standards, infrastructure, and tools support and facilitate effective self-assessment. The process is consistent across the Laboratory, yet flexible to organizational needs. Roles, responsibilities, authorities, and accountabilities for the process are clear. The vision and strategic agenda are clearly communicated so the right self-assessments are performed. This characteristic has an average weighted importance of $25 \%$.

Self-assessment helps foster a learning culture. Laboratory leaders create an open, self-critical environment that encourages improvement. Staff members, who do the work and know what needs to be improved, influence self-assessment selection. Staff members want to do better and are willing to change and adapt. Self-assessment is valued because it provides performance information needed for individual and organizational learning and growth. This characteristic has an average weighted importance of $19 \%$. 
Self-assessment helps build austomer relationships by providing quantifiable performanceinformation. Using self-assessment plans and results, managers communicate vision and strategy goals, and subsequent progress to customers and stakeholders. Self-assessment enhances customer and stakeholder relationships through this communication. It creates customer trust by demonstrating that the organization is actively measuring and managing progress and credibly meeting customer needs, legal requirements, and commitments to stakeholders. This characteristic has an average weighted importance of $11 \%$.

Self-assessment is independently validated. Internal and external experts independently validate effectiveness of self-assessment. This characteristic has an average weighted importance of $7 \%$.

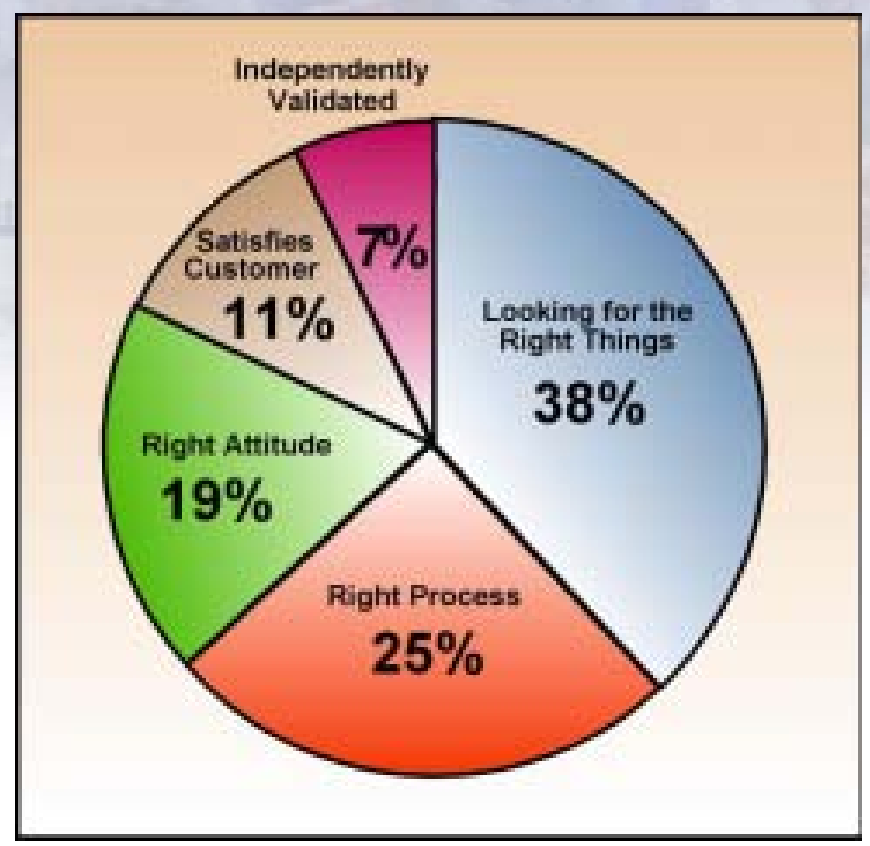

Figure III.2. Level 1 Managers agree on five characteristics of selfassessment and their relative importance. 


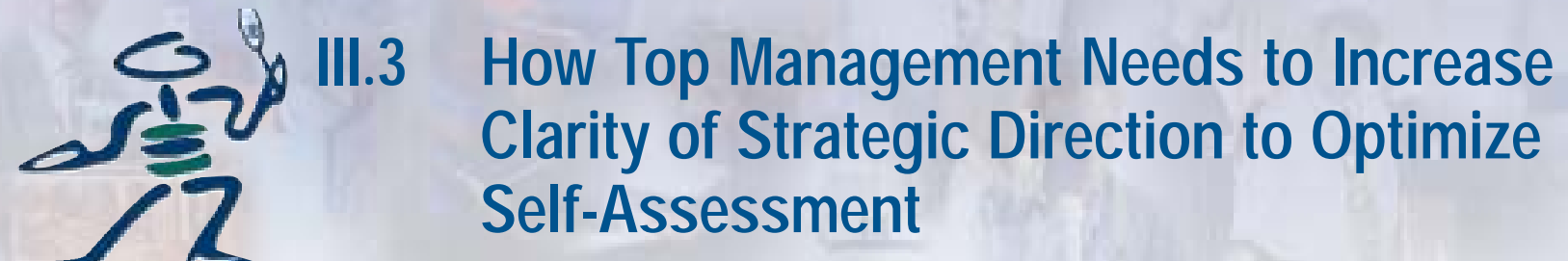

\section{O ur robust self-assessment program highlights the need for senior management to more clearly set and communicate strategy, expectations, and acceptable levels of risk.}

\begin{abstract}
Senior and mid-level management commitment to self-assessment is strong. Managers are motivated to plan and conduct meaningful self-assessments and indicate that these assessments yield valuable results approximately $76 \%$ of the time. O ur managers have evidence that self-assessment results contribute to continued performance improvement and overall Laboratory success. They link assessment activities to business plan outcomes and use their own dashboards to provide directoratelevel performance information that is easily accessible and shows targeted and actual levels of performance. Managers indicate that, overall, the self-assessment process, its tools and capabilities are improving.
\end{abstract}

Our managers also say that higher levels of effectiveness can be achieved in self-assessment through greater, clarity, communication, flowdown, and agreement on Laboratory level strategic direction, research and operational performance expectations, and acceptable levels of risk. Specifically, our managers want to know:

- What criteria must be met to demonstrate that performance requires no further improvement?

- What are the Directorate performance targets needed to achieve Laboratory goals and standards?

- To whom are Directors accountable for meeting performance goals and standards?

- What measures are needed from each organization on a regular basis to manage performance?

Historically, the Directorate business plans have driven Laboratory strategy rather than the other way around. The imbalance in strategic direction is depicted in Figure III.3 by the arrows between Laboratory governancelevel strategy and directorate-level strategy. Our managers say they need better understanding of the "big picture" and how their performance aligns with longterm Battelle and DOE goals for operating PNNL. Increased clarity and communication of the Laboratory strategy and associated performance expectations will direct the focus of self-assessment to an optimal level. Managers can focus their self-assessments on the most important activities that affect Laboratory success. With continued emphasis on cost cutting, it is imperative that we assess the right things with the right level of rigor. We strive to eliminate unneeded assessment activities without increasing the risks to unacceptable levels and still achieve aggressive performance outcomes for D O E. Unless senior leaders' expectations for achievement of the strategy are clearly and consistently communicated to direct reports, the focus of self-assessment plans will not improve.

Managers will be more effective at setting priorities and implementing a graded approach in selecting self-assessment topics and performance measure targets if acceptable levels of risk are better defined. Managers said that a well-defined, sustainable risk envelope provides another opportunity to increase alignment of self-assessment. We do not have a consistent approach or process to help reach consensus about accepting risk at the Laboratory governance level. By deciding on risk acceptance limits, our managers will be able to:

- Conduct self-assessments that provide decision information associated with acceptable risk limits and/ or effectiveness and efficiency of processes to manage risk,

- D etermine when self-assessment is no longer contributing substantial value and can be curtailed or reduced in frequency, and

- Reduce disagreements among Laboratory managers, subject matter experts, and D OE over risk limits and performance needs.

In FY2003 we will be acting on recommended improvements to Laboratory governance strategy communication and our risk management approach and process as we implement our new contract. 


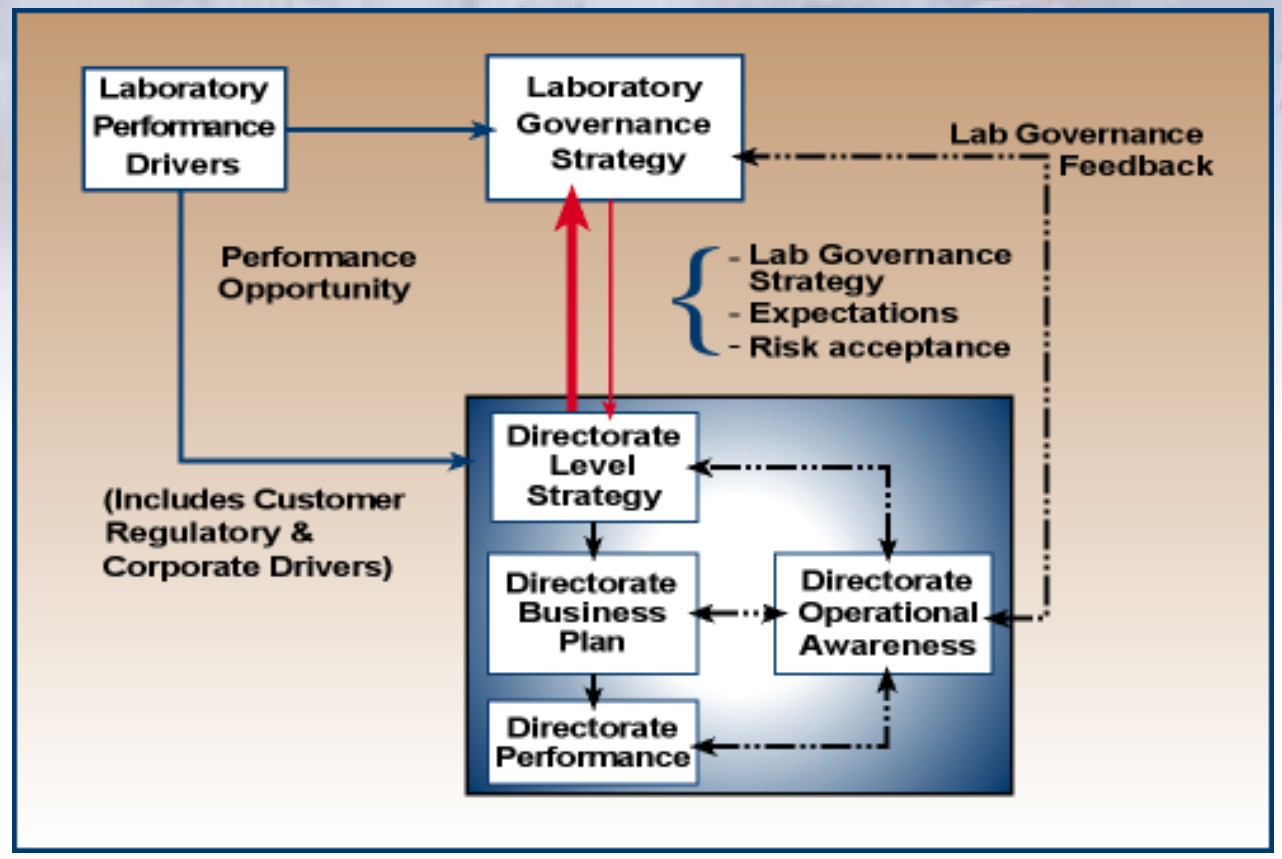

Figure III.3. Currently strategy is set primarily using directorate level strategies. Level 1 and 2 Managers identified the need to increase flow of top-down communications between Laboratory Governance and the Directorates. 


\section{Appendix A Peer Review}




\title{
A.1 Assuring the Scientific Quality and Relevance of Our Work to Our DOE Customers through Peer Review
}

\author{
PNNL conducts five kinds of peer review to assure scientific quality, relevance, \\ leadership, performance, and strategic alignment.
}

Directorate Review Committees (DRCs) comprehensively assess the strategic plans, mission, and goals of each of the Associate Laboratory Directors serving a specific DOE mission area. Expert external reviewers from industry and academia deliver advice based on their assessment that helps our leaders set the direction of their science and engineering or technology strategies and validate the quality and relevance of the work. The committee also recommends modifications in the programmatic mix and advises in the identification of new approaches, directions, and opportunities for scientific development. At PNNL, we have four DRCs, one for each of the research directorates aligned with a specific D OE mission area. D RCs conduct an annual peer review that covers the directorate's activities on a 3-year, rotating basis. For the key D RC messages, please see this Appendix, Sections A.2 - A.5.

\section{The purpose of the Laboratory Advisory Board} (LAB) is to review the alignment of PN NL capabilities with national research needs and corporate expectations, and advise the Laboratory Director. The Director will use the advice and recommendations from the LAB to guide strategic direction during our business planning process. The LAB concept, developed in FY2002 to be implemented in FY2003, is an expansion of the former Laboratory Advisory Committee. This expansion is represented by the LAB's three standing committees:

- The Executive Committee to strengthen corporate oversight.

- The Operations Committee with a focus on laboratory operations.

- The Lab Advisory Committee with a focus on advocacy/markets. Note that this committee includes representatives from our four D irectorate Review Committees.
In redesigning our lab advisory function, we reviewed advisory board structures of other national laboratories and those used in industry including benchmark companies that have recently won the Malcolm Baldrige award for quality. We discovered that the most effective and efficient model would feature a more structured committee with options for ad hoc committees to advise on specific topics for a limited time. The Board will be highly beneficial in helping us anticipate and respond to changing priorities in the national research agenda.

\section{Programmatic peer reviews tell us whether or not our programs are meeting customer needs. PNNL focuses on tactically and strategically aligning scientific work with what the customer is requesting and making sure we deliver it cost effectively. To ensure our strategic alignment and quality delivery we ask external reviewers to validate our work and recommend changes to our program alignment based on their assessment.}

Awards or recognition for scientific/ technical excellence also validate our programmatic work:

- Federal Laboratory Consortium (FLC) awards. PNNL ranks first among the other multiprogram labs here.

- R\&D 100 awards. PNNL ranks fourth among the other multiprogram labs here.

- American Chemical Society National Award.

- Election to prestigious professional boards, committees or organizations.

- Congressional testimony citations.

Technical peer review is a fundamental aspect of all our work. It validates the scientific diligence that defines the quality of our work and helps assure the protection of intellectual property. We use technical peer review, not only to assess our scientific and engineering deliverables including publications, but also for propos- 
als and presentations. Each research directorate defines and implements an internal peer review process for such externally visible products. We do this in order to make sure our communications of scientific and technical information reflect positively on the professionalism and excellence of this D OE laboratory.

For proposals such as those submitted to national programs, including the Environmental Management Science Program (EMSP), we review scientific and technical content for soundness of methodology, analysis and conclusion, adequate and accurate documentation, and responsiveness to client requirements. The level of detail for each review is based on risk factors including importance of the work to the organization's programmatic portfolio; business and operational hazards associated with the proposed work; difficulty of the proposed work; and dollar value of the proposal. The specific EMSP review process and its proven success are discussed in Appendix A.3.
Finally, Initiative Advisory Committees serve as review and advisory bodies for the Laboratorylevel initiatives and LDRD projects. The reviews assess progress on continuing business and technical activities, and review all prospective business and technical activities for the next fiscal year. Advisory Committees serve three functions:

- Provide technical and business guidance to the initiative leader in terms of scope, strategy, and market needs;

- Conduct an annual review of the initiative's business, and science and engineering activities (i.e., review the initiative plan and LDRD project proposals); and

- Provide the Laboratory Director and Research Council with assessments of the quality of activities for a given initiative necessary for their decisionmaking on funding Laboratory-level initiatives. 


\section{A.2 Fundamental Science Peer Review \\ Peer reviewers provided valuable review and guidance on overall Fundamental Science Directorate (FSD) direction and two specific research programs.}

\section{Directorate Review Committee}

The committee, consisting of four returning and four new members, met at the Lab on May 29-30. They commended Directorate leadership for "an excellent agenda, well prepared talks and very well coordinated logistics for the meeting." The Lab Director and FSD Associate Lab Director provided overviews of status and strategy.

Based on the summaries presented, the committee rated the program and initiatives presented as follows:

- Computational Science and Engineering Initiative Excellent

- Biomolecular Systems Initiative - emerging program, premature to rate

- Nanoscience and Nanotechnology - Very Good

- Metal Oxide - Excellent

- Global Environmental Change - O utstanding

- Trace Detection - Excellent

"The Committee was unanimous in its view that retention of key scientific personnel is of the highest priority across all of the Lab's programs."

The Committee was very pleased with plans to grow in Computational Science and Nanotechnology because of the D irectorate's unique strengths. The acquisition of the HP platform was viewed as a highly creative step and applauded, with Nanotechnology seen as dovetailing nicely with recognized Directorate strengths, particularly EMSL. The Committee strongly supported focusing efforts on the link between large-scale computation and experimental science. As in the past, the Committee agreed it is important to focus initially on prokaryotic biology where PNNL has established excellence.

The Committee felt there was insufficient detail presented to comment on the Joint Institute with University of Washington and requested a more comprehensive review of progress and problems of the Institute in a future review. Insufficient information was presented on the proposed growth in Nanobiology, but the Committee had concerns about whether this built on existing strengths.
The following programs were highlighted with specific comments.

Metal Oxide Research:

- The "research is truly excellent"

- The quality of staff, quantity of high quality publications, and potential impact of this research should not be underestimated

- The research is underfunded at the Lab

- There is a major opportunity to capitalize on unique talents and capabilities

- Integration of theory and experiment is "first rate"

- Several scientific staff members are truly exceptional

- Lab leadership should ensure continued growth in this area.

Global Environmental Change:

- Committee considers Global Change initiatives "crown jewels" in the Lab's portfolio

- Two areas "best in class"; Atmospheric Radiation Monitoring (ARM) program and impact on national policy via the Technology Strategy Project

- "The scientific staff internally, and the scientific collaborations, represent the very best of the world's scientific experts in this area."

- Committee strongly endorses continued growth and staffing of ARM

- Concern about allocation of high-intensity computational power on the new HP computer to nonEMSL users such as the atmospheric modeling effort - review of policy requested for next review meeting

- Technology Strategy project led by one of a very few outstanding authorities in the field has impacted highest levels of government

Trace D etection Research

- Portfolio particularly important and timely

- Lab has unique capabilities for end-to-end research in this area from data collection and observation to data processing and instrumentation

FY2002 Annual Self-Evaluation Report 
- Essential elements for a successful program all in place in EMSL

- Value of this technology widespread, notably in counter-terrorism and national security

Recommendations:

- Continue to expand aggressively the scope of its collaborative research across leading research institutions of the nation

- Find more funding for EMSL

- Move aggressively into Genomes to Life, by securing substantial funding for research growth, additional staff, and capital investment including facilities

- Consider a modified organizational structure that more tightly couples each unit to its primary funding agency
- Add essential scientific staff to the Biomolecular Systems Initiative (Committee wants an update on the staffing plans and success in recent funding competition)

- Get strong retention tools to keep world-class scientific staff at the Lab

\section{Office of Basic Energy Science (BES) Program Reviews}

Program reviews were held in Chemical Physics and Molecular Processes. Formal reports were not available in time for incorporation into this report, however, preliminary reports indicate outstanding performance. 


\section{A.3 Environmental Technology Peer Review}

\section{The Environmental Technology Directorate (ETD) uses a multiple level Peer Review process to validate the quality and strategic direction of our environmen- tal science and technology.}

\section{Formal Peer Review}

The FY2002 DRC was charged by the ETD Associate Laboratory Director (ALD) with evaluating our stewardship of PNNL's core radiological capabilities, Marine Science Laboratory Growth Agenda, and to review the Directorate's progress since the last review.

O ur FY2002 DRC meeting was held on March 28 and 29, 2002. Following its evaluation, "the D RC concluded that ETD's overall program should continue to be rated as outstanding."

Overall, the D RC found that, "In spite of budgetary and programmatic uncertainties... ETD continues to display positive progress." It also cautioned however, that the ETD Leadership team should not "just harvest the results of past work. It must continue to re-energize."

The DRC made two overall recommendations for our business direction:

- focus the ETD strategic development process on synthesizing activities with the D irectorate, and

- take a comprehensive look at our facility needs for the future.

In addition, several recommendations related to the specific charges by the ETD ALD

were assigned to actionees and will be resolved prior to the next D RC meeting.

ETD also delivers high quality science to the DOE. We utilize a rigorous internal peer review process to optimize EMSP pre-proposal candidates and proposal submissions. This process has been responsible for PNNL being the leader of EMSP awards across the complex. Since the program's inception in 1996, PNNL has been awarded a total of 103 EMSP research grants. More significantly, in addition to providing high quality, high value science to the DOE-EM clean-up mission, we are also making contributions to the quality of science across multiple D OE offices. O ur EMSP portfolio contains projects investigating the application of bioremediation technologies to reduce risks faced by EM in facility D \&D and in the Groundwater/ Vadose Zone. These projects draw on our PNNL's capabilities in the Environmental Molecular Sciences Laboratory and are making advances in fundamental sciences that are being transferred to projects and proposals under OBER and NABIR, the primary programs for the development of bioremediation technologies within DOE.

We continue to communicate the successes achieved at both PNNL and throughout the program. Our work is documented in peer reviewed journals such as the Journal of the A merican Chemical Society and Science, in presentations made throughout the DOE complex and in feature articles on the $O$ ffice of Science's website.

Finally, in addition to providing significant results to D OE's critical cleanup problems, we continue to demonstrate significant leadership in the EMSP program. By pre-screening proposals for relevance to critical EM problems, coaching Principle Investigators during the early stages of awards, and actively transitioning the projects to the next stage in maturity, all PNNL EMSP projects have successfully achieved major goals with a high level of networking to end-users and delivering technology and/ or data to facilitate clean-up activities across the D OE complex. O ur leadership in EMSP was demonstrated by the award of 16 EMSP project awards in FY 2001 (including six project renewals and ten new start awards), and nine FY 2002 project awards (two renewals and seven new starts).

\section{Informal Peer Review}

In addition to providing an external view of the management of PNNL's environmental technology portfolio, and optimizing its role in EMSP, ETD uses informal peer review to review the results of work performed for their customer. This includes peer review of selected project activities before starting work, evaluating research and technology development approaches, data and conclusions, and to providing internal peer review of articles to be submitted to externally peer reviewed technical journals and publications. 
Together, the combination of business and programmatic review performed by the Directorate Review Committee, the internal peer review process for investments for the development of new business, and our informal process of peer reviews of projects, products and services provide for a solid framework of high quality, high value technical performance coupled with significantly positive programmatic leadership.
The results of our FY 2002 review by the ETD Directorate Review Committee coupled with our outstanding performance and leadership in the EMSP lend credence to our belief that the Environmental Technology D irectorate's performance was outstanding in FY2002. 


\section{A.4 National Security Peer Review}

\section{The National Secunity Directorate (NSD) Peer Review process validates the quality and direction of our National Security science and technology.}

The Directorate Review Committee (D RC) of the NSD of the Pacific Northwest National Laboratory (PNNL) met at the Laboratory 11-13 June 2002. The purpose of the meeting was to conduct the annual review of NSD programs and research activities. Members of the Committee present for the review were Carl Poppe (D RC Chair); John Ahearne; Ron Ewing; Paul G reenberg; Jeremiah Sullivan; and James Williams, a new member to the Committee this year.

Because of its timeliness, the June 2002 meeting focused on the Directorate's newly organized "Combating Terrorism" program. In addition, the Special Programs area was reviewed because of its synergism with Combating Terrorism.

\section{Committee summaries of 2002 annual meeting:}

Leadership The Committee remains very pleased with the excellent job Mike Kluse is doing in leading the D irectorate. It is a far more coordinated, streamlined, and enthusiastic unit than several years ago. Funding has been maintained and has even experienced growth in certain areas, morale is high, NSD facilities and housing have been improved, and there are significant opportunities for growth in the National Security arena in the future. The Committee commends Mike for his underscoring the support of NSD for the IC. The Committee believes that PNNL and NSD are making good progress in gaining recognition in the National Nuclear Security Administration (NNSA).

Combating Terrorism The Laboratory has moved to respond to the nation's need for technology and technical assistance to support the war on terrorism by organizing a new Combating Terrorism Program (CbT). This is a suitable and timely activity for PNNL attention, and the Committee believes the Laboratory has much to offer. The Committee recommends continuing efforts to organize this into a well-defined program based on critical technologies and viewed as corresponding to the nationally defined problem areas.
Homeland Security Initiative PNNL has embarked on the challenging task of defining a science and technology niche in homeland security. This is a three year initiative currently Lab funded at \$1M (LD RD) with an additional funding of $\$ 800 \mathrm{~K}$ from NSD. There are prospects of an added $\$ 1.2 \mathrm{M}$ support funding from other Directorates across the Lab. Combined, this would constitute a substantial investment by the Lab into what is clearly a national imperative. The Committee commends this investment and was impressed with the strong show of support to date by senior management. Equally impressive was what appears to be a strong collaboration of science and technology expertise from throughout PNNL's science base.

Intelligence Mission The Committee believes that Associate Director Kluse's decision to call out specifically the intelligence mission of the Directorate was a very positive step forward.

Special Programs Special Programs responds to the technical and analysis needs of its client set. The program appears to be well managed and organized, and the Committee was most impressed with the overall effort of Special Programs at PNNL. The program has a good reputation. It provides an excellent complement to the new CbT. These two areas should work together closely to take advantage of the synergism.

Debt for Nonproliferation The Committee was gratified to hear Jim Fuller's detailed and comprehensive explanation of this project. It appears to be a practical approach to generating additional funding for an increasingly important national security problem and fully supportive of national anti-terrorism programs. The Committee was very pleased that PNNL supported the development of this project that goes beyond the mainstream of Laboratory activities, yet has great potential for the nonproliferation of nuclear weapons.

Strategic planning The Committee is very pleased to see a substantial improvement in the strategic planning process in NSD. It has reached a very credible level, thanks in part to reorganization and the efforts of Marilyn Q uadrel and Reinhold Mann. 
Key Process Change in 2002: "Actionable" Issues identified at the annual meeting.

The primary change to the $\mathrm{DRC}$ reporting process this year was the establishment of a process that

- identified issues needing action (with concurrence on issues by both NSD ALD and DRC Chair),

- assigned an NSD staff member responsibility for addressing the issue, and

- assigned a DRC point-of-contact for the NSD staff member to interface with.
These "actionable" issues will be formally tracked to closure, upon DRC acceptance of resolution.

The two "actionable" issues and the responsible parties from the June 2002 meeting are:

a) Describe the connection between the Homeland Security Initiative and the active PL 44 portfolio. Integrate the story. (D oug Lemon, Steve Martin, Ted Divine/ Ron Ewing, Joe Kielman)

b) Develop a one-viewgraph focus slide for Homeland Security (Steve Martin/ Joe Kielman) 


\section{A.5 Energy Science \& Technology Peer Review}

\section{The Energy Sciences and Technology Directorate (ESTD) Peer Review process validates quality, relevance, and direction of our Energy science and technology.}

The ESTD Peer Review process integrates the results of the Directorate Review Committee, initiative peer reviews, and major program reviews to assess the caliber, value, and focus of our Energy science and technology and to validate our strategic direction.

In FY2003 we will restructure our D irectorate Review Committee to be more strategic and balanced, among our four main business areas, Energy and Engineering, Materials Science, Information Science and Engineering, and Nuclear Science. This structure will provide more timely feedback on our progress in each key area.

\section{Summary}

The results from our FY2002 ESTD Peer Review process have affirmed the quality and focus of our Energy science and technology. ESTD's continuing efforts to mange the program effectively and efficiently, with active engagement of stakeholders, will enhance PNNL's impact on the DOE Energy mission. Specific recommendations from all the external reviews will be used by Directorate management in charting the course of Energy science and technology as part of the on-going planning and assessment process.

\section{Directorate Review Committee}

Each year PNNL's Energy Sciences and Technology D irectorate hosts an external peer review comprised of nationally recognized external experts from both industry and academia in disciplines and business areas associated with our technical thrusts. The D irectorate Review Committee (DRC) looks broadly at the resource technical capability, the research agenda, and the desired business and technical outcomes.

For the past three years, D RCs have focused on technical thrusts from one of our three main business areas; 1) Energy Sciences and Engineering, 2) Materials Science, and 3) Information Science and Engineering. In June 2002, a D RC of nine external reviewers convened at the Laboratory to review the three technical thrust areas of our Energy \& Engineering Division (EED): Computational Engineering Sciences, Energy Systems, and Robotics Technology. The Committee was asked to use the Office of Management and Budget (OMB) investment criteria to evaluate our federally sponsored research and development programs. Overall the D RC found our work in these areas to be "excellent in terms of quality, relevance, and performance." Highlights from the committee's summary report follow.

Computational Engineening Sciences Four components were reviewed: 1) Advanced Materials and Manufacturing; 2) Emissions; 3) Structural Reliability of Nuclear Power Pressure Vessel Boundary Components, and 4) Solid Oxide Fuel Cell Modeling. The D RC found that the work in the Computational Engineering Sciences to be excellent in terms of quality, relevance, and performance. The D RC said that the level of engineering $\mathrm{R} \& \mathrm{D}$ was appropriate. The committee gave the highest marks for technical approach and for the originality of the research, but they noted some difficulty in understanding the relationship between projects within the thrust areas. An emphasis on higher publication rate was recommended. The computational research associated with fuel cells was viewed as state-of-the-art, and the committee recommended that additional resources be found for the electrochemical modeling efforts.

Energy Systems Four components were reviewed: 1) D iagnostics and Control; 2) Transmission Reliability;

3) Energy Security, and 4) the Energy System Transformation Initiative (ESTI). The D RC found the work in the Energy Systems area to be excellent in terms of quality, relevance, and performance. The D RC felt that the level of engineering $R \& D$ was appropriate for a national laboratory. The four components were considered to align well with documented DOE focus areas and to be of high importance to most energy industry companies. Progress in ESTI was noted to be strategic, visionary, and ahead of the competition, combining technology and public policy. The energy security work was seen as an area of opportunity. The committee suggested that some thought and effort be put into the effects on the private sector of a more dynamic grid of the future and on the implications to public policy beyond the 10-year horizon. 
Robotics Technology Three components were reviewed: 1) Teleoperated Systems for Hazardous Environments; 2) Remote Robotic Systems for National Security, and 3) Autonomous Robotics Control. The DRC felt that although the Robotics Technology area includes sound engineering development activity; this area does not have the level of accomplishment and research evidenced in the other two areas. The Robotics Technology area was given an overall rating of very good. Robotics Technology has made significant contributions to environmental management projects at the Hanford Site through the timely and innovative use of mobile robotic characterization platforms. It is believed that the robotics area has significant potential for growth and the achievement of a greater research signature. (The committee noted the lack of a formal business plan for this area and the other two as well.)

\section{Initiative Peer Reviews}

In FY2002, external reviews were conducted on the following two Laboratory Level Initiatives stewarded by ESTD.

Carbon Management Initiative The Carbon Management Initiative was reviewed by an Advisory Committee of four external and two internal reviewers in August 2002. The Advisory Committee found the initiative management has done a very good job of analyzing the market and selecting areas for technical focus. It reported that the initiative is well managed, well focused, and avoids areas with strong existing competition. However, the initiative may want to consider the balance in investments among near- and long-term options. Seven technical proposals were reviewed and six of these proposals were recommended for funding in FY2003.

Energy Systems Transformation Initiative In addition to the DRC June review, the ESTI was reviewed by an initiative Advisory Committee of three external and one internal reviewer in August 2002. The committee found that overall, the business and technical integration of the initiative is excellent and focused on their main goals. The ESTI scope is ambitious, but the initiative team has demonstrated leadership and a chance for significant success for PNNL, D OE and the US. This is an appropriate project for PNNL since industry will not engage in such a broad and fundamentally risky endeavor.

Because the initiative is broad, the committee suggested a focus on solving some specific problems, recommending two of three technical proposals for FY 2003 funding. The initiative needs to continue to maintain the close linkage between science and technology development, technology integration, and business development.

\section{Program Reviews}

In FY 2002, specific programmatic reviews were conducted on the following D OE Energy Efficiency and Renewable Energy programs.

\section{Building Technology Program Office: In} August 2002, the new D OE Building Technology Program Office manager and a member of his management team visited PNNL to review Building Technology research and development projects and to solicit our recommendations regarding future $R \& D$ initiatives. The review was very successful in terms of the performance of ongoing projects, identification of new building technology capabilities, and recommendations for new building related initiatives.

\section{FreedomCAR \& Vehicle Technologies: In} April 2002, PNNL hosted the former D OE Office of Heavy Vehicle Technologies Annual Program Review attended by over 80 D OE and National Laboratory participants. PNNL projects reviewed very well with positive feedback. D OE program manager Dr. Sid Diamond reviewed PNNL's project in the HighStrength Weight-Reduction Materials, validating PNNL's major contributions to his office's technical success.

Industrial Technologies: In November 2001, PNNL hosted Glass Industry of the Future Annual Program Review and the G lass Manufacturing Industry Council Review and Board meeting, attended by more than 80 industry, D OE, university and national laboratory participants. PNNL projects reviewed extremely well based on the feedback from the industry and D OE program managers. 


\section{Appendix B \\ National Security Mission}




\section{Office of Defense Nuclear Nonproliferation (NA-20)}

\section{FY2002 PNNL NA-20 Programs}

Pacific Northwest National Laboratory (PNNL) is once again very proud of the outstanding quality of our support in FY2002 to Defense Nuclear Nonproliferation (NA-20). The amount of work we were tasked to perform by NA-20 grew by more than 40\% over FY 2001 . There was also similar growth in other non-NA-20 national security programs during the same period. This growth was due, we believe, to recognition by a variety of U.S. security agencies and organizations of the value of involving PNNL in their programs. This is a credit to our long legacy in national security dating back to WWII, as well as being a multi-mission, science-based, policyoriented laboratory with a strong track record in international project management.

We continued our leadership of the International Nuclear Safety Program (INSP), and helped recognize, the tenth year of its existence through the visit to Russia by our laboratory director and senior management, along with the fact that during this ten-year period there have been no core damage accidents in Soviet-designed reactors. Additionally, there has been a concomitant reduction by $45 \%$ in the frequency of minor nuclear events at these plants during this same period.

Another crowning achievement during FY2002 was the unanimous passage by the Senate Foreign Relations Committee, and then the full Senate, of the BidenLugar-Helms D ebt Reduction for Nonproliferation Act. The concept of Debt for Nonproliferation (DfN) originated at the PNNL Pacific Northwest Center for G lobal Security (PNWCG S). Subsequent to this action by Congress, President Bush included it as a component of his G-8 Global Partnership initiative (10 Plus 10 Over 10) at the July Kananaskis G -8 Summit - a proposal that was unanimously accepted by the participants, including Russia. Of additional note, a PNNL staff member was asked to testify before the House International Relations Committee in preparation for conference committee deliberations. Additional D fN activities this year included leadership of a Carnegie Endowment for International Peace D ialogue in Moscow and an invited presentation to the European Commission European Nuclear Cities Initiative workshop in Brussels. This initiative is now expected to produce $\$ 1-\$ 2$ billion per year in additional Russian nonproliferation financial support, heavily leveraging NA20 activities.
Additional work included being tasked by NA-20 to lead the newly established Elimination of Weapons Grade Plutonium Production (EWGPP) program, as well as taking on the NA-20 Nonproliferation G raduate Program to place competitively selected Masters-level interns throughout the organization. The commencement of these two new roles was not without some challenges, but we are successfully resolving them in partnership with Headquarters.

The impact and visibility of the outreach and policycentric Pacific Northwest Center for Global Security also grew in FY2002. Collaborations with the University of Washington Institute of Global and Regional Security Studies expanded, and resulted in the placement of several NA-20 interns into the Headquarters Nonproliferation $\mathrm{G}$ raduate Program on a fast-track basis after some of the initially selected graduates from other sources were rejected due to personal background issues. Collaborations with various Northwest state and nongovernmental organizations remained strong, particularly with the Foundation for Russian American Economic Cooperation, the National Bureau of Asian Research, the Washington China Relations Council, and the Washington Council on International Trade. O ur nonproliferation seminar series remained strong by continuing to focus on one objective of exposure of NA-20 programs to international authorities.

Key speeches at the laboratory in FY2002 included Ambassador Brooks, a heavily attended series on the Islamic faith in cooperation with the University of Washington Jackson School of International Studies following the events of September $11^{\text {th }}$, as well as representatives from the Nuclear Threat Initiative and the Washington Council on International Trade. D uring this period we were also able to make convincing arguments to Battelle corporate attorneys that PNWCG S funding was not subject to recent Congressional restrictions, so we were able to return originally provided programmatic funding to NA-20, yet expand our activities at the same time.

\section{Assessment for the Office of Nonproliferation Research and Engineering, NA-22}

The scientific and programmatic achievements for NA-22 reflect exemplary performance through successful research, development of prototypes, test and evaluation of developed sensors, and technology transfer.

PNNL scientists expanded the large, high resolution, 0.1 wave number infrared spectral library of special 
chemicals that is both quantified and qualified through joint efforts with the National Institutes of Science and Technology. This library now serves as the United States database for current and future sensor development and application, for both the U.S. D epartment of Energy (DOE) and the users of its research. An export control released version was made available to both public and private users this year. Sensors developed to exploit these signatures set new records for chemical sensitivity in laboratory experiments of both point and remote sensor systems.

PNNL developed and transferred the technology for a multi-role national security radionuclide sampling and analysis system that met user requirements to a manufacturer. PNNL scientists supporting the Nuclear Explosion Monitoring (NEM) program were recognized for their outstanding performance by being chosen to lead the statistics element of the NEM Program with the Department of Defense.

A high-speed, high-resolution counting method was developed for acoustic array sensors (e.g. Flexural Plate Wave) that allows them to be used as gas chromatograph chemical detectors. PNNL and academic partners at the University of Arizona and Indiana University achieved a breakthrough in multi-collector mass spectrometry by the development of a Micro-Faraday, Focal-Plane Array D etector.

O utstanding collaborations were developed with Washington State University and industry partner eV Products in materials research aimed at the development of room temperature semiconductor gamma and neutron radiation detectors such as CdZnTe and BN. A passive radiation portal monitor was developed for the detection of Highly Enriched Uranium and has been installed at the Hanford HAMMER facility in preparation for test and evaluation. Scientists at PNNL identified and evaluated two concepts for long-range radiation detection that have the potential to dramatically increase the range of detection.

PNNL scientists established collaborations with Lawrence Livermore National Laboratory (LLNL) and O ak Ridge National Laboratory (ORNL) to bringing our unique proteomic capabilities and biological detection expertise to bear on chemical and biological national security problems. An automated luminex bead trapping system developed by PNNL was tested at LLNL and provided bio-detection results that are better than their manual gold standard. PNNL scientists revised the BEAD S biochemistry to be compatible with the ORNL Biochip D etector.

Scientists from PNNL responded to the events of September $11^{\text {th }}$ by contributing to the development of the National Nuclear Security Administration (NNSA) Counter Terrorism Roadmap, analyzing detection capabilities for specific threat scenarios, and pursuing the near-term development and implementation of technologies. Four of the five PNNL technologies briefed to Secretary Abraham and G overnor Ridge at the Counter Terrorism Expo in November 2001 were technologies that were initially developed by NA-22. Later in the fiscal year, PNNL was awarded a Work for Others (WFO) project by the U.S. Customs Service for the purpose of fielding radiation detection equipment at northern border crossings. This came as a surprise to some within the NNSA, a situation for which we have established new procedures at PNNL to rectify for all future homeland security WFO tasks.

\section{Assessment for the Office of International Nuclear Safety and Cooperation, NA-23}

As mentioned earlier, FY 2002 marks the tenth anniversary of the NNSA's highly successful INSP. The goal of the INSP is to improve safety at all Soviet-designed nuclear power plants. The primary indicator of nuclear plant safety is the frequency of core damaging accidents. Since the inception of the INSP, there have been no core damage accidents at Soviet-designed nuclear power plants, clearly demonstrating the viability and success of the program. A secondary nuclear safety indicator, the frequency of minor nuclear events, has also shown significant improvement. Since 1992, nuclear events have declined $45 \%$ in Russia and Ukraine. In commemoration of this anniversary, the laboratory director and other high-level PNNL managers (Kluse, Fuller) traveled to Russia in June to meet with officials there to evaluate program impacts and observe specific accomplishments. D uring meetings with the Russian Ministry of Atomic Energy (Minatom), with the Russian regulator G osatomnadzor, and at the Leningrad nuclear power plant, Russian officials reiterated that INSP had made real and meaningful impacts in improving the safety of Russia's nuclear plants.

The laboratory continued to receive positive feedback from the O ffice of International Nuclear Safety and Cooperation (NA-23) for their performance as manager of the INSP. PNNL has continued to be NA-23's laboratory of choice to lead ongoing INSP activities, and has 
also received significant new work related to NA-23's global nuclear safety mission.

PNNL's competence in managing and implementing complex technical projects in the former Soviet Union was ably demonstrated this year by the completion of a multi-unit safety parameter display system at the Zaporizhzhya nuclear power plant in Ukraine. This system allows operators to quickly and easily review critical safety parameters for all six units at the Zaporizhzhya site such that they can avoid or successfully mitigate the consequences of abnormal safety events. The Zaporizhzhya system is the eleventh and final safety parameter display system installed in Ukraine, each of which cost approximately $\$ 3$ million. These systems have significantly improved nuclear safety and helped to reduce the number of safety significant events at all thirteen of Ukraine's nuclear reactors.

A second intricate technical project completed in FY2002 was the Russia piping integrity project, which evaluated and devised solutions for a critical pipe-cracking problem at Russian nuclear power plants. Rupture of pressurized piping at a nuclear power plant is one of the most significant risks for causing a nuclear accident. The project analyzed the pipe cracking phenomena, prioritized potential solutions, and provided prototype mechanical stress improvement systems to correct the problem at several of Russia's nuclear plants. In addition, two PNNL personnel managed working groups for the International Atomic Energy Agency's project to resolve this significant nuclear safety issue.

In testimony of their confidence in PNNL's capability to manage large, complex international projects, NA-23 selected the laboratory to lead the Elimination of Weapons G rade Plutonium Production project. This project will facilitate closure of the three remaining plutonium production reactors in Russia by completing large fossil plants that will provide replacement power. The project is expected to cost $\$ 460$ million over five years. The EWGPP work suffered a setback when the project was placed on hold in June after four months of significant progress on planning and framework activities. The project was halted when congressional concerns arose related to PNNL starting work prior to receiving project funding from NNSA. PNNL started the project early with the support of NNSA headquarters personnel through a formal, longstanding PNNL project anticipatory process that placed Battelle corporate funds at risk. The immediate and vital national security risk of ongoing plutonium production in Russia motivated both
Headquarters and PNNL personnel. These reactors produce enough plutonium to make 16 atomic bombs per month, and PNNL and NNSA were proactively seeking the cessation of this proliferation risk at the earliest possible time. PNNL stopped all work until such time as new funding is received that is subject to Senate Arms Services Committee language rectifying the situation. It is estimated that the project will resume work when NNSA funding is transferred to PNNL in FY2003.

PNNL was also selected by NA-23 to lead their efforts to begin nuclear safety work in China. Laboratory personnel planned and carried out a nuclear safety workshop in China to help initiate NA-23's nuclear safety work there, and are leading the effort to conduct a follow-on workshop in the United States for Chinese nuclear specialists.

\section{Assessment for the Office of Nonproliferation and International Security, NA-24}

PNNL provided outstanding support to all of the NA-24 organizations in FY2002. For the Office of Nonproliferation Policy, PNNL conducted a study of the options for disposition of spent nuclear fuel in North Korea in accordance with the Agreed Framework with the D PRK. The study evaluated the options for continued storage in the D PRK, the need for further treatment to prepare the fuel for shipment, transportation options to move the fuel for processing or disposal, and processing and disposal options. PNNL staff continued to provide leadership to one of the world's largest and most important nonproliferation programs, the Kazakhstan spent fuel project. PNNL provides program management for the overall program at NNSA headquarters and leads the conceptual design study for the dual use cask development for the canned spent fuel from the BN-350 Fast Breeder Reactor in Kazakhstan. PNNL is providing leadership in the Nonproliferation Assessment Methodology Development project, leading the technological history task, and providing a technical oversight role in the overall working group.

PNNL is a lead player in the Warhead Safety and Security Exchange (WSSX) Program with Russia that provides for the exchange of information on technologies that promote the safety and security of active and dismantled warheads. PNNL focuses on cooperative work on technologies to monitor dismantled warheads, with lead roles in non-nuclear measurement technologies, information barrier technologies, and remote monitoring technologies. These technologies likely will play an im- 
portant role in the safety and security of dismantled warheads as the U.S. and Russia reduce their nuclear forces in accordance with the provisions of the Treaty of Moscow. PNNL manages the Russian engagement on these technical issues: jointly developing ideas and work scopes and coordinating approvals from the Joint Russian and U.S. WSSX coordinating committees, coordinating equipment exports through the U.S. D epartment of Commerce, and providing technical assistance and monitoring for Russian technical deliverables.

For the Office of Export Control Policy and Cooperation, PNNL developed a commercial prototype of a material identification device to be used by customs inspectors. In support of the O ffice of International Safeguards, PNNL played a leadership role in the Trilateral Initiative for implementing international safeguards at the Mayak nuclear material storage facility in Russia. PNNL also provides environmental monitoring and technical support to the IAEA Iraq action team.

The Office of New Independent States Transition Assistance includes two programs, Initiatives for Proliferation Prevention (IPP) and the Nuclear Cities Initiative (NCI). For the IPP Program, PNNL is collaborating with two U.S. companies and Russian scientists to develop a more effective treatment for autoimmune diseases, such as rheumatoid arthritis and multiple sclerosis. Two U.S. firms, Advance Biotherapy and New Horizon Diagnostics, are matching DOE's funding through combined inkind investment and intellectual property. For the NCI, PNNL led the development of a software company and upgraded a wood products plant in Zheleznogorsk, providing new jobs through the creation of sustainable businesses. PNNL turned over the day-to-day management of the NCI International D evelopment Centers (IDCs) to a Pacific Northwest NGO, the Foundation for Russian American Economic Cooperation

(FRAEC), which had been our strategic partner in developing the IDCs. PNNL retains a seat on the board of directors of the two ID Cs, which have been very successful in creating sustainable development in two of the nuclear cities in Russia.

\section{Assessment for the Office of International Material Protection and Cooperation, NA-25}

PNNL support to NA-25 was outstanding again this year. PNNL supported each of several individual Headquarters program managers in efficiently and effectively managing a complex multi-laboratory program with an annual budget of over $\$ 270$ million. PNNL staff mem- bers assist NA-25 in managing most of the MPC\&A infrastructure projects in Russia, including all the training and education projects, and two regulatory development projects. These projects build upon the considerable specialized expertise in these areas at PNNL. A key example is PNNL leadership in the development of two new Technical Support Centers. Lesson plans and training expertise from the mature, PNNL-led programs at the Russian Methodological Training Center and the Intergovernmental Security Training Center in O bninsk are being used to establish these two new Technical Support Centers. A clear measure of the trust NA-25 places in PNNL is the increasing assignment of leadership roles to PNNL staff. An individual from PNNL was assigned to a major leadership role in evaluating the action needed to prevent radiation sources in Russia from being used as radiation dispersal devices. In successfully leading the Mayak project, PNNL has responsibility for one of the largest facilities in the Russian nuclear weapons complex. The project is developing a comprehensive upgrade program for the Mayak reprocessing facility and is protecting the highly enriched uranium that is a product of reprocessing. PNNL has built upon its leadership in training foreign border security forces to provide training expertise to the Second Line of D efense program managed by NA-25. In addition, PNNL has taken the lead in providing strategy development and force protection equipment for nuclear site protective forces throughout the former Soviet Union.

\section{Assessment for the Office of Fissile Materials Disposition, NA-26}

In FY 2002, PNNL made significant scientific contributions to the NNSA's O ffice of Fissile Materials Disposition (NA-26) by utilizing both the 1830 and 1831 Battelle contracts with DOE. Under the 1830 contract, PNNL is leading the development of regulations for nonreactor nuclear facilities in Russia for the disposition of weapons grade plutonium $(\mathrm{Pu})$, is the primary laboratory member of the Monitoring and Inspection Working Group led by NA-26, and is coordinating closeout activities associated with conducting waste acceptance tests of immobilized Pu waste forms. These contributions are essential to ensure the successful implementation of the bilateral Pu Disposition Agreement between the United States and Russia. Under the 1831 contract, PNNL is providing key support to the Title I design activities associated with the Pit Disassembly and Conversion Facility (PD CF), which will be commissioned to prepare 25 metric tons of weapons grade 
$\mathrm{Pu}$ in the United States for conversion to commercial nuclear fuel. PNNL is serving as the Pu technology lead for the project, as well as the lead for environmental safety and health, and criticality safety. With the prime contractor (Washington Group International - WGI), PNNL staff significantly reduced the size of the PDCF footprint to meet a $\$ 735$ million targeted estimate. This resulted in an overall programmatic reduction of more than $\$ 250$ million for facility construction. PNNL helped identify the facility and process improvements needed to effect the reduction in facility footprint size, which significantly reduced construction cost estimates. Associated with this activity, PNNL successfully renegotiated a reduced cost project baseline to complete Title I design in FY 2002 and allow the PDCF project to continue through Title II design completion under current programmatic financial constraints.

PNNL is the national laboratory lead for the NA-26 effort to help develop and review Russian Federation regulations necessary for plant construction and operation to meet the requirements of the bilateral Pu Disposition agreement. PNNL provided its regulatory and policy expertise to support the Russian regulatory agency G osatomnadzor (GAN). Upgrading GAN's capabilities in this area is essential for effective licensing and operation of Pu disposition facilities in Russia. In FY2002, PNNL:

- established contracts with GAN for the development of ten regulations addressing the use of $\mathrm{Pu}$ in MOX form in the civilian fuel cycle

- collaborated with the European Union to support the development of 12 additional regulations

- coordinated the review and comment cycle for the first series of Russian Federal Regulations for nonreactor nuclear facilities

- orchestrated the review and compiled comments from the U.S. and European Union participants for the second draft of regulations by the Russian regulatory agency, GAN.

PNNL's contributions are essential toward developing regulations for $\mathrm{Pu}$ disposition activities, which are needed by the Russian Federation to meet its bilateral agreement obligations to dispose of 34 metric tons of excess weapons-grade Pu. PNNL participated as an active team member of NA-26's Monitoring and Inspection Working $\mathrm{G}$ roup. In conjunction with other national laboratories, this working group utilizes PNNL's consid- erable expertise in remote monitoring and inspection to help establish the strategy for verification of the disposition of excess weapons grade material. PNNL's key contributions in FY2002 included establishing the preliminary technical basis for verifying the origin of weapons grade Pu processing by correlating gamma and neutron emissions data with known Russian inventories. At NA-26's request, PNNL participated in the Joint Technical Aspects Working G roup (JTAW) in Moscow to establish a work plan to advance monitoring and inspection approaches utilized in the Plutonium Management and Disposition Agreement. These contributions are viewed as key to the successful implementation of the bilateral $\mathrm{Pu}$ disposition agreement.

In January 2002, the Secretary of Energy announced the decision to cancel the Plutonium Immobilization Facility in favor of a MOX only option for the disposition of 34 metric tons of weapons grade plutonium. PNNL, which had continued to provide data on the long-term radiation effects and leach behavior of immobilized $\mathrm{Pu}$ ceramic waste forms to support repository waste form acceptance, began closeout activities to remove and dispose of Pu bearing samples and associated glove box contamination. PNNL devised innovative ways of minimizing material disposal costs during closeout activities. For instance, when faced with new disposal requirements calling for disposition of material in more than 130 drums, PNNL devised an overpacking method for disposing material in a single drum thereby eliminating $\$ 400,000$ in cost growth.

Meanwhile, PNNL continued to collect NQA-1 data on radiation damage effects on $\mathrm{Pu}-238$ and $\mathrm{Pu}-239$ doped materials to complete the data set necessary to support licensing in the event orphan material could not be converted to MOX fuel. NA-26 completed an audit of PNNL's immobilization waste form qualification activities, which is conducted in conformance with DOE/ RW-033P Q uality Assurance Requirements and D escription. The audit findings reported that PNNL met the requirements for adequacy and effectiveness, noting exceptional performance in PNNL's oversight process.

\section{Summary of Opportunities for Improvement}

The issue related to the Nonproliferation G raduate Program was associated with the fast tracking of recent college graduates into Headquarters domestic and overseas internship positions requiring Q-level security clearance. PNNL was approached for the next rotation of this program due in part to our lower and more trans- 
parent costs. An issue developed because more than half of the candidates selected by Headquarters, after a recruiting program conducted by another national laboratory for NA-20, were judged by the DOE Richland Operations Office to have significant enough derogatory information in their background that the necessary waiver, given prior to actually obtaining a clearance to be immediately allowed into a position requiring a security clearance, could not be granted. PNNL project managers had no prior knowledge (and still do not) about the specifics of the derogatory information due to Privacy Act limitations. The review and adjudication of sensitive, personal background information is entirely the role of the D OE security personnel. This situation jeopardized the entire NGP program, cast aspersion on the ability of PNNL to successfully conduct the program, and created great hardship at Headquarters because the various offices were counting on these interns to help with pressing work. To rectify the specific nearterm situation, PNNL was able to significantly engage and elicit the strong support of operations office lab management staff in order to effectively communicate the seriousness and impact of the problem to DOE security personnel. We were able through the University of Washington IG RSS program to identify exceptional candidates who could step in on short notice to fill a majority of the billets of personnel who could not be hired. In terms of future recruiting and orientation, in which PNNL will now be fully involved, we will work with Headquarters to complete the recruiting cycle earlier, and include, during both the recruiting and orientation phases, considerably more introductory information about the security clearance requirements. This should help dissuade candidates that have significant derogatory backgrounds from applying to a fast-track, short-term program requiring a Top Secret security clearance.

The anticipatory funding issue related to the EWG PP program has already been described in some detail in the NA-23 assessment section of this report. This issue was exacerbated by the fact that the PNNL NA-20 subsector leader erroneously informed Headquarters that the longstanding PNNL project anticipatory process, the mechanism at PNNL that allows staff to actually begin work in advance of booking of funds, was based on the use of Battelle corporation funds. In fact, as was learned as a result of this situation, it is based on the use of unspent client funds and a DOE letter of credit as components to a process in which Battelle assumes the ultimate financial risk. In this specific case, since Congress had not formally approved the transfer of the funding that needed to accompany the transfer by president of the EWGPP program from the D efense D epartment to NNSA, this point became a matter of heightened significance. Battelle was later required by the O perations O ffice to reimburse DOE for all EWGPP costs incurred and drawn down from the DOE letter of credit, which it did immediately. PNNL has been heavily supported by NA-20 during this entire rectification of these issues, support that has been very much appreciated. It appears now that the Senate Arms Services Committee has a heightened interest in the matter, that this particular issue is very close to closure, and that we will be able to reinitiate work on the extremely critical issue of completely stopping Russian weapons plutonium production before the end of the fiscal year.

The remaining significant situation that developed during this fiscal year was the surprise and, again, reported disappointment by the NNSA Acting Administrator in not knowing of the fact that the U.S. Customs Service (USCS) had selected PNNL to perform a major piece of U.S. border security radiation detection work. While all established WFO procedures were followed by PNNL and the receipt of this work was effectively reviewed by the Operations Office, the situation was exacerbated by the fact that the USCS had directly requested NNSA support at a much higher level of communication, and the fact that competitive labs were on Capitol Hill selling their own homeland security capabilities. At one point PNNL radiation detection credentials were even questioned and we were called to Congress to testify on this matter. Any loss of confidence in PNNL is unjustified. PNNL communicated the USCS radiation detection requirements document to NA-22 in April for review - a process that could and should have been communicated up through the NA-20 chain so that senior management would not be surprised. Additionally, PNNL informally communicated the fact of this work to the NNSA front office point of contact in the early June timeframe. Since early August, we have committed to directly inform the Acting Deputy Administrator of all our homeland security efforts to assure that NA-20 and NNSA senior management are kept abreast of these efforts. Since these events occurred, we have already supplied several written and verbal reports to this level at Headquarters. 


\section{Office of Intelligence (IN) and Related Intelligence Work for Others (IWFO) Programs}

\section{Leadership}

PNNL's nuclear and other science-based intelligence analysis products continue to make impactful contributions to DOE and national policy decision makers. These products routinely go directly to the Energy Secretary; the D OE Assistant Secretaries; the Administrator, D OE National Nuclear Security Administration (NNSA); the Director of Central Intelligence (DCI); the National Intelligence Council (NIC) and the National Security Council (NSC). O ur science and technology products produced on behalf of intelligence-related clients are also recognized for their outstanding quality and contributions to critical mission requirements. Virtually every client organization in the Intelligence Community (IC) has benefited from PNNL's S\&T expertise during this past year. (See Figure B.1)

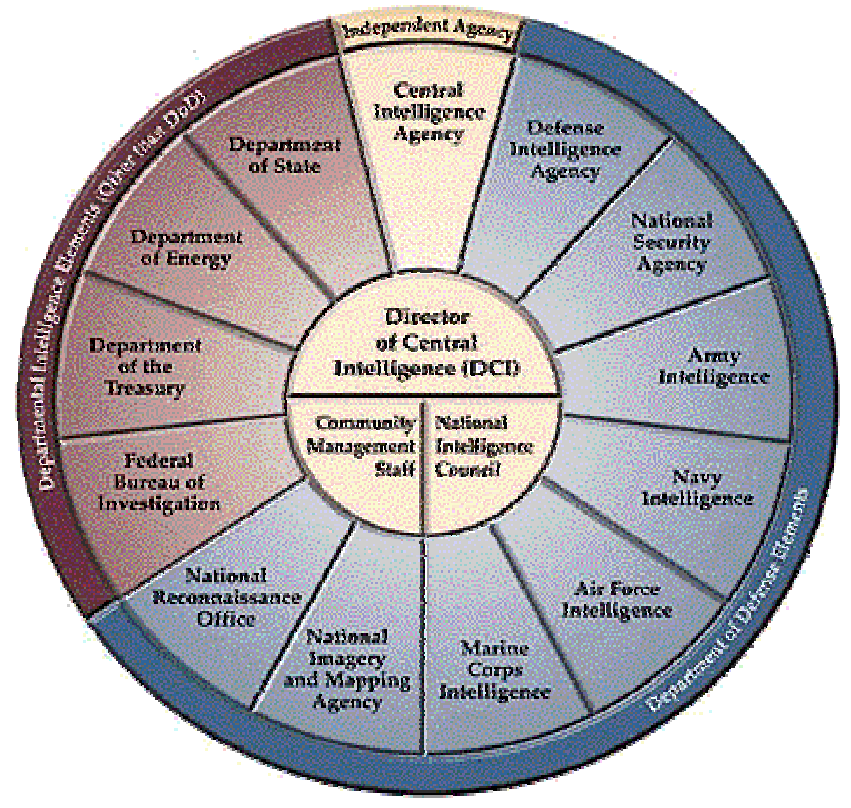

Figure B.1. The Client Community

Particularly notable accomplishments this fiscal year include: 1) D evelopment and integration of new technicalanalytical methods for performing forensic analysis of cybersecurity and network information. This analytical program made substantive discoveries to pressing national intelligence issues during the past year. 2) Further development of our information technology tools for visualizing massive, complex data bases of information;
3) Accelerated development of long-lived small power sources; 4) Enhanced millimeter wave imaging systems; and 5) Design and development of small scale decontamination devices for deactivating chemical and biological agents in vehicular air supplies.

Another indicator of the value we bring to our clients has been the growth in the number of opportunities PNNL has had to place nationally recognized technical staff on Interdepartmental Personnel Assignments (IPAs). Such assignments are made at the request of our client agencies. By early FY2003, PNNL will have senior technical staff in eight federal organizations. More and more of our client organizations seek out our staff to fill key technical leadership assignments that cannot otherwise be filled from within the federal government. These are in addition to a core team of expert staff we maintain at D O E-IN as senior intelligence analysts.

Another notable accomplishment has been the successful completion of our expanded SCIF that nearly quadruples the secure office space available to support highly classified work within PNNL. This $\$ 1.5$ million improvement is fully occupied with programs as we move into FY2003.

In summary, PNNL's work for DOE-IN and the rest of the IC provides science and technology excellence to all key process steps in the general intelligence cycle (see Figure B.2). In one venue or another our analytical

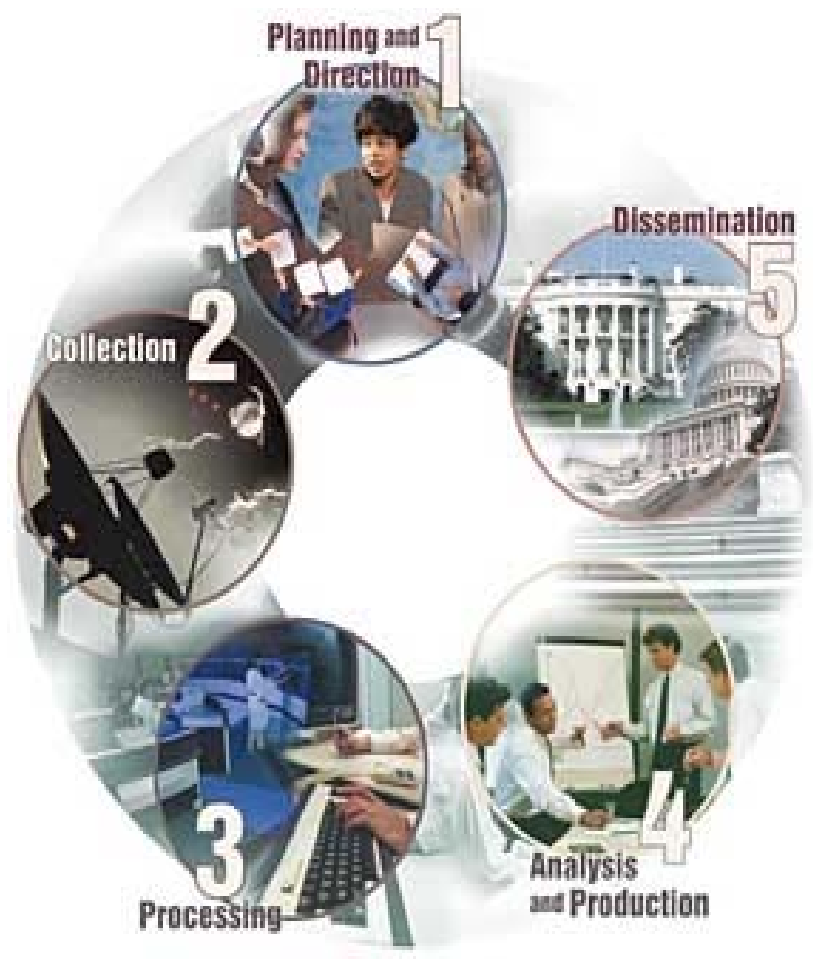

Figure B.2. The Intelligence Cycle 
work, our technical staff assignments, and our laboratory research and development represent key contributions to virtually every one of the five steps in the intelligence process.

Overall, a key measure of the increasing value DOE-IN and other members of the IC place on PNNL contributions is the growth in our funding base of about $66 \%$ over the FY2001 amount.

Additional detailed highlights supporting the conclusion that our sustained performance continues to be outstanding are noted below for both our intelligence analysis contributions as well as our science and technology performance during the year.

\section{Science and Technology Excellence}

O ur analysis programs specifically rely on the depth of senior technical expertise resident at PNNL in an increasing variety of skills including energy technologies, information science and cybersecurity. However, PNNL is historically known for its nuclear expertise applied to intelligence matters, which continues to be our hallmark contribution to technical analysis.

\section{Analysis Programs}

O ur D OE and IWFO clients in our technical-analytical programs have recognized four notable accomplishments during FY2002, namely: laboratories in defining policy issues and needs for this expanded mission for DOE-IN and its field intelligence elements.

- PNNL continued many years of sustained excellence in delivering technical nuclear analytical expertise in support of IN and related IC programs. We have begun application of our technically advanced massive information fusion/ visualization tools to site analysis and technical characterization problems as illustrated below.

- As noted previously, PNNL established a cybersecurity and network forensics analytical center in Washington, DC as an extension of DOE-IN cybersecurity analysis needs. This technical integration center is now supported by multiple DOD and IC clients including DOE-IN.

- PNNL developed a repository of technical data related to power systems Supervisory Control and D ata Acquisition (SCADA) components and protocols to expand the knowledge base for an IC client and serve as a technical reference source on technologies used in energy infrastructures. This accomplishment again draws on a unique pool of electrical engineering talent resident within PNNL.

- O ur clients recognize PNNL as one of the most knowledgeable and technically competent centers of excellence for energy infrastructure information.

- PNNL

provided the technicaleconomic expertise to assist D OEIN in definition of an implementing architecture for a nonnuclear energy intelligence program. In taking on this initiative we provided the thought leadership for DOE-IN and the other national

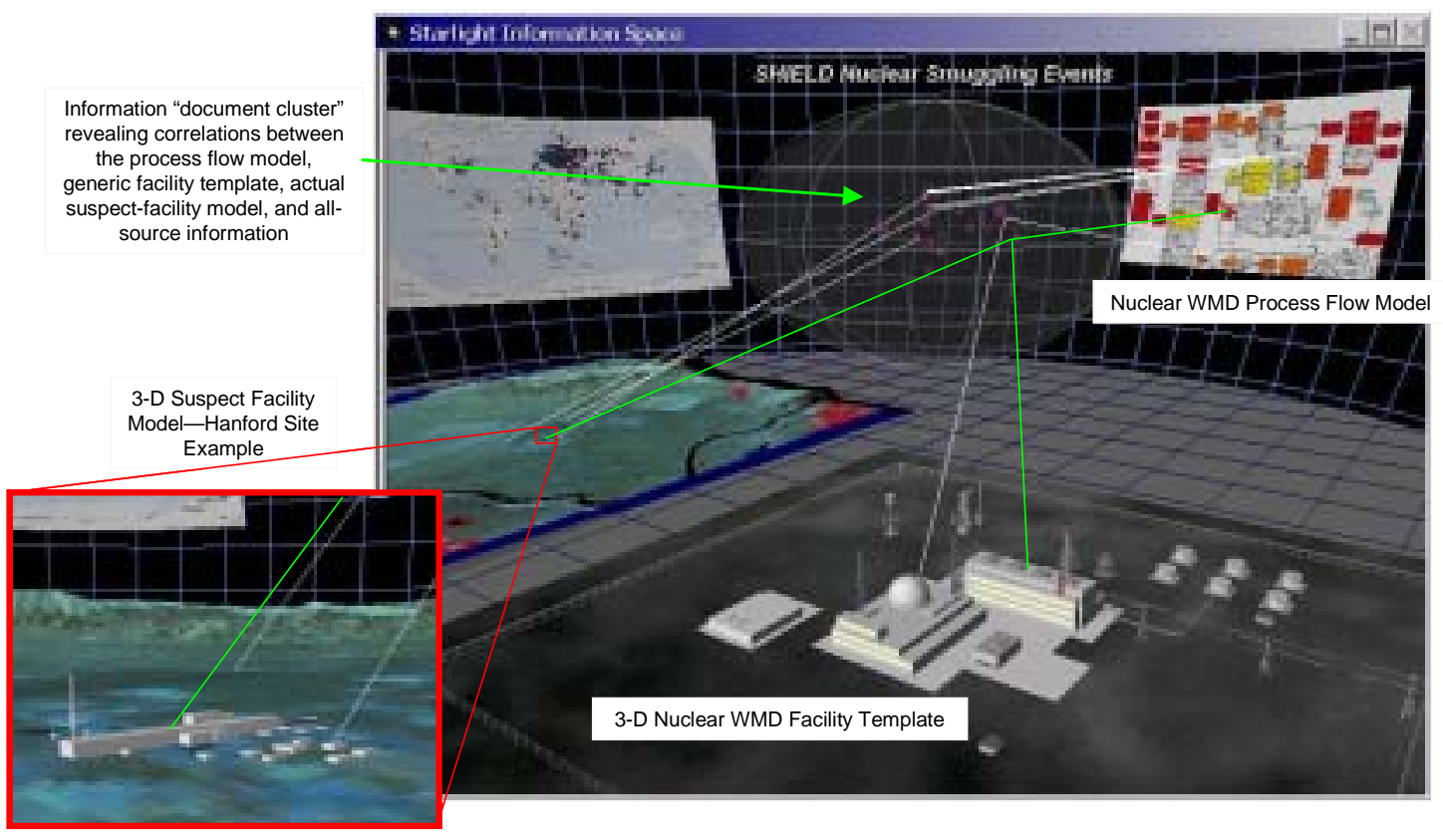

Figure B.3. Future Vision ... Geospatial Intelligence Integration, Exploitation and Visualization for Information Dominance 


\section{Science \& Technology Programs}

O ur science and technology contributions to the Intelligence mission principally focus on development of new or enhanced technical means for collection, processing, and analysis. Representative examples of client-recognized accomplishments by PNNL during FY2002 include the following:

- PNNL extended its nationally recognized millimeter wave imaging expertise to solve a precision imaging problem for an IC client

- PNNL successfully accelerated prototyping, fabrication and testing of its continuing program to produce several radioisotope stirling generators for a timecritical small power source application with the first unit scheduled to be available in D ecember 2002

- The Western Regional Information Science Research Center (WRISRC), established by PNNL for ARDA in late FY2001, has successfully completed and demonstrated a key technical solution to its first "Community Challenge" research problem, coordinating technical contributions from five DOE National Laboratories, the Naval Postgraduate School (Monterey), and three groups from the IT industry

- PNNL IO/IW expertise continued to solve IC information analysis challenges in areas of data ingestion, mining, visualization, and management across the IC

- PNNL was and continues to be recognized by its client as performing a key national leadership role for a new electric power grid-related program

- PNNL successfully qualified software for and implemented a network-server based installation of an upgraded SPIRE information visualization system on an IC client secure network; and

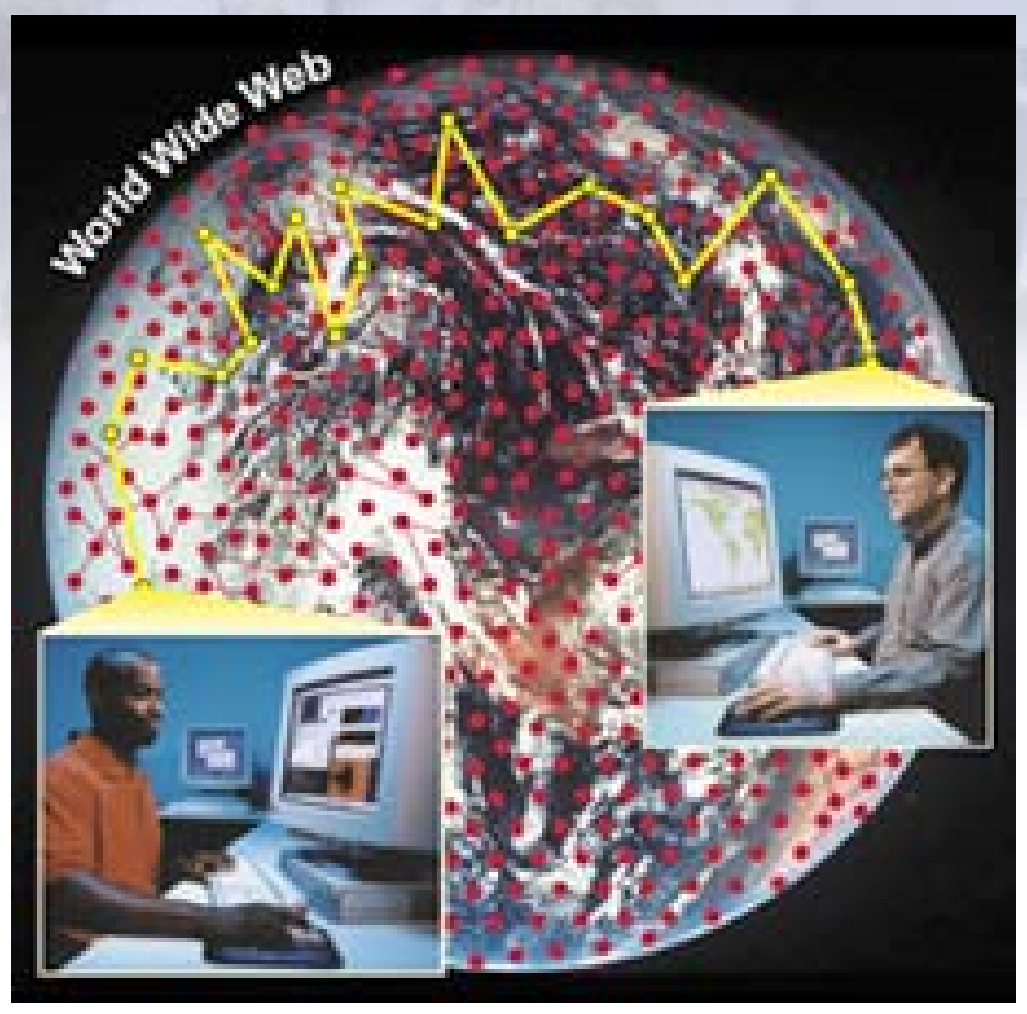

Figure B.4. Cybersecurity

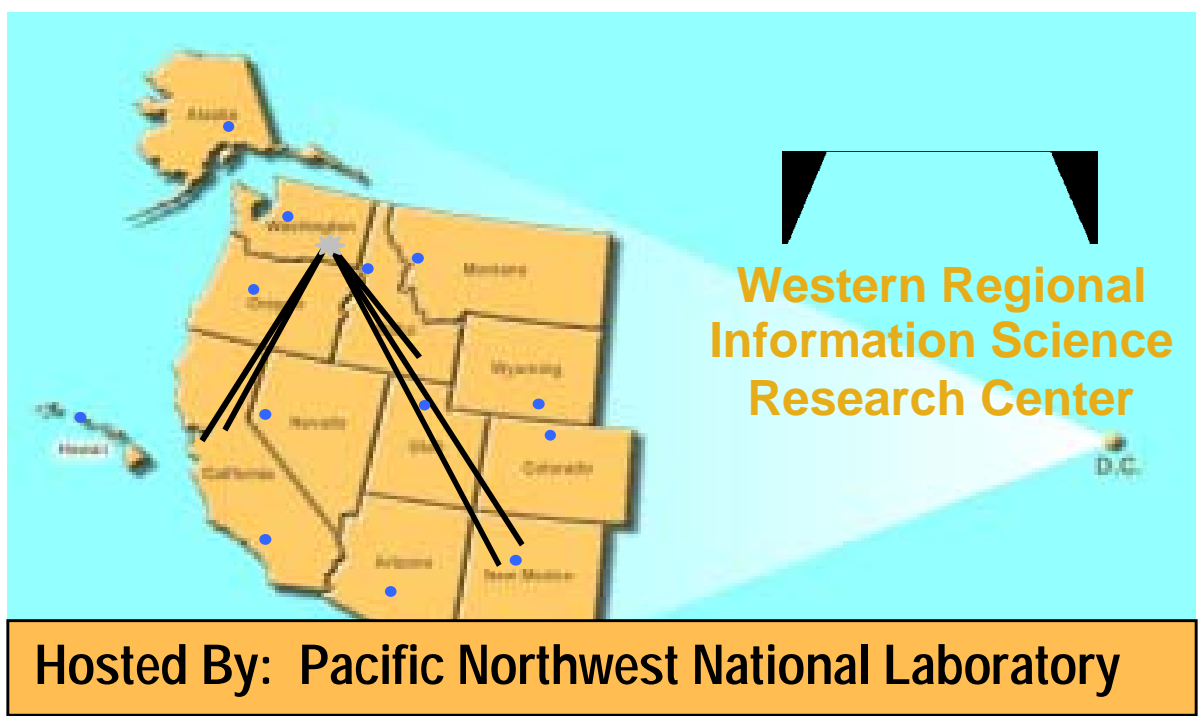

Figure B.5. ARDA Western Regional Information Science Research Center 
Relevance to the DOE Mission, National Needs and Management Effectiveness

Special Programs at PNNL strives to ensure that both our analytical and laboratory programs and projects are closely aligned with our DOE and IN missions and higher level national needs. In doing so we believe that our execution of those programs continues to represent strong management effectiveness.

\section{Relevance to the DOE Mission and National Needs}

PNNL continuously interacts with D OE-IN and senior IC leadership to ensure close alignment with current DOE and national needs. This is accomplished through frequent visits by high-ranking client representatives to PNNL and by PNNL staff and management meetings with clients in their facilities. In addition, PNNL has specifically placed several senior staff in key Interdepartmental Personnel Assignment (IPA) roles with most of our IC clients in order to ensure mission awareness with and provide essential technical liaison to these key clients.

- PNNL realigned staff assignments at D OE-IN to support a new organization of IN

- PNNL hosted frequent visits by deputy director and technical director-level government executives and military officers at PNNL during FY 2002 and has engaged several active and retired officials from the IC as external advisors to several laboratory directed research and development (LDRD) initiatives

- PNNL will staff the DOE-IN liaison position to USSO CO M by the start of FY 2003 as a result of bilateral agreements with DOE-IN and USSO COM

- PNNL will provide a senior executive to the Central MASINT Office (CMO) in FY2003 who will serve as the CMO liaison to all members of the IC and the D OE national laboratories.

\section{Management Effectiveness}

Every program executed by PNNL under the auspices of Special Programs during FY2002 has been accomplished within budget, scope, and schedule guidelines as agreed to with our various client representatives. We consistently meet and exceed our client expectations for high-quality and timely deliverables.

PNNL internal investment has resulted in considerably enhanced, secure facilities to support our growing business base in national security programs. These investments include:
- SCIF expansion program in FY 2002 quadrupled secure floor space at the SCI level at PNNL

- video teleconference capabilities for both SRD and SCI Levels have been upgraded during FY 2002

- enlargement of our Limited Area Island (LAI) and secure communications facility supporting PNNL's Marine Sciences Laboratory at Sequim, WA.

\section{Office of Counterintelligence (CN)}

\section{The CI Program Collaborates with PNNL RD Staff To Achieve CN's National Objective}

The PNNL Counterintelligence (CI) Sector is comprised of three separate elements assigned to its National Security Directorate (NSD). O ne of those elements is the CI Program O rganization. This group has as its primary function the duty to perform essential CI mission responsibilities defined in the Laboratory D OE contract. That mission is to protect D OE/ NNSA classified and sensitive programs and information, personnel, and assets from foreign intelligence and international terrorist activities; and to detect and deter trusted insiders who would engage in activities on behalf of a foreign intelligence service or terrorist organization.

The CI Program Organization is managed and supervised by a Senior Counterintelligence O fficer, who reports concurrently to the Director of CN and Senior Management at PNNL. With its total staff of ten fulltime and one part-time employees, the PNNL CI Program has grown into one of the complex's largest and most active CI efforts. The other two significant elements that make up the PNNL CN Sector consist of special PNNL teams that support CN projects involving its Information / Special Technology Program (ISTP), in particular the Inquiry Management and Analysis Capability (IMAC) coupled with its O perational Analysis Center (OAC); the CN Inspection Program; and the D OE Polygraph Program. The combined FY 2002 budget for each of the three PNNL CN Sector elements totals approximately $\$ 15$ million.

CN managers consistently recognize the PNNL CN Sector as an important contributor to their national program goals and objectives as well as one of their most effective elements in the complex. This assessment has been validated by the consecutive outstanding ratings awarded PNNL during the last three fiscal years and, more recently, by the extremely high adjective rating its 
Inspection Program Team provided to PNNL during their June 2002 bi-annual review. PNNL continues to sustain this level of outstanding performance, as evidenced by the laudatory feedback received this fiscal year from $\mathrm{CN}$ managers during scheduled review conferences. PNNL's NSD attaches high importance to client satisfaction, and emphatically considers it to be its primary performance indicator and benchmark to measure success.

CN elements at PNNL are fully committed to the fundamental principle that their basic existence is to provide support to both the five over-arching national goals defined in the CN 2002 Strategic Plan, as well as the critical outcome objectives defined by PNNL in its articulated strategy. Execution of these responsibilities is accomplished with deference toward understanding the importance of preserving an open, but appropriate, scientific environment, to include sound management of foreign interactions beneficial to national security interests. Additionally, it is continuously stressed that an effective CI effort enhances our over-all reputation in scientific circles, thus contributing in a positive way to our ability to provide quality science. Additionally, achieving balance and integration in each key function area is another fundamental foundation in the PNNL CI strategic effort. This integrated approach is illustrated in the table below.

PNNL CI managers generally implement their respective program responsibilities using a team/ collaborative approach, partnering with key security professionals, scientists, and administrative personnel through pertinent working groups, special projects, and PNNL initiatives. Emphasis on CI awareness, sound and wellresearched threat analysis, and thorough and aggressive investigative responses supported by effective liaison within the IC-both in the traditional and cyber sectors of CI-have been vital to achieving the program's successful execution.

The June 2002 bi-annual inspection of PNNL's CI Program was very complimentary toward its staff and their accomplishments. The Lead Inspector, during his outbriefing, indicated that he summarily rated the CI Program as "excellent", the highest evaluation possible according to their unique and extremely rigid standards. The program was described as "... a mature, integrated program, with high morale, very productive, dedicated, and committed staff, with strong management and all elements in place and functioning effectively...." The Inspection Team also identified the existence of a number of best practices.

The strategic goals of the PNNL CI Program continue to be focused on: 1) identifying hostile foreign intelligence collection and terrorist activities in order to address their respective threats against our staff and programs; 2) identifying and eliminating risks of espionage (both traditional and economic); and 3) educating our staff to recognize hostile foreign intelligence collection and terrorist activities. Evaluation of PNNL's success in achieving these goals is regularly assessed and updated through processes based on qualitative and

\section{Essential Mission: Detection, assessment, and neutralization of foreign adversary targeting while preserving an open scientific environment}

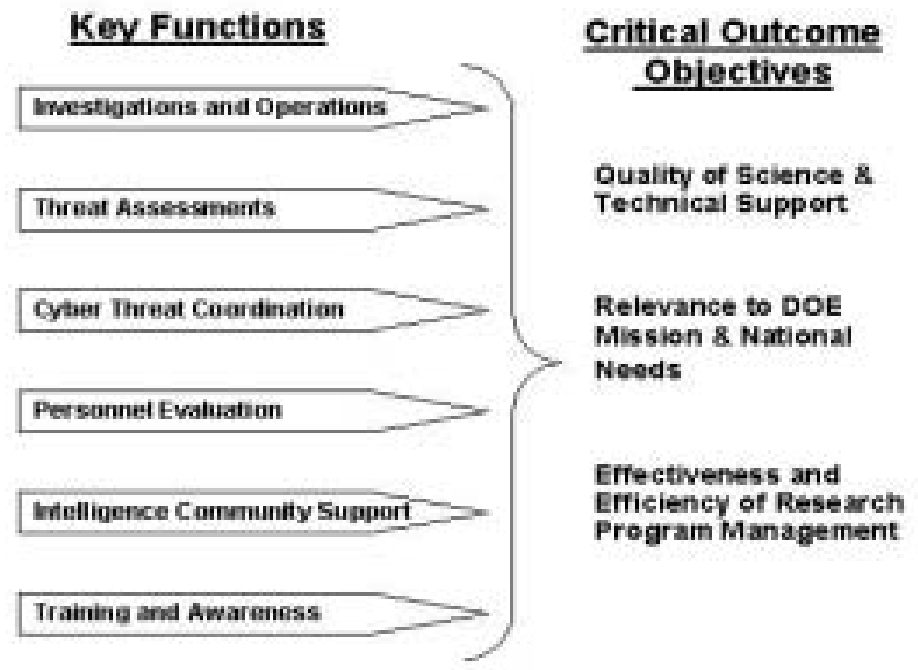

Figure B.6. Strategic Planning: CN/PNNL Integration 
quantitative performance standards that are consistent with CN's 2002 Strategic Plan and previous directives.

Some noteworthy accomplishments achieved by PNNL's CN elements, matched against their relevant critical outcome objectives, are as follows:

\subsection{Quality of Science and Technology}

Through an effective CI Program, the integrity and reputation of the PNNL scientific community is enhanced to a degree that positively impacts the Laboratory's potential to achieve its defined mission. The outstanding quality of the science and technology we deliver to our client is best reflected by the results we have achieved in the CI Program's key function areas.

- Implemented / completed special analytical initiatives that positively contributed to achieving D OE goals to protect sensitive information and technologies from exploitation by hostile foreign intelligence services and/ or terrorist organizations.

- Conducted special analytical reviews to determine risk and vulnerabilities relative to staff interactions involving foreign national visits and assignments, unsolicited or suspect electronic communications, and other contacts and project matters.

- Conducted and documented formal investigative inquiries to resolve anomalous reports from PNNL staff and other sources related to incidents of CI concern.

- Completed on schedule the implementation of the initial phase of the IMAC and established dedicated facilities, staff, and operational protocols to support its related OAC.

- O rganized and conducted multiple CI awareness presentations for PNNL science and technology staff on foreign collection and terrorism issues related to staff travel and other foreign interactions.

- D eveloped a standard training model covering CI awareness issues applicable for cyber work performed by the system administrator population.

- D eveloped an improved CI Program website to assist staff in the ready retrieval of timely issuerelevant CI information.

\subsection{Relevance to DOE Mission and National Needs}

PNNL has fully integrated key elements of CN's 2002 Strategic Plan into all aspects of CI project management, and its CI Program is a positive contributor to the critical outcomes defined in the Laboratory's Institutional Plan.

- Provided significant support to CN in its 2002 redraft of its national CI Strategic Plan and chaired a working group that defined the role of DOE's CI Awareness Sub-Program in that Strategic Plan.

- PNNL CI staff were active participants in technical and policy committees for DOE and the Site.

- Through the efforts of the PNNL OAC, enhanced the value added quality of cyber intrusion data through the production of Information Intelligent Reports (IIR) directed toward members of the Intelligence Community, and other special reports that supported threat analysis conducted by D OE CI staff at other national laboratories and field sites.

- Enhanced Intelligence Community liaison channels by developing an active role for the PNNL CI Program in the Northwest Regional Counterintelligence Coordinating Committee (NWRCCC).

\subsection{Effectiveness and Efficiency of Research Program Management}

The priorities and strategies promulgated by PNNL's $\mathrm{CN}$ elements are based on effective integration in the program's key function areas and full coordination with its all CN sub-Program resources.

- Researched and published the first comprehensive regional CI threat assessment that addressed potential hostile foreign intelligence collection efforts at PNNL, the Hanford Site, and the Richland O perations O ffice, described during the PNNL CI Program inspection as "the best we've seen."

- Developed a new model that integrated CI cyber expertise into traditional CI investigative and analytical functions.

- Instituted a CI cyber relevant data collection and analysis process for CI threat review.

- Continued its progress toward growing a CI work force of excellence through on the job mentoring and special training initiatives. 


\section{Appendix C \\ Critical Outcome Performance Ratings}




\section{Appendix C - Critical Outcome Performance Ratings}

Battelle's performance rating for FY 2002 is developed by determining the year-end level of performance for each performance indicator, compared to the individual targets established in the FY 2002 Performance Evaluation \& Fee Agreement. This level of performance is then judged against the metrics developed for each performance indicator and an appropriate adjectival rating is assigned. The adjectival rating for each performance indicator is inserted into the rating tables and Value Points are assigned, based on the following scale:

$\begin{array}{ll}\text { Outstanding } & 4 \text { points } \\ \text { Excellent } & 3 \text { points } \\ \text { Good } & 2 \text { points } \\ \text { Marginal } & 1 \text { point } \\ \text { Unsatisfactory } & 0 \text { points }\end{array}$

The Value Points are added to the rating tables and are multiplied by the weight of each performance indicator and then added to develop the $\mathrm{O}$ bjective score. The O bjective scores are then multiplied by the Objective weightings and are added to develop the overall score for the Critical O utcome. The values from the individual Critical Outcome tables found in this Appendix are then transferred to Table C.1, and compared against the ranges found in Table C.2 to determine the Critical O utcome (adjectival) performance rating.

The individual (weighted) Critical O utcome scores are summed to determine the overall Laboratory score. This value is compared against the ranges found in Table C.2 to determine the Laboratory's overall FY2002 (adjectival) performance rating.

All numbers are rounded to the nearest hundredth and carried forward to the final Laboratory overall all rating, which is then rounded to the nearest tenth, using standard rounding convention.

Table C.1. FY2002 Overall Performance Score

\begin{tabular}{|lclccc|}
\multicolumn{1}{|c}{ Critical O utcome } & $\begin{array}{c}\text { Value } \\
\text { Points }\end{array}$ & $\begin{array}{c}\text { Adjectival } \\
\text { Rating }\end{array}$ & Weight & $\begin{array}{c}\text { Weighted } \\
\text { Score }\end{array}$ & $\begin{array}{c}\text { Total } \\
\text { Score }\end{array}$ \\
\hline $\begin{array}{l}\text { 1.0 } \begin{array}{l}\text { Scientific and Technological Excellence } \\
\text { (roll-up from Table C.3) }\end{array} \\
\text { 2.0 }\end{array}$ & 3.95 & Outstanding & $60 \%$ & 2.37 \\
$\begin{array}{l}\text { Management and Operations Excellence } \\
\text { (roll-up from Table C.9) }\end{array}$ & 3.91 & Outstanding & $25 \%$ & 0.98 \\
$\begin{array}{l}\text { 3.0 Leadership Excellence } \\
\text { (roll-up from Table C.13) }\end{array}$ & 4.00 & Outstanding & $15 \%$ & 0.60 & \\
\hline & & & & $\begin{array}{c}\text { Total } \\
\text { Score }\end{array}$ & 3.9 \\
\hline
\end{tabular}

Table C.2. FY2002 Adjectival Rating Scale

\begin{tabular}{|lccccc|}
\hline Total Score & $4.0-3.5$ & $3.4-2.5$ & $2.4-1.5$ & $1.4-0.5$ & $<0.5$ \\
Final Rating & Outstanding & Excellent & G ood & Marginal & Unsatisfactory \\
\hline
\end{tabular}


Table C.3. Scientific and Technological Excellence Critical Outcome Performance Rating

\begin{tabular}{|c|c|c|c|c|c|c|}
\hline ELEMENT & $\begin{array}{l}\text { Adjectival } \\
\text { Rating }\end{array}$ & $\begin{array}{l}\text { Value } \\
\text { Points }\end{array}$ & $\begin{array}{l}\text { Indicator } \\
\text { Weight }\end{array}$ & $\begin{array}{l}\text { Total } \\
\text { Points }\end{array}$ & $\begin{array}{l}\text { Objective } \\
\text { Weight }\end{array}$ & $\begin{array}{l}\text { Total } \\
\text { Points }\end{array}$ \\
\hline \multicolumn{7}{|l|}{$\begin{array}{l}1.0 \text { Scientific and Technological } \\
\text { Excellence }\end{array}$} \\
\hline $\begin{array}{l}\text { Objectives } 1.1 \text { through 1.4: Program } \\
\text { Office Total Scores (from Table C.4) }\end{array}$ & Outstanding & & & 4.00 & $85 \%$ & 3.40 \\
\hline \multicolumn{7}{|l|}{$\begin{array}{l}1.5 \text { Create leading-edge scientific } \\
\text { capabilities to support evolving } \\
\text { DOE Mission needs. }\end{array}$} \\
\hline 1.5.1 Progress against Biomolecular & Outstanding & 4.00 & $50 \%$ & 2.00 & & \\
\hline $\begin{array}{l}\text { 1.5.2 Progress against Computational } \\
\text { Sciences and Engineering Initiative } \\
\text { expected outcomes (roll up from Table }\end{array}$ & $\begin{array}{l}\text { Outstanding } \\
\text { C. } 6 \text { ) }\end{array}$ & 4.00 & $35 \%$ & 1.40 & & \\
\hline \multirow[t]{2}{*}{$\begin{array}{l}\text { 1.5.3 Progress against the Nanoscience and } \\
\text { Technology expected outcomes } \\
\text { (roll up from Table C.7) }\end{array}$} & Outstanding & 4.00 & $15 \%$ & 0.60 & & \\
\hline & & \multicolumn{2}{|c|}{ Objective 1.5 Total } & 4.00 & $10 \%$ & 0.40 \\
\hline \multicolumn{7}{|l|}{$\begin{array}{l}1.6 \text { Create and maintain strategic } \\
\text { academic partnerships that } \\
\text { strengthen scientific capabilities }\end{array}$} \\
\hline \multicolumn{7}{|l|}{$\begin{array}{l}\text { 1.6.1 Impact of the Joint G lobal Change } \\
\text { Research Institute with University of } \\
\text { Maryland }\end{array}$} \\
\hline \multirow[t]{3}{*}{$\begin{array}{l}\text { 1.6.2 Impact of the Joint Research } \\
\text { Institute with University of } \\
\text { Washington (roll up from Table C.8) }\end{array}$} & Outstanding & 4.00 & $50 \%$ & 2.00 & & \\
\hline & & Object & ive 1.6 Total & 3.00 & $5 \%$ & 0.15 \\
\hline & & & Critict & al Outc & me 1.0 Total & 3.95 \\
\hline
\end{tabular}

Table C.4. Objectives 1.1 through 1.4 Evaluation Score Calculation for Program Offices

\begin{tabular}{|lccccc}
\multicolumn{1}{|c}{ HQ Program Office } & $\begin{array}{c}\text { Value } \\
\text { Points }\end{array}$ & $\begin{array}{c}\text { Adjectival } \\
\text { Rating }\end{array}$ & $\begin{array}{c}\text { Weight } \\
\text { Office of Science }\end{array}$ & $\begin{array}{c}\text { Weighted } \\
\text { Score }\end{array}$ & $\begin{array}{c}\text { Overall } \\
\text { Weighted } \\
\text { Score }\end{array}$ \\
Assistant Secretary for Environmental & 4 & Outstanding & $30 \%$ & 1.20 \\
Management & 4 & Outstanding & $25 \%$ & 1.00 \\
Office of D efense Nuclear Nonproliferation & 4 & Outstanding & $15 \%$ & 0.60 \\
Office of Intelligence & 4 & Outstanding & $5 \%$ & 0.20 \\
Office of Counterintelligence & 4 & Outstanding & $5 \%$ & 0.20 \\
Assistant Secretary for Energy Efficiency & & Outstanding & $10 \%$ & 0.40 \\
and Renewable Energy & 4 & Outstanding & $10 \%$ & 0.40 \\
Assistant Secretary for Fossil Energy & 4 & Overall Program Office Total & 4.00 \\
\hline
\end{tabular}


Table C.5. Performance Indicator 1.5.1 Score Calculation

\begin{tabular}{|llcccc|}
\multicolumn{1}{|c}{ ELEMENT } & $\begin{array}{c}\text { Value } \\
\text { Points }\end{array}$ & $\begin{array}{c}\text { Adjectival } \\
\text { Rating }\end{array}$ & Weight & $\begin{array}{c}\text { Overall } \\
\text { Weighted } \\
\text { Score }\end{array}$ & $\begin{array}{c}\text { Weighted } \\
\text { Score }\end{array}$ \\
1.5.1 & $\begin{array}{l}\text { Progress against Biomolecular } \\
\text { Systems Initiative expected outcomes }\end{array}$ & & & & \\
1.5.1.1 & Recruiting & 4 & Outstanding & $20 \%$ & 0.80 \\
1.5.1.2 & Program D evelopment & 4 & Outstanding & $20 \%$ & 0.80 \\
1.5.1.3 Partnerships and Collaborations & 4 & Outstanding & $20 \%$ & 0.80 \\
1.5.1.4 $\begin{array}{l}\text { Continued Technical and Scientific } \\
\text { Progress }\end{array}$ & 4 & Outstanding & $20 \%$ & 0.80 \\
1.5.1.5 Peer-Review & 4 & Outstanding & $20 \%$ & 0.80 \\
\hline
\end{tabular}

Table C.6. Performance Indicator 1.5.2 Score Calculation

\begin{tabular}{|c|c|c|c|c|c|c|}
\hline & ELEMENT & $\begin{array}{l}\text { Value } \\
\text { Points }\end{array}$ & $\begin{array}{c}\text { Adjectival } \\
\text { Rating }\end{array}$ & Weight & $\begin{array}{l}\text { Weighted } \\
\text { Score }\end{array}$ & $\begin{array}{l}\text { Overall } \\
\text { Weighted } \\
\text { Score }\end{array}$ \\
\hline 1.5 .2 & $\begin{array}{l}\text { Progress against Computational } \\
\text { Sciences and Engineering Initiative } \\
\text { expected outcomes }\end{array}$ & & & & & \\
\hline 1.5.2.1 & $\begin{array}{l}\text { Continued Technical and Scientific } \\
\text { Progress }\end{array}$ & 4 & Outstanding & $75 \%$ & 3.00 & \\
\hline 1.5.2.2 & $\begin{array}{l}\text { Establish a CS\&EI Advisory } \\
\text { Committee }\end{array}$ & 4 & O utstanding & $25 \%$ & 1.00 & \\
\hline & & & & Indi & 1.5.2 Total & 4.00 \\
\hline
\end{tabular}

Table C.7. Performance Indicator 1.5.3 Score Calculation

\begin{tabular}{|c|c|c|c|c|c|c|}
\hline & ELEMENT & $\begin{array}{l}\text { Value } \\
\text { Points }\end{array}$ & $\begin{array}{l}\text { Adjectival } \\
\text { Rating }\end{array}$ & Weight & $\begin{array}{l}\text { Weighted } \\
\text { Score }\end{array}$ & $\begin{array}{l}\text { Overall } \\
\text { Weighted } \\
\text { Score }\end{array}$ \\
\hline 1.5.3 & $\begin{array}{l}\text { Progress against the Nanoscience } \\
\text { and Technology expected outcomes }\end{array}$ & & & & & \\
\hline 1.5.3.1 & $\begin{array}{l}\text { Increase Visibility of Nanoscience } \\
\text { and Nanotechnology Activities at } \\
\text { PNNL }\end{array}$ & 4 & Outstanding & $33 \%$ & 1.32 & \\
\hline 1.5.3.2 & Project and Program D evelopment & 4 & Outstanding & $33 \%$ & 1.32 & \\
\hline 1.5.3.3 & Overall Initiative Impact & 4 & Outstanding & $34 \%$ & 1.36 & \\
\hline \multicolumn{6}{|c|}{ Indicator 1.5.3 Total } & 4.00 \\
\hline
\end{tabular}


Table C.8. Performance Indicator 1.6.2 Score Calculation

\begin{tabular}{|c|c|c|c|c|c|c|}
\hline & ELEMENT & $\begin{array}{l}\text { Value } \\
\text { Points }\end{array}$ & $\begin{array}{l}\text { Adjectival } \\
\text { Rating }\end{array}$ & Weight & $\begin{array}{l}\text { Weighted } \\
\text { Score }\end{array}$ & $\begin{array}{l}\text { Overall } \\
\text { Weighted } \\
\text { Score }\end{array}$ \\
\hline 1.6 .2 & $\begin{array}{l}\text { Impact of the Joint Research Institute } \\
\text { with University of Washington }\end{array}$ & & & & & \\
\hline 1.6.2.1 & $\begin{array}{l}\text { Impact of the Nanoscience and } \\
\text { Nanotechnology Institute with the } \\
\text { University of Washington's }\end{array}$ & 4 & Outstanding & $60 \%$ & 2.40 & \\
\hline 1.6.2.2 & $\begin{array}{l}\text { Joint Program in Cell Signaling with } \\
\text { the University of Washington's Cell } \\
\text { System's Initiative and the } \\
\text { Laboratory's Biomolecular } \\
\text { Systems Initiative }\end{array}$ & 4 & Outstanding & $40 \%$ & 1.60 & \\
\hline & & & & Ind & 1.6.2 Total & 4.00 \\
\hline
\end{tabular}


Table C.9. Management and Operational Excellence Critical Outcome Performance Rating

\section{ELEMENT}

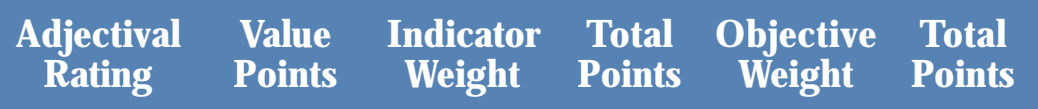

\subsection{Management and Operational Excellence}

2.1 Provide management and operational excellence in achieving key contract performance requirements

2.1.1 Provide E S\&H management systems that sustain and enhance Laboratory operations

2.1.2 Performance against business management sub-indicators (roll up from Table C.10)

Outstanding $\quad 4.00 \quad 25 \% \quad 1.00$

Excellent

2.1.3 Sustain and enhance the effectiveness of Integrated Safeguards and Security (roll up from Table C.11)

O utstanding

4.00

$25 \%$

2.1.4 Provide management and operational excellence in achieving adequate investment in maintenance and energy conservation efforts (roll up from Table C.12)

\subsection{Maintain and enhance Laboratory capabilities to meet current and future mission needs}

2.2.1 Effective execution of the Information Technology (IT) Infrastructure Strategic Plan to provide the IT infrastructure needed to achieve the 2010 Vision of O utstanding the Laboratory

2.2.2 Effective execution of the Facilities Strategic Plan to provide the facility space and infrastructure revitalization needed to achieve the 2010 Vision of the Laboratory

2.2.3 Effective execution of the Facilities Strategic Plan to provide the facility space and infrastructure modernization Outstanding needed to achieve the 2010 Vision of the Laboratory

\subsection{Provide integrated management systems that enable effective and efficient business performance}

2.3.1 Progress against selected Operations Improvement Initiative (OII) projects designed to increase the efficiency and Outstanding effectiveness of laboratory management systems 
Table C.10. Performance Indicator 2.1.2 Score Calculation

\begin{tabular}{|c|c|c|c|c|c|c|}
\hline \multicolumn{2}{|r|}{ ELEMENT } & \multirow[t]{2}{*}{$\begin{array}{l}\text { Value } \\
\text { Points }\end{array}$} & \multirow[t]{2}{*}{$\begin{array}{l}\text { Adjectival } \\
\text { Rating }\end{array}$} & \multirow[t]{2}{*}{ Weight } & \multirow[t]{2}{*}{$\begin{array}{l}\text { Weighted } \\
\text { Score }\end{array}$} & \multirow[t]{2}{*}{$\begin{array}{l}\text { Overall } \\
\text { Weighted } \\
\text { Score }\end{array}$} \\
\hline 2.1 .2 & $\begin{array}{l}\text { Performance against Business } \\
\text { Management sub-indicators }\end{array}$ & & & & & \\
\hline 2.1.2.1 & $\begin{array}{l}\text { Cost Management Trends: } \\
\text { Overhead cost as a percent of } \\
\text { Laboratory's } 1830 \text { fully burdened } \\
\text { average charge out rate }\end{array}$ & 4 & Outstanding & $50 \%$ & 2.00 & \\
\hline 2.1.2.2 & $\begin{array}{l}\text { Cost Management Trends: Total } \\
\text { O verhead cost as a multiplier on } \\
\text { the Laboratory's total direct costs } \\
\text { charged to customers }\end{array}$ & 1 & Marginal & $25 \%$ & 0.25 & \\
\hline 2.1.2.3 & $\begin{array}{l}\text { Resource Management Trends: } \\
\text { Direct FTE's as a percent of the } \\
\text { total Laboratory FTE's }\end{array}$ & 4 & O utstanding & $25 \%$ & 1.00 & \\
\hline & & & & Indi & 2.1.2 Total & 3.25 \\
\hline
\end{tabular}

Table C.11. Performance Indicator 2.1.3 Score Calculation

\begin{tabular}{|c|c|c|c|c|c|c|}
\hline \multicolumn{2}{|r|}{ ELEMENT } & \multirow[t]{2}{*}{$\begin{array}{l}\text { Value } \\
\text { Points }\end{array}$} & \multirow[t]{2}{*}{$\begin{array}{l}\text { Adjectival } \\
\text { Rating }\end{array}$} & \multirow[t]{2}{*}{ Weight } & \multirow[t]{2}{*}{$\begin{array}{l}\text { Weighted } \\
\text { Score }\end{array}$} & \multirow[t]{2}{*}{$\begin{array}{l}\text { Overall } \\
\text { Weighted } \\
\text { Score }\end{array}$} \\
\hline 2.1 .3 & $\begin{array}{l}\text { Sustain and enhance the } \\
\text { effectiveness of Integrated } \\
\text { Safeguards and Security }\end{array}$ & & & & & \\
\hline 2.1.3.1 & $\begin{array}{l}\text { SAS is integrated into the culture } \\
\text { of the organization for effective } \\
\text { deployment of the management } \\
\text { system }\end{array}$ & 4 & Outstanding & $40 \%$ & 1.60 & \\
\hline 2.1.3.2 & $\begin{array}{l}\text { Safeguards and Security (SAS) } \\
\text { training and knowledge are } \\
\text { commensurate with assigned } \\
\text { responsibilities }\end{array}$ & 4 & Outstanding & $20 \%$ & 0.80 & \\
\hline 2.1.3.3 & $\begin{array}{l}\text { External evaluations of } \\
\text { performance in SAS programmatic } \\
\text { areas reflect satisfactory protection } \\
\text { of assets and compliance }\end{array}$ & 4 & Outstanding & $20 \%$ & 0.80 & \\
\hline 2.1.3.4 & $\begin{array}{l}\text { Emerging threats are identified, } \\
\text { reported, and mitigated as } \\
\text { necessary }\end{array}$ & 4 & Outstanding & $20 \%$ & 0.80 & \\
\hline & & & & Indi & 2.1.3 Total & 4.00 \\
\hline
\end{tabular}


Table C.12. Performance Indicator 2.1.4 Score Calculation

\begin{tabular}{|c|c|c|c|c|c|c|}
\hline \multicolumn{2}{|r|}{ ELEMENT } & \multirow[t]{2}{*}{$\begin{array}{l}\text { Value } \\
\text { Points }\end{array}$} & \multirow[t]{2}{*}{$\begin{array}{l}\text { Adjectival } \\
\text { Rating }\end{array}$} & \multirow[t]{2}{*}{ Weight } & \multirow[t]{2}{*}{$\begin{array}{l}\text { Weighted } \\
\text { Score }\end{array}$} & \multirow[t]{2}{*}{$\begin{array}{l}\text { Overall } \\
\text { Weighted } \\
\text { Score }\end{array}$} \\
\hline 2.1 .4 & $\begin{array}{l}\text { Performance against Facilities } \\
\text { and Operations maintenance } \\
\text { sub-indicators }\end{array}$ & & & & & \\
\hline 2.1.4.1 & $\begin{array}{l}\text { Annual actual maintenance cost } \\
\text { for PNNL facilities as a } \\
\text { percentage of the Replacement } \\
\text { Plant Value (RPV) }\end{array}$ & 4 & Outstanding & $40 \%$ & 1.60 & \\
\hline 2.1.4.2 & $\begin{array}{l}\text { Identification and implementation } \\
\text { of energy conservation measures } \\
\text { that are commensurate with the } \\
\text { Laboratory's strategy to establish } \\
\text { a sustainable environment for } \\
\text { conducting research and } \\
\text { development }\end{array}$ & 4 & Outstanding & $60 \%$ & 2.40 & \\
\hline & & & & Indic & 2.1.4 Total & 4.00 \\
\hline
\end{tabular}

Table C.13. Leadership Excellence Critical Outcome Performance Ratings

\begin{tabular}{|c|c|c|c|c|c|c|}
\hline ELEMENT & $\begin{array}{l}\text { Adjectival } \\
\text { Rating }\end{array}$ & $\begin{array}{l}\text { Value } \\
\text { Points }\end{array}$ & $\begin{array}{l}\text { Indicator } \\
\text { Weight }\end{array}$ & $\begin{array}{l}\text { Total } \\
\text { Points }\end{array}$ & $\begin{array}{l}\text { Objective } \\
\text { Weight }\end{array}$ & $\begin{array}{l}\text { Total } \\
\text { Points }\end{array}$ \\
\hline $\begin{array}{l}\text { 3.0 Leadership Excellence } \\
\text { 3.1 Attract, develop and retain the } \\
\text { critical staff necessary to achieve } \\
\text { simultaneous excellence in } S \& T \text {, } \\
\text { operations, and community trust }\end{array}$ & & & & & & \\
\hline $\begin{array}{l}\text { 3.1.1 Implement a Laboratory level } \\
\text { assessment that establishes a baseline } \\
\text { for measuring staff engagement }\end{array}$ & Outstanding & 4 & $20 \%$ & 0.80 & & \\
\hline $\begin{array}{l}\text { 3.1.2 Achieve and maintain competitive } \\
\text { base pay levels for all job } \\
\text { classifications }\end{array}$ & Outstanding & 4 & $40 \%$ & 1.60 & & \\
\hline $\begin{array}{l}\text { 3.1.3 Achieve and maintain an voluntary } \\
\text { separation rate (VSR) at or below } \\
\text { industry average }\end{array}$ & Outstanding & 4 & $40 \%$ & 1.60 & & \\
\hline & & Object & ve 3.1 Total & 4.00 & $30 \%$ & 1.20 \\
\hline $\begin{array}{l}\text { 3.2 Help define and shape the future } \\
\text { of the Region by helping to } \\
\text { establish a robust, sustainable, } \\
\text { regional economy }\end{array}$ & & & & & & \\
\hline $\begin{array}{l}\text { 3.2.1 The number of new businesses started } \\
\text { or expanded in the local area where } \\
\text { Battelle had a material role in their } \\
\text { establishment }\end{array}$ & O utstanding & 4 & $30 \%$ & 1.20 & & \\
\hline $\begin{array}{l}\text { 3.2.2 Effectiveness in providing technical } \\
\text { assistance to regional firms }\end{array}$ & Outstanding & 4 & $35 \%$ & 1.40 & & \\
\hline $\begin{array}{l}\text { 3.2.3 D evelop and champion at least one } \\
\text { new economic development initiative }\end{array}$ & Outstanding & 4 & $35 \%$ & 1.40 & & \\
\hline & & Objec & 3.2 Total & 4.00 & $30 \%$ & 1.20 \\
\hline
\end{tabular}


Table C.13. (continued)

\begin{tabular}{|c|c|c|c|c|c|c|c|}
\hline & ELEMENT & $\begin{array}{l}\text { Adjectival } \\
\text { Rating }\end{array}$ & $\begin{array}{l}\text { Value } \\
\text { Points }\end{array}$ & $\begin{array}{l}\text { Indicator } \\
\text { Weight }\end{array}$ & $\begin{array}{l}\text { Total } \\
\text { Points }\end{array}$ & $\begin{array}{l}\text { Objective } \\
\text { Weight }\end{array}$ & $\begin{array}{l}\text { Total } \\
\text { Points }\end{array}$ \\
\hline \multicolumn{8}{|c|}{$\begin{array}{l}\text { 3.3 Demonstrate the relevance of the } \\
\text { National Laboratory and other } \\
\text { Northwest research institutions to } \\
\text { the economic, science and } \\
\text { technology needs of the region }\end{array}$} \\
\hline 3.3.1 & $\begin{array}{l}\text { Establish meaningful partnerships to } \\
\text { link regional needs to science and } \\
\text { technology strategies }\end{array}$ & Outstanding & 4 & $35 \%$ & 1.40 & & \\
\hline 3.3.2 & $\begin{array}{l}\text { Focus efforts of the regions' research } \\
\text { institutions and business communities } \\
\text { and units of government on } \\
\text { implementing new S\&T solutions to } \\
\text { a critical few consensus needs of } \\
\text { the Northwest }\end{array}$ & Outstanding & 4 & $35 \%$ & 1.40 & & \\
\hline \multirow[t]{2}{*}{ 3.3.3 } & $\begin{array}{l}\text { Initiate efforts to analyze and leverage } \\
\text { the Intellectual property (IP) of the } \\
\text { major regional research and } \\
\text { development institutions }\end{array}$ & Outstanding & 4 & $30 \%$ & 1.20 & & \\
\hline & & & Objec & ive 3.3 Total & 4.00 & $20 \%$ & 0.80 \\
\hline \multicolumn{2}{|c|}{$\begin{array}{l}\text { 3.4 Continue excellence of the } \\
\text { Laboratory's K-20 programs to } \\
\text { further and enhance science, } \\
\text { mathematics and technology } \\
\text { education }\end{array}$} & & & & & & \\
\hline & $\begin{array}{l}\text { Impacts of Laboratory-sponsored } \\
\text { programs for K-12 teachers of } \\
\text { science, mathematics, and } \\
\text { technology education in } \\
\text { partner school districts }\end{array}$ & Outstanding & & $65 \%$ & 2.60 & & \\
\hline \multirow[t]{2}{*}{3.4 .2} & $\begin{array}{l}\text { Impacts of Laboratory-sponsored } \\
\text { programs for secondary and } \\
\text { post-secondary students in the areas } \\
\text { of science, mathematics, engineering } \\
\text { and technology }\end{array}$ & Outstanding & & $35 \%$ & 1.40 & & \\
\hline & & & Object & ve 3.4 Total & 4.00 & $20 \%$ & 0.80 \\
\hline
\end{tabular}


Appendix D Acronyms 


\section{Appendix D - Acronyms}

\begin{tabular}{|c|c|}
\hline AAAS & American Association for the Advancement of Science \\
\hline ACPI & Accelerated Climate Prediction Initiative \\
\hline $\mathrm{AD} M$ & Archer Daniels Midland Corporation \\
\hline AESS & Aerospace and Electronics Systems Society \\
\hline ALD & Associate Laboratory Director \\
\hline ARMC & Assistant Manager River Corridor \\
\hline AMI & Assistant Manager for Integration \\
\hline ANL & Argonne National Laboratory \\
\hline AMT & Associate Manager for Science and Technology \\
\hline ANL & Argonne National Laboratory \\
\hline APA & Asset Protection Agreements \\
\hline $\mathrm{ARC}$ & Ames Research Center \\
\hline ARDA & Advanced Research and D evelopment Activity \\
\hline ARM & Atmospheric Radiation Monitoring program \\
\hline ASCR & Advanced Scientific Computing Research \\
\hline BER & U.S. D epartment of Energy, Office of Biological and Environmental Research \\
\hline BERAC & BER Advisory Committee \\
\hline BES & U.S. D epartment of Energy, O ffice of Basic Energy Science \\
\hline BMI & Battelle Memorial Institute \\
\hline BNI & Bechtel National Inc. \\
\hline BPA & Bonneville Power Administration \\
\hline $\mathrm{BRP}$ & Bioengineering Research Partnerships \\
\hline BSI & Biomolecular Systems Initiative \\
\hline C3T & Cleanup Constraints and Challenges Team \\
\hline CASB & Computational \& Analytical Sciences Building \\
\hline $\mathrm{CBC}$ & Columbia Basin College \\
\hline $\mathrm{CbT}$ & Combating Terrorism Program \\
\hline CCI & Community College Institute \\
\hline CERTS & Consortium for Electric Reliability Solutions \\
\hline CHG & CH2M HILL \\
\hline CI & PNNL Counterintelligence \\
\hline CID I & Compression Injection D irect Injection \\
\hline CMO & Central MASINT Office \\
\hline $\mathrm{CN}$ & U.S. D epartment of Energy, Office of Counterintelligence \\
\hline COTS & Commercial Off The Shelf \\
\hline CR & Compa-Ratio \\
\hline CRADA & Cooperative Research and D evelopment Agreement \\
\hline CRN & Climate Reference Network \\
\hline CS\&EI & Computational Science \& Engineering Initiative \\
\hline CSI & Computational Science \& Engineering Initiative \\
\hline DARPA & D efense Advanced Research Projects Agency \\
\hline DCI & D irector of Central Intelligence \\
\hline D E \&ER & D istributed Energy \& Energy Reliability Program \\
\hline $\mathrm{DfN}$ & D ebt for Nonproliferation \\
\hline D NA & D eoxyribose Nucleic Acid \\
\hline DNFSB & D efense Nuclear Facilities Safety Board \\
\hline
\end{tabular}




\begin{tabular}{|c|c|}
\hline D oD & D epartment of D efense \\
\hline DOE & U.S. D epartment of Energy \\
\hline DOELAP & D epartment of Energy Laboratory Accreditation Program \\
\hline DOE-CN & U.S. D epartment of Energy, Office of Counterintelligence \\
\hline DOE-EM & U.S. D epartment of Energy, Office of Environmental Management \\
\hline DOE-FE & U.S. D epartment of Energy, Office of Fossil Energy \\
\hline DOE-HQ & U.S. D epartment of Energy, Headquarters \\
\hline DOE-IN & U.S. D epartment of Energy, O ffice of Intelligence \\
\hline D O E-NA-20 & U.S. Department of Energy, O ffice of Defense Nuclear Nonproliferation \\
\hline DOE-NE & U.S. D epartment of Energy, O ffice of Nuclear Energy \\
\hline DOE-ORP & U.S. D epartment of Energy, O ffice of River Protection \\
\hline DOE-RL & U.S. D epartment of Energy, Richland Operations \\
\hline DOE-SC & U.S. D epartment of Energy, Office of Science \\
\hline D RC & D irectorate Review Committee \\
\hline DPRK & Democratic Peoples Republic of Korea \\
\hline D SO M & D ecision Support for Operations and Maintenance \\
\hline DST & Hanford D ouble-Shell Tank \\
\hline $\mathrm{EAB}$ & External Advisory Board \\
\hline EED & Energy \& Engineering Division \\
\hline EERE & U.S. D epartment of Energy, O ffice of Energy Efficiency and Renewable Energy \\
\hline EESB & Energy and Environmental Sciences Building \\
\hline EEOICPA & Energy Employee O ccupational Illness Compensation Program Act \\
\hline EFCOG & Energy Facility Contractors G roup \\
\hline E M & U.S. D epartment of Energy, Office of Environmental Management \\
\hline EMSL & Environmental Molecular Science Laboratory \\
\hline EMSP & Environmental Management Science Program \\
\hline EPA & Environmental Protection Agency \\
\hline EPR & Electronic Prep \& Risk \\
\hline EPS & Essential Power System \\
\hline EPSCoR & Experimental Program to Stimulate Competitive Research \\
\hline ERICA & Electronic Records and Information Capture Architecture \\
\hline ERS & EMSL Resource System \\
\hline ES\&H & Environment Safety \& Health \\
\hline E SH\&Q & Environment, Safety, Health and Q uality \\
\hline ESnet & Energy Sciences Network \\
\hline ESTD & Energy Science \& Technology Directorate \\
\hline ESTI & Energy System Transformation Initiative \\
\hline ETD & Environmental Technology Directorate \\
\hline EWGPP & Elimination of Weapons Grade Plutonium Production \\
\hline FaST & Faculty and Student Teams Program \\
\hline FBI & Federal Bureau of Investigation \\
\hline $\mathrm{FE}$ & U.S. D epartment of Energy, Office of Fossil Energy \\
\hline FEMP & Federal Energy Management Program \\
\hline FERC & Federal Energy Regulatory Commission \\
\hline $\mathrm{FH}$ & Fluor Hanford \\
\hline FLC & Federal Laboratory Consortium \\
\hline F\&O & Facilities and O perations \\
\hline FMS & Functionalized Mesoporous Silica \\
\hline FRAEC & Foundation for Russian American Economic Cooperation \\
\hline FSD & Fundamental Sciences Directorate \\
\hline FTE & Full Time Equivalent \\
\hline FWP & Field Work Proposal \\
\hline
\end{tabular}




$\begin{array}{ll}\text { G-1 } & \text { Gulfstream One } \\ \text { GA } & \text { Global Array } \\ \text { GAN } & \text { Gosatomnadzor - Russian regulatory agency } \\ \text { G M } & \text { General Motors } \\ \text { GPRA } & \text { Government Performance and Results Act } \\ \text { GTL } & \text { Genomes to Life program } \\ \text { GUI } & \text { Graphic User Interface }\end{array}$

$\begin{array}{ll}\text { HAB } & \text { Hanford Advisory Board } \\ \text { HiTEC } & \text { High Temperature Electrochemistry Center } \\ \text { HLW } & \text { High Level Waste } \\ \text { HP } & \text { Hewlett-Packard } \\ \text { HVAC } & \text { Heating, Ventilation, and Air Conditioning } \\ \text { HVAC } & \text { High Voltage Alternating Current }\end{array}$

ID C International Development Center

IC Intelligence Community

IFMA International Facility Management Association

IGRSS Institute for G lobal and Regional Security Studies

IIR Information Intelligent Reports

IMAC Inquiry Management and Analysis Capability

IN U.S. D epartment of Energy, Office of Intelligence

INE EL Idaho National Engineering and Environmental Laboratory

I-NERI International Nuclear Research Initiative

INIE Innovations in Nuclear Infrastructure Education

INSP International Nuclear Safety Program

IOPS Integrated Operations System

IP Intellectual Property

IPA Interdepartmental Personnel Assignments

IPEP Integration Project Expert Panel

IPP Initiatives for Proliferation Prevention

IRS Internal Revenue Service

ISI Institute for Scientific Information

ISM Integrated Safety Management

ISO International O rganization for Standardization

ISSM Integrated Safeguards and Security Management

ISU Iowa State University

IT Information Technology

ITP Integrated Technical Plan

IWFO Intelligence Work for O thers

JG CRI Joint G lobal Change Research Institute

JI

JIN

Joint Institute

Joint Institute for Nanoscience

JTAW Joint Technical Aspects Working Group

LAB Laboratory Advisory Board

LAI Limited Area Island

LASER Leadership and Assistance for Science Education Reform

LBNL Lawrence Berkeley National Laboratory

LBNL/ UC Lawrence Berkeley National Laboratory/ University of California 


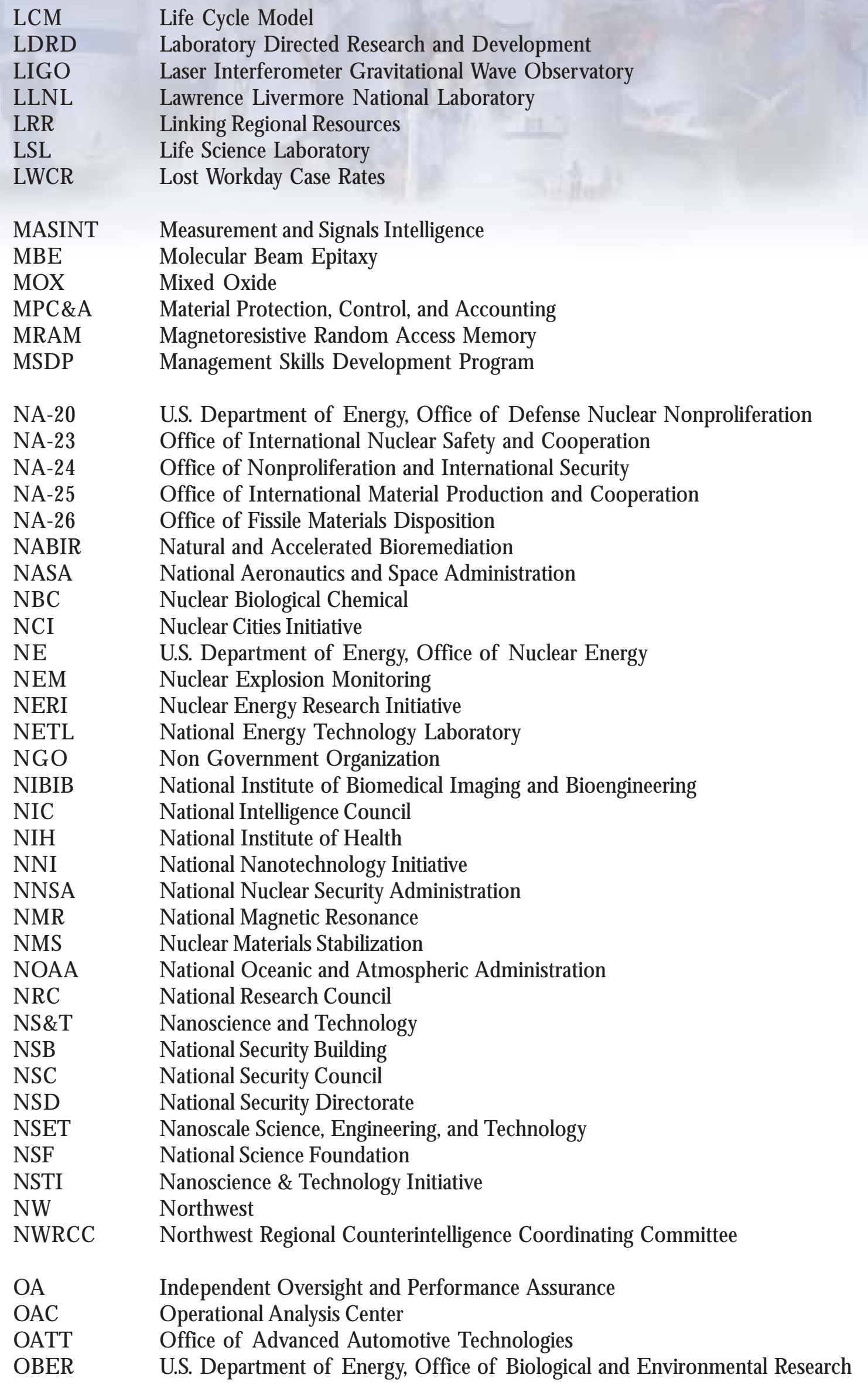




\begin{tabular}{|c|c|}
\hline FCVT & O ffice of Freedom Car and Vehicle Technologies \\
\hline OHSU & O regon Health Sciences University \\
\hline OHVT & O ffice of Heavy Vehicle Technologies \\
\hline OII & Operations Improvement Initiative \\
\hline $\mathrm{OMB}$ & Office of Management and Budget \\
\hline OPA & Outstanding Performance Award \\
\hline $\mathrm{OPH}$ & Organophosphorus Hydrolase \\
\hline ORNL & Oak Ridge National Laboratory \\
\hline $\mathrm{ORNL} / \mathrm{UT}$ & Oak Ridge National Laboratory/ University of Tennessee \\
\hline ORP & U.S. D epartment of Energy, O ffice of River Protection \\
\hline OSHA & O ccupational Safety and Health Administration \\
\hline OSTI & Office of Science and Technology Information \\
\hline PALS & Partnership for Arid Lands Stewardship \\
\hline PDCF & Pit D isassembly and Conversion Facility \\
\hline PEFA & Performance Evaluation and Fee Agreement \\
\hline PI & Principal Investigator \\
\hline PiCEIS & Parallel Computational Environment for Imaging Science \\
\hline PKI & Public Key Infrastructure \\
\hline PNAS & Proceedings of the National Academy of Sciences \\
\hline PNNL & Pacific Northwest National Laboratory \\
\hline PNWCGS & Pacific Northwest Center for Global Security \\
\hline PSRPP & Public Safety and Resource Protection Program \\
\hline PST & Pre-Service Teacher \\
\hline$R \& D$ & Research and D evelopment \\
\hline RCC & River Corridor Cleanup \\
\hline $\mathrm{RCHN}$ & Richland North Network \\
\hline REX & Radiological Exposure System \\
\hline RFP & Request for Proposal \\
\hline RL & U.S. Department of Energy, Richland Operations \\
\hline RMT & Radioactive Material Tracking \\
\hline ROD & Record of Decision \\
\hline ROK & Republic of Korea \\
\hline RPL & Radiochemical Processing Laboratory \\
\hline RPP & Hanford's River Protection Project \\
\hline RPV & Replacement Plant Value \\
\hline S\&E & Science and Engineering \\
\hline S\&T & Science and Technology \\
\hline SAC & System Assessment Capability \\
\hline SAMMS & Self-Assembled Monolayers on Mesoporous Supports \\
\hline SAS & Safeguards and Security \\
\hline SBIR & Small Business Innovation Research \\
\hline SBMS & Standards Based Management System \\
\hline SC & U.S. D epartment of Energy, Office of Science \\
\hline SCADA & Supervisory Control and D ata Acquisition \\
\hline SCIF & Sensitive Compartmentalized Information Facility \\
\hline SCW & Special Case Waste \\
\hline SciDAC & Scientific D iscovery through Advanced Computing \\
\hline SCIF & Sensitive Compartmented Information \\
\hline SECA & Solid Energy Conversion Alliance \\
\hline
\end{tabular}




\begin{tabular}{|c|c|}
\hline SEPA & State Environmental Policy Act \\
\hline SGI & Silicon G raphics Inc. \\
\hline SIGN & Surgical Implant Generation Network \\
\hline SNF & Spent Nuclear Fuel \\
\hline SOFC & Solid Oxide Fuel Cells \\
\hline SPIRE & Spatial Paradigm for Information Retrieval and Exploration \\
\hline SRAP & Student Research Apprenticeship Program \\
\hline SRD & Secret Restricted Data \\
\hline SRI & Student Research Intern Program \\
\hline SRS & Savannah River Site \\
\hline SRTC & Savannah River Technology Center \\
\hline SST & Hanford Single-Shell Tank \\
\hline STEM & Science, Technology, Engineering and Mathematics \\
\hline SULI & Science Undergraduate Laboratory Internship \\
\hline TFA & Tank Focus Area \\
\hline TRCR & Total Recordable Case Rate \\
\hline TPA & Tri-Party Agreement \\
\hline TRA & Topographical Risk Assessment \\
\hline TRIM & Total Records Information Management \\
\hline TRP & Teacher Research Participation \\
\hline TSC & Technical Support Centers \\
\hline UHF & User Housing Facility \\
\hline UI & University of Idaho \\
\hline US CECOM & U.S. Army Communications-Electronics Command \\
\hline USDA & United States D epartment of Agriculture \\
\hline USPTO & US Patent and Trademark Office \\
\hline USSCC & Ultrascale Scientific Simulation Computer Capability \\
\hline USSO COM & United States Special Operations Command \\
\hline UW & University of Washington \\
\hline VPP & Voluntary Protection Program \\
\hline VSR & Voluntary Separation Rate \\
\hline WaFAST & Washington State Federal and State Technology Partnership \\
\hline WAMS & Wide Area Measurement System \\
\hline WEA & Workplace Engagement A ssessment \\
\hline WFO & Work for O thers \\
\hline WG I & Washington G roup International \\
\hline WISHA & Washington Industrial Safety and Health Act \\
\hline WMD & Weapons of Mass D estruction \\
\hline WNSA & Western Nuclear Science Alliance \\
\hline WRISRC & Western Regional Information Research Center \\
\hline WSCC & Western Systems Coordinating Council \\
\hline WSSX & Warhead Safety and Security Exchange \\
\hline WSU & Washington State University \\
\hline WTC & Washington Technology Center \\
\hline WTP & Waste Treatment Plant \\
\hline WVDP & West Valley D emonstration Project \\
\hline YWiS & Young Women in Science Program \\
\hline
\end{tabular}

